\author{
UNIVERSIDADE DE SÃO PAULO \\ ESCOLA DE ENGENHARIA DE SÃO CARLOS \\ DEPARTAMENTO DE HIDRÁULICA E SANEAMENTO
}

\title{
ESTUDO EXPERIMENTAL E MATEMÁTICO DE QUALIDADE DA ÁGUA COM BASE NA ECOHIDROLOGIA FLUVIAL DE PEQUENAS BACIAS: ESTUDO DE CASO DO RIO CANHA, BAIXO RIBEIRA DE IGUAPE, SP.
}

Flávia Bottino

Dissertação apresentada ao Programa de Pós-Graduação em Hidráulica e Saneamento da Escola de Engenharia de São Carlos, Universidade de São Paulo, como parte dos requisitos para obtenção do título de Mestre.

Orientador: Prof. Dr. Eduardo Mario Mendiondo 



\section{AUTORIZO A REPRODUÇÃO E DIVULGAÇÃO TOTAL OU PARCIAL DESTE TRABALHO, POR QUALQUER MEIO CONVENCIONAL OU ELETRÔNICO, PARA FINS DE ESTUDO E PESQUISA, DESDE QUE CITADA A FONTE.}

Ficha catalográfica preparada pela Seção de Tratamento da Informação do Serviço de Biblioteca - EESC/USP

Bottino, Flávia
B751e Estudo experimental e matemático de qualidade da água com base na
ecohidrologia fluvial de pequenas bacias: estudo de caso do Rio Canha, Baixo Ribeira de
Iguape, SP / Flávia Bottino ; orientador Eduardo Mario Mendiondo. -- São Carlos, 2008.

Dissertação (Mestrado-Programa de Pós-Graduação e Área de Concentração em Hidráulica e Saneamento) -- Escola de Engenharia de São Carlos da Universidade de São Paulo, 2008.

1. Qualidade da água. 2. Ecohidrologia. 3. Qual2K. 4. Rio Canha. I. Titulo. 
FOLHA DE JULGAMENTO

\section{Candidata: Licenciada FLÁVIA BOTTINO}

Dissertação defendida e julgada em 30/04/2008 perante a Comissão Julgadora:

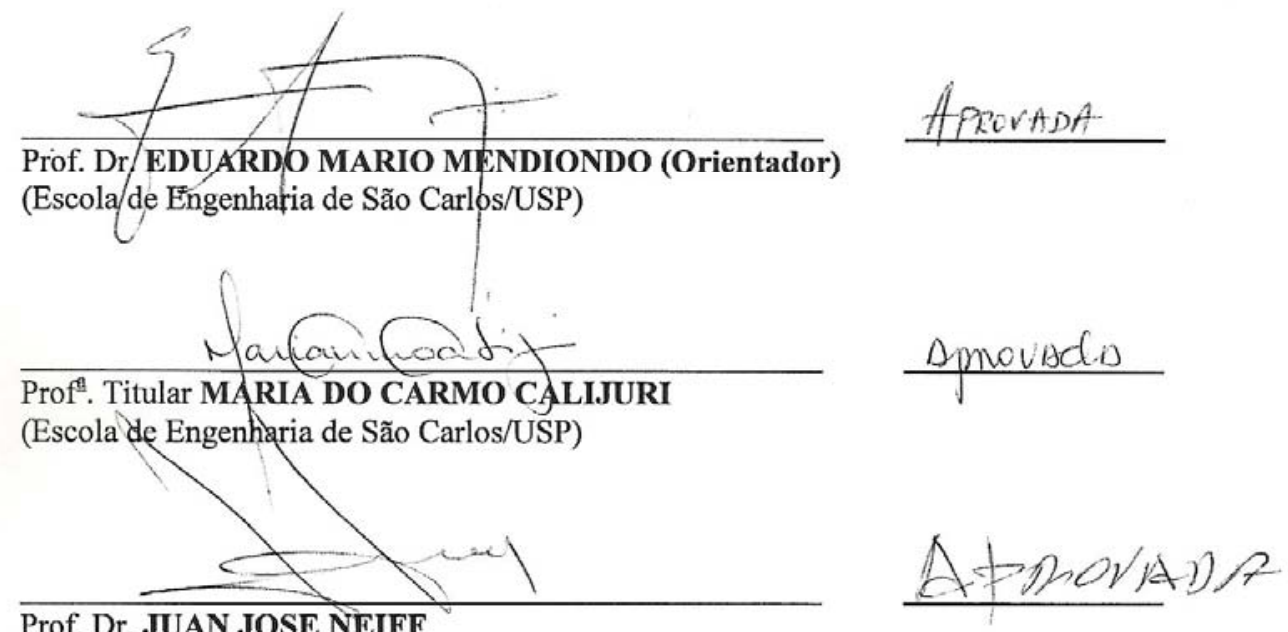

(Universidad Nacional del Nordeste/UNNE)

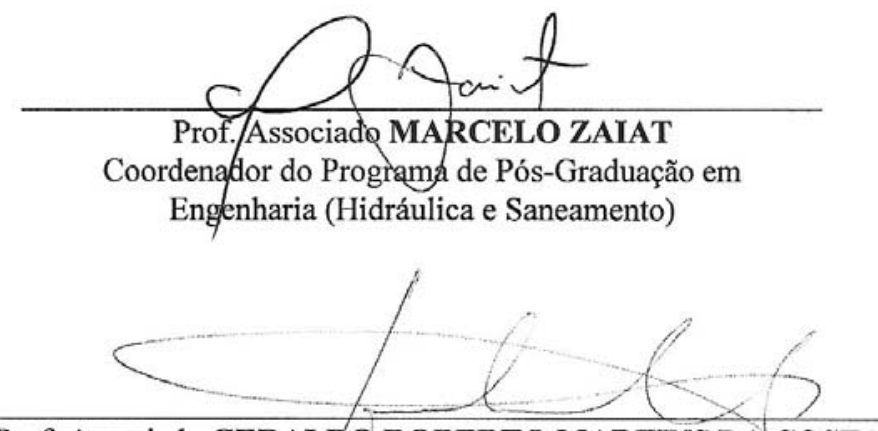

Prof. Associado GERALDO ROBERTO MARTINS DA'COSTA

Presidente da Comíssão da Pós-Graduação da EESC 
$\grave{A}$ todas as pessoas que acreditam na educação como base para um desenvolvimento justo e sustentável 
Se falo na Natureza não é porque não saiba o que ela é, Mas porque a amo, e amo-a por isso, Porque quem ama nunca sabe o que ama Nem sabe o que ama, nem o que é amar...

\section{Fernando Pessoa - Alberto Caeiro}




\section{AGRADECIMENTOS}

Agradeço primeiramente à Deus, pela oportunidade de aprender cada vez mais e por me dar força nas horas mais difíceis.

Ao Prof. Dr. Eduardo Mario Mendiondo pela oportunidade e pela orientação.

À Prof. Tit. Maria do Carmo Calijuri por me ajudar nos momentos de necessidade.

À Prof. Dra. Silvana Martinez Baraldi Artoni, UNESP campus de Jaboticabal-SP, pelas oportunidades e por me ensinar a fazer pesquisa.

Aos técnicos Betão e Miro e ao Sr. Benê por auxiliarem na obtenção dos dados de campo e por tornarem nossas viagens muito divertidas. Betão, muito obrigada por me explicar incansavelmente toda a parte de hidráulica e hidrologia em campo.

Aos técnicos do laboratório de Geotecnia, José Luis e Oscar, que nos acudiram nos momentos finais.

Ao Conselho Nacional de Desenvolvimento Científico e Tecnológico (CNPq) pela bolsa de mestrado concedida e à Fundação de Amparo à Pesquisa do Estado de São Paulo - FAPESP pelos auxílios recebidos, indispensáveis para execução desse trabalho (Projeto Temático - Proc. $\left.\mathrm{n}^{\circ} 02 / 3449-1\right)$.

Ao Sr. Hélio e sua família por permitirem a montagem do laboratório de campo em sua casa, sempre nos recepcionando muito bem. Ao Sr. Tarcísio e Sra. Tânia por nos atenderem sempre e prontamente, dando extrema relevância aos nossos trabalhos e realizando a importantíssima leitura das réguas hidrométricas. Não posso deixar de agradecer os convites para o almoço e os iogurtes do Sr. Tarcísio.

A todos os integrantes do Núcleo Integrado de Bacias Hidrográficas (NIBH), em especial ao Ignazio Giuntoli, meu grande amigo, e à Tatiane Furlaneto de Souza, que sempre me socorreu 
com a maior boa vontade, ouviu meus desabafos e agüentou meu mau humor. Obrigada Tati, você foi mais que uma irmã nesses dois últimos anos!

A todas as meninas do BIOTACE, principalmente à Juliana Moccelin pela amizade e ajuda e à Ive Ciola Ferraz, minha "amiga de rio", que nem tenho palavras para agradecer.

À pessoa indispensável pela colaboração na utilização do modelo, Julio Gonçalves.

Ao Ivan Ciola Ferraz, que mesmo sem conhecer pessoalmente, me ajudou bastante com a obtenção dos dados cartográficos.

Ao Aníbal Santiago por me ajudar, muitas vezes sem poder, a conseguir os dados sobre a bacia de estudo.

À D. Diva e Sr. Mathias agradeço por tudo o que vocês fizeram e fazem por mim.

À minha mãe Sandra e minha irmã Fernanda que sempre me incentivaram e me apoiaram nos momentos mais difíceis.

Finalmente agradeço ao Eduardo, que sempre me apoiou, desde a prova de seleção quando me ajudou com a parte de engenharia, até os momentos finais da elaboração da dissertação, sempre ouvindo minhas reclamações e dúvidas, oferecendo seu ombro para minhas lágrimas e me levantando quando eu estava prestes a cair.

À todos que acreditaram em mim e que de alguma forma tenham contribuído para a execução deste trabalho. 


\section{SUMÁRIO}

LISTA DE TABELAS............................................................................................................

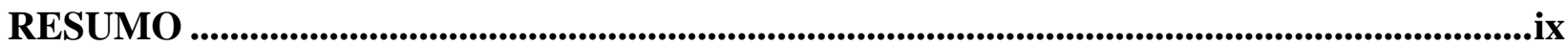

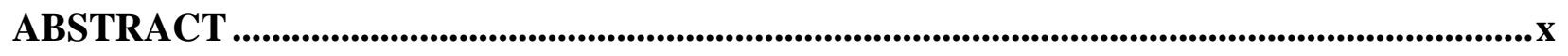

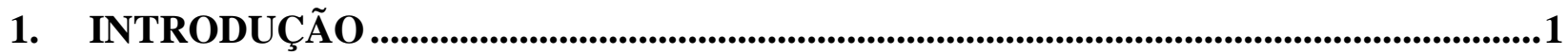

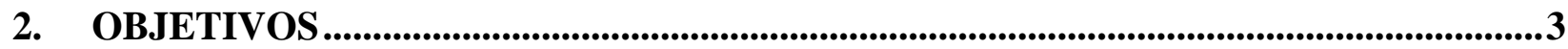

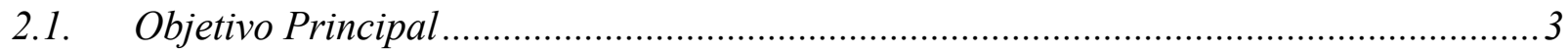

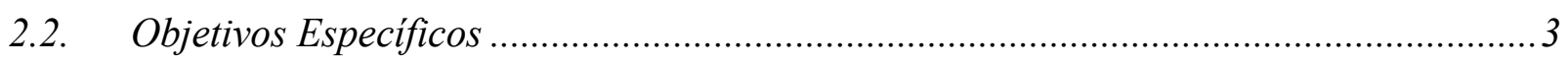

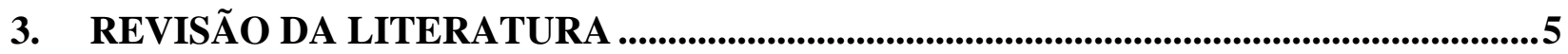

3.1. A Bacia hidrográfica como unidade de estudo ............................................................ 5

3.2. Autodepuração nos corpos de água ……..............................................................

3.3. Ecohidrologia: Conceitos e Aplicações ..................................................................11

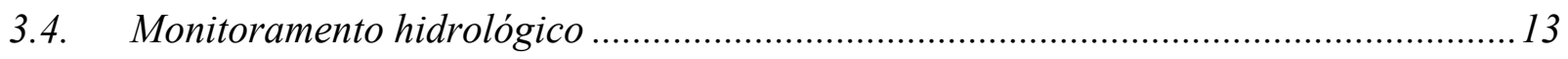

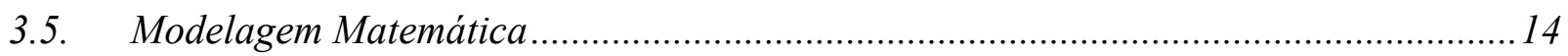

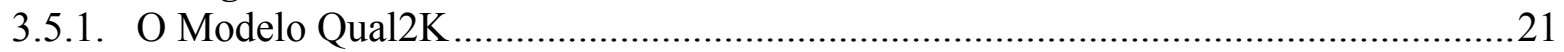

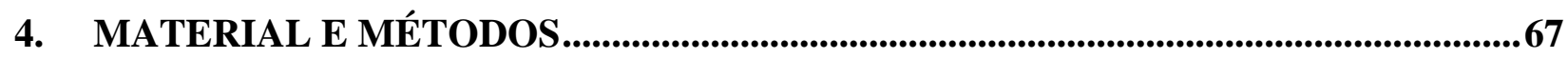

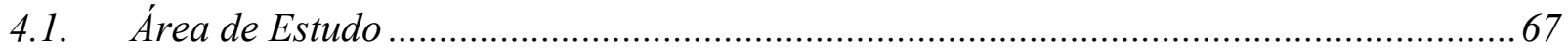

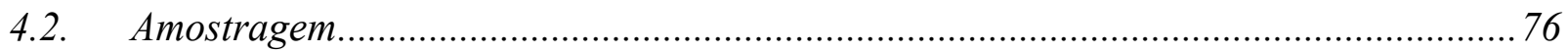

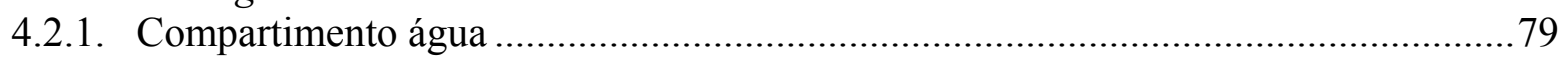

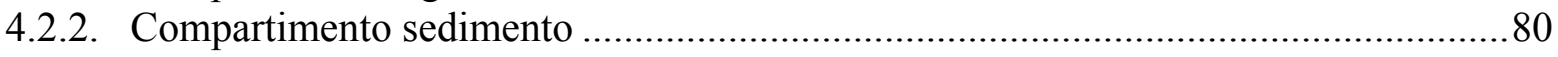

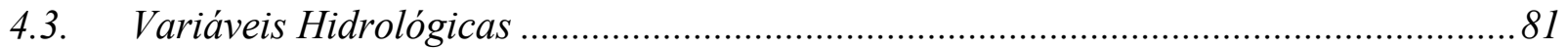

4.3.1. Precipitação, Nível d'água, Velocidade de escoamento e Vazão ...............................81

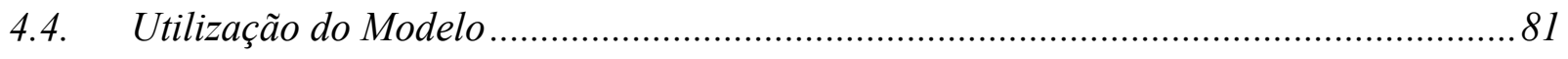

5. RESULTADOS................................................................................................................................ 86

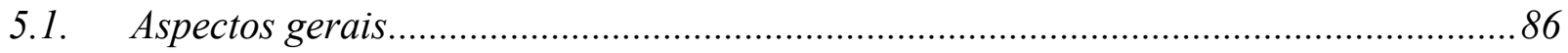

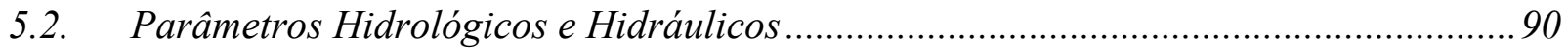

5.3. Parâmetros Físicos e Químicos da água ………...................................................... 100

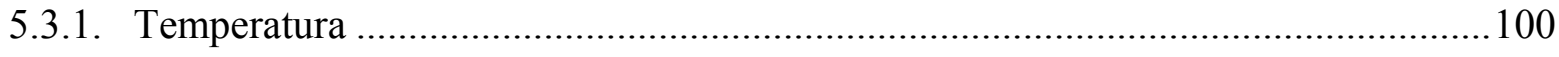




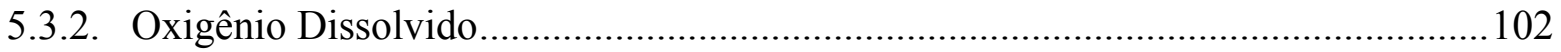

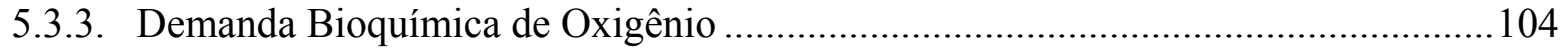

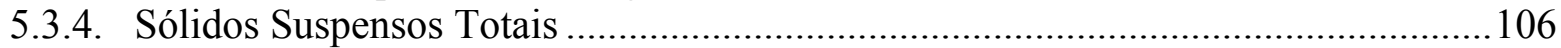

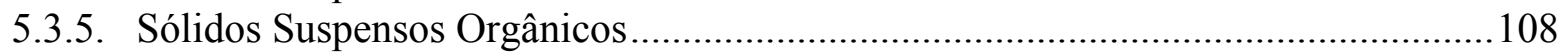

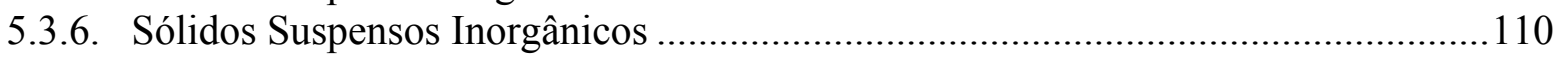

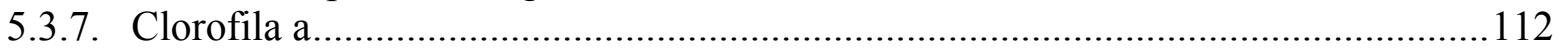

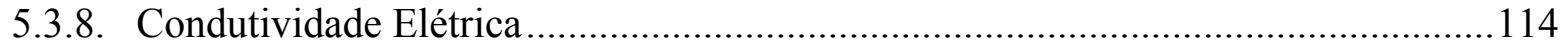

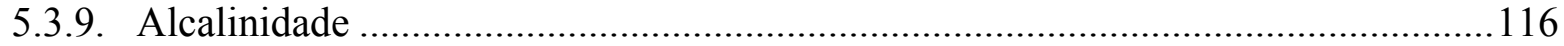

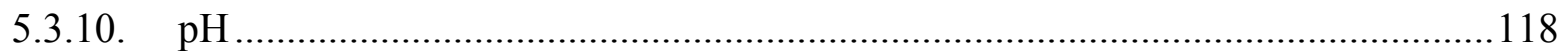

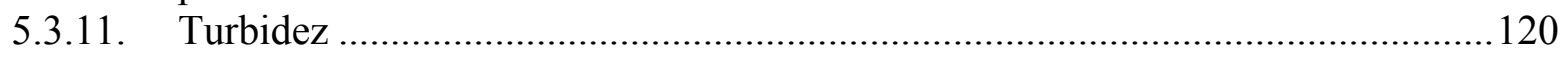

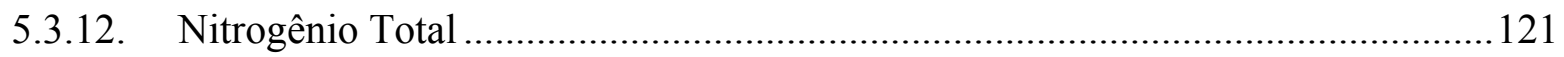

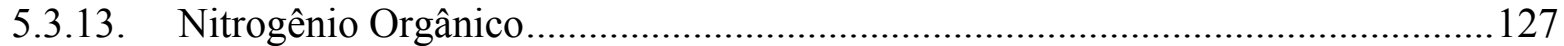

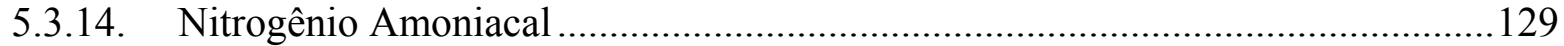

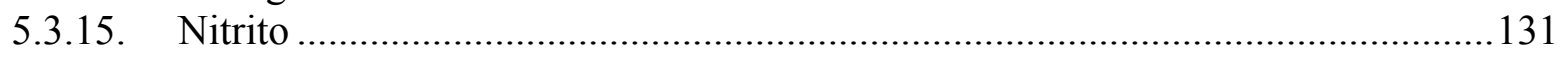

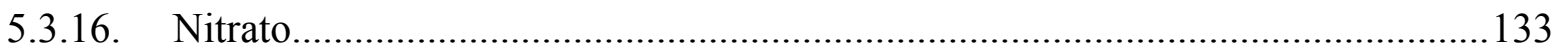

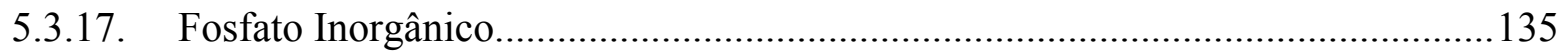

6. DISCUSSÃ

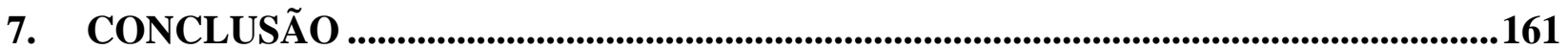

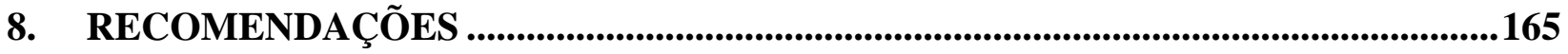

9. REFERÊNCIAS BIBLIOGRÁFICAS ......................................................................... 166

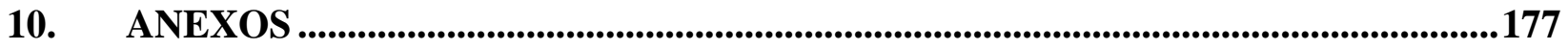




\section{LISTA DE FIGURAS}

Figura I: Atividades realizadas e resultados a serem obtidos.............................................

Figura II: Componentes da dispersão.............................................................................20

Figura III: Diagrama de um corpo hídrico ausente de tributários.........................................22

Figura IV: Diagrama da representação de um rio com seus tributários. .....................................23

Figura V: Subdivisão dos trechos em “n” elementos de igual comprimento..............................23

Figura VI: Modelo cinético e processo de transferência de massa..........................................39

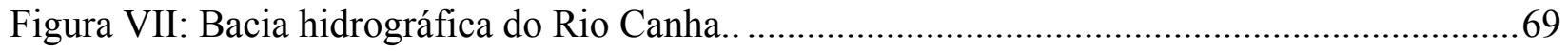

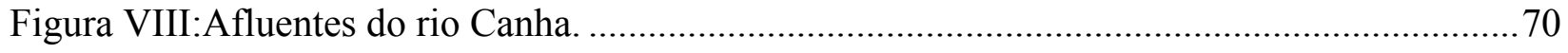

Figura IX Uso e ocupação do solo da Bacia do Rio Canha. ......................................................71

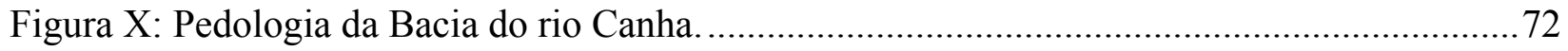

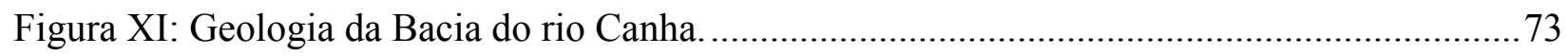

Figura XII: Declividade da Bacia do rio Canha............................................................ 74

Figura XIII: Hipsografia da Bacia do rio Canha............................................................. 75

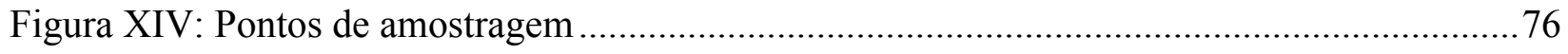

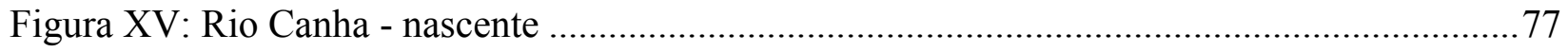

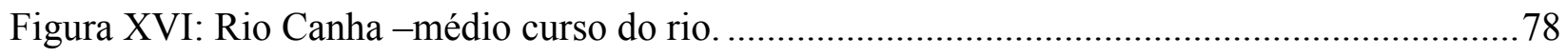

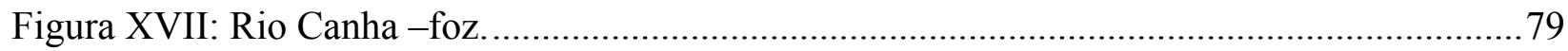

Figura XVIII: Estrutura morfológica e da seção transversal de um canal fluvial do tipo G4........86

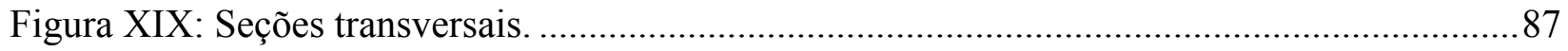

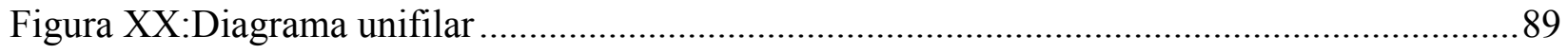

Figura XXI: Polígono de Thiessen ......................................................................... 90

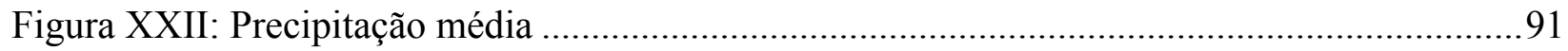


Figura XXIII: Relação precipitação e nível da água.........................................................91

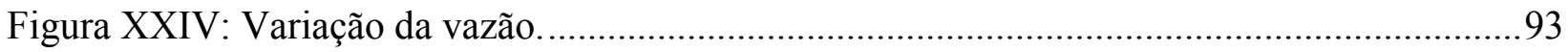

Figura XXV: Curva de permanência .......................................................................... 94

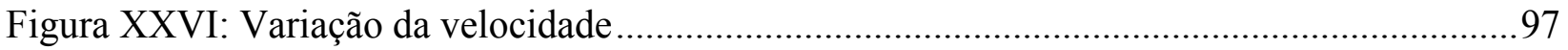

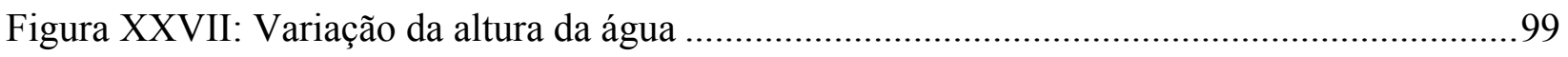

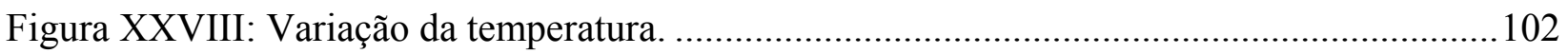

Figura XXIX: Variação de oxigênio dissolvido................................................................. 103

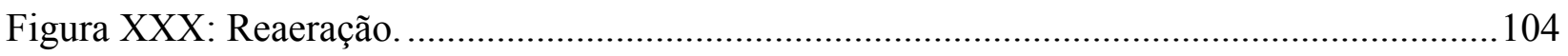

Figura XXXI: Variação da demanda bioquímica de oxigênio...............................................105

Figura XXXII: Variação de Sólidos Suspensos Totais ........................................................ 107

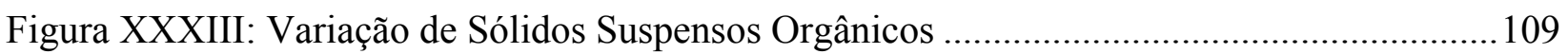

Figura XXXIV: Variação de Sólidos Suspensos Inorgânicos.................................................111

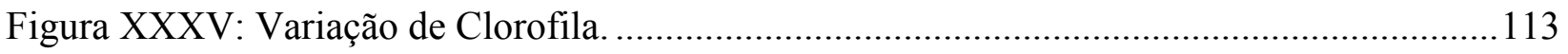

Figura XXXVI: Vazões de permanência, vazões observadas e dados de clorofila $a$.................114

Figura XXXVII: Variação de Condutividade Elétrica.........................................................115

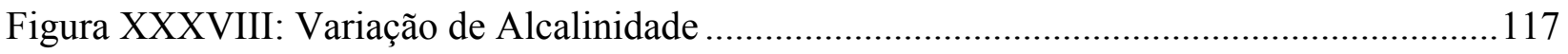

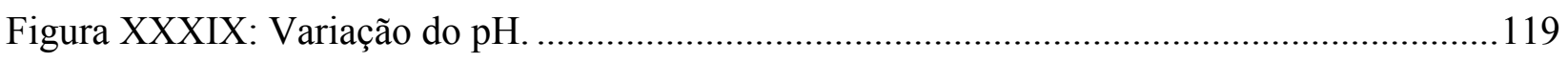

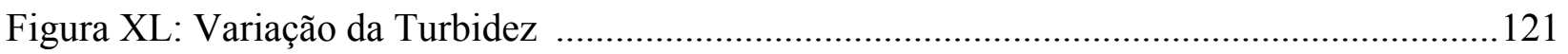

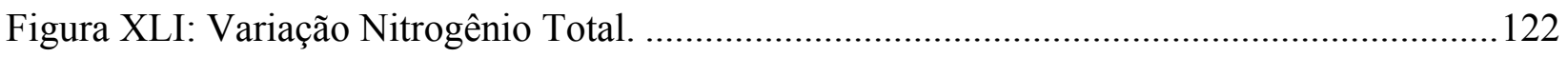

Figura XLII: Balanço de massa para o nitrogênio total ...................................................... 125

Figura XLIII: Variação da carga específica de Nitrogênio Total e composição do sedimento ...126

Figura XLIV: Variação de Nitrogênio Orgânico a................................................................ 128

Figura XLV: Variação de Nitrogênio Amoniacal. ..................................................................130 


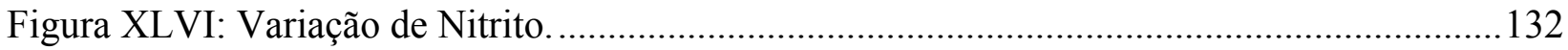

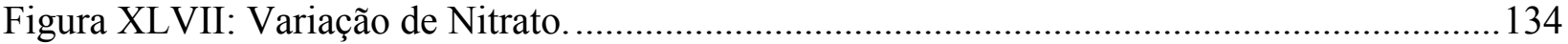

Figura XLVIII: Variação de Fosfato Inorgânico.................................................................... 136 


\section{LISTA DE TABELAS}

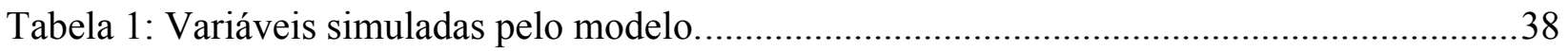

Tabela 2. Métodos de determinação das variáveis físicas e químicas analisadas na água.............80

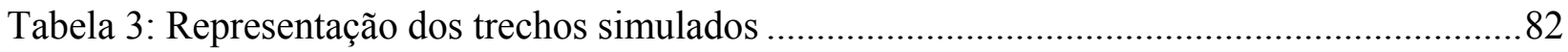

Tabela 4: Representação dos elementos simulados.......................................................... 82

Tabela 5: Áreas de drenagem acumuladas, comprimento do canal e respectivos tipos de usos e

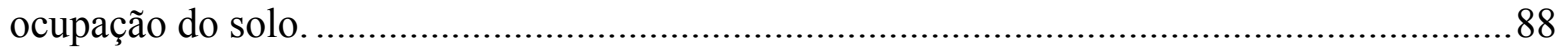

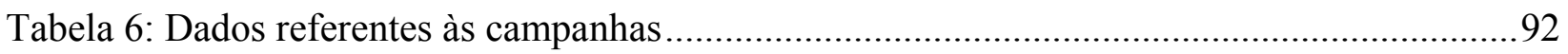

Tabela 7: Velocidade de Escoamento (m/s), área de casa seção $(\mathrm{m} 2)$, vazão $(\mathrm{L} / \mathrm{s})$, número de Froude e número de Reynolds ao longo do eixo longitudinal do rio Canha ........................95

Tabela 8: Alterações antrópicas dos sistemas fluviais ........................................................ 139 


\section{LISTA DE EQUAÇÕES}

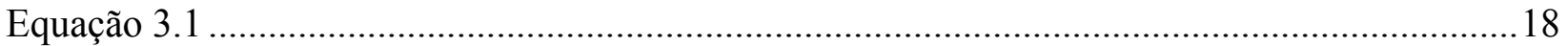

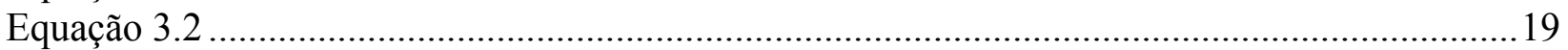

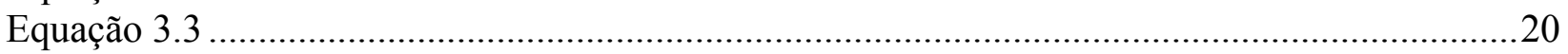

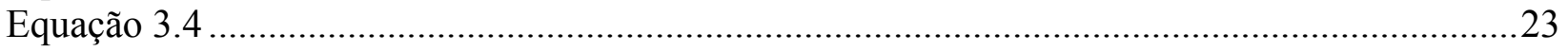

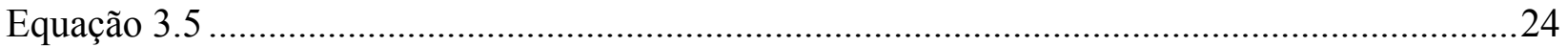

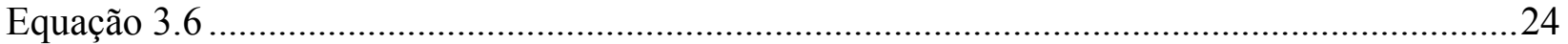

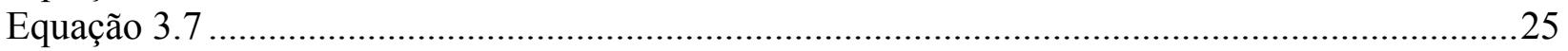

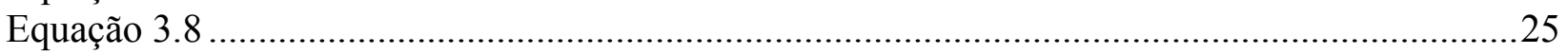

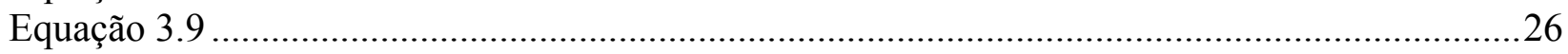

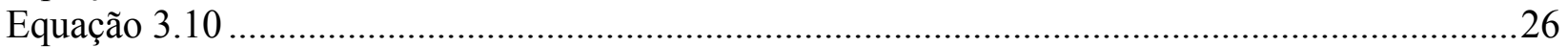

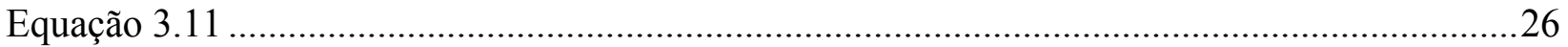

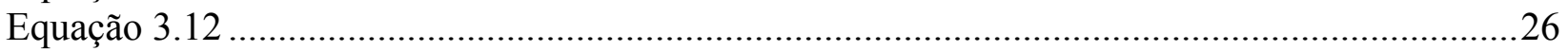

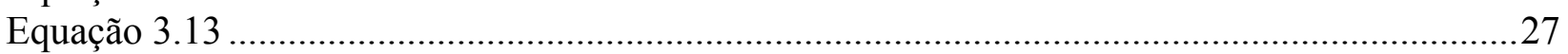

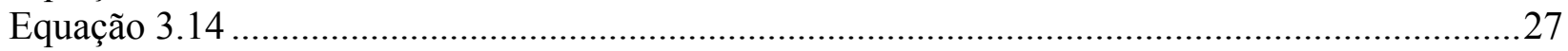

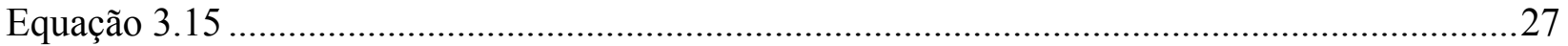

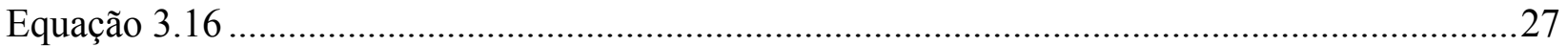

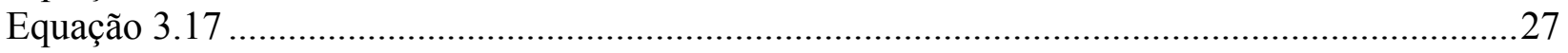

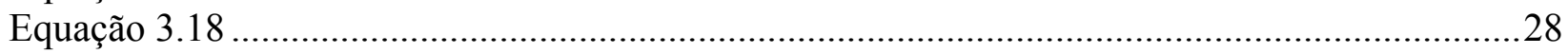

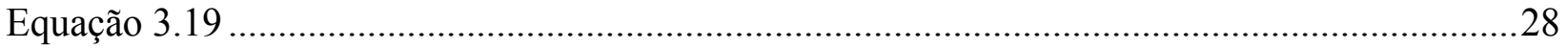

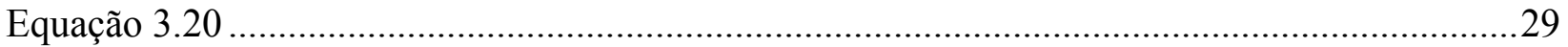

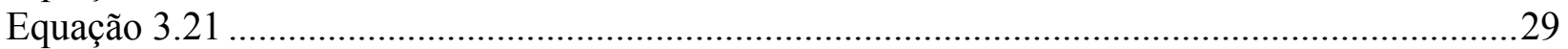

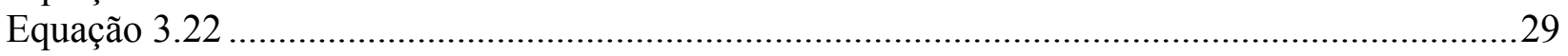

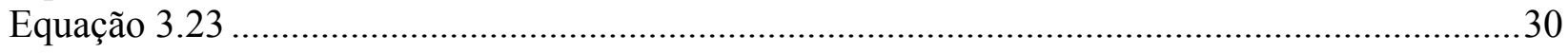

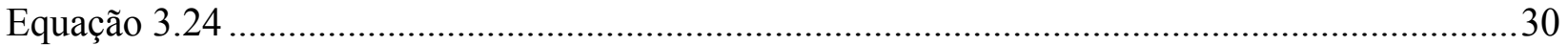

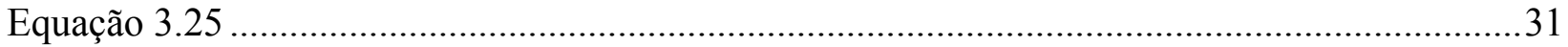

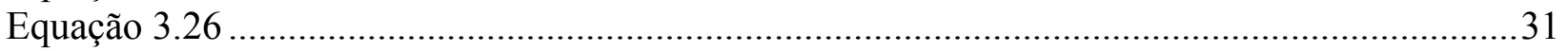

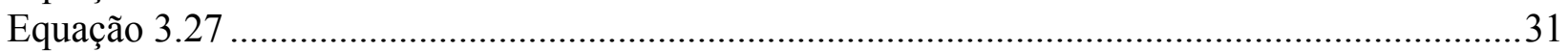

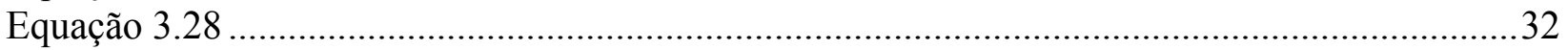

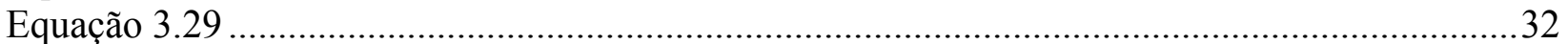

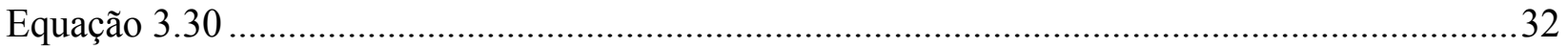

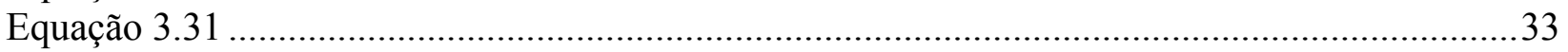

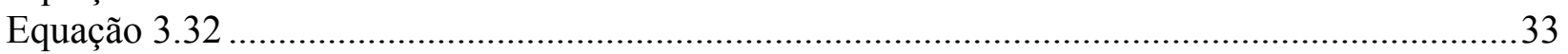

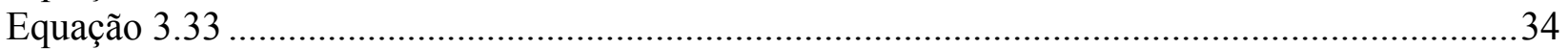

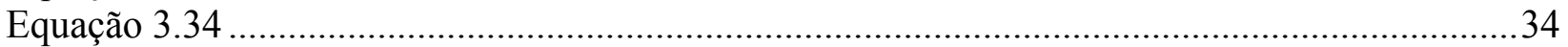

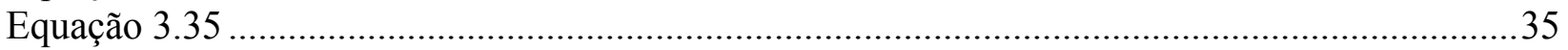

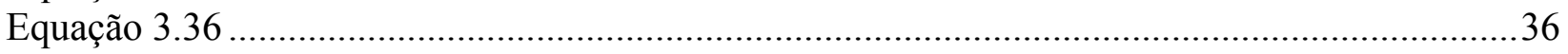

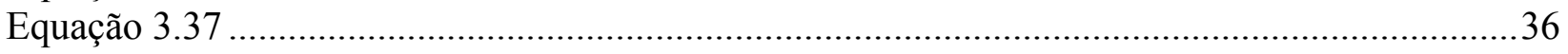

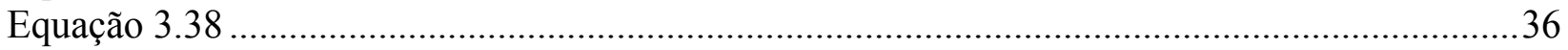

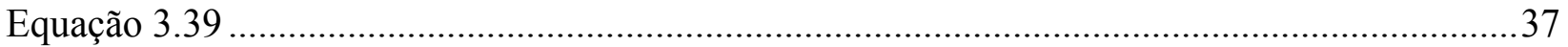

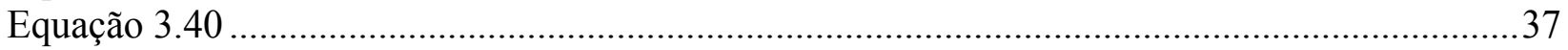

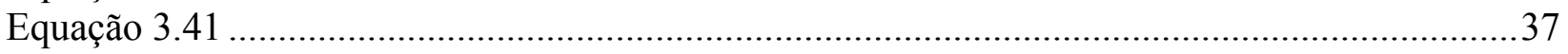

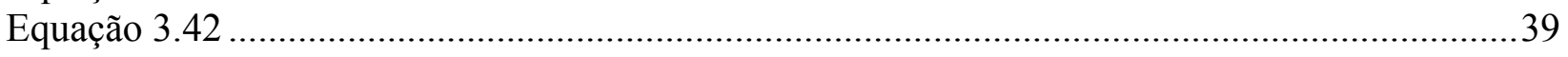

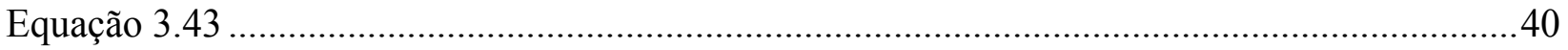

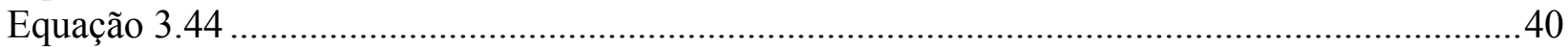

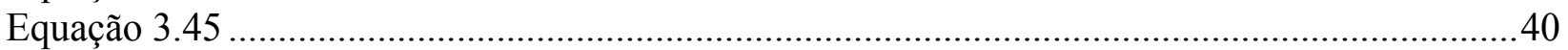




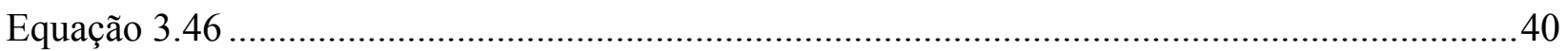

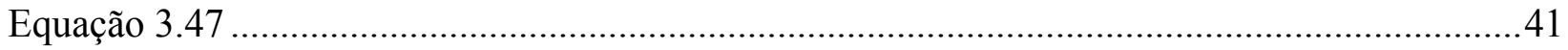

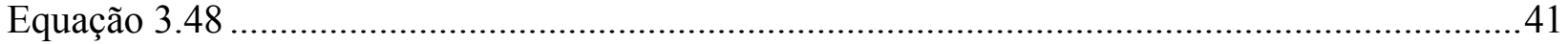

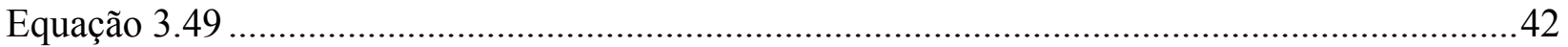

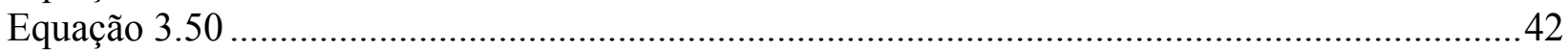

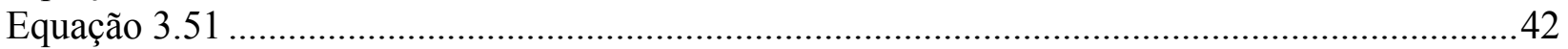

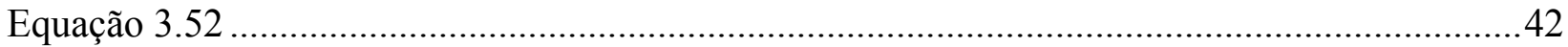

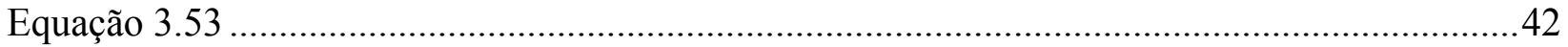

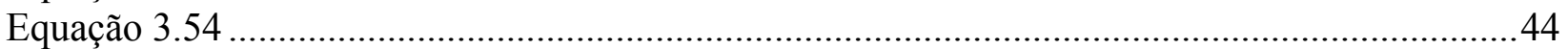

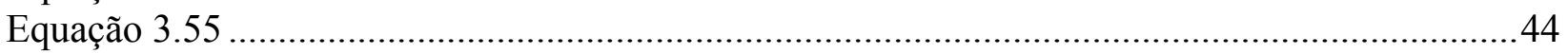

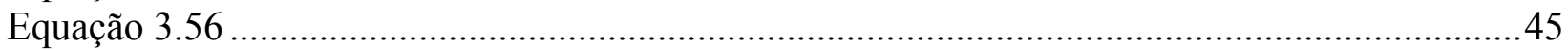

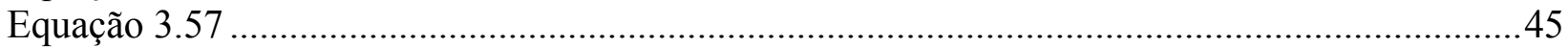

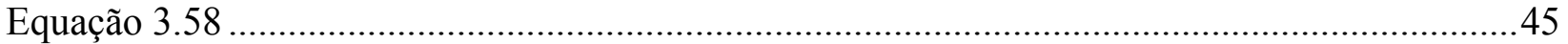

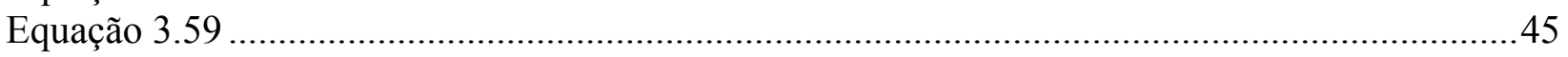

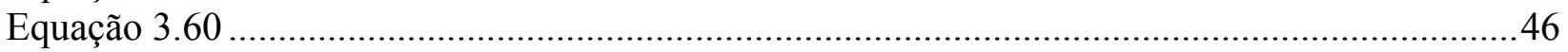

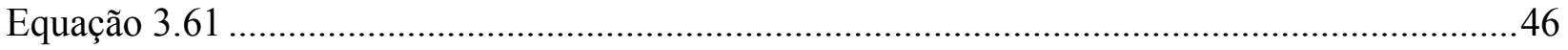

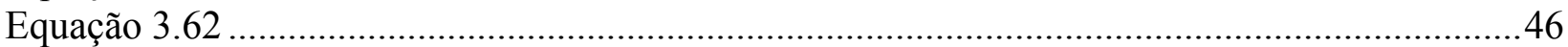

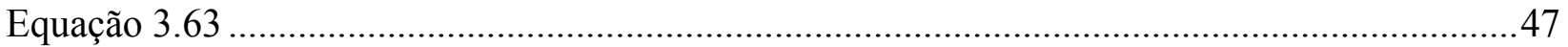

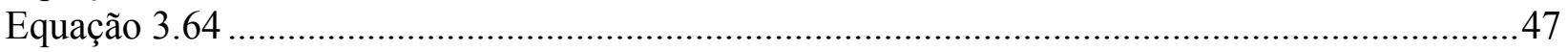

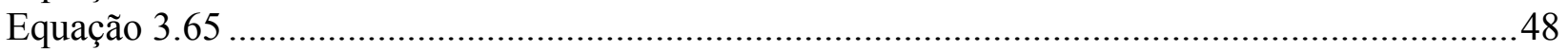

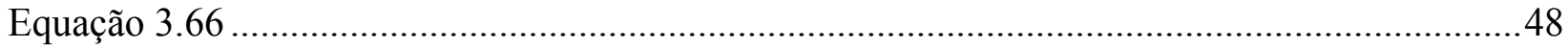

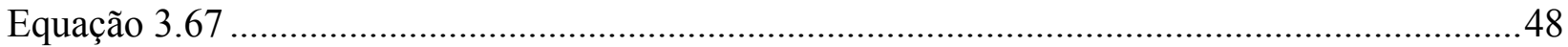

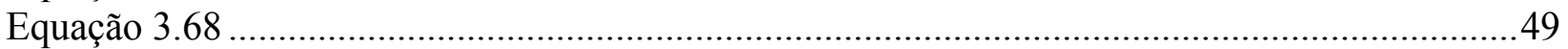

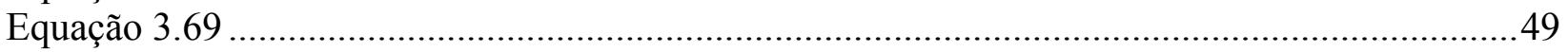

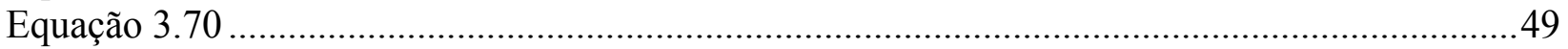

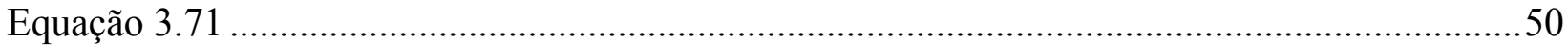

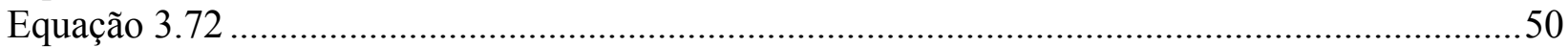

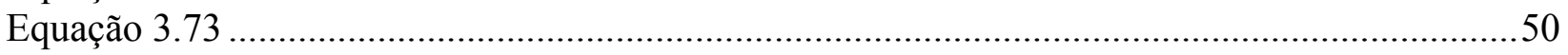

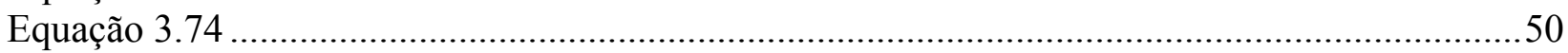

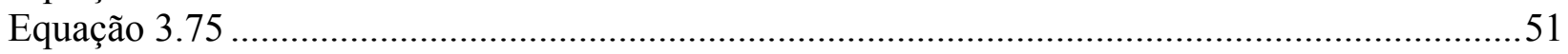

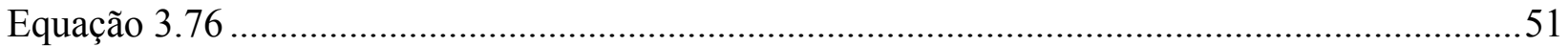

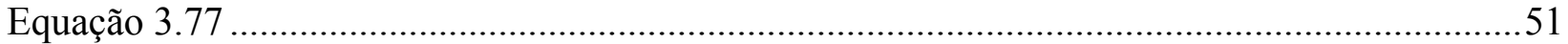

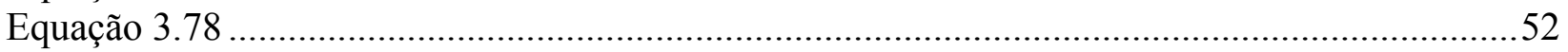

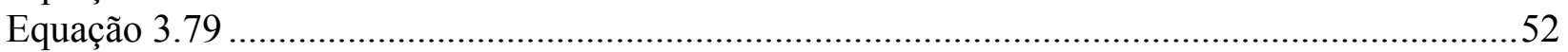

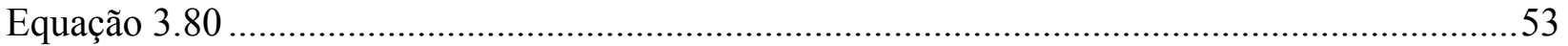

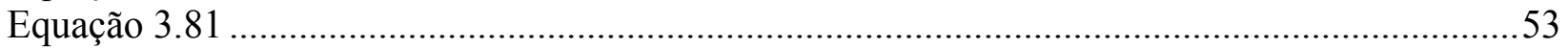

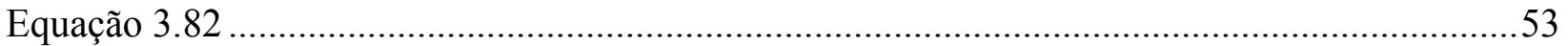

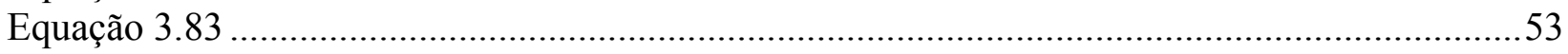

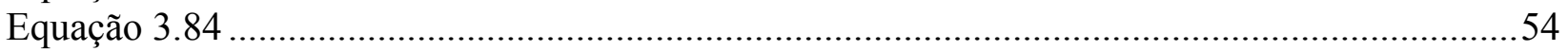

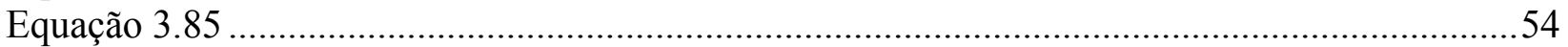

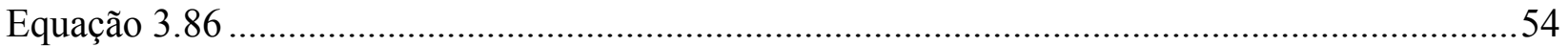

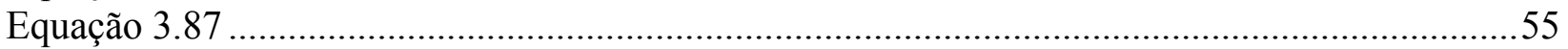

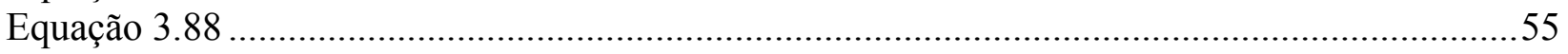

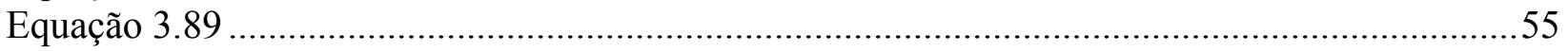

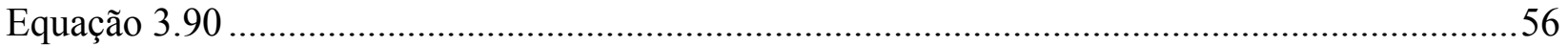

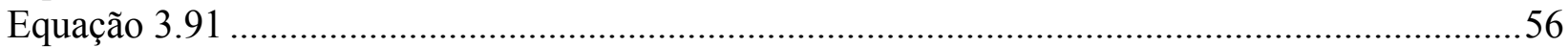

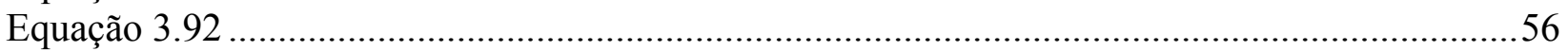




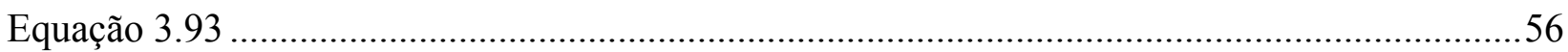

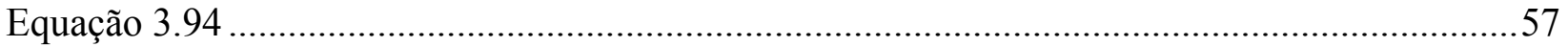

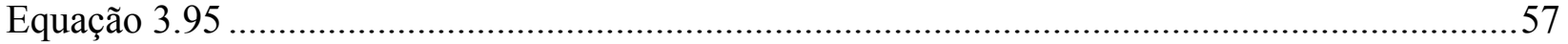

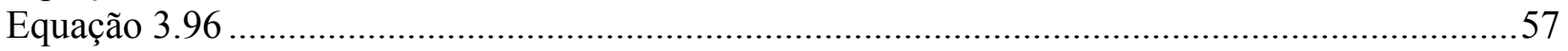

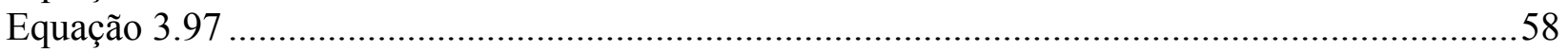

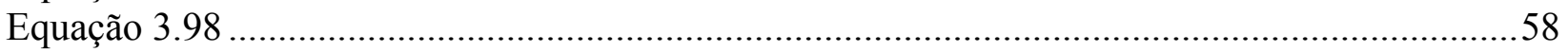

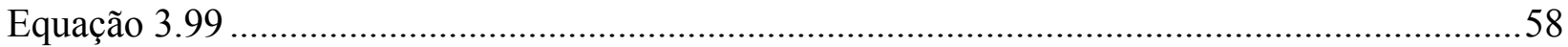

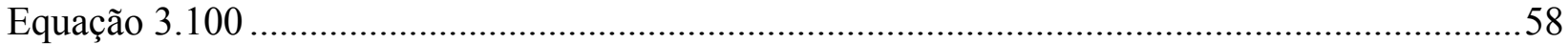

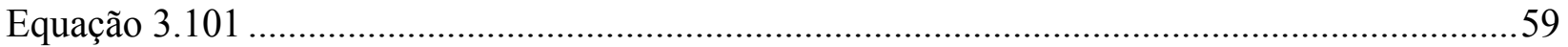

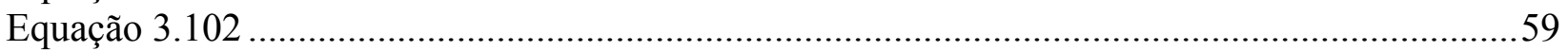

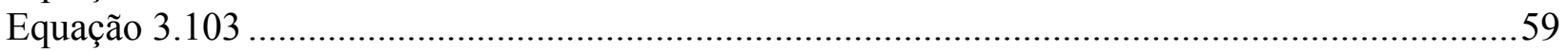

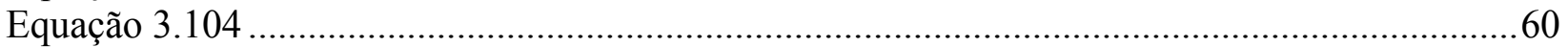

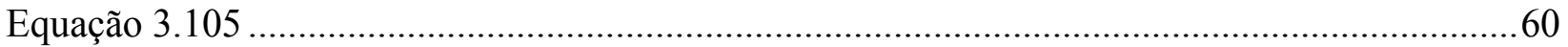

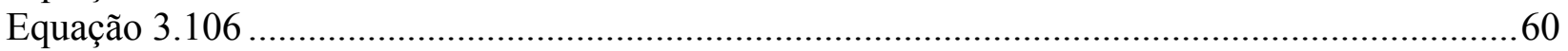

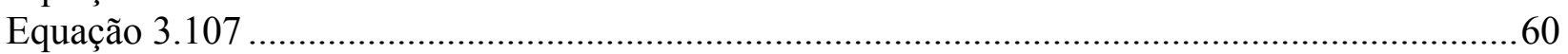

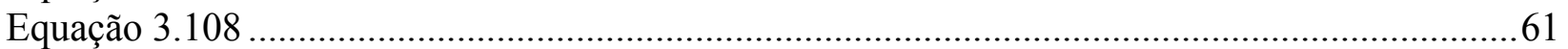

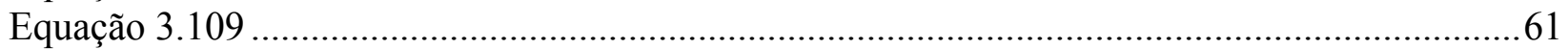

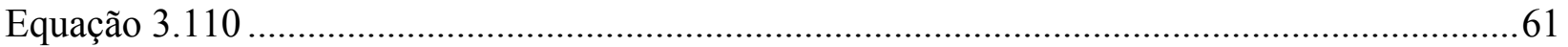

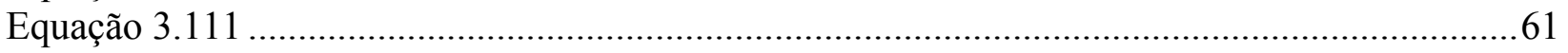

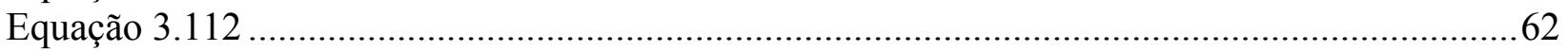

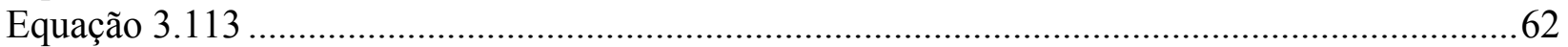

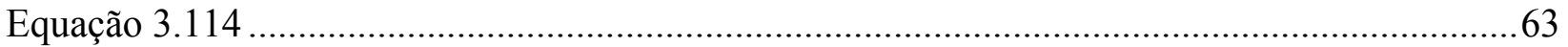

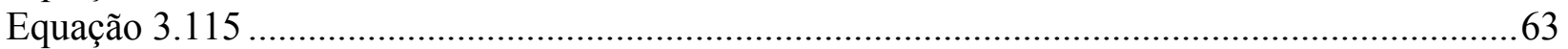

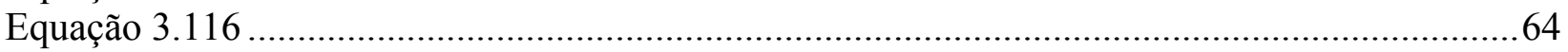

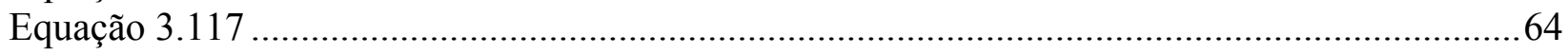

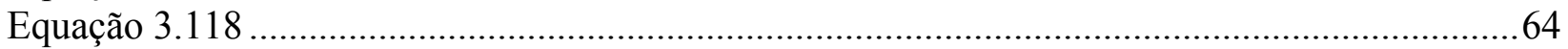

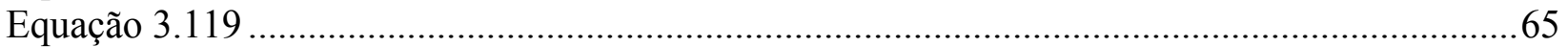

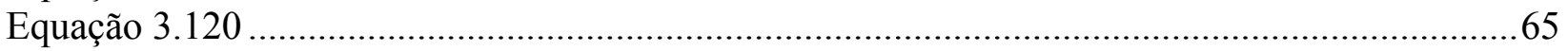

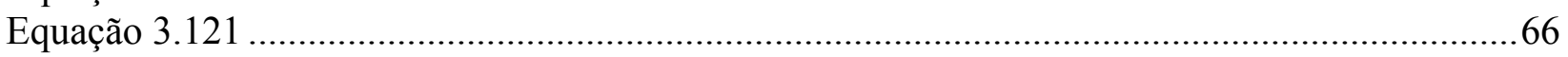

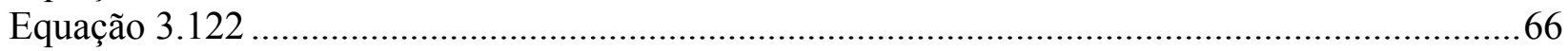

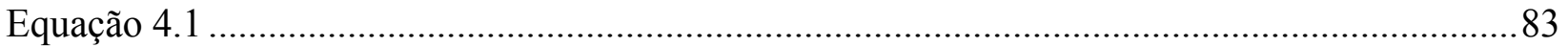

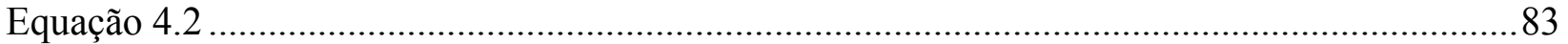

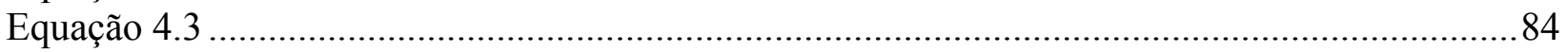

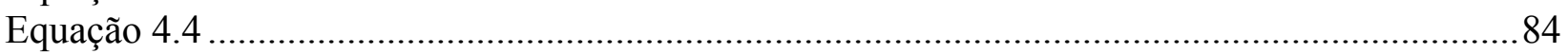

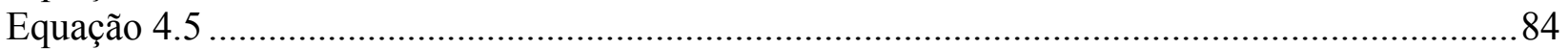

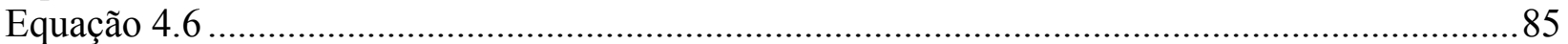




\section{RESUMO}

BOTTINO, F. (2008). Estudo experimental e matemático de qualidade da água com base na ecohidrologia fluvial de pequenas bacia: estudo de caso do rio Canha, Baixo Ribeira de Iguape, SP. Dissertação de Mestrado. São Carlos: Escola de Engenharia de São Carlos, Universidade de São Paulo.

Os cursos d'água são ecossistemas predominantemente heterotróficos com gradiente longitudinal e possuem uma capacidade natural de depurar a matéria orgânica Entretanto, o lançamento indiscriminado de efluentes ultrapassa a capacidade de suporte do ambiente aquático. O principal objetivo do presente estudo foi analisar como a qualidade da água do rio, em termos experimentais e de modelagem matemática, expressa processos ecohidrológicos nas escalas espaço-temporais, para variações de variáveis físicas, químicas e hidrológicas. O presente estudo foi conduzido através da abordagem de bacias embutidas em seções transversais com áreas incrementais do rio principal e com 17 variáveis analisadas. A aplicação dessa metodologia foi feita para o rio Canha, com área de drenagem total de $126 \mathrm{Km}^{2}$, situada num bioma subtropical, caracterizando-se por ser uma bacia rural e peri-urbana, localizada no Baixo Ribeira de Iguape São Paulo. As amostragens foram feitas de setembro de 2006 a março de 2007, em oito seções transversais ao longo do eixo longitudinal do rio Canha. A fim de validar os dados obtidos em campo, um modelo matemático foi utilizado. Deste modo, o modelo 1D de fluxo permanente, o modelo QUAL2K, ajustou-se de maneira satisfatória para a maioria dos dados experimentais. Dados hidráulicos e hidrológicos obtidos em campo foram empregados como condição de contorno para calibração do modelo. Os resultados experimentais e simulados foram expressos tanto em termos de concentração $(\mathrm{mg} / \mathrm{L})$ como de cargas específicas (Kg/ano/ha). Esta comparação permite obtenção dos resultados através de um continuum a partir do aumento das escalas, enquanto fornece base para confrontá-los com hipóteses ecohidrológicas. A existência de duas estações distintas, seca e chuvosa, foi observada. Durante a estação chuvosa, observou-se maior diluição dos compostos no corpo d'água, porém em alguns casos, a influência da poluição difusa, devido à lixiviação do solo, foi verificada. As altas vazões tiveram impacto direto sobre as cargas específicas. Na estação seca, para a maioria das variáveis analisadas, evidenciou-se aumento na concentração, sugerindo que períodos de baixa vazão diminuem a capacidade de assimilação do rio. Por exemplo, as concentrações e cargas específicas de nitrogênio total foram altas para ambos os períodos, seco e chuvoso. Quando comparado com o sedimento do rio, ficou evidente que o nitrogênio é originário de fontes não pontuais.

Palavras-chave: qualidade da água, ecohidrologia, QUAL2K e rio Canha. 


\section{ABSTRACT}

BOTTINO, F. (2008). Experimental and mathematical analysis of water quality based on fluvial ecohydrology: a study in the Canha River, at Ribeira de Iguape Basin, Brazil. M.Sc. Dissertation. São Carlos: Engineering School of São Carlos, University of São Paulo.

Water courses are predominantly heterotrophic ecosystems with longitudinal gradient and present a capacity of self purification from organic matter. However, the uncontrolled release of effluents can exceed the carrying capacity of the aquatic ecosystem. The main objective of this study was to analyze how the river water quality, in terms of experimental surveys faced with mathematical modeling, envisages the processes evidences of fluvial ecohydrology at various spatiotemporal scales, for either seasonal or longitudinal changes of physic, chemical and hydrological variables. That study was performed through a nested catchment experiment, at cross-sections located at incremental drainage areas of the main river stem of the watershed and with 17 sampled variables. The application of this methodology was made at the Canha River, with a total drainage area of 126 $\mathrm{Km}^{2}$, under subtropical biome, with mixed, rural to peri-urban, land-uses, located at the downstream of the Ribeira de Iguape river basin, sited at State of Sao Paulo, Brazil. Four field campaigns were carried with sampling from September, 2006 to July, 2007, in eight cross-sections along the longitudinal axis of the Canha river. In order to cross-validate experimental samples at the river continuum scale with the drainage basin scale, a mathematical model was tested to simulate the water quality dynamics. In spite of 1-D, quasi-state modeling restrictions assumed, the QUAL2K model fits well to experimental data of most of variables surveyed during campaigns. Hydraulic basic samples and hydrological weather data were utilized as initial conditions to feed the mathematical model. Both experimental results and model simulations were expressed as mean river-concentrations (mass.volume ${ }^{-1}$ ) as drainage-area-specific loadings or yield (mass.time ${ }^{-1} \cdot$ area $^{-1}$ ). The existence of two main seasons, dry and wet, was observed. During the rainy season, the ability to better dilute water loads was outlined; however, on some circumstances, the influence of diffuse pollution entered the stream due to soil leach is also depicted. High-water discharges had a direct impact on area-specific loads. In the dry season and for most of variables, high concentrations were evident, suggesting low-water discharges provoked a loss of the river's carrying capacity. For instance, nitrogen concentrations and nitrogen specific loads were quite high during both (dry, wet) periods. When compared to the river bottom sediments, it was evident that nitrogen could be originated from non-point sources outside the riparian areas. The results let the river continuum integrated processes across increasing scales, thereby providing the basis for confronting ecohydrological hypotheses.

Key-words: water quality, ecohydrology, QUAL2K model and Canha river 


\section{INTRODUÇÃO}

Com o advento da revolução industrial, houve um grande êxodo da população rural para as cidades, além do crescente avanço tecnológico. Conseqüentemente, houve um considerável aumento da demanda pelos recursos naturais, principalmente por água. Esse cenário tornou-se mais agravante à medida que o crescimento urbano e industrial intensificou-se, aumentando assim a necessidade por água e também a produção de resíduos.

$\mathrm{O}$ crescimento urbano e industrial acelerado estão entre os fatores que mais afetam a disponibilidade de água, seja pela crescente demanda por este recurso ou pela produção de resíduos que são lançados nos corpos d'água sem tratamento adequado (BENASSI, 2002).

A falta de tratamento ou tratamento inadequado dos resíduos, tanto industriais como domésticos, afetam sobremaneira a qualidade das águas. Calijuri \& Bubel (2006) citam, no entanto, que os processos de urbanização e industrialização não são os únicos responsáveis pela degradação dos recursos hídricos, sendo necessário considerar também o manejo inadequado do solo.

Nesse contexto, Benassi (2002) relata que os cursos d'água possuem uma capacidade natural de depurar a matéria orgânica, já que os rios são ecossistemas predominantemente heterotróficos e possuem um gradiente logitudinal. Entretanto, o lançamento indiscriminado de efluentes ultrapassa a capacidade de suporte do ambiente aquático, ou seja, excede a capacidade do rio em suportar ou mesmo estimular alterações nos processos químicos, físicos e biológicos para manutenção da qualidade das águas.

Assim, nos últimos anos, muitos estudos sobre o processo de autodepuração foram realizados no sentido de avaliar a carga de poluentes que determinado corpo d'água poderia receber sem causar prejuízos para sua biota, ou seja, uma avaliação de sua capacidade de suporte.

A resolução 357/05 do Conselho Nacional do Meio Ambiente (CONAMA - BRASIL, 2005) preconiza que os efluentes devem passar por um tratamento adequado de forma a não comprometer o ecossistema aquático e atender os padrões de qualidade do corpo receptor. Nesse sentido, torna-se imprescindível o tratamento de qualquer tipo de efluente antes de seu lançamento num curso d'água, além de estudos que visem minimizar problemas gerados pela poluição, com o intuito de recuperar, conservar e monitorar as reservas hídricas de todo planeta. 
Os modelos matemáticos para determinação da qualidade da água em rios têm sido amplamente utilizados como ferramenta para planejamento, gestão e monitoramento das condições dos cursos d'água. Desta maneira, sendo o Rio Canha, localizado no Baixo Ribeira de Iguape, utilizado para abastecer a cidade de Jacupiranga, o presente trabalho propõe um estudo das variáveis limnológicas, bem como aplicação de um modelo matemático para avaliação do processo de autodepuração deste sistema, com base nos preceitos da ecohidrologia, a fim de verificar se as normas preconizadas por órgãos ambientais são de fato atendidas. 


\section{OBJETIVOS}

\subsection{Objetivo Principal}

Avaliar experimental e matematicamente a variação longitudinal e sazonal de indicadores de qualidade de água da microbacia do rio Canha, com base na ecohidrologia do sistema fluvial de pequena bacia hidrográfica.

\subsection{Objetivos Específicos}

- Coletar experimentalmente indicadores físicos e químicos da água, temporalmente (sazonais) e espacialmente (longitudinais) no rio;

- Estudar os controles morfo-hidráulicos do curso d'água e suas variáveis hidrológicas em dependência sazonal do ciclo de transformação chuva-vazão;

- Estimar a influência do uso e ocupação do solo na bacia hidrográfica sobre os indicadores experimentais e conforme os controles ecohidrológicos;

- Calibrar e simular um modelo matemático unidimensional de qualidade da água no curso d'água da bacia experimental contrastando hipóteses de processos ecohidrologicos do sistema fluvial com os dados experimentais coletados longitudinal e sazonalmente

A figura I sintetiza as atividades realizadas no presente trabalho. 


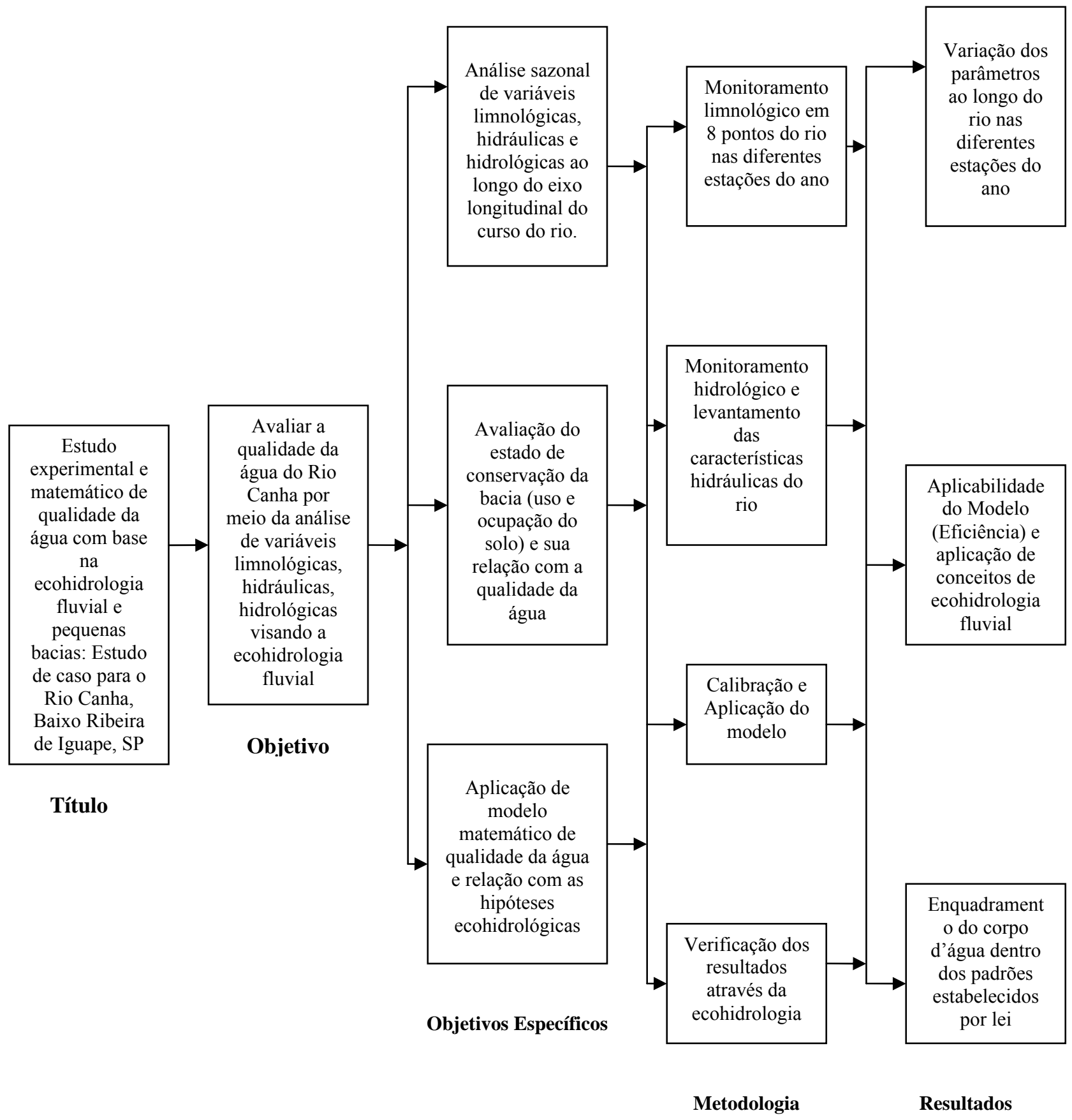

Figura I: Quadro síntese das etapas realizadas. 


\section{REVISÃO DA LITERATURA}

\subsection{A Bacia hidrográfica como unidade de estudo}

Bacia hidrográfica é uma área de drenagem que carreia diversos tipos de materiais ao longo de um curso d'água. Assim, qualquer ponto da superfície terrestre faz parte de uma bacia hidrográfica e não pode, portanto ser considerado de maneira isolada (CALIJURI et al., 2000).

Nesse sentido, o Conselho Nacional do Meio Ambiente (CONAMA), através da Resolução 001/86, considera a bacia hidrográfica como unidade para estudos de impacto ambiental. Em 1997, a Política Nacional de Recursos Hídricos implantou a lei $\mathrm{n}^{\mathrm{o}}$ 9.433, caracterizada por adoção do conceito de bacia hidrográfica como unidade de conservação e de planejamento, garantindo o uso e o reconhecimento da água como bem finito e vulnerável.

Visão holística refere-se a uma compreensão da realidade em função de totalidades integradas cujas propriedades não podem ser reduzidas a unidades menores. Assim, o uso de recursos naturais, sua conservação, sua preservação e a recuperação de ecossistemas relacionamse com a visão sistêmica e integrada da unidade bacia hidrográfica.

Uma bacia hidrográfica, considerada como unidade de estudo, apresenta inúmeras características fundamentais, das quais podem ser destacadas as interações entre os seus principais componentes, desde as interações entre fatores abióticos (clima, relevo) e bióticos (comunidade de plantas e animais), até a interação do homem e o impacto de suas atividades na qualidade da água. Portanto, as abordagens "bacia hidrográfica" e "qualidade da água" permitem compor um sistema que indica mecanismos de funcionamento das bacias hidrográficas e seus efeitos na qualidade da água.

Calijuri et al. (2000) cita ainda que uma bacia hidrográfica apresenta características que interagem entre si, formando uma rede interligada, de relações mútuas, permitindo assim uma análise integrada do potencial ecológico de acordo com a influência antrópica no sistema.

Atualmente, o conceito de microbacias vem sendo apontado como objeto de estudo na ciclagem de nutrientes, hidrologia e outros processos naturais. Deste modo, Calijuri \& Bubel (2006) citam que cada bacia é formada por um conjunto de microbacias e que os estudos de manejo devem ser direcionados de escala menores para maiores, uma vez que os processos ocorrem de montante (sistemas de cabeceiras - microbacias) a jusante (bacia hidrográfica). 
De acordo com Lima et al. (2000), a distinção entre bacia e microbacia é feita em relação ao tamanho, porém hidrologicamente é preciso considerar, não somente o tamanho, mas a influência de certos fatores na geração do deflúvio, pois uma das características típicas das microbacias é a grande sensibilidade a chuvas intensas e fatores como cobertura vegetal e geomorfologia.

Odum (1988) ressalta que as causas e soluções para problemas relacionados aos recursos hídricos não serão encontradas levando-se em consideração apenas a água, mas sim toda a bacia de drenagem, já que, na maioria das vezes, a gestão incorreta destrói os recursos hídricos.

Mendiondo et al. (2002) descrevem a importância de trabalhos desenvolvidos em bacias incrementais, visto que é possível integrar a resposta hidrológica do sistema em grande escala, uma vez que os eventos hidrológicos causam respostas do ambiente, as quais dependem do grau de degradação do mesmo.

Nesse contexto, estudos sobre qualidade da água, manejo e recuperação se tornam mais eficazes com a adoção da bacia hidrográfica como unidade de estudo, além da compreensão dos processos que ocorrem de montante a jusante, os quais permitem relacionar características naturais da bacia, como geomorfologia, hidrografia, pedologia, composição da comunidade animal e vegetal com atividades antrópicas que são, na maioria das vezes, responsáveis pela degradação dos recursos hídricos. A bacia hidrográfica, portanto, deve ser vista como unidade de controle, considerando-a como sistema integrado e complexo.

Apesar da grande importância dos sistemas lóticos, segundo Margalef (1983), somente recentemente esses passaram a ser estudados através de uma abordagem ecossistêmica. Apenas em 1970, quando Hynes publicou a obra "The ecology of the running waters" iniciaram-se os estudos da ecologia dos sistemas lóticos na Limnologia. Assim, desde o final do século passado, os estudos visavam uma abordagem holística, analisando conceitos e considerando os rios como resultados de combinações interdependentes das paisagens terrestre e aquática. Surge então, a análise ecossistêmica que utiliza como ferramenta de estudo, a unidade básica chamada bacia hidrográfica ou bacia de drenagem.

O transporte horizontal é o principal fator atuante em ecossistemas lóticos. Nos rios, a análise da variação longitudinal de determinadas variáveis físicas e químicas e a produção alóctone favorecida pela extensão lateral das bacias de cabeceira (microbacias) propiciaram a elaboração de algumas teorias ecológicas gerais para ecossistemas lóticos. 
Segundo a teoria proposta por Vannote et al. (1980) sobre Contínuo Fluvial ou "River Continum Concept", há ao longo do curso de um rio ou riacho, um gradiente de variáveis ecológicas da nascente à foz, assim ocorrem alterações no metabolismo das comunidades, na diversidade biológica, na largura, na profundidade, na temperatura, na concentração de nutrientes e no tamanho das partículas suspensas. Em função dessas alterações físicas e químicas ocorrem sucessões de espécies animais e vegetais desde a região das cabeceiras até a foz, resultando em diversos padrões de tamanho, transporte, utilização e estoque de matéria orgânica ao longo do rio.

De acordo com a teoria supracitada, os rios podem ser divididos em três segmentos ou zonas geomorfologicamante distintas: a primeira zona, caracterizada por nascente ou cabeceiras, as quais são fortemente influenciadas pelo sombreamento da mata ciliar e pela produção alóctone, além da baixa variação sazonal da temperatura, baixa diversidade biológica e substrato formado essencialmente por pedras e cascalhos.

A segunda zona, chamada zona intermediária ou médio curso, caracteriza-se por ampla variação sazonal da temperatura, alta diversidade biológica, diminuição da velocidade de escoamento e aumento da produção autóctone. Nesta zona, devido a características hidráulicas estáveis, a taxa de sedimentação se assemelha à taxa de remoção dos nutrientes e matéria orgânica do substrato.

$\mathrm{Na}$ terceira zona, ou baixo curso, há maior profundidade e fluxo reduzido, ocasionando maior deposição de substrato, geralmente partículas sedimentadas que foram erodidas de segmentos superiores. Este local possui menor heterogeneidade espacial e pequena variação térmica.

Essa teoria, no entanto, tem se mostrado limitada, uma vez que foi desenvolvida para ambientes isentos de atuação antrópica. Em ecossistemas lóticos com distintas características de altitude, latitude e meteorologia, além de intervenção humana, a proposta de Vannote (op. cit) pode sofrer desvios, mostrando restrições como indicam os estudos de Minshall (et al. 1985); Statzner \& Higler (1985) e Sabater (1989).

Nesse contexto, em 1983 foi proposto por Ward \& Stanford, o conceito de Descontinuidade Serial para ser aplicado em bacias hidrográficas impactadas pelo homem. De acordo com esses autores uma interferência humana como, por exemplo, a construção de uma barragem pode acarretar em alterações longitudinais dos processos bióticos e abióticos, sendo que a direção dessas alterações depende da posição da atividade impactante. 
Sabater et al. (1989) comentam que a teoria da Descontinuidade Serial pode ser utilizada para avaliar as variações ocasionadas por outros tipos de intervenções antrópicas como poluição, além da entrada de tributários e o processo de autodepuração.

Uma teoria que ganhou grande enfoque na ecologia dos ecossistemas fluviais foi proposta por Elwood et al. (1983), sobre espiral de nutrientes ou "nutrient spiralling concept". De acordo com esses autores os nutrientes não são ciclados em um determinado local, assim como em ambientes terrestres, pois devido ao movimento contínuo da água, a ciclagem é interrompida.

Outra teoria desenvolvida para o estudo de sistemas lóticos foi postulada por Junk et al (1989), a qual é utilizada para rios tropicais de médio e grande porte. De acordo com a teoria “Flood Pulse Concept in River Floodplain System”, os rios tropicais que possuem grandes áreas alagáveis estão sujeitos a inundações periódicas, as quais ocorrem em forma de pulsos que promovem significativas mudanças ecológicas em toda bacia hidrográfica. Deste modo, as interações no rio são dependentes direta ou indiretamente dos processos que ocorrem na planície alagável e não do transporte de cargas que ocorrem de montante a jusante.

Em 1999, Montgomery propôs o Process Domain Concept (Conceito de Domínio de Processos), como alternativa para o conceito de Contínuo Fluvial de Vannote et al. (1980). De acordo com o Conceito de Domínio de Processos os processos geomorfológicos têm grande influência na variabilidade espaço-temporal que ocorre nos ecossistemas aquáticos. Desta maneira, as características dos habitats são mais semelhantes dentro de uma mesma unidade litotrófica do que em uma mesma bacia hidrográfica que possua diferentes unidades litotróficas.

Rice (et. al. 2001) sugeriram que os tributários são importantes para caracterização das mudanças de gradientes físicos de um rio, como, vazão, velocidade, volume de água e declividade, além de assumirem um papel de destaque no transporte de sedimentos. Os autores citam ainda que essas mudanças são dependentes da escala da bacia e que de acordo do tamanho do tributário que adentra o rio principal, a confluência passa a ter características de cabeceira. Já para represas ou demais interferências antrópicas, Rice (et. al. 2001) assumiram que estas funcionam como tributários. 


\subsection{Autodepuração nos corpos de água}

Atualmente, devido ao crescimento populacional e ao desenvolvimento econômico, há uma crescente demanda por água, a qual muitas vezes se realiza de forma desordenada e inconsciente. Assim, efluentes dos mais diversos gêneros são lançados indiscriminadamente nos cursos d'água afetando consequentemente sua qualidade.

É importante ressaltar que a qualidade da água está intimamente relacionada com o tipo de uso que se faz da mesma e sua deterioração se dá, de maneira geral, ao tipo de uso e ocupação da bacia hidrográfica (VON SPERLING, 1995).

Margalef (1983) evidenciou que a composição química dos rios reflete a natureza das rochas e o grau de maturidade e conservação do solo, portanto as características dos ecossistemas adjacentes, diferentemente do que ocorrem em lagos. $\mathrm{O}$ autor (op. cit.) cita ainda que existe uma íntima relação entre composição da água e o meio terrestre que constitui as microbacias, uma vez que os rios drenam os solos e o estado de conservação deste exerce grande influência na variação dos componentes da água.

Recentemente, trabalhos como os de Santos (2000), Benassi (2002), Oliveira (2003 a, b) e Câmara (2004) concluíram que as variáveis limnológicas encontradas em sistemas lóticos estão intimamente ligadas às atividades presentes em sua bacia de drenagem, ou seja, estudos realizados em rios devem compreender também a caracterização dos processos que ocorrem em seu entorno, como uso e ocupação do solo.

Os rios têm, segundo Margalef (1994), um grande poder depurador que foi definido como a capacidade de "consumir" as formas poluentes. Von Sperling (1995) complementa que os corpos d'água possuem uma capacidade essencialmente natural de recuperação após o lançamento de um efluente. De acordo com Battalha (et. al.1986), as águas residuárias, domésticas ou industriais, quando lançadas num curso d'água sofrem um processo natural de purificação que se realiza por meio de processos físicos, químicos e biológicos.

Eiger (2003 a) comenta que no processo de autodepuração, mecanismos físicos, químicos e biológicos atuam na alteração da concentração de poluentes lançados em cursos d'água, sendo que, no caso de substâncias conservativas, a diminuição dessas concentrações se dá a partir do ponto de despejo, ao passo que no caso de sais nutrientes, por exemplo, a concentração dessas substâncias pode aumentar devido à reações existentes no meio aquático.

Von Sperling (1995) define quatro zonas de autodepuaração em um rio: 
- Zona de degradação: local de lançamento do efluente. A água torna-se turva, devido à presença de sólidos suspensos, que após sedimentação, formam os bancos de lodo. A decomposição ainda é incipiente, portanto, há oxigênio dissolvido na água para manutenção da vida aquática. $\mathrm{O}$ número de indivíduos menos adaptados às condições atuais são extintos e a presença de algas é rara, uma vez que a penetração de luz é pequena.

- Zona de decomposição ativa: nessa fase se inicia o processo de perturbação do sistema e os microorganismos desempenham ativamente a decomposição da matéria orgânica, consequentemente há uma drástica diminuição da concentração do oxigênio dissolvido (diminuindo o número de organismos aeróbios). A água apresenta coloração bastante acentuada com depósito de lodo escuro no fundo. O nitrogênio apresenta-se ainda na forma orgânica, embora grande parte já se encontre na forma de amônia.

- Zona de recuperação: grande parte da matéria orgânica já foi degradada, o que implica num baixo consumo de oxigênio. A água torna-se clara favorecendo a penetração de luz e consequentemente o processo de fotossíntese, intensificando a entrada de oxigênio na água. Há também introdução de oxigênio atmosférico na massa líquida. A amônia é convertida a nitrito e este a nitrato, além disso, os compostos de fósforo são transformados em fosfatos, acarretando na fertilização do meio. Nessas condições, a presença de microcrustáceos, moluscos, vermes, esponjas, dinoflagelados, larvas de alguns insetos e até mesmo alguns peixes mais tolerantes torna-se possível.

- Zona de águas limpas: o ecossistema encontra-se mais estável. Predominam as formas mais oxidadas e estáveis dos compostos de nitrogênio e fósforo. Em relação ao oxigênio dissolvido e à matéria orgânica, o corpo d'água volta às condições normais.

Von Sperling (1995) cita também que o conceito de autodepuração é relativo, uma vez que a água pode ser considerada depurada mesmo que não esteja totalmente purificada em termos higiênicos. Deve-se considerar que a água está depurada quando suas características não sejam conflitantes com sua utilização, pois não existe depuração absoluta. $\mathrm{O}$ ecossistema pode atingir um estado de equilíbrio, mas em condições diferentes devido ao aumento da concentração de certos produtos da decomposição.

De acordo com Benassi (2002) uma água pode ser considerada depurada sob o ponto de vista ecológico, mesmo que ainda seja considerada imprópria em termos higiênicos, assim a capacidade depurativa está intimamente relacionada com os usos preponderantes a que a água se destina. Baseado no fato de que a maioria dos corpos d'água encontra-se degradado e que estes 
têm capacidade natural de recuperação, quando leva-se em consideração sua capacidade de suporte, torna-se imprescindível o estudo do processo autodepurativo desses ecossistemas atrelado ao limite de assimilação dos corpos d'água, de forma a não comprometer a qualidade dos mesmos.

O presente trabalho avaliou a capacidade de autodepuração do Rio Canha, de acordo com a variação da precipitação e empregando-se conceitos da ecohidrologia, a fim de verificar se os parâmetros limnológicos estão de acordo com os propostos pela Resolução CONAMA 357/05 para classe 2.

\subsection{Ecohidrologia: Conceitos e Aplicações}

Pesquisas que abordam a interface hidrologia-ecologia não são recentes (Eagleson, 1978, Vannote et al., 1980, Junk et al. 1989), entretanto ainda não se utilizava os termos atuais. A literatura recente trata dos termos ecohidrologia e hidroecologia como o surgimento de uma nova disciplina que marca a influência da hidrologia nos processos ecológicos, principalmente àqueles referentes aos sistemas de água doce. Entretanto os autores acima citam que há necessidade de se explicitar se os termos ecohidrologia e hidroecologia são bem explicados e entendidos, além de que é necessário esclarecer se esses termos e suas definições tratam-se de uma mudança de paradigmas ou apenas uma outra visão científica a respeito dos processos hidrológicos e ecológicos.

De acordo ainda com os autores supracitados, primeiramente é preciso enfatizar que quando se nos referimos à ecohidrologia, o prefixo "eco" modifica a palavra hidrologia, portanto a ciência com maior ênfase, nesse caso, é a hidrologia. Já no caso da hidroecologia ocorre o inverso. Contudo, ambos os termos referem-se a uma abordagem interdisciplinar, na qual há uma sobreposição dos processos ecológicos e hidrológicos, a qual considera a influência da hidrologia nos ecossistemas e vice-versa.

Em pesquisas realizadas pelos autores anteriormente citados, em sites como Web of Science demonstraram, a partir da busca por palavras chave como "ecohidrologia", "eco-hidrologia", "hidroecologia" e "hidro-ecologia" que o termo mais frequentemente empregado é "ecohidrologia".

Zalewski (et al., 1997) afirma que a ecohidrologia é o estudo da inter-relação funcional entre hidrologia e biota em escala de bacia. Esta definição é bastante funcional no que diz respeito à 
conservação biológica, particularmente em termos de se obter e avaliar respostas de sistemas submetidos à stress natural ou antropogênico.

Dunbar e Acreman ${ }^{1}$ (2001) apud Hannah (et al. 2004) definem ecohidrologia como a ligação do conhecimento hidrológico, hidráulico, geomorfológico e biológico/ecológico para predizer a variação das respostas da biota e do ecossistema como um todo à variação dos fatores abióticos em escala temporal e espacial.

Alguns autores como Zalewski e Robarts (2003) consideram a ecohidrologia como um novo paradigma, uma disciplina emergente na interface das ciências hidrológicas e ecológicas. Porém autores como Bonell (2002) acreditam que a ecohidrologia é uma importante mudança do pensamento científico, principalmente devido à integração de ciências distintas operadas por profissionais de diferentes áreas que se associam em trabalhos interdisciplinares, entretanto não concordam que seja uma abordagem inteiramente nova.

Shrivastava (2006) ressalta ainda a importância de se considerar as escalas espaciais (bacia) e temporais (sazonalidade) em pesquisas que tratam de ecohidrologia, uma vez que o regime hidrológico de uma determinada região rege diferentes habitats nas diferentes estações do ano, além disso, cada habitat tem sua peculiaridade, necessitando de mais ou menos água em determinados momentos.

A crescente demanda por água e os métodos incipientes de tratamento de poluição fizeram com que o conceito de ecohidrologia crescesse nos últimos anos, sendo estimulado pela UNESCO-IHP (ZALEWSKI e ROBARTS, 2003). Segundo os mesmos autores (op cit.) o ponto de partida para trabalhos que integrem duas ciências distintas e profissionais de áreas, que até então, eram consideradas opostas foi a formulação de três princípios básicos: o ecológico, o hidrológico e o ecotecnológico.

Para aplicação e implementação da ecohidrologia, Zalewski e Robarts (op cit.) utilizam como exemplo o sistema de tratamento de esgotos de cidades de pequeno à médio porte, que muitas vezes não surte o efeito desejado devido à problemas financeiros, comprometendo assim a qualidade das águas doces de rios e reservatórios. Uma alternativa barata e tanto ecologicamente como socialmente viável seria, de acordo com os autores anteriormente citados, a utilização de wetlands naturais ou artificiais para retenção de poluentes. Essas wetlands empregariam espécies

\footnotetext{
${ }^{1}$ DUNBAR, M.J.; ACREMAN, M.C.(2001). Applied hidro-ecological sciece for twenty-first century. In: Hydroecology: linking hydrology and aquatic ecology. Acreman, M.C. (ed).IAHS Publication n²66, IAHS Press: Wallingford 1-17
} 
vegetais adequadas, que por sua vez participariam do ciclo hidrológico, além de poderem ser utilizadas para absorção de carbono do meio. O resíduo resultante do tratamento poderia ser utilizado como fertilizante em plantações e a produção de bioenergia geria empregos.

Almeida-Neto (2007) reporta a influência do pulso de inundação em wetland natural localizadas às margens do rio Jacupiranguinha - SP. De acordo com esse autor a concentração e carga de alguns indicadores de qualidade da água sofreram alterações com a flutuação da cota hidrométrica e vazão. A interpretação de problemas tanto relacionados à ecologia como à hidrologia devem levar em consideração conceitos como resiliência, vulnerabilidade, dinâmica e diversidade, a fim de se propor alternativas em escalas espaciais e temporais (ALMEIDA-NETO e MENDIONDO, 2008). Os autores (op cit.) ressaltam ainda que esta abordagem permite inferir resultados para cenários de longo prazo, através de vazões de permanência e análise se incertezas.

\subsection{Monitoramento hidrológico}

As condições hidrológicas são extremamente importantes para manutenção dos sistemas fluviais, uma vez que afetam a diversidade, a produção primária, o transporte de sedimentos e os ciclos de um modo geral. Em relação ao processo de autodepuração, o monitoramento hidrológico torna-se fundamental para entender as alterações nas concentrações de poluentes nas diferentes estações do ano.

Borges et. al. (2005) comentam que o comportamento hidrológico de determinada área influencia na implantação de medidas que contemplem o desenvolvimento sustentável, uma vez que a relação entre quantidade e qualidade da água é responsável direta por um manejo adequado dos recursos hídricos e a conseqüente promoção da sustentabilidade.

Medidas hidrológicas como precipitação, vazão e evaporação são essenciais para o entendimento do comportamento hidrológico de uma bacia hidrográfica, sejam para um evento em particular ou para um dado período de tempo. Estes dados dão suporte à calibração e à validação de modelos hidrológicos e, consequentemente, de hipóteses científicas incorporadas nestes modelos (MARTINS e PAIVA, 2001).

Segundo Almeida-Neto (2006), o aproveitamento das águas se dá por captação superficial, assim, as águas subterrâneas são utilizadas apenas ocasionalmente. Dessa maneira, o estudo do ciclo hidrológico constitui-se em um tópico de grande importância em hidrologia. 
Todos os processos componentes do ciclo hidrológico (precipitação, infiltração, escoamento superficial, evaporação e transpiração), além das atividades antrópicas integram-se em um ciclo dinâmico que se estende por todo o planeta.

\subsection{Modelagem Matemática}

Para Chapra (1999), os modelos matemáticos de qualidade da água têm se desenvolvido satisfatoriamente desde os últimos anos do século vinte e seguem o seguinte histórico.

Os primeiros modelos estavam focados nos problemas urbanos de cargas poluidoras e esgoto. Ainda nos primórdios dos trabalhos de modelagem, surgiu o trabalho pioneiro desenvolvido por Streeter e Phelps de 1925. Posteriormente surgiram trabalhos investigativos sobre o nível de oxigênio na água, além de modelos relacionados à patógenos, como certas bactérias.

Devido à falta de disponibilidade de computadores e ferramentas computacionais, os modelos mais antigos eram do tipo "caixa preta" e as equações eram limitadas à cinética linear, geometrias simples e fluxo de água contínuo. Já na década de 60, os computadores eram ferramentas mais acessíveis, o que levou a um avanço nos modelos, bem como na aplicação dos mesmos.

O primeiro modelo mais avançado ainda tinha como foco o oxigênio, mas o computador permitia análises mais complexas das variáveis enfocadas, possibilitando estudar a bacia de drenagem como um todo.

Nos anos 70 um movimento ambiental estava nascendo e a consciência ecológica mudou o foco dos modelos de qualidade da água, que até então trabalhavam oxigênio dissolvido e cargas pontuais de poluição urbana. O principal problema ambiental em discussão nessa época era a eutrofização, assim engenheiros ambientais trabalhavam para inserir em seus modelos representações de processos ecológicos e graças à existência de ferramentas computacionais foi possível empregar reações cinéticas não lineares e outros procedimentos relacionados à ecologia nos modelos.

Uma vez que a grande preocupação era a eutrofização, maior atenção foi dada às cargas não pontuais de poluição, já que estas podem contribuir sobremaneira para o incremento de nutrientes na água. Esse tipo de variável passou a ser inserida nos modelos subseqüentes. No 
entanto, os modelos relacionados à eutrofização não tiveram muito sucesso no que diz respeito ao gerenciamento de recursos hídricos, pois a eutrofização é um processo muito dinâmico, complexo e computacionalmente intenso em relação aos outros problemas antes enfocados pelos modelos.

O mais recente estágio dos modelos de qualidade da água evoluiu a partir da metade da década de 70, quando foram feitos grandes esforços para controlar a poluição, principalmente àquelas relacionadas ao prejuízo da saúde humana, como contaminação por substâncias tóxicas e chuva ácida.

Os modelos mais avançados deste período enfocavam o papel da matéria sólida no transporte e destino de substâncias tóxicas, particularmente a precipitação e ressuspensão dessas substâncias e mecanismos de controles para as mesmas. Além disso, fitoplâncton e detritos orgânicos tornaram-se uma grande preocupação uma vez que eles são a base da cadeia alimentar e podem passar consequentemente substâncias poluidoras para organismos maiores. Assim, a cadeia alimentar passou a ser considerada nos modelos, pois entende-se seu papel de concentradora e transportadora de substâncias tóxicas.

Desse modo, os modelos passaram a englobar diversos fenômenos, dando um enfoque cada vez mais próximo à realidade através da inserção de diferentes processos, por meio de uma visão mais integrada do ecossistema.

Apesar da complexidade dos processos hidrológicos, físicos, químicos e biológicos que ocorrem nos corpos d'água, os modelos matemáticos têm sido empregados de forma a englobálos de maneira simplificada e prática (GASTALDINI, 1982).

Battalha (1986) também cita a utilização de modelos matemáticos para compreensão dos processos que ocorrem num corpo de água, levando em consideração os mecanismos de autodepuração para melhoria da qualidade da água.

Uma alternativa para estimativa do impacto de despejos na qualidade das águas em rios é a utilização de modelos matemáticos, prática que tem crescido drasticamente nos últimos anos e vem se consolidando como uma nova ferramenta para a gestão dos recursos hídricos (DROLC \& KONCAN, 1996)

Rauch et al. (1998) apresentaram um estado da arte sobre modelos de qualidade da água e concluíram que os mesmos podem ser usados como ferramenta para controle de lançamentos de poluentes. 
Tucci (1998) apresenta modelos de qualidade da água para rios e lagos utilizando equações que levam em consideração parâmetros físicos, químicos e biológicos da água, além das condições hidrológicas.

Benassi (2002) utilizou o modelo QUAL2E para simular a autodepuração no ribeirão Bonito e concluiu que este modelo pode ser utilizado para predição do funcionamento do sistema, auxiliando na determinação de cenários.

Park et al. (2002) realizaram um estudo da qualidade da água em um rio da Coréia através de modelagem matemática. Este estudo comparou dois modelos, o conhecido e amplamente utilizado QUAL2E e sua forma mais atual, o QUAL2K, destacando que as modificações feitas neste último possibilitaram resultados mais precisos, os quais serviram como ferramenta para tomadas de decisão em âmbito político.

Os modelos que consideram qualidade da água, uso e ocupação do solo e hidrologia são poucos e pobremente difundidos, porém possuem uma excelente capacidade preditiva, e hoje em dia, com os avanços das disciplinas e tecnologias torna-se possível inserir nesses modelos maior número de variáveis ecológicas capazes de predizer sobre o fluxo da água na bacia e seu impacto nos cursos d'água, dependendo do uso e ocupação do solo (HORMANN et. al. 2005).

Tundisi (1999) cita que no futuro os profissionais ligados à área de recursos hídricos deverão apresentar cenários com várias possibilidades de gerenciamento, além de propor alternativas adequadas para os mesmos. Sendo assim, a modelagem ecológica será a principal ferramenta para suporte à tomadas de decisão.

De acordo com Tucci (1998), os modelos matemáticos de qualidade da água devem ser vistos como ferramentas importantes para simular questões neste âmbito, uma vez que permitem representar alternativas propostas e simular condições reais. Deste modo, a utilização de um modelo matemático poderia revelar a adequação do mesmo em responder como o ambiente reagiria a diferentes inputs de nutrientes, tornando-se uma ferramenta de grande utilidade para gerenciamento de corpos d'água e até mesmo para proposição de metas de recuperação ambiental.

Os modelos matemáticos podem propiciar uma visão abrangente dos impactos ambientais resultantes das atividades humanas, no entanto a escolha de um modelo para determinado estudo deve ser feita de forma crítica, uma vez que, em alguns casos, os mesmos são extremamente precisos para representar a realidade, já em outros, os modelos são apenas mera aproximação da realidade (EIGER, 2003b). O referido autor destaca ainda que em ambientes muito complexos o 
modelo adotado pode gerar erros de grande magnitude e conclusões duvidosas. Além disso, em fenômenos de transporte de poluentes a dimensionalidade deve ser muito bem examinada antes da adoção de determinado modelo, adotando-se critérios adequados de validade e estudos em campo, sempre que possível.

Os modelos de qualidade da água disponíveis atualmente e mais amplamente utilizados são, de acordo com Cox (2003):

- SIMCAT (SIMulation CATchment) - modelo unidimensional, que simula em fluxo permanente e não utiliza o modelo de advecção-dispersão para transporte de poluentes.;

- TOMCAT (Temporal/Overall Model for CATchment) - modelo unidimensional e conceitualmente idêntico ao SIMCAT, utiliza também uma abordagem estocástica de Monte Carlo;

- QUAL2E - modelo unidimensional que simula em condições de fluxo permanente. É, dentre todos, o modelo mais utilizado com grande número de artigos científicos documentando seus resultados. Tal modelo é capaz de contabilizar efeitos de variações meteorológicas. Embora o QUAL2E seja um modelo de fluxo permanente, sua conceitualização é muito mais avançada quando comprada com o SIMCAT e o TOMCAT, já que o QUAL2E permite que o rio seja dividido em uma série de elementos computacionais a serem simulados;

- QUASAR, HERMES e QUESTOR - todos esses modelos são atualmente as versões do denominado QUASAR, a principal diferença entre eles está no modo como o sistema é implementado. Unidimensional, é um modelo dinâmico, ou seja, o transporte e a transformação de substâncias variam no tempo. QUASAR e QUESTOR ainda possuem a opção de simular estocasticamente de acordo com a metodologia de Monte Carlo. HERMES já é um modelo mais simplificado em relação ao QUASAR e QUESTOR, os quais são capazes de simular grandes rios com múltiplas influências;

- MIKE-11 - Modelo unidimensional que simula um fluxo dinâmico em rios sob condições homogêneas dentro do canal. O transporte de substâncias é simulado segundo equações de advecção-dispersão;

- ISIS - modelo dinâmico é bastante utilizado por grupos de defesa de enchentes, pois possibilita boa adequação dos dados.

Assim o autor supracitado classifica:

- Modelos simples: SIMCAT e TOMCAT;

- Modelos intermediários: QUAL2E e QUASAR; 
- Modelos complexos: MIKE-11 e ISI.

É válido lembrar a importância da calibração dos modelos e do teste de sensibilidade para validação dos dados, salientando que em simulações para diferentes períodos do ano com condições climáticas extremamente diferentes de vazão e temperatura, por exemplo, novas calibrações devem ser consideradas (DROLC \& KONCAN, 1996; KNAPIK et al. 2006).

Em relação ao transporte de poluentes, Cunge et al. (1980) destacam que embora muitos aspectos da modelagem de qualidade das águas possam ser considerados de modo independente, o transporte de substâncias dissolvidas ou suspensas devem ser relacionados com o tipo de escoamento em canais abertos nas modelagens. Dentre os tipos de transporte de substâncias destacam-se o processo de dispersão, convecção e difusão turbulenta.

A dispersão caracteriza-se pela difusão de uma molécula em uma substância neutra, sendo que esse fluxo é proporcional ao seu gradiente de concentração e matematicamente esse processo ocorre em três dimensões, através da equação (CUNGE op cit.):

\section{Equação 3.1}

$\left(\frac{\partial C}{\partial t}\right)=\frac{\partial}{\partial x}\left(\in m \frac{\partial C}{\partial x}\right)+\frac{\partial}{\partial y}\left(\in m \frac{\partial C}{\partial y}\right)+\frac{\partial}{\partial z}\left(\in m \frac{\partial C}{\partial z}\right)$

em que:

$C=$ é a concentração de determinada substância

$\epsilon_{m}=$ é o coeficiente de difusão molecular $\left(\mathrm{m}^{2} / \mathrm{s}\right)$

O autor supracitado comenta ainda que pelo processo de dispersão um ponto de tinta que cai na água leva 24 horas para alcançar um diâmetro de 1 metro, sob condições de regime permanente. Entretanto se a água segue um regime turbulento, ocorre outro fenômeno, o da dispersão turbulenta.

Se um pequeno número de partículas fosse liberado numa substância neutra num ponto $\mathrm{P}$ qualquer, seria possível notar que em certa distância à jusante, tais partículas estariam bastante dispersas umas das outras. Esse processo é caracterizado como dispersão turbulenta (CUNGE et al. 1980). A descrição matemática do processo de dispersão é dada por: 


\section{Equação 3.2}

$\left(\frac{\partial C}{\partial t}\right)+u \frac{\partial C}{\partial x}+v \frac{\partial C}{\partial y}+w \frac{\partial C}{\partial z}=\frac{\partial}{\partial x}\left(\in m \frac{\partial C}{\partial x}\right)+\frac{\partial}{\partial y}\left(\in m \frac{\partial C}{\partial y}\right)+\frac{\partial}{\partial z}\left(\in m \frac{\partial C}{\partial z}\right)$

em que:

$u, v$ e $w=$ componentes das velocidades instantâneas $x, y$ e $z$, respectivamente.

De acordo com Cunge et al. (op cit.), o movimento de uma determinada partícula em uma solução neutra pode estar sujeito a três tipos de influência: difusão molecular, velocidade média temporal e flutuações da velocidade turbulenta. A difusão molecular é frequentemente negligenciada em modelos de transportes em rios (devido à sua pequena ordem de grandeza), já a velocidade média temporal pode ser estimada facilmente. A grande dificuldade é relacionar o transporte de massa devido à flutuações da velocidade turbulenta.

O referido autor ressalta ainda que a distribuição da difusividade turbulenta em um escoamento não é uniforme, mas depende da orientação da velocidade de flutuação e da distância das paredes. Contudo, em sistemas reais, as velocidades médias tridimensionais ( $\mathrm{x}, \mathrm{y}$ e $\mathrm{z})$ não são bem conhecidas ou difíceis de serem obtidas, assim devido à profundidade de um rio ser frequentemente menor quando comparada com a largura, essa componente pode ser desprezada na modelagem de sistemas fluviais.

Deste modo, em um rio, uma substância torna-se verticalmente bem misturada num curto espaço de tempo. Consequentemente a distribuição da concentração na dimensão vertical torna-se uniforme muito rapidamente, antes da uniformidade horizontal ser obtida. É importante ter em mente as conseqüências das simplificações, mas também é essencial saber que elas são indispensáveis para trabalhos com modelagens. (CUNGE op cit.). A figura 2 apresenta os componentes do processo de dispersão. 


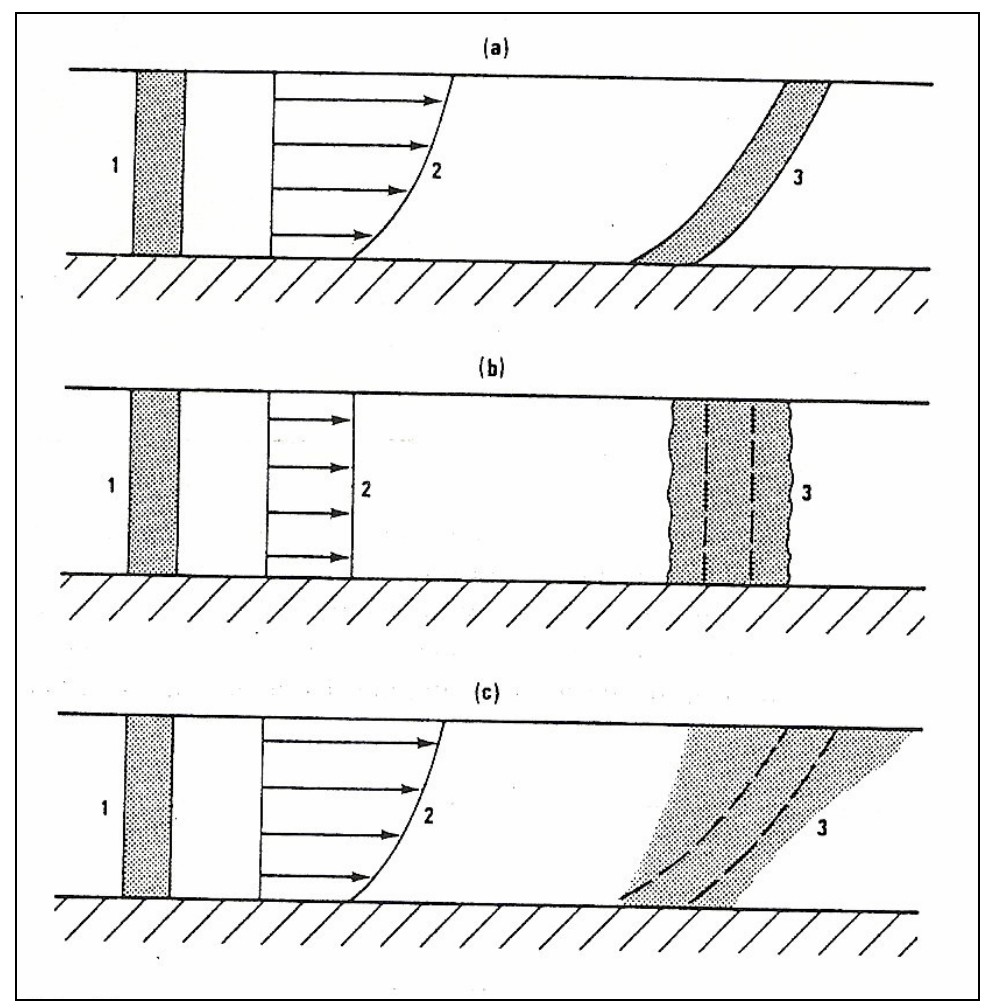

Figura II: Componentes da dispersão. 1, distribuição inicial de uma substância; 2, perfil de velocidade; 3, distribuição da substância após um período de tempo. (a) Convecção diferencial sem difusão. (b) Difusão sem convecção diferencial. (c) Combinação de convecção diferencial e difusão = dispersão.

Para os modelos de dispersão unidimensionais, como é o caso do QUAL2K, Cunge et al. (1980) relata ainda que uma substância através do processo de dispersão longitudinal, sendo totalmente misturada numa dada seção transversal, de acordo com o processo de difusão de Fick. A equação de dispersão é dada por:

\section{Equação 3.3}

$\frac{\partial C}{\partial t}\left(A C_{a}\right)+\frac{\partial}{\partial x}\left(A U C_{a}\right)=\frac{\partial}{\partial x}\left(A K_{x} \frac{\partial C}{\partial x}\right)$

sendo que:

$C_{a}=$ média da concentração na seção transversal $(\mathrm{mg} / \mathrm{L})$

$U=$ média das velocidades na seção $(\mathrm{m} / \mathrm{s})$

$A$ = área da seção $\left(\mathrm{m}^{2}\right)$

$K_{x}=$ coeficiente de mistura longitudinal 


\subsubsection{O Modelo Qual2K}

3.4.1.1 Manual do modelo (Adaptado de Chapra et. al. 2006)

O QUAL2K (Q2K) é um modelo de qualidade da água de rios e córregos, elaborado para representar uma moderna versão do modelo QUAL2E (Q2E). O modelo Q2K é similar ao modelo Q2E nos seguintes aspectos:

- Unidimensional. Concentração do material em estudo é homogênea numa mesma seção transversal;

- A simulação é feita com vazão constante. Não uniforme;

- Balanço de calor ao longo das variações diáriaș;

- Entrada de calor e massa. Simulação das fontes pontuais e difusas de entrada e saída.

O modelo Q2K se difere do modelo Q2E nos seguintes aspectos:

- Software com interfaces ambiental. O Q2K é implementado em extensão Microsoft Windows. Este programa utiliza como macro linguagem o Visual Basic. O Excel é utilizado como interface gráfica;

- Modelo de segmentação. O modelo Q2E requer que o sistema hídrico seja segmentado em elementos de igual tamanho. Já o modelo Q2K permite a segmentação de trechos com elementos de tamanhos diferentes, além de permitir em cada elemento inserir múltiplas cargas e abstrações;

- Especificações da DBO. O modelo Q2K usa duas formas de representar o carbono orgânico. Estas formas representam à oxidação lenta, DBO lenta, e a oxidação rápida, DBO rápida, da matéria orgânica. $\mathrm{O}$ modelo simula também material particulado orgânico, detritos, não vivos;

- O modelo Q2K considera a redução de compostos em nível zero de oxigênio, fase anóxica. O processo de desnitrificação é modelado em uma reação de primeira ordem, o qual torna-se efetivo em baixas concentrações de oxigênio;

- $\quad$ Algas de fundo. O modelo simula as algas presas ao fundo;

- Inibição da luz. A taxa de inibição da luz é calculada em função das algas, detritos e sólidos inorgânicos;

- $\quad \mathrm{pH}$. Tanto a Alcalinidade como o Carbono Inorgânico Total são simulados. O pH do rio é calculado de acordo com estas duas variáveis;

- Patógenos. É simulado um agente patogênico qualquer. A remoção dos agentes patogênicos é simulada em função da temperatura, da luz e da sedimentação. 
- Parâmetros cinéticos específicos de cada trecho. O modelo Q2K permite especificar vários parâmetros cinéticos de um trecho específico.

\section{Representação Conceitual}

O Q2K considera toda extensão do rio com características hidráulicas constantes, em cada trecho, como por exemplo: inclinação do talude, largura de fundo, etc. Na Figura III é apresentada um corpo hídrico dividido em trechos que são numerados em ordem crescente, sendo que o primeiro trecho começa no ponto mais alto do corpo hídrico (cabeceira). É importante observar que as fontes pontuais e as fontes difusas podem ser posicionadas em qualquer trecho, assim como os pontos de abstração e as fontes difusas de abstração.

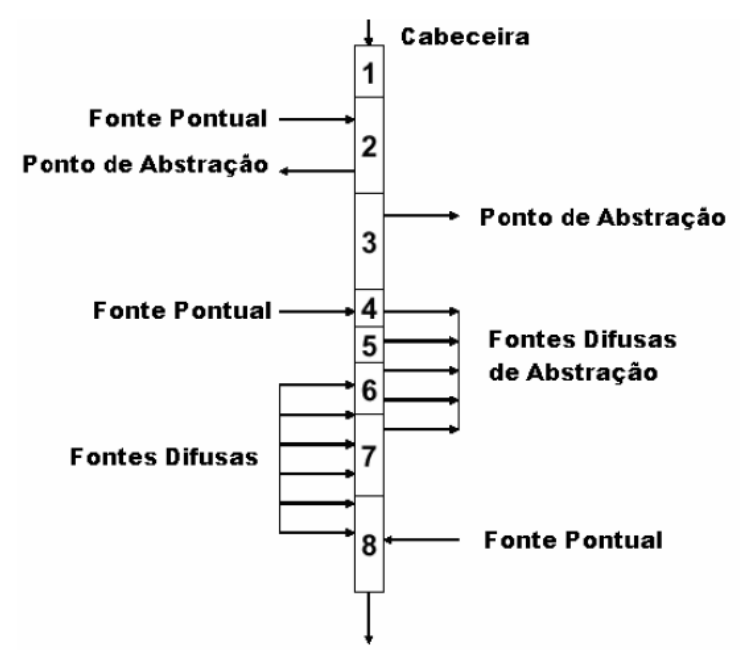

Figura III: Diagrama de um corpo hídrico ausente de tributários. Fonte: Adaptado de Chapra et al. (2006).

Na Figura IV é apresentado um diagrama de um corpo hídrico com seus tributários. A segmentação e a numeração dos trechos segue de acordo com o diagrama anterior (Figura III), porém, quando ocorre à junção de um tributário a numeração prossegue consecutivamente do ponto mais alto (segmento de cabeceira) deste tributário. Salienta-se que, o curso principal e seus tributários são diferenciados numericamente para que haja uma distinção entre os mesmo. Esta diferenciação é uma prática importante porque o software gera um lote para cada tributário e para o curso principal. Finalmente, a distância de cada trecho pode ser subdividida em um série elementos computacionais. Na Figura V, é especificado o número de elementos que se deseja para cada trecho. 


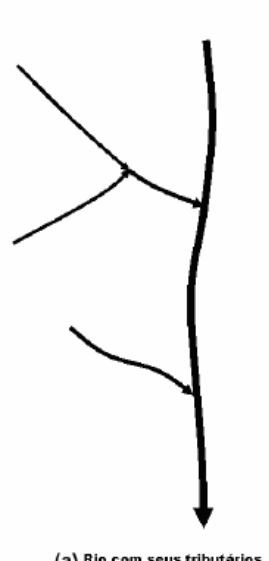

(a) Rio com seus tributários

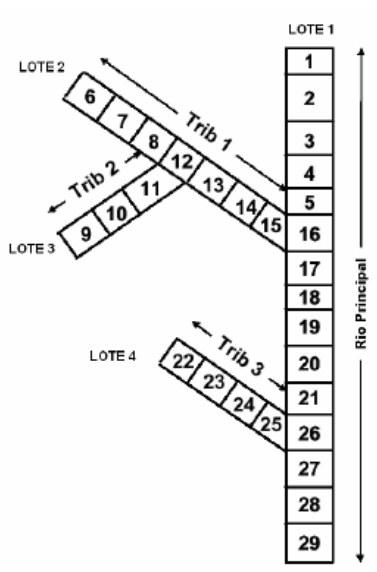

(b) Representação dos Trechos

Figura IV: Diagrama da representação de um rio com seus tributários (a), representaão dos trechos e numeração dos tributários (b). Fonte: Adaptado de Chapra et al. (2006).

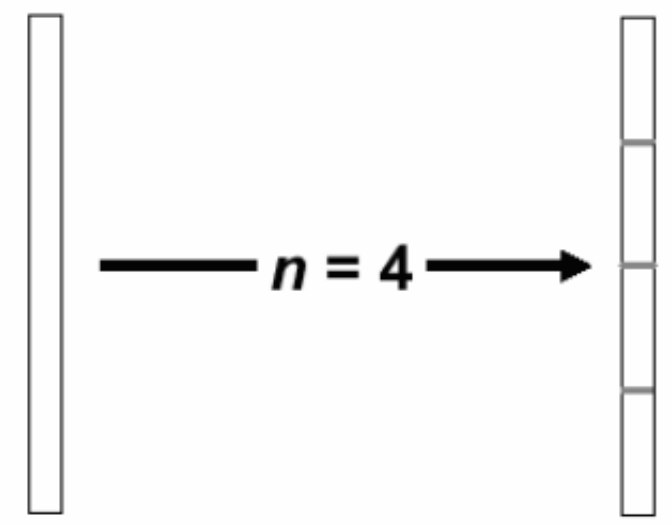

Trecho

Elementos

Figura V: Subdivisão dos trechos em "n" elementos de igual comprimento. Fonte: Adaptado de Chapra et al. (2006).

\section{Representação Funcional}

\section{Balanço de Vazão}

Em cada elemento computacional é realizado um balaço da vazão, considerando o escoamento em regime permanente (Figura 4). Na Equação 1, apresenta-se o procedimento para o cálculo da vazão de saída $i$.

\section{Equação 3.4}

$Q_{i}=Q_{i-1}+Q_{i n, i}-Q_{o u t, i}$ 
em que:

$Q_{i}=$ vazão de saída do elemento $i$ e de entrada do elemento $i+1$ a jusante $\left(\mathrm{m}^{3} / \mathrm{d}\right)$;

$Q_{i-1}=$ vazão de saída do elemento $i-1$ a montante do elemento $i\left(\mathrm{~m}^{3} / \mathrm{d}\right)$;

$Q_{i n, i}=$ vazão de entrada no elemento $i$ por fontes pontuais e/ou difusas $\left(\mathrm{m}^{3} / \mathrm{d}\right)$;

$Q_{\text {out }, i}=$ vazão de abstração do elemento $i$ por fontes pontuais e/ou difusas $\left(\mathrm{m}^{3} / \mathrm{d}\right)$

O balanço geral da vazão de entrada é descrito pela Equação 2:

\section{Equação 3.5}

$Q_{i n, i}=\sum_{j=1}^{p s, i} Q_{p s, i, j}+\sum_{j=1}^{n p s, i} Q_{n p s, i, j}$

sendo que:

$Q_{p s, i} j=$ vazão de entrada no elemento $i\left(\mathrm{~m}^{3} / \mathrm{d}\right)$ - fonte pontual $j$;

$p s i=$ número total de fontes pontuais no elemento $i$;

$Q_{n p s, i, j}=$ vazão de entrada no elemento $i\left(\mathrm{~m}^{3} / \mathrm{d}\right)$ - fonte difusa $j$;

$n p s i=$ número total de fontes difusas no elemento $j$

O balanço geral da vazão de abstração é descrito pela Equação 3:

\section{Equação 3.6}

Qout $, i=\sum_{j=1}^{p a i} Q p a, i, j+\sum_{j=1}^{n p a i} Q n p a, i, j$

em que:

$Q_{p a, i, j}=$ vazão de abstração no elemento $i\left(\mathrm{~m}^{3} / \mathrm{d}\right)$ - fonte pontual $j$;

$p a i=$ número total de fontes pontuais de abstração no elemento $i$;

$Q_{n p a, i, j}=$ vazão de abstração no elemento $i\left(\mathrm{~m}^{3} / \mathrm{d}\right)$ - fonte difusa $j$;

$n p a i=$ número total de fontes não pontuais de abstração no elemento $i$ 


\section{Características Hidráulicas}

Uma vez que a vazão de cada elemento é calculada, a profundidade e a velocidade podem ser obtidas das seguintes maneiras: represas, curva-chave (h vs. Q) e equações de Manning.

- Se altura e largura da represa forem colocadas como dados de entrada, então a opção "represa" será implementada;

- Se a altura e a largura da represa são admitidas como zero e os coeficientes das curvas chave (a e $\alpha$ - coeficientes empíricos determinados a partir da velocidade-vazão e altura-vazão das curvas chave) forem colocados como dados de entrada, a opção "rating curves" será implementada.

- Se nenhuma das condições acima for implementada pelo usuário, o Q2K utilizará a equação de Manning.

No presente trabalho será utilizada a equação de Manning para o cálculo da profundidade e velocidade. Assim, cada elemento é idealizado pelo modelo como um canal trapezoidal. Sob condições de fluxo permanente, a equação de Manning pode ser utilizada para expressar a relação entre vazão e profundidade, como:

\section{Equação 3.7}

$Q=\frac{S_{0}{ }^{1 / 2}}{n} \frac{A c^{5 / 3}}{P^{2 / 3}}$

em que:

$\mathrm{Q}=$ vazão $\left(\mathrm{m}^{3} / \mathrm{s}\right)$;

$\mathrm{S}_{\mathrm{o}}=$ declividade de fundo $(\mathrm{m} / \mathrm{m})$;

$\mathrm{n}$ = coeficente de rugosidade de Manning;

$\mathrm{A}_{\mathrm{c}}=$ área da seção transversal $\left(\mathrm{m}^{2}\right)$;

$\mathrm{P}=$ perímetro molhado $(\mathrm{m})$

A área da seção transversal do canal trapezoidal é calculada por:

\section{Equação 3.8}

$A c=\left[B_{0}+0,5\left(s_{s 1}+s_{s 2}\right) H\right]$ 
em que:

$\mathrm{B}_{0}=$ largura do canal $(\mathrm{m})$;

$\mathrm{s}_{\mathrm{s} 1}$ e $\mathrm{s}_{\mathrm{s} 2}=$ declividade dos lados do canal $(\mathrm{m} / \mathrm{m})$;

$\mathrm{H}=$ profundidade do elemento $(\mathrm{m})$

A fórmula seguinte apresenta o cálculo do perímetro molhado:

\section{Equação 3.9}

$$
P=B 0+H \sqrt{s_{s 1}^{2}+1}+H \sqrt{s_{s 2}^{2}+1}
$$

Substituindo as equações 3.8 e 3.9, a equação 3.7 pode ser resolvida da seguinte forma:

\section{Equação 3.10}

$H_{k}=\frac{(Q n)^{3 / 5}\left(B_{0}+H_{k-1} \sqrt{s_{s 1}^{2}+1}+H_{k-1} \sqrt{s_{s 2}^{2}+1}\right)^{2 / 5}}{S^{3 / 10}\left[B_{0}+0,5\left(s_{s 1}+s_{s 2}\right) H_{k-1}\right]}$

em que:

$\mathrm{k}=1,2 . . \mathrm{n}, \mathrm{n}=$ número de repetições. Como hipótese inicial emprega-se $\mathrm{H}_{0}=0$. $\mathrm{O}$ cálculo termina quando o erro estimado é menor que um valor especificado de $0,001 \%$. O erro estimado é calculado por:

\section{Equação 3.11}

$\varepsilon_{a}=\left|\frac{H_{k+1}-H_{k}}{H_{k+1}}\right| 100 \%$

A velocidade pode ser estimada a partir da equação de continuidade:

\section{Equação 3.12}

$U=\frac{Q}{A_{c}}$ 
A largura média do elemento, B (m), é calculada da seguinte forma:

\section{Equação 3.13}

$B=\frac{A_{c}}{H}$

A largura do topo, B1(m), é calculada pela equação 11:

\section{Equação 3.14}

$B_{1}=B_{0}+\left(s_{s 1}+s_{s 2}\right) H$

A área da superfície e o volume do elemento podem ser calculados como:

\section{Equação 3.15}

$A_{s}=B_{1} \Delta x$

\section{Equação 3.16}

$V=B H \Delta x$

sendo que:

$\Delta x=$ comprimento do elemento

\section{Tempo de residência}

O tempo de residência de cada elemento é calculado da seguinte maneira:

\section{Equação 3.17}

$\tau_{k}=\frac{V_{k}}{Q_{k}}$

em que: 
$\tau_{K}=$ tempo de residência do elemento $k^{\text {th }}(\mathrm{d})$;

$V k=$ volume do elemento $k^{\text {th }}\left(\mathrm{m}^{3}\right)$

$\mathrm{Q} k=$ vazão do elemento $\mathrm{k}^{\text {th }}\left(\mathrm{m}^{3} / \mathrm{s}\right)$

O volume é dado por:

\section{Equação 3.18}

$V k=A_{c, k} \Delta_{x, k}$

em que:

$\mathrm{A}_{\mathrm{c}, \mathrm{k}}=$ área da seção transversal do elemento $\mathrm{k}^{\text {th }}\left(\mathrm{m}^{2}\right)$;

$\Delta_{\mathrm{x}, \mathrm{k}}=$ comprimento do elemento $\mathrm{k}^{\text {th }}(\mathrm{m})$

Esses tempos são então acumulados para determinar o tempo de residência ao longo de cada um dos segmentos do rio. Por exemplo, o tempo de residência do início ao final do elemento j num segmento é calculado como:

\section{Equação 3.19}

$t_{t, j}=\sum_{k=1}^{j} \tau_{k}$

em que:

$t_{\mathrm{tj}}=$ tempo de residência $(\mathrm{d})$

\section{Dispersão longitudinal}

Duas opções são utilizadas para determinar a dispersão longitudinal entre dois elementos: na primeira opção o usuário pode inserir dados de entrada na planilha do Excel denominada "Reach". Se o usuário não inserir tais dados, uma fórmula é empregada internamente para calcular a dispersão de acordo com as características hidráulicas do canal, como é apresentado na equação 20 : 


\section{Equação 3.20}

$E_{p, i}=0,011 \frac{U_{i}{ }^{2} B_{i}{ }^{2}}{H_{i} U^{*}{ }_{i}}$

em que:

$\mathrm{E}_{\mathrm{p}, \mathrm{i}}=$ dispersão longitudinal entre os elementos $i$ e $i+1\left(\mathrm{~m}^{2} / \mathrm{s}\right)$;

$\mathrm{U}_{\mathrm{i}}=$ velocidade $(\mathrm{m} / \mathrm{s})$;

$\mathrm{B}_{\mathrm{i}}=$ largura do canal $(\mathrm{m})$;

$\mathrm{H}_{\mathrm{i}}=$ profundidade média $(\mathrm{m})$;

$\mathrm{U}^{*}{ }_{\mathrm{i}}=$ velocidade de cisalhamento $(\mathrm{m} / \mathrm{s})$, a qual é dada por:

\section{Equação 3.21}

$U^{*}{ }_{i}=\sqrt{g H_{i} S_{i}}$

em que:

$\mathrm{g}=$ aceleração da gravidade $\left(\mathrm{m}^{2} / \mathrm{s}\right)$;

$\mathrm{S}=$ declividade do canal $(\mathrm{m} / \mathrm{m})$

Após o cálculo de $E_{\mathrm{p}, \mathrm{i}}$ a dispersão numérica é calculada:

\section{Equação 3.22}

$$
E_{n i}=\frac{U_{i} \Delta x_{i}}{2}
$$

O modelo de dispersão $E_{i}$ é então calculado como segue:

- $\quad$ Se $\mathrm{E}_{\mathrm{n}, \mathrm{i}}<\mathrm{E}_{\mathrm{p}, \mathrm{i}}$, o modelo de dispersão usado será $\mathrm{E}_{\mathrm{p}, \mathrm{i}}-\mathrm{E}_{\mathrm{n}, \mathrm{i}}$;

- $\quad$ Se $\mathrm{E}_{\mathrm{n}, \mathrm{i}}>\mathrm{E}_{\mathrm{p}, \mathrm{i}} \mathrm{O}$ modelo de dispersão é igual a zero.

\section{Modelagem da Temperatura}

O balanço de calor leva em consideração a transferência de calor entre elementos adjacentes, cargas, abstrações, a atmosfera e o sedimento, de acordo com a seguinte fórmula: 


\section{Equação 3.23}

$$
\begin{aligned}
& \frac{d T}{d t}=\frac{Q_{i-1}}{V_{i}} T_{i-1}-\frac{Q_{i}}{V_{i}} T_{i}-\frac{Q_{o u t, i}}{V_{i}} T_{i}+\frac{E_{i-1}^{\prime}}{V_{i}}\left(T_{i-1}-T_{i}\right)+\frac{E_{i}^{\prime}}{V_{i}}\left(T_{i+1}-T_{i}\right)+\frac{W_{h, i}}{\rho_{w} C_{p w} V_{i}}\left(\frac{m^{3}}{10^{6} m^{3}}\right) \\
& +\frac{J a i}{\rho_{w} C_{p w} H_{i}}\left(\frac{m}{100 \mathrm{~cm}}\right)+\frac{J_{s i}}{\rho_{w} C_{p w} H_{i}}\left(\frac{m}{100 \mathrm{~cm}}\right)
\end{aligned}
$$

sendo que:

$\mathrm{T}_{\mathrm{i}}=$ temperatura no elemento $i\left({ }^{\circ} \mathrm{C}\right)$;

$\mathrm{t}=$ tempo $(\mathrm{d})$;

$\mathrm{E}_{\mathrm{i}}{ }_{\mathrm{i}}=$ carga do coeficiente de dispersão entre os elementos $i$ e $i+1\left(\mathrm{~m}^{3} / \mathrm{s}\right)$;

$\mathrm{W}_{\mathrm{h}, \mathrm{i}}=$ fontes de calor pontuais e não pontuais no elemento $i$ (cal/d);

$\rho \mathrm{w}=$ densidade da água $\left(\mathrm{g} / \mathrm{cm}^{3}\right)$;

$\mathrm{C}_{\mathrm{pw}}=$ calor específico da água $\left(\mathrm{cal} / \mathrm{g}{ }^{\circ} \mathrm{C}\right)$;

$\mathrm{J}_{\mathrm{ai}}=$ fluxo de calor ar-água $\left(\mathrm{cal} / \mathrm{cm}^{2} \mathrm{~d}\right)$;

$\mathrm{J}_{\mathrm{si}}=$ fluxo de calor sedimento-água.

A carga do coeficiente de dispersão é dada por:

\section{Equação 3.24}

$$
E_{i}^{\prime}=\frac{E_{i} A_{c, i}}{\left(\Delta x_{i}+\Delta x_{i+1}\right) / 2}
$$

Para esta situação dois tipos de condições limites podem ser empregadas:

- Condição de dispersão igual a zero (condição limite natural);

- Condição pré- estabelecida - Dirichlet condition.

A escolha entre as duas opções descritas acima deve ser feita pelo usuário na planilha do Excel denominada "Downstream".

As fontes de calor podem ser calculadas como segue: 


\section{Equação 3.25}

$W_{h, i}=\rho C_{p}\left[\sum_{j=1}^{p s i} Q_{p s i, j} T_{p s i, j}+\sum_{j=1}^{n p s i} Q_{n p s i},{ }_{j} T_{n p s i, j}\right]$

em que:

$\mathrm{T}_{\mathrm{psi}, \mathrm{j}}=\mathrm{j}^{\text {th }}$ fonte pontual de temperatura para o elemento $i\left({ }^{\circ} \mathrm{C}\right)$;

$\mathrm{T}_{\mathrm{npsi}, \mathrm{j}}=\mathrm{j}^{\text {th }}$ fonte não pontual de temperatura para o elemento $i\left({ }^{\circ} \mathrm{C}\right)$

\section{Fluxo de calor superficial}

A troca de calor superficial é modelada com uma combinação de cinco processos:

\section{Equação 3.26}

$J_{n}=I(0)+J_{a n}-J_{b r}-J_{c}-J_{e}$

em que:

$\mathrm{I}(0)$ = radiação solar de onda curta na superfície da água;

$\mathrm{J}_{\mathrm{an}}=$ radiação atmosférica de onda longa;

$\mathrm{J}_{\mathrm{br}}=$ reflexão de onda longa pela água;

$\mathrm{J}_{\mathrm{c}}=$ condução;

$\mathrm{J}_{\mathrm{e}}=$ evaporação (todos os fluxos são expressos em cal $/ \mathrm{cm}^{2} / \mathrm{d}$ )

\section{Radiação solar}

O modelo calcula a quantidade de radiação solar que entra na água em determinadas latitudes $\left(\mathrm{L}_{\mathrm{at}}\right)$ e longitudes $\left(\mathrm{L}_{\mathrm{lm}}\right)$ da superfície da Terra. Tal radiação á dada em função de:

\section{Equação 3.27}

$I(0)=I_{0} a_{t} a_{c}(1-R s)(1-S f)$ 
em que:

$\mathrm{I}(0)=$ radiação solar na superfície da água $\left(\mathrm{cal} / \mathrm{cm}^{2} / \mathrm{d}\right)$;

$\mathrm{I}_{0}=$ radiação extraterrestre, isto é, no topo da atmosfera terrestre;

$\mathrm{a}_{\mathrm{t}}=$ atenuação atmosférica;

$\mathrm{a}_{\mathrm{c}}=$ atenuação por nuvens;

Rs = albedo (fração refletida);

Sf = sombreamento (fração bloqueada por vegetação, topografia)

A radiação extraterrestre é calculada de acordo com a equação 3.28:

\section{Equação 3.28}

$I_{0}=\frac{W_{0}}{r^{2}} \sin \alpha$

em que:

$\mathrm{W}_{0}=$ constante solar $\left(1367 \mathrm{~W} / \mathrm{m}^{2}\right.$ ou $\left.2823 \mathrm{cal} / \mathrm{cm}^{2} / \mathrm{d}\right)$;

$\mathrm{r}=$ raio da órbita da Terra em relação ao sol;

$\alpha=$ altitude do sol (radianos), que é calculada como:

\section{Equação 3.29}

$\sin \alpha=\sin \delta L_{a t}+\cos \delta \cos L_{a t} \cos \tau$

em que:

$\delta=$ declinação solar (radianos);

Lat = latitude local (radianos);

$\tau=$ ângulo horário solar (radianos)

O ângulo horário do sol é dado por:

\section{Equação 3.30}

$\tau=\left(\frac{\text { trueSolarTime }}{4}-180\right) \frac{\pi}{180}$ 
em que:

\section{Equação 3.31}

trueSolarTime $=$ localTime + eqtime $-4 . L_{l m}$. timezone

sendo que:

trueSolarTime $=$ tempo solar determinado a partir da posição do sol no céu;

localTime $=$ tempo local em minutos;

Llm = longitude do local;

timezone $=$ hora local em relação ao Greenwich;

$\mathrm{O}$ valor de eqtime representa a diferença entre trueSolarTime e menaSolarTime.

O Q2K calcula a declinação solar, ângulo horário, altitude solar e distância entre a Terra e o sol, bem como nascer e pôr do sol utilizando um algoritmo implementado por NOAA's Surface Radiation Research Branch.

O fotoperíodo $f$ (horas) é dados por:

\section{Equação 3.32}

$f=t_{s s}-t_{s r}$

em que:

$\mathrm{t}_{\mathrm{ss}}=$ pôr do sol;

$\mathrm{t}_{\mathrm{sr}}=$ nascer do sol

\section{Atenuação atmosférica}

Existem vários métodos para o cálculo da atenuação atmosférica da radiação solar. $\mathrm{O}$ Q2K oferece duas alternativas metodológicas:

- $\quad$ Bras (1990)

- Ryan e Stolzenbach (1972)

A diferença entre ambas é que a metodologia proposta por Bras (1990) leva em consideração a turbidez atmoférica (céu claro ou com fumaça/neblina), bem como sua dispersão na massa de ar. Já o método de Ryan e Stolzenbach (1972) considera o coeficiente de transmissão 
atmosférica, o qual é calculado de acordo com a altitude solar. A escolha entre as duas metodologias deve ser feita na planilha denominada "Light and Heat" do Excel.

\section{Atenuação por nuvens}

A atenuação da radiação solar devido à cobertura do céu por nuvens é dada por:

\section{Equação 3.33}

$a_{c}=1-0,65 C_{L}^{2}$

em que:

$\mathrm{C}_{\mathrm{L}}=$ fração do céu coberta por nuvens

\section{Reflectividade}

A reflectividade é dada pela equação 3.34:

\section{Equação 3.34}

$R_{s}=A \alpha_{d}^{\beta}$

em que:

$\mathrm{A}$ e $\mathrm{B}=$ coeficientes relacionados à cobertura do céu por nuvens, seus valores são tabelados

\section{Sombra}

A sombra é um parâmetro de entrada no modelo Q2K, o qual se relaciona com o bloqueio de raios solares devido à vegetação e/ou topografia. Os dados de entrada devem ser inseridos na planilha do Excel denominada "Shade". 


\section{Radiação atmosférica de onda longa}

O fluxo de ondas longas advindo da atmosfera é um dos maiores termos no balanço de calor no modelo. Esse fluxo é calculado utilizando a lei de Stefan-Botzmann:

\section{Equação 3.35}

$J_{a n}=\sigma\left(T_{a i r}+273\right)^{4} \varepsilon_{s k y}\left(1-R_{L}\right)$

em que:

$\sigma=$ constante de Stefan-Botzmann $\left(11,7 \times 10^{-8} \mathrm{cal} / \mathrm{cm}^{2} \mathrm{dK}^{4}\right)$;

$\mathrm{T}_{\text {air }}=$ temperatura do ar $\left({ }^{\circ} \mathrm{C}\right)$;

$\varepsilon_{\text {sky }}=$ emissividade efetiva da atmosfera (adimensional);

$\mathrm{R}_{\mathrm{L}}=$ coeficiente de reflexão de onda longa (geralmente assumido como 0,03 - adimensional)

A modelagem da radiação de onda longa deve ser selecionada na planilha do Excel "Light and Heat". Três métodos são disponibilizados elo modelo para o cálculo da emissividade efetiva $\left(\varepsilon_{\text {sky): }}\right.$

- Brutsaert (1982);

- $\quad$ Brunt (1932);

- $\quad$ Koberg (1964)

Para condições de nevoeiro, a emissividade deve aumentar como resultado do aumento do vapor de água. Grandes nuvens do tipo cirrus têm efeito negigenciável na emissividade atmosférica, mas nuvens do tipo stratus e cumulus possuem um efeito significativo nesse parâmetro. O método de Koberg leva em consideração o efeito das nuvens na emissividade de ondas longas, enquanto que as metodologias propostas por Brunt e Brutsaert determinam a emissividade a partir de um céu claro, não considerando portanto o efeito das nuvens.

\section{Radiação aquática de onda longa}

A radiação que volta da superfície da água é representada pela lei de Stefan-Botzmann: 


\section{Equação 3.36}

$J_{b r}=\varepsilon \sigma(T+273)^{4}$

em que:

$\varepsilon=$ emissividade da água $(0,97)$;

$\mathrm{T}=$ temperatura da água $\left({ }^{\circ} \mathrm{C}\right)$

\section{Condução e convecção}

Ambos os processos de condução e convecção podem ocorrer na interface ar-água e são descritos por:

\section{Equação 3.37}

$J_{c}=c_{1} f(U w)\left(T_{s}-T_{\text {air }}\right)$

em que:

$\mathrm{c}_{1}=$ coeficiente de Bowen $\left(0,47 \mathrm{mmHg} /{ }^{\circ} \mathrm{C}\right)$;

$f(U w)=$ define a dependência de transferência pela velocidade do vento sob a água;

$U w=$ velocidade do vento medida a uma distância fixa sobre a superfície da água.

Existem muitas teorias para expressar a dependência do vento, mas apenas três estão disponíveis para o cálculo de $f(U w)$ no Q2K:

- $\quad$ Brady, Graves e Geyer (1969)

- $\quad$ Adams et al (1987)

\section{Evaporação e Condensação}

A perda de calor devido a evaporação é representada pela lei de Dalton:

\section{Equação 3.38}

$J_{e}=f(U w)\left(e_{s}-e_{a i r}\right)$ 
em que:

$\mathrm{e}_{\mathrm{s}}=$ pressão do vapor de saturação na superfície da água $(\mathrm{mmHg})$;

$\mathrm{e}_{\text {air }}=$ pressão do vapor de $\operatorname{ar}(\mathrm{mmHg})$

A pressão do vapor de ar é dada por:

\section{Equação 3.39}

$e_{\text {air }}=4,696 e^{\frac{17,27 T}{237,3+T}}$

\section{Transferência de calor sedimento-água}

O balanço de calor do sedimento subjacente à água do elemento $i$ é escrito pela equação:

\section{Equação 3.40}

$$
\frac{d T_{s, i}}{d t}=-\frac{J_{s, i}}{\rho_{s} C_{p s} H_{s e d, i}}
$$

em que:

$\mathrm{T}_{\mathrm{s}, \mathrm{i}}=$ temperatura do sedimento do elemento $i\left({ }^{\circ} \mathrm{C}\right)$;

$\mathrm{J}_{\mathrm{s}, \mathrm{i}}=$ fluxo de calor sedimento-água $\left(\mathrm{cal} / \mathrm{cm}^{2} \mathrm{~d}\right)$;

$\rho_{\mathrm{s}}=$ densidade do sedimento $\left(\mathrm{g} / \mathrm{cm}^{3}\right)$;

$\mathrm{C}_{\mathrm{ps}}=$ calor específico do sedimento (cal $/ \mathrm{g}{ }^{\circ} \mathrm{C}$ );

$\mathrm{H}_{\text {sed,i }}=$ espessura da camada do sedimento $(\mathrm{cm})$

O fluxo de calor sedimento-água é calculado como segue:

\section{Equação 3.41}

$$
J_{s, i}=\rho_{s} C_{p s} \frac{\alpha_{s}}{H_{s e d, i} / 2}\left(T_{s i}-T_{i}\right) \frac{86400}{d}
$$


em que:

$\alpha_{\mathrm{s}}=$ difusividade térmica do sedimento $\left(\mathrm{cm}^{2} / \mathrm{s}\right)$

As propriedades térmicas dos sedimentos, até mesmo compostos por materiais naturais, possuem valores tabelados e podem ser encontrados no manual do usuário do modelo Qual2K.

\section{Constituintes do modelo e balanço de massa geral}

Tabela 1: As variáveis simuladas pelo modelo estão listadas abaixo.

\begin{tabular}{|c|c|c|}
\hline Variáveis & Símbolo & Unidade \\
\hline Condutividade & $\mathrm{s}$ & $\mu \mathrm{mhos}$ \\
\hline Sólido Suspensos Inorgânicos & $\mathrm{m}_{\mathrm{i}}$ & $\mathrm{mgD} / \mathrm{L}$ \\
\hline Oxigênio Dissolvido & $\mathrm{o}$ & $\mathrm{mgO}_{2} / \mathrm{L}$ \\
\hline DBOC reação lenta & $\mathrm{c}_{\mathrm{s}}$ & $\mathrm{mgO}_{2} / \mathrm{L}$ \\
\hline DBOC reação rápida & $\mathrm{c}_{\mathrm{f}}$ & $\mathrm{mgO}_{2} / \mathrm{L}$ \\
\hline Nitrogênio Orgânico & $\mathrm{n}_{\mathrm{o}}$ & $\mu \mathrm{gN} / \mathrm{L}$ \\
\hline Nitrogênio Amoniacal & $\mathrm{n}_{\mathrm{a}}$ & $\mu \mathrm{gN} / \mathrm{L}$ \\
\hline Nitrato & $\mathrm{n}_{\mathrm{n}}$ & $\mu \mathrm{gN} / \mathrm{L}$ \\
\hline Fósforo Orgânico & $\mathrm{p}_{\mathrm{o}}$ & $\mu \mathrm{gP} / \mathrm{L}$ \\
\hline Fósforo Inorgânico & $\mathrm{p}_{\mathrm{i}}$ & $\mu \mathrm{gP} / \mathrm{L}$ \\
\hline Fitoplâncton & $\mathrm{a}_{\mathrm{p}}$ & $\mu \mathrm{gA} / \mathrm{L}$ \\
\hline Detritos & $\mathrm{m}_{\mathrm{o}}$ & $\mathrm{mgD} / \mathrm{L}$ \\
\hline Patógenos & $\mathrm{X}$ & $\mathrm{Cfu} / 100 \mathrm{~mL}$ \\
\hline Alcalinidade & $\mathrm{Alk}_{\mathrm{k}}$ & $\mathrm{mgCaCO} / \mathrm{L}$ \\
\hline Carbono Inorgânico Total & $\mathrm{cT}$ & $\mathrm{Mole} / \mathrm{L}$ \\
\hline Biomassa de Algas de Fundo & $\mathrm{a}_{\mathrm{b}}$ & $\mathrm{mgA} / \mathrm{m}^{2}$ \\
\hline Nitrogênio de Algas de Fundo & $\mathrm{IN}_{\mathrm{b}}$ & $\mathrm{mgN} / \mathrm{m}^{2}$ \\
\hline Fósforo de Algas de Fundo & $\mathrm{IP}_{\mathrm{b}}$ & $\mathrm{mgP} / \mathrm{m}^{2}$ \\
\hline
\end{tabular}

No Q2K é realizado o balanço de massa para cada constituinte do modelo, exceto para variáveis relacionadas às algas de fundo. O modelo utiliza como volume de controle os elementos computacionais, ou seja, em cada elemento computacional a equação geral do balanço de massa é aplicada (Equação 3.42). A figura VI apresenta, de forma esquemática as reações aplicadas no modelo. 


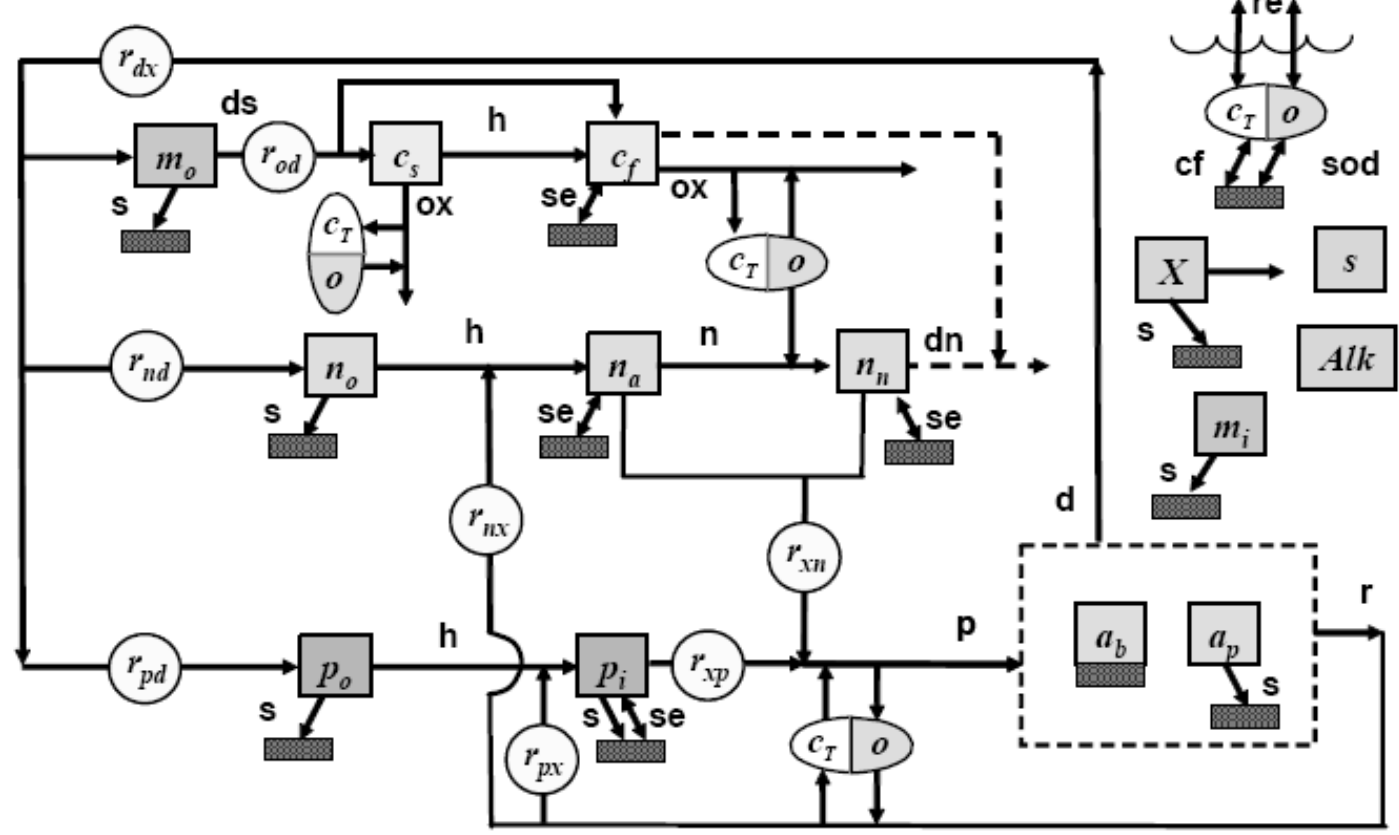

Figura VI: Modelo cinético e processo de transferência de massa. Os processos cinéticos são: dissolução (ds), hidrólise (h), oxidação (ox), nitrificação (n), desnitrificação (dn), fotossíntese (p), morte (d) e respiração (n). Os processos de transferência de massa são: reaeração (re), sedimentação (s), demanda de oxigênio pelo sedimento (SOD), fluxo do sedimento (se), fluxo de carbono inorgânico no sedimento (cf). Os índices subscrito x são conversões estequiométricas para a clorofila a (a) e peso seco (d) para fitoplâncton e algas de fundo, respectivamente. Os quadrados representam as variáveis de entrada do modelo, os círculos representam os coeficientes estequiométricos, as linhas cheias representam as reações e as linhas pontilhadas as entradas e abstrações (Adaptado de Chapra et. al. 2006).

\section{Equação 3.42}

$$
\frac{d c_{i}}{d t}=\frac{Q_{i-1}}{V_{i}} c_{i-1}-\frac{Q_{i}}{V_{i}} c_{i}-\frac{Q_{\text {out }, i}}{V_{i}} c_{i}+\frac{E_{i-1}^{\prime}}{V_{i}}\left(c_{i-1}-c_{i}\right)+\frac{E_{i}^{\prime}}{V_{i}}\left(c_{i+1}-c_{i}\right)+\frac{W_{i}}{V_{i}}+S_{i}
$$

em que:

$\mathrm{W}_{\mathrm{i}}=$ carga externa do elemento $i(\mathrm{~g} / \mathrm{d}$ ou $\mathrm{mg} / \mathrm{d}) ;$

$\mathrm{S}_{\mathrm{i}}=$ fontes externas e/ou sumidouros de constituintes devido aos mecanismos de transferência de massa e reações $\left(\mathrm{g} / \mathrm{m}^{3} / \mathrm{d}\right.$ ou $\left.\mathrm{mg} / \mathrm{m}^{3} / \mathrm{d}\right)$

A carga externa é calculada como: 


\section{Equação 3.43}

$W i=\sum_{j=1}^{p s i} Q_{p s, i, j} c_{p s, i, j}+\sum_{j=1}^{n p s i} Q_{n p s, i, j} c_{n p s, i, j}$

em que:

$\mathrm{c}_{\mathrm{ps}, \mathrm{i}, \mathrm{j}}=\mathrm{j}^{\text {th }}$ concentração de entrada no elemento $i$ proveniente de fonte pontual $(\mathrm{mg} / \mathrm{L} \mathrm{ou} \mu \mathrm{g} / \mathrm{L})$;

$\mathrm{c}_{\mathrm{nps}, \mathrm{i}, \mathrm{j}}=\mathrm{j}^{\text {th }}$ concentração de entrada no elemento $i$ proveniente de fonte pontual $(\mathrm{mg} / \mathrm{L}$ ou $\mu \mathrm{g} / \mathrm{L})$

Para algas de fundo os termos de carga e transporte são omitidos:

\section{Equação 3.44}

$\frac{d_{a b, i}}{d t}=S_{b, i}$

\section{Equação 3.45}

$\frac{d I N_{b}}{d t}=S_{b N, i}$

\section{Equação 3.46}

$\frac{d I P_{b}}{d t}=S_{b P, i}$

em que:

$\mathrm{S}_{\mathrm{b}, \mathrm{i}}=$ fontes e sumidouros da biomassa das algas de fundo $\left(\mathrm{mgA} / \mathrm{m}^{2} / \mathrm{d}\right)$;

$\mathrm{S}_{\mathrm{bN}, \mathrm{i}}=$ fontes e sumidouros de nitrogênio das algas de fundo devido a reações $\left(\mathrm{mgN} / \mathrm{m}^{2} / \mathrm{d}\right)$;

$\mathrm{S}_{\mathrm{bP}, \mathrm{i}}=$ fontes e sumidouros de fósforo das algas de fundo devido a reações $\left(\mathrm{mgP} / \mathrm{m}^{2} / \mathrm{d}\right)$

\section{Reações bioquímicas}

O modelo utiliza reações químicas para representar as maiores reações bioquímicas, como:

- Fotossíntese e Respiração

- Nitrificação e Desnitrificação 


\section{Estequiometria da matéria orgânica}

O modelo requer que a estequiometria da matéria orgânica (relacionada ao fitoplâncton e detritos) seja especificada pelo usuário. O manual do usuário do Q2K sugere alguns exemplos.

\section{Geração e consumo de oxigênio}

O modelo requer que as taxas de consumo e geração de oxigênio sejam prescritas. As taxas dependem das substâncias (amônia ou nitrato) que são usadas como substrato.

\section{Efeito da temperatura nas reações}

O efeito da temperatura para todas as reações de primeira ordem é representado por:

\section{Equação 3.47}

$k(T)=K(20) \theta^{T-20}$

em que:

$\mathrm{K}(\mathrm{T})=$ taxa de reação $(/ \mathrm{d})$ na temperatura $\left({ }^{\circ} \mathrm{C}\right)$;

$\theta=$ coeficiente de temperatura

\section{Variáveis compostas}

Em relação às variáveis de estado do modelo, o Q2K apresentas diversas variáveis compostas que são calculadas de acordo com:

- Carbono orgânico total $(\mathrm{mgC} / \mathrm{L})$

\section{Equação 3.48}

$$
T O C=\frac{c_{b}+c_{f}}{r_{a}}+r_{c a} a_{p}+r_{c d}+m_{o}
$$


- $\quad$ Nitrogênio Total $(\mu g \mathrm{~g} / \mathrm{L})$

\section{Equação 3.49}

$T N=n_{o}+n_{a}+n_{n}+r_{n a}+a_{p}$

- $\quad$ Nitrogênio Kjeldhal $(\mu g N / L)$

\section{Equação 3.50}

$T K N=n_{o}+n_{a}+r_{n a} a_{p}$

- $\quad$ Fósforo Total $(\mu \mathrm{gP} / \mathrm{L})$

\section{Equação 3.51}

$T P=p_{o}+p_{i}+r_{p a} a_{p}$

- Sólidos Suspensos Totais (mgD/L)

\section{Equação 3.52}

$T S S=r_{d a} a_{p}+m_{o}+m_{i}$

- $\quad$ DBO última $\left(\mathrm{mgO}_{2} / \mathrm{L}\right)$

\section{Equação 3.53}

$C B O D_{u}=c_{s}+c_{f}+r_{o c} r_{c a} a_{p}+r_{o c} r_{c d} m_{o}$ 


\section{Relação entre as variáveis do modelo e dados}

Para todas as variáveis do modelo, exceto DBO lenta e rápida $\left(\mathrm{c}_{\mathrm{s}}\right.$ e $\left.\mathrm{c}_{\mathrm{f}}\right)$, existe uma relação entre as variáveis de estado do modelo e medidas padrão de qualidade da água. Essas estão descritas posteriormente, então será discutido agora um assunto mais complexo a DBO.

\section{Variáveis e Dados do modelo}

As seguintes medidas são necessárias para geração de dados de saída do modelo:

$\mathrm{TEM}=$ temperatura $\left({ }^{\circ} \mathrm{C}\right)$;

$\mathrm{TKN}=$ nitrogênio Kjeldhal total ou $\mathrm{TN}=$ nitrogênio total $(\mu \mathrm{gN} / \mathrm{L})$;

$\mathrm{NH}_{4}=$ amônio $(\mu \mathrm{gN} / \mathrm{L})$;

$\mathrm{NO}_{2}=$ nitrito $(\mu \mathrm{gN} / \mathrm{L})$;

$\mathrm{NO}_{3}=$ nitrato $(\mu \mathrm{gN} / \mathrm{L})$;

CHLA $=$ clorofila a $(\mu \mathrm{gA} / \mathrm{L})$;

$\mathrm{TP}=$ fósforo total $(\mu \mathrm{gP} / \mathrm{L}) ;$

$\mathrm{SRP}=$ fósforo solúvel reativo $(\mu \mathrm{gP} / \mathrm{L})$;

$\mathrm{TSS}=$ sólidos suspensos totais $(\mathrm{mgD} / \mathrm{L})$;

$\mathrm{VSS}=$ sólidos suspensos voláteis $(\mathrm{mgD} / \mathrm{L})$;

TOC = carbono orgânico total $(\mathrm{mgC} / \mathrm{L}) ;$

$\mathrm{DOC}=$ carbono orgânico dissolvido $(\mathrm{mgC} / \mathrm{L})$;

$\mathrm{DO}=$ oxigênio dissolvido $\left(\mathrm{mgO}_{2} / \mathrm{L}\right)$;

$\mathrm{PH}=\mathrm{pH}$;

$\mathrm{ALK}=$ alcalinidade $\left(\mathrm{mgCaCo}_{3} / \mathrm{L}\right)$;

COND $=$ condutância específica $(\mu \mathrm{mhos})$

As variáveis de estado do modelo podem ser relacionadas como segue:

$$
\begin{aligned}
& \mathrm{s}=\mathrm{COND} \\
& \mathrm{m}_{\mathrm{i}}=\mathrm{TSS}-\mathrm{VSS} \text { ou TSS } \mathrm{r}_{\mathrm{dc}}(\mathrm{TOC}-\mathrm{DOC}) \\
& \mathrm{o}=\mathrm{DO} \\
& \mathrm{n}_{\mathrm{o}}=\mathrm{TKN}-\mathrm{NH}_{4}-\mathrm{r}_{\mathrm{a}} \mathrm{CHLA} \text { ou } \mathrm{n}_{\mathrm{o}}=\mathrm{TN}^{-N_{2}}-\mathrm{NO}_{3}-\mathrm{NH}_{4}-\mathrm{r}_{\mathrm{na}} \mathrm{CHLA} \\
& \mathrm{n}_{\mathrm{a}}=\mathrm{NH}_{4} \\
& \mathrm{n}_{\mathrm{n}}=\mathrm{NO}_{2}+\mathrm{NO}_{3}
\end{aligned}
$$


$\mathrm{p}_{\mathrm{o}}=\mathrm{TP}-\mathrm{SRP}-\mathrm{rp} \mathrm{p}_{\mathrm{a}} \mathrm{CHLA}$

$\mathrm{p}_{\mathrm{i}}=\mathrm{SRP}$

$\mathrm{a}_{\mathrm{p}}=$ CHLA

$\mathrm{pH}=\mathrm{PH}$

$\mathrm{Alk}=\mathrm{ALK}$

\section{DBO}

O modelo baseia-se para o cálculo de $\mathrm{DBO}$, na DBO última (tempo máximo de incubação da amostra), assim duas aproximações podem feitas:

- Longo período de incubação para que a DBO última seja medida;

- Uso da DBO5 e a extrapolação do respectivo resultado para DBO última, isso é feito por:

\section{Equação 3.54}

$C B O D F N U=\frac{C B O D F N 5}{1-e^{-K 15}}$

em que:

$\mathrm{CBODFNU}^{2}=\mathrm{DBO}_{\text {ult }}\left(\mathrm{mgO}^{2} / \mathrm{L}\right)$;

CBODFN5 $=\mathrm{DBO}_{5}\left(\mathrm{mgO}_{2} / \mathrm{L}\right)$;

$\mathrm{k}_{1}=$ taxa de decomposição da $\operatorname{DBO}(/ \mathrm{d})$.

\section{Substâncias conservativas}

Por definição, substâncias conservativas são aquelas que não estão sujeitas a reações:

\section{Equação 3.55}

$$
S_{s}=0
$$

Fitoplâncton ( $\left.\mathbf{a}_{\mathbf{p}}\right)$ : aumenta devido à fotossíntese e possui perdas via crescimento (colonização) e morte. 


\section{Equação 3.56}

$S_{a p}=$ PhytoPhoto - Phyto Resp - PhytoDeath - PhytoSettl

Fotossíntese: a fotossíntese é calculada por:

\section{Equação 3.57}

PhytoPhoto $=\mu_{p} a_{p}$

em que:

$\mu_{\mathrm{p}}=$ taxa de fotossíntese $(/ \mathrm{d})$, a qual é função da temperatura, nutrientes e luz:

\section{Equação 3.58}

$\mu_{p}=k_{g p}(T) \phi_{N p} \phi_{L p}$

em que:

$\mathrm{k}_{\mathrm{gp}}=$ taxa máxima de fotossíntese na temperatura $\mathrm{T}(/ \mathrm{d})$;

$\phi_{\mathrm{Np}}=$ fator de atenuação de nutrientes (adimensional, número entre 0 e 1)

$\phi_{\mathrm{Lp}}=$ Fator de atenuação de luz (adimensional, número entre 0 e 1)

\section{Limitação de nutrientes}

As equações de Michaelis-Menten são utilizadas para representar a limitação do crescimento do fitoplâncton por nitrogênio inorgânico, fósforo e carbono inorgânico. O mínino valor é utilizado para calcular o fator de atenuação.

\section{Equação 3.59}

$\phi_{N P}=\min \left(\frac{n_{a}+n_{n}}{k_{s n p}+n_{a}+n_{n}}, \frac{p_{i}}{k_{s P p}+p_{i}}, \frac{\left[\mathrm{H}_{2} \mathrm{CO}_{3}^{*}\right]+\left[\mathrm{HCO}_{3}^{-}\right]}{k_{s C p}+\left[\mathrm{H}_{2} \mathrm{CO}_{3}^{*}\right]+\left[\mathrm{HCO}^{-}\right]}\right)$ 
em que:

$\mathrm{k}_{\mathrm{sNp}}=$ constante de saturação do nitrogênio $(\mu \mathrm{gN} / \mathrm{L})$;

$\mathrm{k}_{\mathrm{sPp}}=$ constante de saturação do fósforo $(\mu \mathrm{gN} / \mathrm{L})$;

$\mathrm{k}_{\mathrm{sCp}}=$ constante de saturação do carbono inorgânico (mole/L);

[H2CO3 $\left.{ }^{*}\right]=$ concentração de dióxido de carbono dissolvido (mole/L);

$\left[\mathrm{HCO}^{-}\right]=$concentração de bicarbonato

\section{Limitação de luz}

A atenuação luminosa através da água segue a lei de Beer-Lambert:

\section{Equação 3.60}

$P A R(z)=P A R(0) e^{-k_{e} z}$

em que:

$\mathrm{PAR}=$ radiação fotossinteticamente disponível numa profundidade $\mathrm{z}$ abaixo da superfície da água $(\mathrm{ly} / \mathrm{d})^{3}$;

$\mathrm{k}_{\mathrm{e}}=$ coeficiente de extinção da luz $\left(\mathrm{m}^{-1}\right)$. A PAR na superfície da água é assumida como uma fração fixa da radiação solar:

\section{Equação 3.61}

$\operatorname{PAR}(0)=0,47 I(0)$

O coeficiente de extinção é dado por:

\section{Equação 3.62}

$k_{e}=k_{e b}+\alpha_{i} m_{i}+\alpha_{o} m_{o}+\alpha_{p} m_{p}+\alpha_{p n} a_{p}^{2 / 3}$

em que:

$\mathrm{keb}=$ coeficiente de extinção do fundo devido à água e cor $(/ \mathrm{m})$; 
ai, $\alpha_{\mathrm{o}}$, ap e $\alpha \mathrm{pn}=$ constantes relacionadas aos impactos de sólidos suspensos inorgânicos $(\mathrm{L} / \mathrm{mgD} / \mathrm{m})$, matéria orgânica particulada $(\mathrm{L} / \mathrm{mgD} / \mathrm{m})$ e clorofila $\left(\mathrm{L} / \mathrm{mgA}^{2 / 3} / \mathrm{m}\right)$, respectivamente. O manual do usuário apresenta valores para esses coeficientes.

Três métodos são apresentados para caracterizar o impacto da luz na fotossíntese:

- Half-Saturation (Michaelis-Menten) Light Model (Baly 1935);

- $\quad$ Smith Function (Smith 1936);

- Steele's Equation (Steele 1962)

\section{Respiração}

A respiração do fitoplâcton é representada por uma equação de primeira ordem que é atenuada pela baixa concentração de oxigênio:

\section{Equação 3.63}

Phyto $\operatorname{Re} s p=F_{o x p} k_{r p}(T)$

em que:

$\mathrm{k}_{\mathrm{rp}}=$ taxa de respiração do fioplâncton dependente da temperatura (/d);

$\mathrm{F}_{\mathrm{oxp}}=$ atenuação devido à baixa concentração de oxigênio (adimensional)

A atenuação de oxig6enio via respiração será apresentada posteriormente.

\section{Morte}

A morte do fitoplâncton é representada por uma equação de primeira ordem:

\section{Equação 3.64}

PhytoDeath $=k_{d p}(T) a_{p}$

em que:

$\mathrm{k}_{\mathrm{dp}}(\mathrm{T})=$ taxa de morte do fitoplâncton dependente da temperatura (/d) 


\section{Crescimento (Colonização)}

O crescimento e/ou colonização do fitoplâncton é dado por:

\section{Equação 3.65}

PhytoSettl $=\frac{v_{a}}{H} a_{p}$

em que:

$\mathrm{V}_{\mathrm{a}}=$ velocidade de povoamento do fitoplâncton $(\mathrm{m} / \mathrm{d})$

\section{Algas de fundo $\left(a_{b}\right)$}

Algas de fundo crescem devido à fotossíntese, as perdas ocorrem devido à respiração e morte.

\section{Equação 3.66}

$S_{b}=$ BotAlg Photo - BotA $\lg \operatorname{Re} s p-$ BotAlg Death

Duas abordagens podem ser usadas para modelar a fotossíntese das algas de fundo: a primeira é baseada numa taxa de temperatura corrigida e de ordem zero, atenuada pela limitação de nutrientes e luz.

\section{Equação 3.67}

BotAlhPhoto $=C_{g b}(T) \phi_{N b} \phi_{L b}$

em que:

$\mathrm{C}_{\mathrm{gb}}(\mathrm{T})=$ taxa máxima de fotossíntese dependente da temperatura e de ordem zero $\left(\mathrm{mgA} / \mathrm{m}^{2} \mathrm{~d}\right)$;

$\phi_{\mathrm{Nb}}=$ fator de atenuação de nutrientes (adimensional, número entre 0 e 1);

$\phi_{\mathrm{Lb}}=$ coeficiente de atenuação da luz (adimensional, número entre 0 e 1 )

A segunda abordagem utiliza um modelo de primeira ordem: 


\section{Equação 3.68}

BotA $\lg$ Photo $=C_{g h}(T) \phi_{N b} \phi_{L b} \phi_{S b} a_{b}$

em que:

$\mathrm{Cgb}(\mathrm{T})=$ taxa máxima de fotossíntese dependente da temperatura em primeira ordem;

$\phi_{\mathrm{Sb}}=$ fator de atenuação pela limitação de espaço

\section{Efeito da temperatura}

Para reações de primeira ordem, um modelo de Arrhenius é empregado para quantificar o efeito da temperatura sobre a fotossíntese das algas de fundo.

\section{Equação 3.69}

$C_{g b}(T)=C_{g b}(20) \theta^{T-20}$

\section{Limitação de nutrientes}

O efeito da limitação de nutrientes na fotossíntese das algas de fundo é modelado de maneira diferente daquela feita para o fitoplâncton.

\section{Equação 3.70}

$\phi_{N b}=\min \left(1-\frac{q_{0 N}}{q_{N}}, 1-\frac{q_{0 P}}{q_{P}}, \frac{\left[\mathrm{H}_{2} \mathrm{CO}_{3}{ }^{*}\right]+\left[\mathrm{HCO}_{3}^{-}\right]}{k_{s C b}+\left[\mathrm{H}_{2} \mathrm{CO}_{3}^{*}\right]+\left[\mathrm{HCO}_{3}^{-}\right]}\right)$

em que:

$\mathrm{q}_{\mathrm{N}}$ e $\mathrm{q}_{\mathrm{P}}=$ cotas de nitrogênio e fósforo nas células $\left(\mathrm{mgNmgA}^{-1}\right)\left(\mathrm{mgPmgA}^{-1}\right)$, respectivamente; $\mathrm{q}_{0 \mathrm{~N}}$ e $\mathrm{q}_{\mathrm{OP}}=$ cotas mínimas de nitrogênio e fósforo nas células $(\mathrm{mgNmgA}-1)\left(\mathrm{mgPmgA}^{-1}\right)$, respectivamente;

$\mathrm{k}_{\mathrm{sCb}}=$ constante de saturação de carbono inorgânico para algas de fundo (mole/L). 
As cotas mínimas nas células são níveis de nutrientes intracelulares, o qual cessa o crescimento das algas. As cotas representam a relação entre nutrientes intracelulares das algas de fundo e o peso seco das mesmas.

\section{Equação 3.71}

$q_{N}=\frac{I N_{b}}{a_{b}}$

em que:

$\mathrm{IN}_{\mathrm{b}}=$ concentração intracelular de nitrogênio $\left(\mathrm{mgN} / \mathrm{m}^{2}\right)$

\section{Equação 3.72}

$q_{P}=\frac{I P_{b}}{a_{b}}$

em que:

$\mathrm{IP}_{\mathrm{b}}=$ concentração intracelular de fósforo $\left(\mathrm{mgP} / \mathrm{m}^{2}\right)$

A variação de nitrogênio e fósforo intracelular nas células das algas de fundo é calculada por:

\section{Equação 3.73}

$S_{b N}=$ BotAlgUptakeN $-q_{N}$ BotA $\lg$ Death

\section{Equação 3.74}

$S_{b P}=$ BotA $\lg$ UptakeP $-q_{P}$ BotA $\lg$ Death

em que:

BotAlgUptakeN e BotAlgUptakeP = taxa de captação de nitrogênio e fósforo pelas lagas de fundo $\left(\mathrm{mgN} / \mathrm{m}^{2} / \mathrm{d}\right.$ e $\left.\mathrm{mgP} / \mathrm{m}^{2} / \mathrm{d}\right)$, respectivamente;

BotAlgDeath = termo definido como "perda",que será definido mais adiante 
A taxa de captação de nitrogênio e fósforo depende tanto dos nutrientes externos como intracelulares, como:

\section{Equação 3.75}

BotA $\lg$ UptakeN $=\rho_{m, N} \frac{n_{a}+n_{n}}{k_{s N b}+n_{a}+n_{n}} \frac{K_{q_{N}}}{K_{q N}+\left(q_{N}-q_{0 N}\right)} a_{b}$

\section{Equação 3.76}

BotA $\lg$ UptakeP $=\rho_{m, P} \frac{p_{i}}{k_{s P b}+p_{i}} \frac{K_{q P}}{K_{q P}+\left(q_{P}-q_{0 P}\right)} a_{b}$

sendo que

$\rho_{\mathrm{m}, \mathrm{N}}$ e $\rho_{\mathrm{m}, \mathrm{P}}=$ taxa máxima de captação de nitrogênio e fósforo $(\mathrm{mgN} / \mathrm{mgA} / \mathrm{d})(\mathrm{mgP} / \mathrm{mgA} / \mathrm{d})$, respectivamente;

$\mathrm{K}_{\mathrm{qN}}$ e $\mathrm{K}_{\mathrm{qP}}=$ constante de saturação para nitrogênio e fósforo intracelular $\left(\mathrm{mgNmgA}^{-1}\right)$

$\left(\mathrm{mgPmgA}^{-1}\right)$, respectivamente.

\section{Limitação de luz}

Ao contrário do fitoplâncton, a limitação luminosa num tempo qualquer é determinada pela quantidade de PAR que chega no fundo da coluna d'água. Essa quantia é calculada pela lei de Beer-Lambert.

\section{Equação 3.77}

$I(H)=I(0) e^{-K e H}$

Assim como para o fitoplâncton, três modelos são usados para caracterizar o impacto da limitação de luz na fotossíntese das algas de fundo:

- Half-Saturation Light Model (Baly,1935);

- $\quad$ Smith Function (Smith, 1936); 
- $\quad$ Steele's Equation (Steele, 1962)

\section{Limitação de espaço}

Se um modelo de crescimento de primeira ordem é usado, um termo deve ser incluído para representar a limitação espacial das algas de fundo, assim:

\section{Equação 3.78}

$$
\theta_{S b}=1-\frac{a_{b}}{a_{b \max }}
$$

em que:

$\mathrm{a}_{\mathrm{bmax}}=$ capacidade de transporte $\left(\mathrm{mgA} / \mathrm{m}^{2}\right)$

\section{Respiração}

A respiração das algas de fundo é representada por um taxa de primeira ordem, que é atenuada pela baixa concentração de oxigênio.

\section{Equação 3.79}

BotA $\lg \operatorname{Re} s p=F_{o x b} k_{r b}(T) a_{b}$

em que:

$\mathrm{k}_{\mathrm{rb}}=$ taxa de respiração dependente da temperatura (/d);

$\mathrm{F}_{\text {oxb }}=$ atenuação devido à baixa concentração de oxigênio (adimensional). A atenuação por baixa concentração de oxigênio será apresentada posteriormente.

\section{Morte}

A morte das algas de fundo é representada por taxas de primeira ordem: 


\section{Equação 3.80}

BotA $\lg$ Death $=k_{d b}(T) a_{b}$

em que:

$\mathrm{k}_{\mathrm{db}}(\mathrm{T})=$ taxa de morte das algas de fundo dependente da temperatura.

\section{Detritos $\left(\mathbf{m}_{0}\right)$}

Os detritos ou matéria orgânica particulada (POM) sofrem um aumento na sua concentração devido à morte dos vegetais. A diminuição da concentração ocorrem via dissolução e precipitação.

\section{Equação 3.81}

$S_{m o}=r_{d a}$ PhytoDeath - BotAlg Death - DetrDiss - DetrSettl

em que:

\section{Equação 3.82}

DetrDiss $=k_{d t}(T) m_{o}$

sendo:

$\mathrm{kdt}=$ taxa de dissolução dos detritos dependente da temperatura (/d).

\section{Equação 3.83}

DetrSett $=\frac{v_{d t}}{H} m_{o}$

em que:

$\mathrm{vdt}=$ velocidade de precipitação $(\mathrm{m} / \mathrm{d})$. 


\section{DBO de reação lenta $\left(c_{s}\right)$}

A DBO carbonácea de reação lenta tem sua concentração aumentada devido à dissolução de detritos, mas a mesma é diminuída via hidrólise e oxidação.

\section{Equação 3.84}

Scs $=(1-$ Ff $)$ rodDetrDiss - SlowCHydr - SlowCOxid

em que:

$\mathrm{Ff}=$ fração de dissolução dos detritos que reagirão com a DBO de reação rápida (adimensional).

\section{Equação 3.85}

SlowHydr $=k_{h c}(T) c_{s}$

em que:

$\mathrm{k}_{\mathrm{hc}}(\mathrm{T})=$ taxa de hidrólise da DBO lenta dependente da temperatura (/d).

\section{Equação 3.86}

SlowCOxid $-F_{o x} c k_{d c s}(T) c_{s}$

em que:

$\mathrm{k}_{\mathrm{dcs}}=$ taxa de oxidação da DBO lenta dependente da temperatura (/d);

$\mathrm{F}_{\mathrm{oxc}}=$ atenuação devido à baixa concentração de oxigênio (adimensional).

\section{DBO de reação rápida $\left(\mathrm{c}_{\mathrm{f}}\right)$}

A DBO carbonácea de reação rápida aumenta sua concentração via dissolução de detritos e hidrólise da DBO lenta, a diminuição de sua concentração ocorre devido oxidação e desnitrificação. 


\section{Equação 3.87}

$S_{c f}=F_{f} r_{o d}$ DetrDiss + SlowCHydr - FastCOxid $-r_{\text {ondn }}$ Denitr

em que:

\section{Equação 3.88}

FastCOxid $=F_{o x c} k_{d c}(T) c_{f}$

em que:

$\mathrm{k}_{\mathrm{dc}}=$ taxa de oxidação da DBO rápida dependente da temperatura (/d);

$\mathrm{F}_{\mathrm{oxc}}=$ atenuação devido à baixa concentração de oxigênio (adimensional);

$\mathrm{r}_{\text {ondn }}=$ taxa de oxigênio equivalente à perda de nitrato que é desnitrificado. O termo "Denitr" é equivalente à taxa de desnitrificação $(\mu \mathrm{gN} / \mathrm{L} / \mathrm{d})$ e será definido posteriormente.

\section{Depleção do oxigênio:}

Três fórmulas são usadas para representar a atenuação do oxigênio:

- Half-Saturation ("saturação média”)

- Exponential (exponencial)

- Second-Order Half-Saturation (saturação media com aproximação de até $2^{\mathrm{a}}$. Ordem)

\section{Nitrogênio Orgânico $\left(\mathbf{n}_{\mathbf{0}}\right)$}

A concentração de nitrogênio orgânico aumenta devido à morte das plantas e diminui por processos de hidrólise e precipitação.

\section{Equação 3.89}

$S_{n o}=r_{n a}$ PhytoDeath $+q_{0 N}$ BotA $\lg$ Death - ONHydr-ONSettl

A taxa de hidrólise do nitrogênio orgânico é calculada por: 


\section{Equação 3.90}

$O N H y d r=k_{h m}(T) n_{o}$

em que:

$\mathrm{k}_{\mathrm{hm}}=$ taxa de hidrólise de nitrogênio orgânico dependente da temperatura (/d).

A taxa de precipitação do nitrogênio orgânico é dada por:

\section{Equação 3.91}

ONSettl $=\frac{v_{o n}}{H} n_{o}$

em que:

$\mathrm{v}_{\mathrm{on}}=$ velocidade de precipitação do nitrogênio orgânico $(\mathrm{m} / \mathrm{d})$.

\section{Amônia (na)}

A concentração da amônia aumenta devido à hidrólise do nitrogênio organico e respiração do fitoplâncton. Já a nitrificação e a fotossíntese diminuem a concentração desse composto.

\section{Equação 3.92}

$S_{n a}=$ DONHydr $-r_{n a}$ Phyto Re $s p-\mathrm{NH}_{4}$ Nitrif $-r_{n a} P_{a p}$ PhytoPhoto $+P_{a b}$ BotA $\lg$ UptakeN

A taxa de nitrificação da amônia é dada por:

\section{Equação 3.93}

$\mathrm{NH}_{4}$ nitrif $=F_{\text {oxna }} k_{n}(T) n_{a}$

em que:

$\mathrm{k}_{\mathrm{n}}(\mathrm{T})=$ taxa de nitrificação da amônia dependente da temperatura (/d); 
$\mathrm{F}_{\text {oxna }}=$ atenuação devido à baixa concentração de oxigênio (adimensional).

Os coeficientes $\mathrm{P}_{a p}$ e $\mathrm{P}_{\mathrm{ab}}$ representam a preferência por amônia como fonte de nitrogênio para fitoplâncton e algas de fundo, respectivamente.

\section{Equação 3.94}

$$
P_{a p}=\frac{n_{a} n_{n}}{\left(k_{\text {hnxp }}+n_{a}\right)\left(k_{\text {hnxp }}+n_{n}\right)}+\frac{n_{a} k_{\text {hnxp }}}{\left(n_{a}+n_{n}\right)\left(k_{\text {hnxp }}+n_{n}\right)}
$$

\section{Equação 3.95}

$P_{a b}=\frac{n_{a} n_{n}}{\left(k_{h n x b}+n_{a}\right)\left(k_{h n x b}+n_{n}\right)}+\frac{n_{a} k_{h n x b}}{\left(n_{a}+n_{n}\right)\left(k_{h n x b}+n_{n}\right)}$

sendo que:

$\mathrm{K}_{\mathrm{nxp}}$ e $\mathrm{k}_{\mathrm{nxb}}=$ coeficiente de preferência do fitoplâncton e das algas de fundo por amônia $\left(\mathrm{mgN} / \mathrm{m}_{3}\right)$, respectivamente;

\section{Amônia não ionizada}

$\mathrm{O}$ modelo simula a amônia total. Na água a amônia total consiste de duas formas, íon amônio $\mathrm{NH}_{4}$ e amônia não ionizada $\mathrm{NH}_{3}$. Em pH normal (6 a 8) a maioria da amônia estará na forma iônica, contudo em pH alto, a amônia não ionizada predomina. A quantidade de amônia não ionizada pode ser calculada por:

\section{Equação 3.96}

$n_{a u}=F_{u} n_{a}$

em que:

$\mathrm{n}_{\mathrm{au}}=$ concentração de amônia não ionizada $(\mu \mathrm{g} / \mathrm{L})$;

$\mathrm{F}_{\mathrm{u}}=$ fração de amônia total que está na forma ionizada. 


\section{Equação 3.97}

$F u=\frac{1}{1+10^{-p H} / K_{a}}$

em que:

$\mathrm{K}_{\mathrm{a}}=$ coeficiente de equilíbrio para reação de dissociação da amônia, que e'relacionado com a temperatura pela seguinte equação:

\section{Equação 3.98}

$p_{K a}=0,09018+\frac{2729,92}{T_{a}}$

em que:

$\mathrm{T}_{\mathrm{a}}=$ temperatura absoluta $(\mathrm{K})$;

$\mathrm{p}_{\mathrm{Ka}}=-\log _{10}\left(\mathrm{~K}_{\mathrm{a}}\right)$

\section{Nitrato $\left(\mathbf{n}_{\mathbf{n}}\right)$}

A concentração de nitrato aumenta devido à nitrificação da amônia e diminui via desnitrificação e fotossíntese.

\section{Equação 3.99}

$S_{n i}=\mathrm{NH}_{4}$ Nitrif - Denitr $-r_{n a}\left(1-P_{a p}\right)$ PhytoPhoto $-\left(1-P_{a b}\right)$ BotA $\lg$ UptakeN

A taxa de desnitrificação é calculada como:

\section{Equação 3.100}

Denitr $=\left(1-F_{\text {oxdn }}\right) k_{d n}(T) n_{n}$

em que:

$\mathrm{K}_{\mathrm{dn}}(\mathrm{T})=$ taxa de desnitrificação do nitrato dependente da temperatura (/d);

$\mathrm{F}_{\mathrm{oxdn}}=$ efeito da baixa concentração de oxigênio na desnitrificação (adimensional). 


\section{Fósforo Orgânico $\left(\mathbf{p}_{\mathbf{0}}\right)$}

A concentração de fósforo orgânico aumenta devido à morte dos vegetais e diminui via hidrólise e precipitação.

\section{Equação 3.101}

$S_{p o}=r_{p a}$ PhytoDeath $+q_{o p}$ BotA $\lg$ Death - OPHydr - OPSettl

A taxa de hidrólise do fósforo orgânico é dada por:

\section{Equação 3.102}

OPHydr $=k_{h p}(T) p_{o}$

em que:

$\mathrm{k}_{\mathrm{hp}}=$ taxa de hidrólise de fósforo orgânico dependente da temperatura (/d);

A precipitação é determinada por:

\section{Equação 3.103}

OpSettl $=\frac{v_{o p}}{H} p_{o}$

em que:

$\mathrm{v}_{\mathrm{op}}=$ velocidade de precipitação $(\mathrm{m} / \mathrm{d})$.

\section{Fósforo inorgânico $\left(p_{i}\right)$}

A concentração de fósforo inorgânico aumenta devido à hidrólise do fósforo orgânico e respiração do fitoplâncton e diminui via fotossíntese. Além disso, inclui-se casos em que o fósforo inorgânico perde-se via sorção. 
Equação 3.104

$S_{p i}=$ DOPHydr $+r_{p a}$ Phyto Re $s p-r_{p a}$ PhytoPhoto - BotA $\lg$ UptakeP - IPSettl

\section{Equação 3.105}

IPSettl $=\frac{v_{i p}}{H} p_{i}$

em que:

$\mathrm{V}_{\mathrm{ip}}=$ velocidade de precipitação do fósforo inorgânico $(\mathrm{m} / \mathrm{d})$.

\section{Sólido Suspenso Inorgânico $\left(\mathbf{m}_{\mathrm{i}}\right)$}

Os sólidos suspensos inorgânicos têm sua concentração diminuída via precipitação.

\section{Equação 3.106}

$S_{m i}=$ InorgSettl

Sendo que:

\section{Equação 3.107}

InorgSettl $=\frac{v_{i}}{H} p_{i}$

em que:

$\mathrm{v}_{\mathrm{i}}=$ velocidade de precipitação dos sólidos suspensos inorgânicos (m/d).

\section{Oxigênio Dissolvido (O)}

A concentração desse gás aumenta devido à fotossíntese e diminui por oxidação da DBO rápida, nitrificação e respiração. Dependendo do grau de saturação de oxigênio na água, este por ser incorporado à massa d'água ou perdido pelo processo de reaeração. 


\section{Equação 3.108}

So $=$ roaPhytoPhoto + rodBotAlhPhoto - rocFastOxid - ronNH4Nitr - roaPhyto $\operatorname{Re} s p$ - rodPhyto $\operatorname{Re} s p-$ rodBotA $\lg \operatorname{Re} s p+O x \operatorname{Re} a e r$

Sendo que:

\section{Equação 3.109}

$O x \operatorname{Re} a e r=k_{a}(T)\left(o_{s}(T\right.$, elev $\left.)-o\right)$

$\mathrm{k}_{\mathrm{a}}(\mathrm{T})=$ coeficiente de reaeração dependente da temperatura $(/ \mathrm{d})$;

$\mathrm{o}_{\mathrm{s}}(\mathrm{T}$, elev $)=$ concentração de saturação de oxigênio $\left(\mathrm{mgO}_{2} / \mathrm{L}\right)$ na temperatura $T$, e elevação acima do nível do mar, elev.

\section{Saturação de Oxigênio}

A seguinte equação é usada para representar a dependência da saturação de oxigênio em função da temperatura:

\section{Equação 3.110}

$\ln o_{s}(T, 0)=-139,34411+\frac{1,575701 \times 10^{5}}{T_{a}}-\frac{6,642308 \times 10^{7}}{T_{a}^{2}{ }_{a}}+\frac{1,243800 \times 10^{10}}{T_{a}^{3}}-\frac{8,621949 \times 10^{11}}{T_{a}^{4}}$

em que:

$\mathrm{O}_{\mathrm{s}}=$ concentração de saturação de $\mathrm{O}_{2}$ na água doce a $1 \mathrm{~atm}\left(\mathrm{mgO}_{2} / \mathrm{L}\right)$;

$\mathrm{T}_{\mathrm{a}}=$ temperatura absoluta $(\mathrm{K})$, sendo que:

\section{Equação 3.111}

$T_{a}=T+273,15$

O efeito da elevação é considerado como: 


\section{Equação 3.112}

$o_{s}(T$, elev $)=e^{\ln o_{s}}(T, 0)(1-0,0001148$ elev $)$

\section{Coeficiente de Reaeração}

O coeficiente de reaeração pode ser prescrito na planilha do Excel denominada "Reach". Se a reaeração não é prescrita pelo usuário, ela é calculada de acordo com as características hidráulicas do rio e, opcionalmente, com a velocidade do vento.

\section{Equação 3.113}

$k_{a}(20)=k_{a h}(20)+\frac{K_{L w}(20)}{H}$

em que:

$\mathrm{k}_{\mathrm{a}}=$ taxa de reaeração a $20^{\circ} \mathrm{C}$ calculada com base nas características hidráulicas do rio $\left(\mathrm{d}^{-1}\right)$; $\mathrm{K}_{\mathrm{L}}(20)=$ coeficiente de reaeração de transferência de massa, calculado de acordo com a velocidade do vento $(\mathrm{m} / \mathrm{d})$;

$\mathrm{H}=$ profundidade média $(\mathrm{m})$.

As equações baseadas nas características hidráulicas do rio são as seguintes:

- O’Connor-Dobbins (O’Connor e Dobbins, 1958);

- Churchill (Churcill et al, 1962);

- Owens-Gibbs (Owens et al 1964);

- Tsivoglou-Neal (Tsivoglou e Neal, 1976);

- Thackston-Dawson (Thackston e Dawson, 2001);

- USGS (Pool-riffle) (Melching e Flores, 1999);

- USGS (Channel-control) (Melching e Flores, 1999);

- Internal (Covar, 1976): essa opção refere-se à opção interna (Internal) da planilha do Excel denominada "Rates", onde a reaeração é calculada internamente segundo um esquema de padronização desenvolvida por Covar (1976).

As equações baseadas na reaeração em função da velocidade do vento são descritas de acordo com três opções:

\section{- $\quad$ Pode ser omitida;}


- $\quad$ Fórmula de Banks-Herrera (Banks, 1975; Banks e Herrera, 1977);

- $\quad$ Fórmula de Wanninshof (1991).

pH

O seguinte equilíbrio, balanço de massa e equações de neutralidade definem um ambiente de água doce dominado por carbono orgânico:

$$
\begin{aligned}
& K_{1}=\frac{\left[\mathrm{HCO}_{3}^{-}\right]\left[\mathrm{H}^{+}\right]}{\left[\mathrm{H}_{2} \mathrm{CO}_{3}{ }^{*}\right]} \\
& K_{2}=\frac{\left[\mathrm{CO}_{2}^{-}{ }_{3}\right]\left[\mathrm{H}^{+}\right]}{\left[\mathrm{HCO}_{3}^{-}\right]} \\
& K_{w}=\left[\mathrm{H}^{+}\right]\left[\mathrm{OH}^{-}\right]
\end{aligned}
$$

\section{Equação 3.114}

$c_{T}=\left[\mathrm{H}_{2} \mathrm{CO}_{3}{ }^{*}\right]+\left[\mathrm{HCO}_{3}^{-}\right]+\left[\mathrm{CO}_{3}^{-2}\right]$

\section{Equação 3.115}

Alk $=\left[\mathrm{HCO}_{3}^{-}\right]+2\left[\mathrm{CO}_{3}{ }^{2-}\right]+\left[\mathrm{OH}^{-}\right]-\left[\mathrm{H}^{+}\right]$

em que:

$\mathrm{K}_{1}, \mathrm{~K}_{2}$ e $\mathrm{K}_{\mathrm{w}}=$ constante dos ácidos;

$\mathrm{Alk}=$ alcalinidade (eqL-1);

$\mathrm{H} 2 \mathrm{CO}_{3}{ }^{*}=$ soma de dióxido de carbono dissolvido e ácido carbônico;

$\mathrm{HCO}_{3}{ }^{-}=$íon bicarbonato;

$\mathrm{CO}_{3}{ }^{2-}=$ íon carbonato;

$\mathrm{H}^{+}=$íon hidrogênio;

$\mathrm{OH}^{-}=$íon hidroxila; 
$\mathrm{c}_{\mathrm{T}}=$ concentração de carbono inorgânico total (mole/L).

As constantes dos gases são corrigidas de acordo com a temperatura como:

- $\quad$ Para $\mathrm{K}_{\mathrm{w}}=$ Harned e Hamer (1933);

- $\quad$ Para $K_{1}=$ Plummer e Busenberg (1982);

- $\quad$ Para $\mathrm{K}_{2}=$ Plummer e Busenberg (1982).

$\mathrm{O} \mathrm{pH}$ pode ser obtido por:

\section{Equação 3.116}

$$
p H=-\log _{10}\left[H^{+}\right]
$$

O usuário do modelo pode optar dois métodos de determinação do pH, Newton-Raphson ou método da bisecção. O método de Newton-Raphson é um método padrão, porém possui algumas divergências, sendo preferível optar-se pelo método da bisecção, mais estável.

\section{Carbono inorgânico total $\left(\mathbf{c}_{\mathrm{T}}\right)$}

A concentração desse composto aumenta devido à rápida oxidação do carbono e pelo processo de respiração e diminui devido à fotossíntese. Dependendo do grau de saturação de $\mathrm{CO}_{2}$ na água, há aumento ou diminuição do mesmo via reaeração.

\section{Equação 3.117}

$S_{c T}=r_{c c o}$ FastCOxid $+r_{c c a}$ Phyto $\operatorname{Re} s p+r_{c c d}$ BotA $\lg \operatorname{Re} s p-r_{c c a}$ PhytoPhoto

$-r_{\text {ccd }}$ BotA $\lg$ Photo $+\mathrm{CO}_{2}$ Re aer

Sendo que:

\section{Equação 3.118}

$\mathrm{CO}_{2} \operatorname{Re}$ aer $=k_{a c}(T)\left(\left[\mathrm{Co}_{2}\right]_{s}-\alpha_{0} c_{T}\right.$ 
em que:

$\mathrm{k}_{\mathrm{ac}}(\mathrm{T})=$ coeficiente de reaeração do dióxido de carbono dependente da temperatura (/d);

$\left[\mathrm{CO}_{2}\right]_{\mathrm{s}}=$ concentração de saturação de dióxido de carbono;

$\alpha_{0}=$ fração de carbono inorgânico total no dióxido de carbono.

\section{Saturação de dióxido de carbono}

A saturação de $\mathrm{CO}_{2}$ é calculada pela Lei de Henry:

\section{Equação 3.119}

$\left[\mathrm{CO}_{2}\right]_{\mathrm{s}}=\mathrm{K}_{\mathrm{H}} p_{\mathrm{CO}_{2}}$

em que:

$\mathrm{K}_{\mathrm{H}}=$ constante da Lei de Henry [mole)L atm $\left.{ }^{-1}\right]$;

$\mathrm{p}_{\mathrm{CO} 2}=$ pressão parcial do dióxido de carbono na atmosfera (atm).

$\mathrm{O}$ valor de $\mathrm{K}_{\mathrm{H}}$ pode ser calculado em função da temperatura, como:

\section{Equação 3.120}

$p_{K H}=\frac{2385,73}{T_{a}}-0,0152672 T_{a}+14,0184$

O valor de $\mathrm{p}_{\mathrm{CO} 2}$ é um dado do programa.

\section{CO2 - Transferência de gás}

O coeficiente de reaeração do $\mathrm{CO} 2$ pode ser calculado através da taxa de reaeração do oxigênio, como: 


\section{Equação 3.121}

$k_{a c}(20)=\left(\frac{32}{44}\right)^{0,25} k_{a}(20)=0,923 k_{a}(20)$

\section{Alcalinidade}

O modelo considera alterações na alcalinidade devido à fotossíntese e respiração, hidrólise de nitrogênio e fósforo, nitrificação e desnitrificação.

\section{Equação 3.122}

$S_{\text {alk }}=\left(-r_{\text {alka }} P_{a p}+r_{\text {alkn }}\left(1-P_{a p}\right)\right.$ PhytoPhoto $+r_{\text {alkaa }}$ Phyto $\operatorname{Re} s p-r_{\text {alkbn }}$ BotA $\lg$ UptakeN

$+r_{\text {alkbn }}\left(1-P_{a p}\right)$ BotA $\lg$ UptakeN $-r_{\text {alkbp }}$ BotA $\lg$ UptakeP $+r_{\text {alkbn }}$ ONHydr $+r_{\text {alkbp }}$ OPHydr

$-r_{\text {alkn }} \mathrm{NH}_{4} \mathrm{Nitr}+r_{\text {alkden }}$ Denitr

em que:

$r=$ coeficientes estequiométricos 


\section{MATERIAL E MÉTODOS}

\section{1. $\quad$ Área de Estudo}

A bacia do rio Ribeira de Iguape, possui uma área de $28.306 \mathrm{~km}^{2}$, é composta por 23 municípios totalizando uma população de 358.565 habitantes sendo que 234.124 habitantes são moradores da zona rural. Está localizada na região sul do estado de São Paulo (61\%) e leste do estado do Paraná (39\%) é denominada também por Unidade de Gerenciamento dos Recursos Hídricos 11 (UGRHI-11) (CETESB, 2005). As principais atividades econômicas da região estão baseadas na agricultura, pesca, indústria alimentícia e mineração, sendo esta última a de maior impacto no ambiente.

A bacia do rio Ribeira de Iguape, representa uma região ecologicamente importante por preservar grande área remanescente da Mata Atlântica - maior concentração do país - entretanto, encontra-se sob contínuo processo de degradação em virtude do acelerado crescimento urbano, desmatamento para a agricultura ou ainda estabelecimento de atividade industrial.

Apesar da grande riqueza natural, a região do Vale do Ribeira, é considerada a mais pobre do estado de São Paulo apresentando altas taxas de mortalidade infantil e doenças de veiculação hídrica, reflexos da baixa qualidade de vida de sua população, das relações de produção desfavoráveis, da fragilidade da base econômica e da carência de assistências médicas e sanitárias.

Dentro do sistema Ribeira de Iguape, o presente estudo foi realizado no rio Canha, pertencente ao município de Jacupiranga (Baixo Ribeira de Iguape).

O município de Jacupiranga, segundo dados do IBGE (2005) abrange uma área de 708 $\mathrm{km}^{2}$. A população local corresponde a 17.929 habitantes, com 11.039 habitantes na área urbana. Neste município, $90 \%$ das casas estão ligadas à rede de abastecimento de água e $87 \%$ a rede de coleta de esgoto. Todo esgoto coletado é tratado em sistema de tratamento de lagoas de estabilização antes de serem lançados no rio Jacupiranga, considerado como classe 2. A economia baseia-se na agricultura, principalmente com a cultura de banana, mandioca, milho e na pecuária além de outras atividades de menor destaque como o artesanato (CETESB, 2005).

$\mathrm{O}$ rio Canha é afluente da margem direita do rio Jacupiranga e possui aproximadamente 27,5 km de extensão (Figura VII). Nasce a partir da junção de pequenos tributários na região da Serra de Pariquera-Açú (latitude: 2452'07'; longitude: 47057'55'), percorre regiões de mata 
fechada e plantações de banana, atravessa bairros da zona rural do município de Jacupiranga, e penetra no mesmo próximo a Estação de Tratamento de Esgoto desse município (latitude: 24\%1'18'; longitude: 47 59'44'). Possui afluentes desde $1^{\text {a }}$ até $5^{\text {a }}$ ordem, como pode ser evidenciado na figura VIII

Segundo a Cetesb (2005) é considerado como pertencente à classe 2, sendo utilizado para captação de água, a qual abastece toda cidade de Jacupiranga. Na maior parte de sua extensão, o rio Canha, apresenta-se bem preservado. A área da nascente encontra-se circundada por mata ciliar, na parte intermediária observa-se predomínio de plantações de banana e na região onde este deságua no rio Jacupiranga, no perímetro urbano desse município, apresenta-se bastante modificada (Figura IX). 


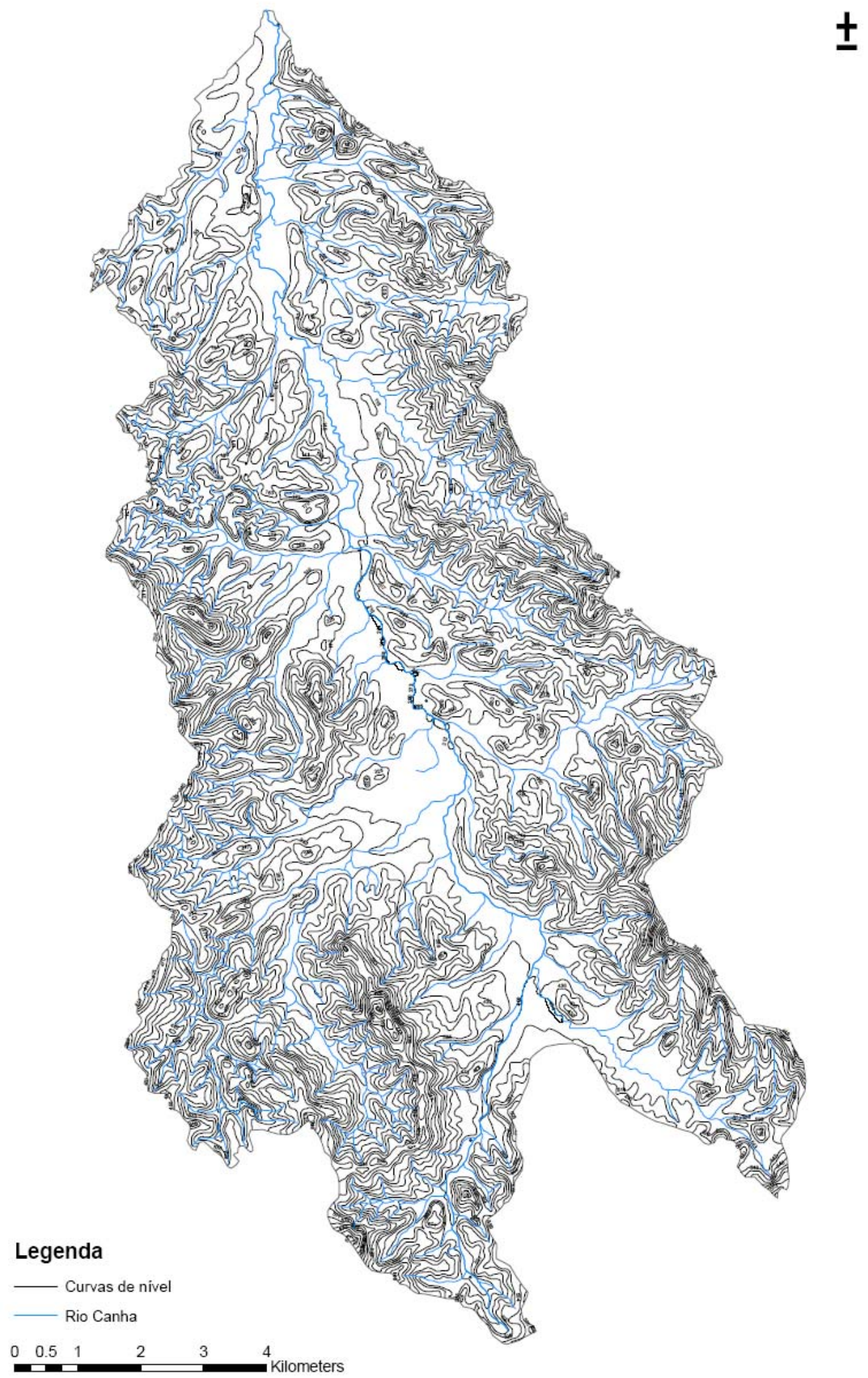

Figura VII: Bacia hidrográfica do Rio Canha. Fonte: Projeto FAPESP nº 02/3449-1. 


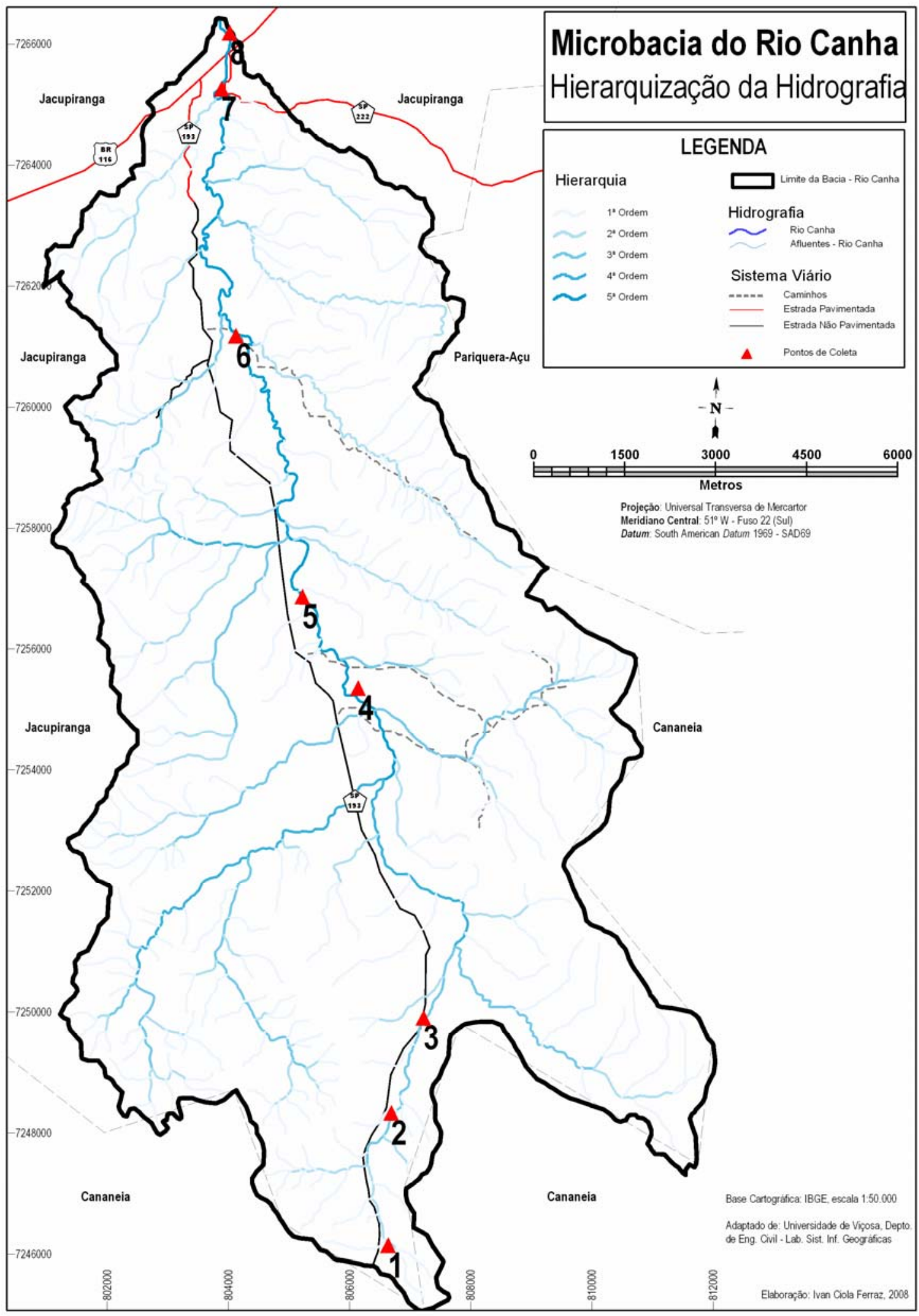

Figura VIII:Hierarquização dos afluentes do rio Canha. Fonte: Projeto FAPESP nº 02/3449-1. 


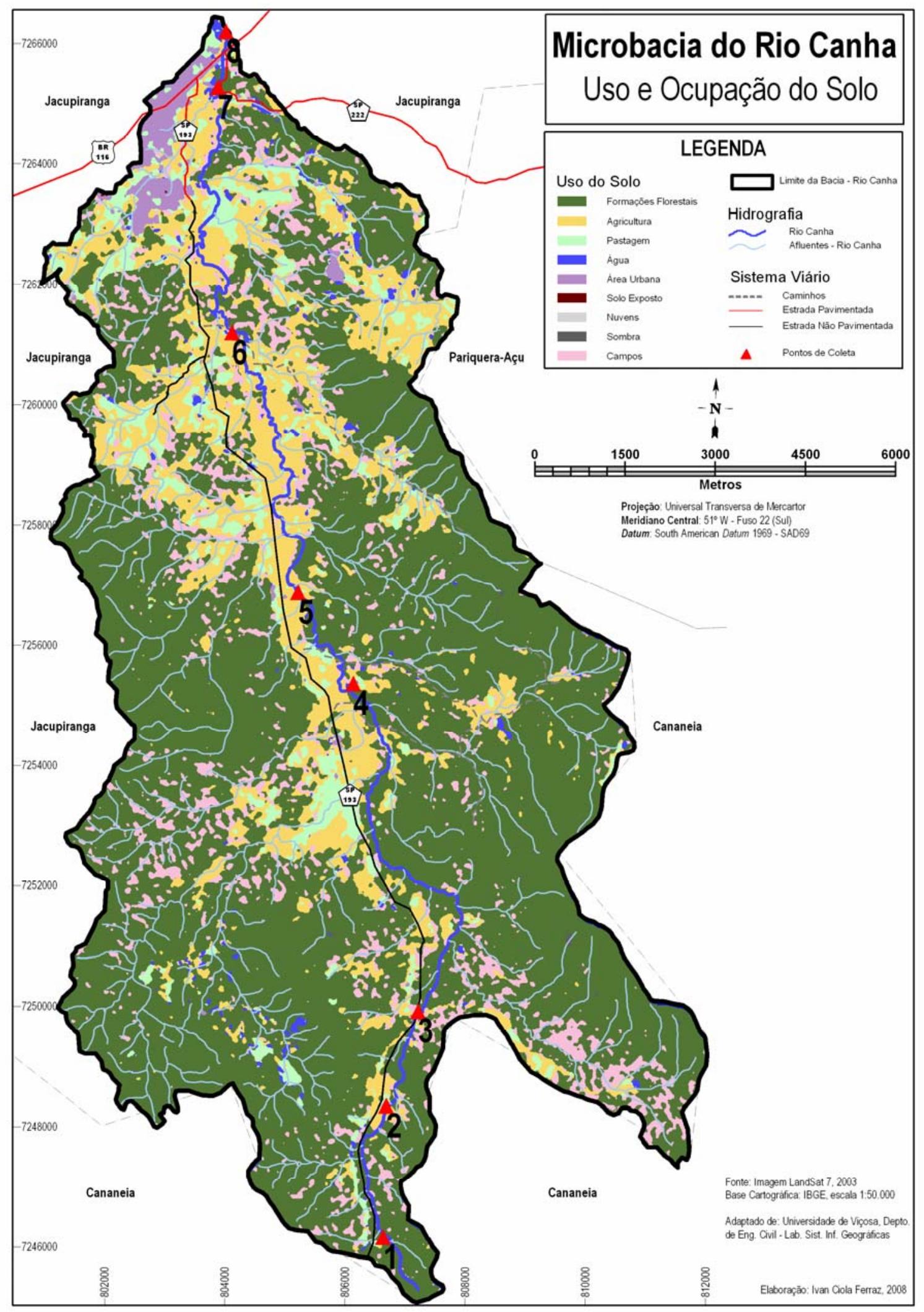

Figura IX Uso e ocupação do solo da Bacia do Rio Canha. Fonte: Projeto FAPESP nº 02/3449-1. 
As figuras X e XI apresentam, respectivamente, a pedologia e a geologia do rio Canha.

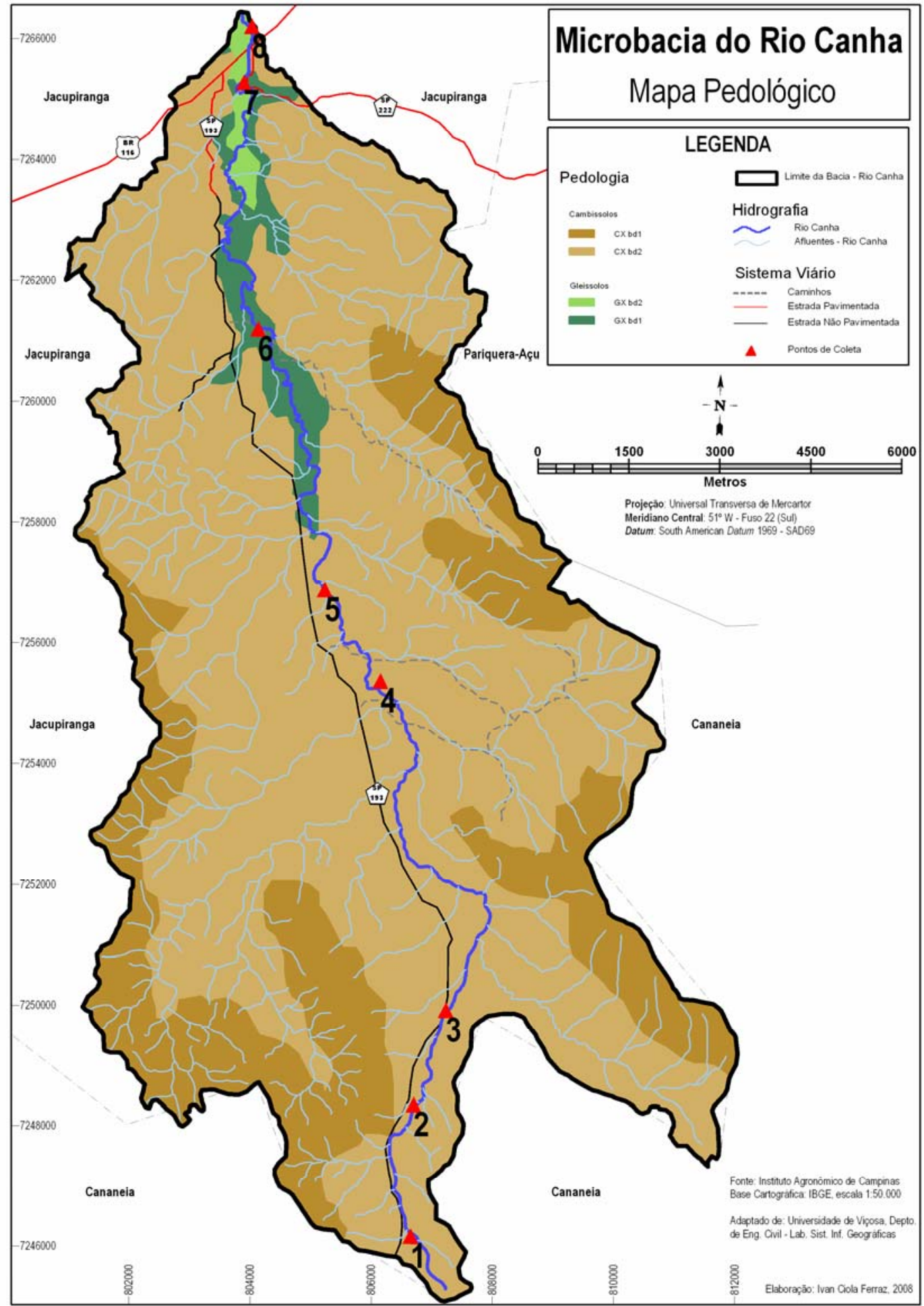

Figura X: Pedologia da Bacia do rio Canha. Fonte: Projeto FAPESP n ${ }^{\circ}$ 02/3449-1. 


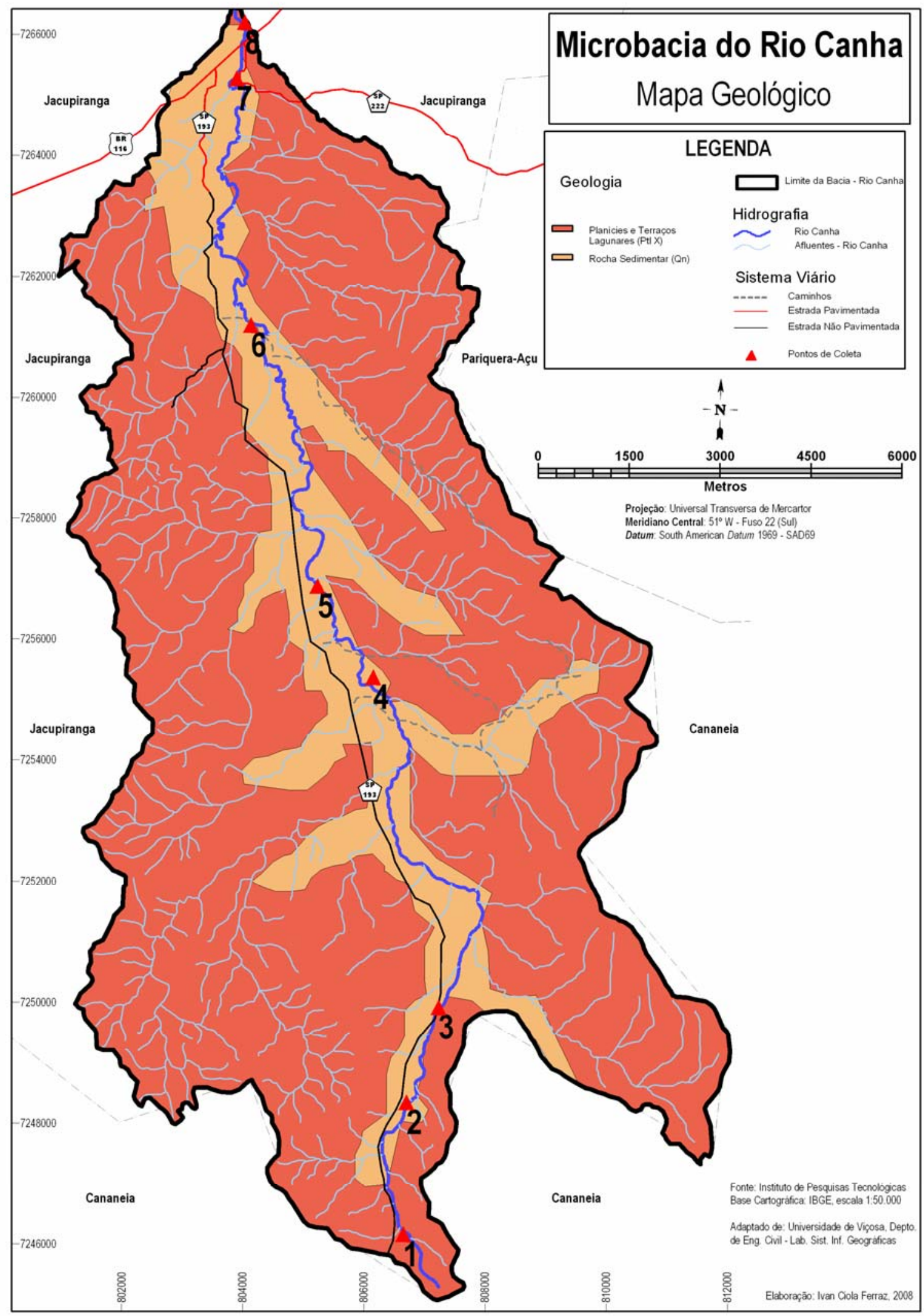

Figura XI: Geologia da Bacia do rio Canha. Fonte: Projeto FAPESP n ${ }^{\circ}$ 02/3449-1. 
Os dados de declividade e hipsografia são detalhados nas figuras XII e XIII

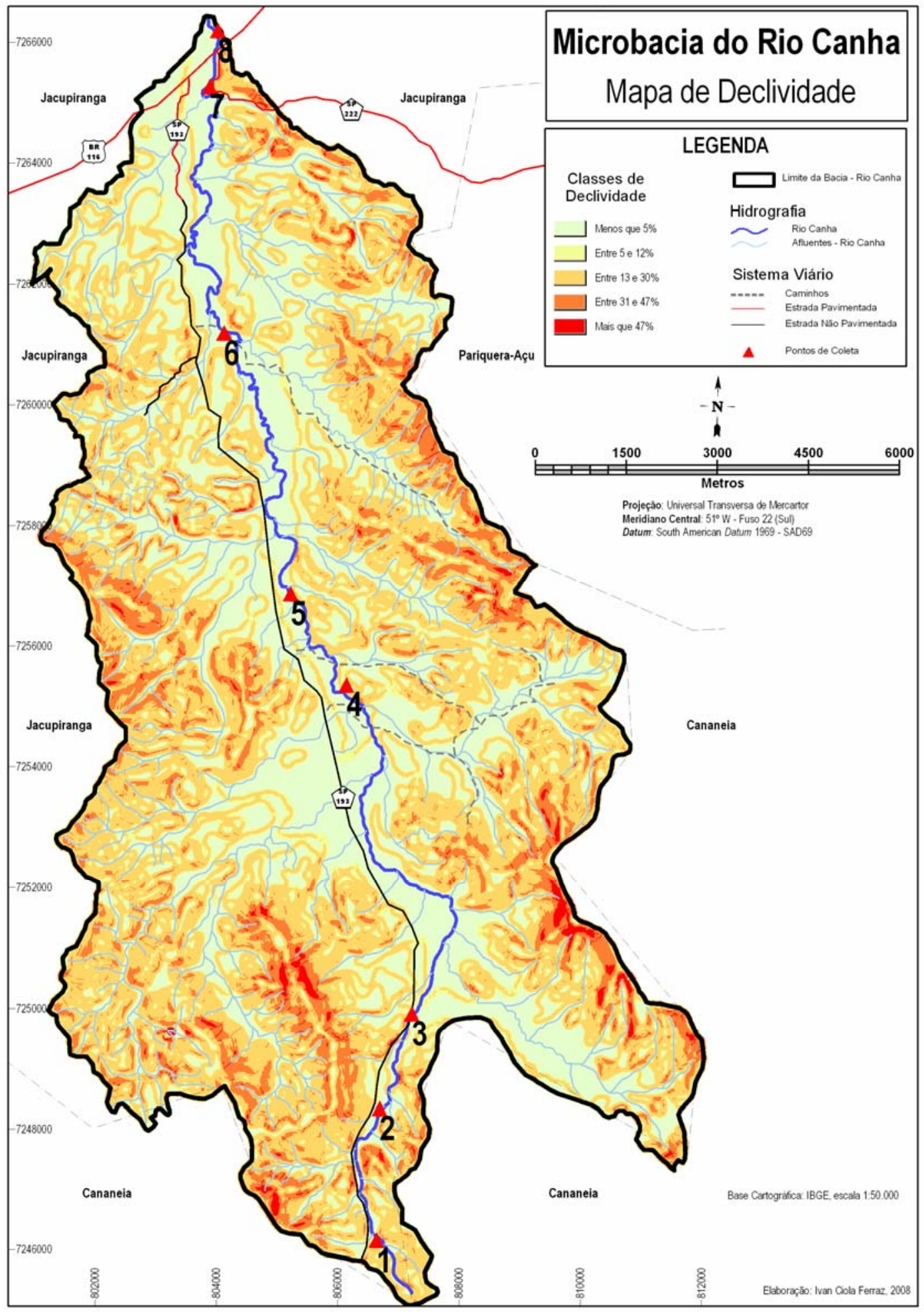

Figura XII: Declividade da Bacia do rio Canha. Fonte: Projeto FAPESP n ${ }^{\circ}$ 02/3449-1. 


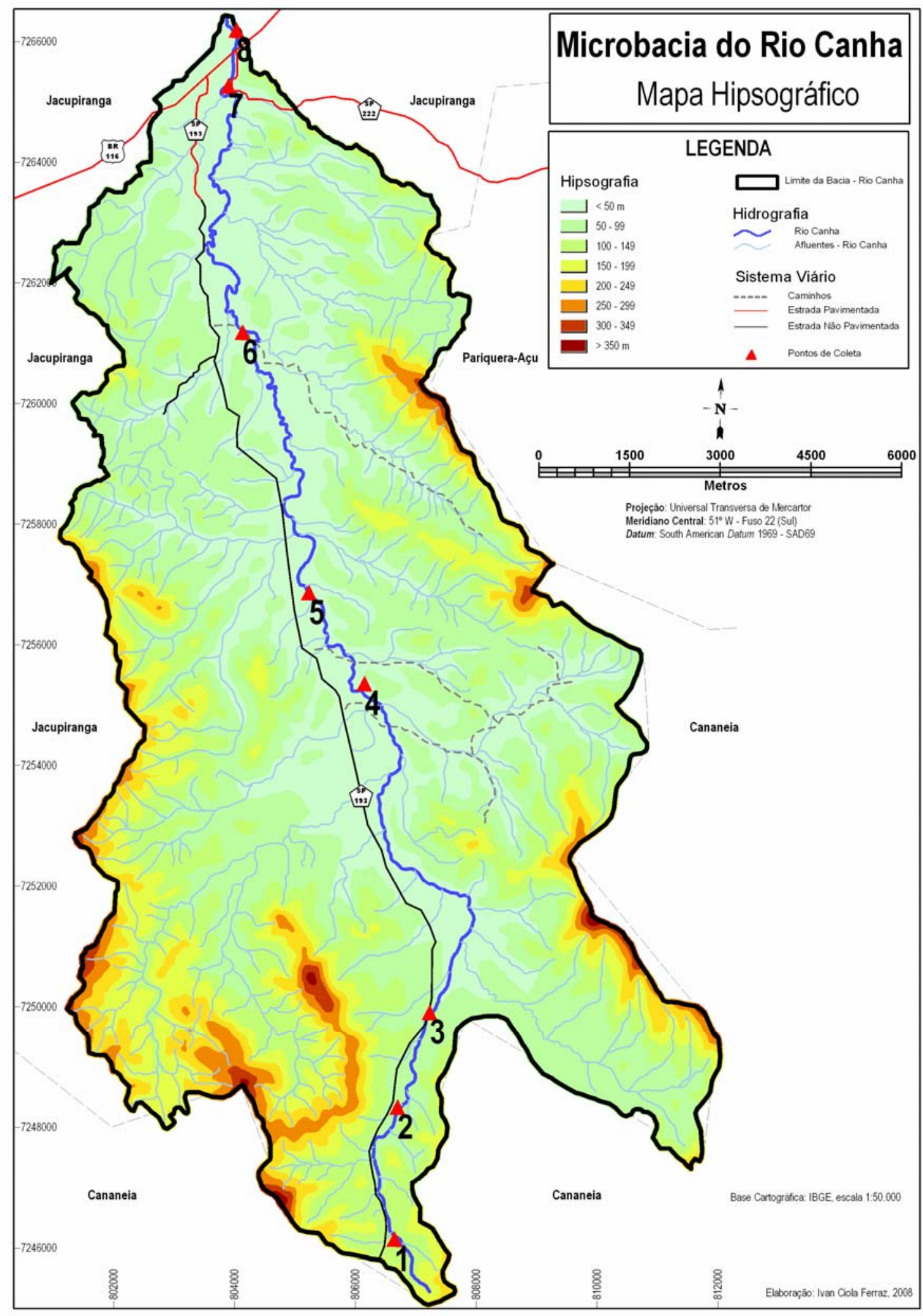

Figura XIII: Hipsografia da Bacia do rio Canha. Fonte: Projeto FAPESP n ${ }^{\circ}$ 02/3449-1. 


\subsection{Amostragem}

As amostragens de água e sedimento foram realizadas em oito estações amostrais ao longo do eixo longitudinal do rio Canha (Figura XIV). As estações amostrais localizam-se em pontos considerados estratégicos, como por exemplo: proximidade da nascente, antes e após a sua passagem por bairros pertencentes ao município, antes do rio Canha desaguar no rio Jacupiranga, entre outros. Tais amostragens foram realizadas em apenas um dia sazonalmente.

\section{Pontos de Amostragem ao Longo do Rio Canha}

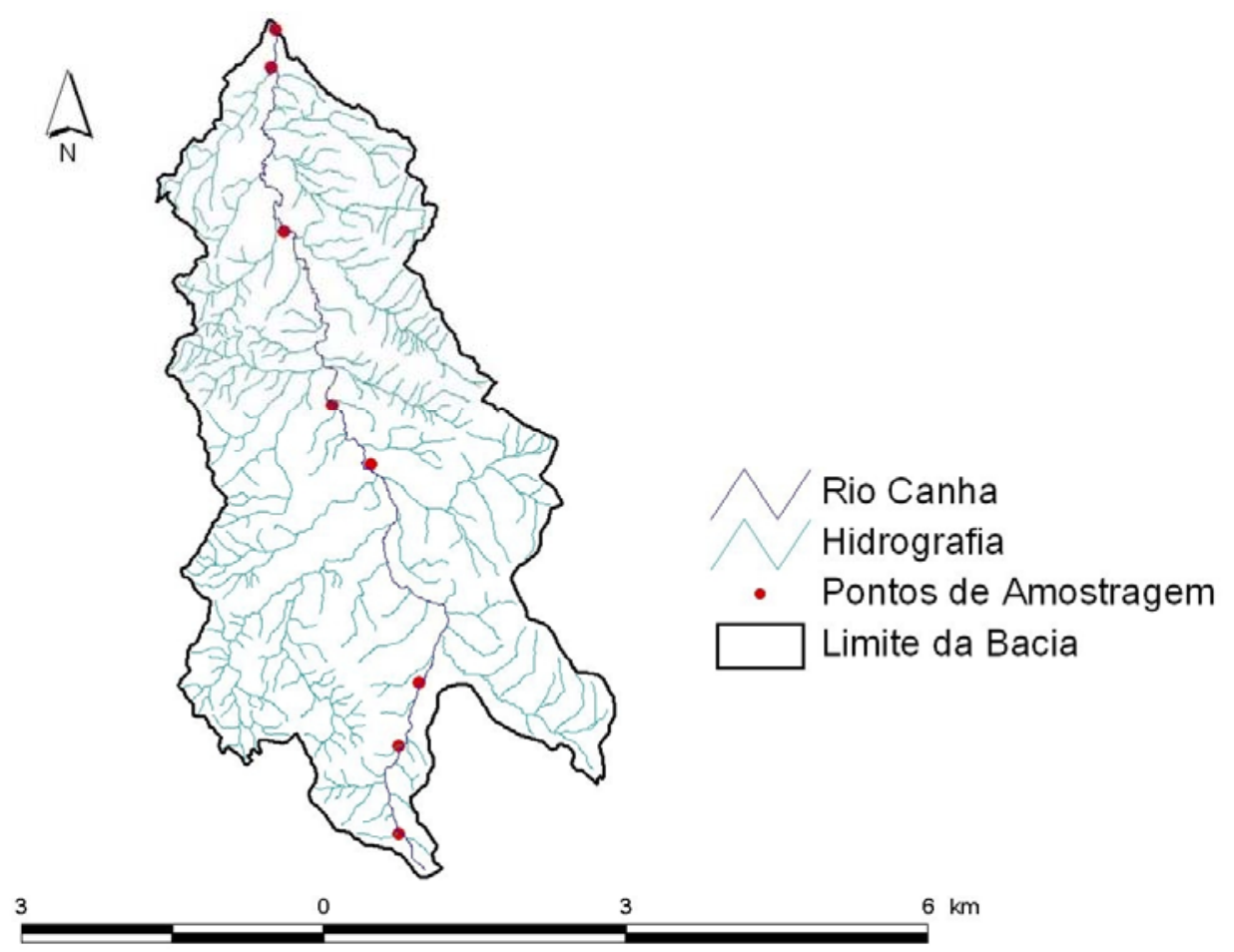

Figura XIV: Pontos de amostragem ao longo do eixo longitudinal do rio Canha. Fonte: Projeto FAPESP n ${ }^{\circ}$ 02/34491.

As figuras a seguir caracterizam o rio Canha, sendo que para o presente trabalho considerou-se como nascente os pontos 1, 2 e 3; médio curso 4, 5 e 6 e foz pontos amostrais 7 e 8. 

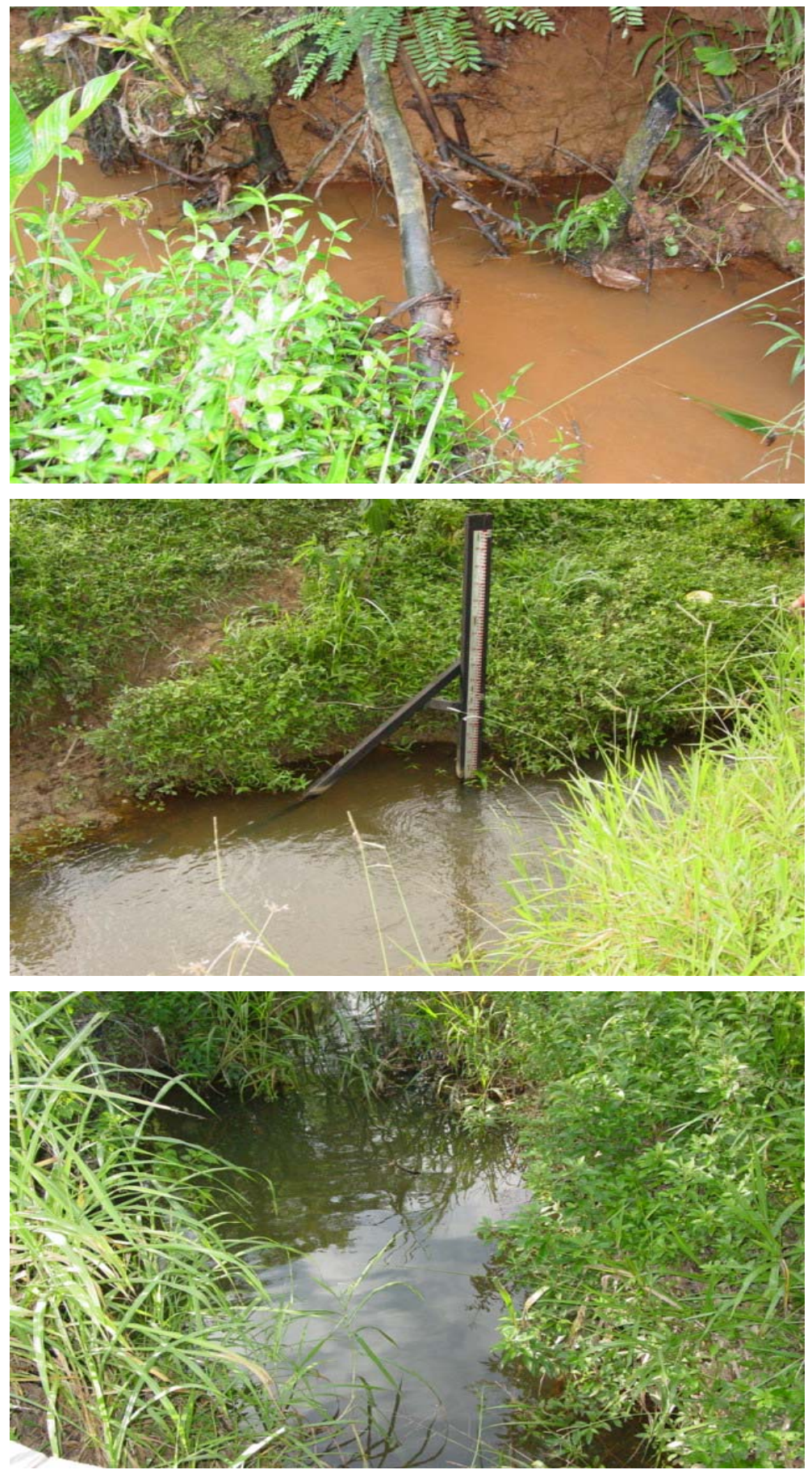

Figura XV: Rio Canha - Pontos amostrais 1, 2 e 3, respectivamente, indicando a nascente 

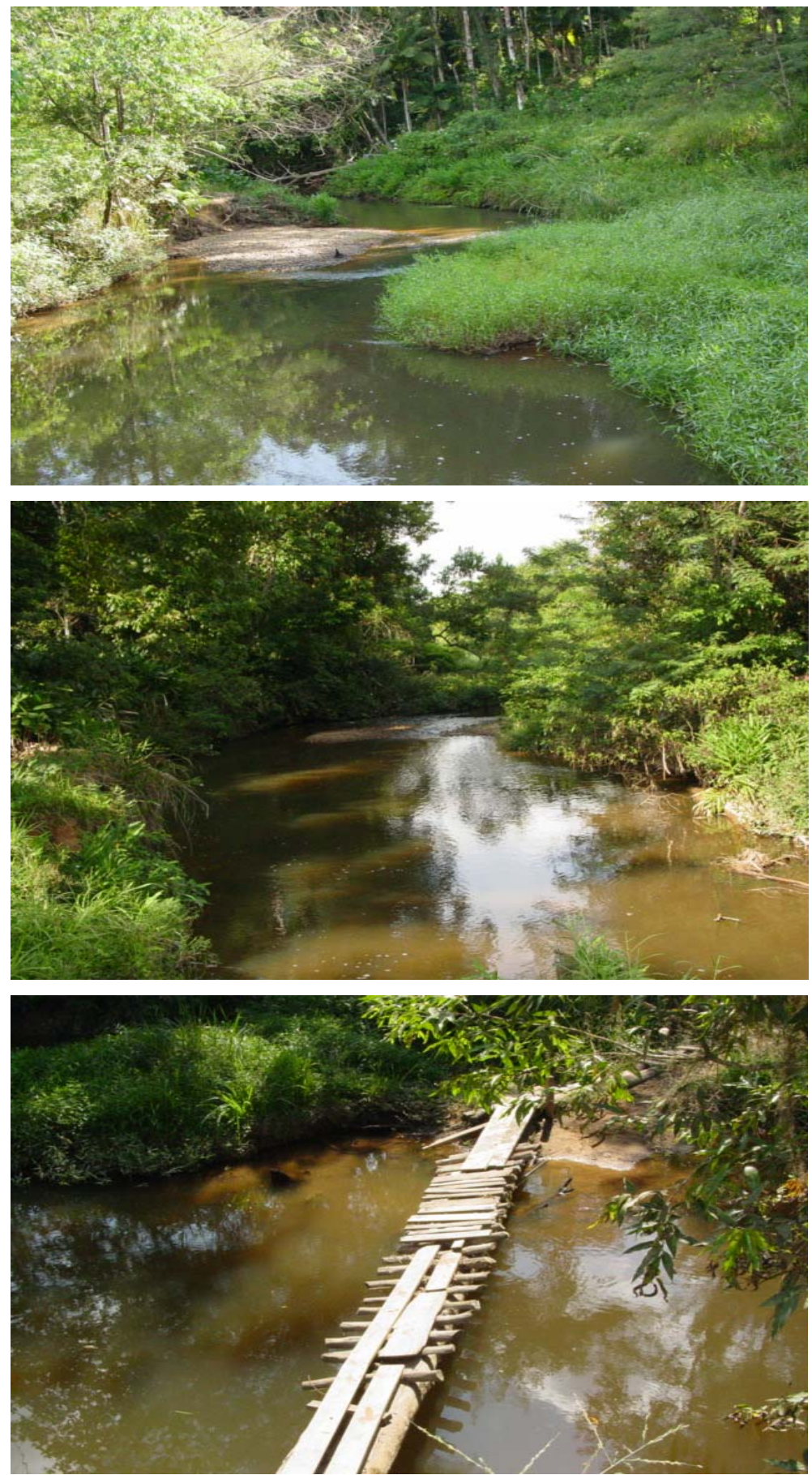

Figura XVI: Rio Canha - Pontos amostrais 4, 5 e 6, respectivamente, indicando o médio curso do rio. 

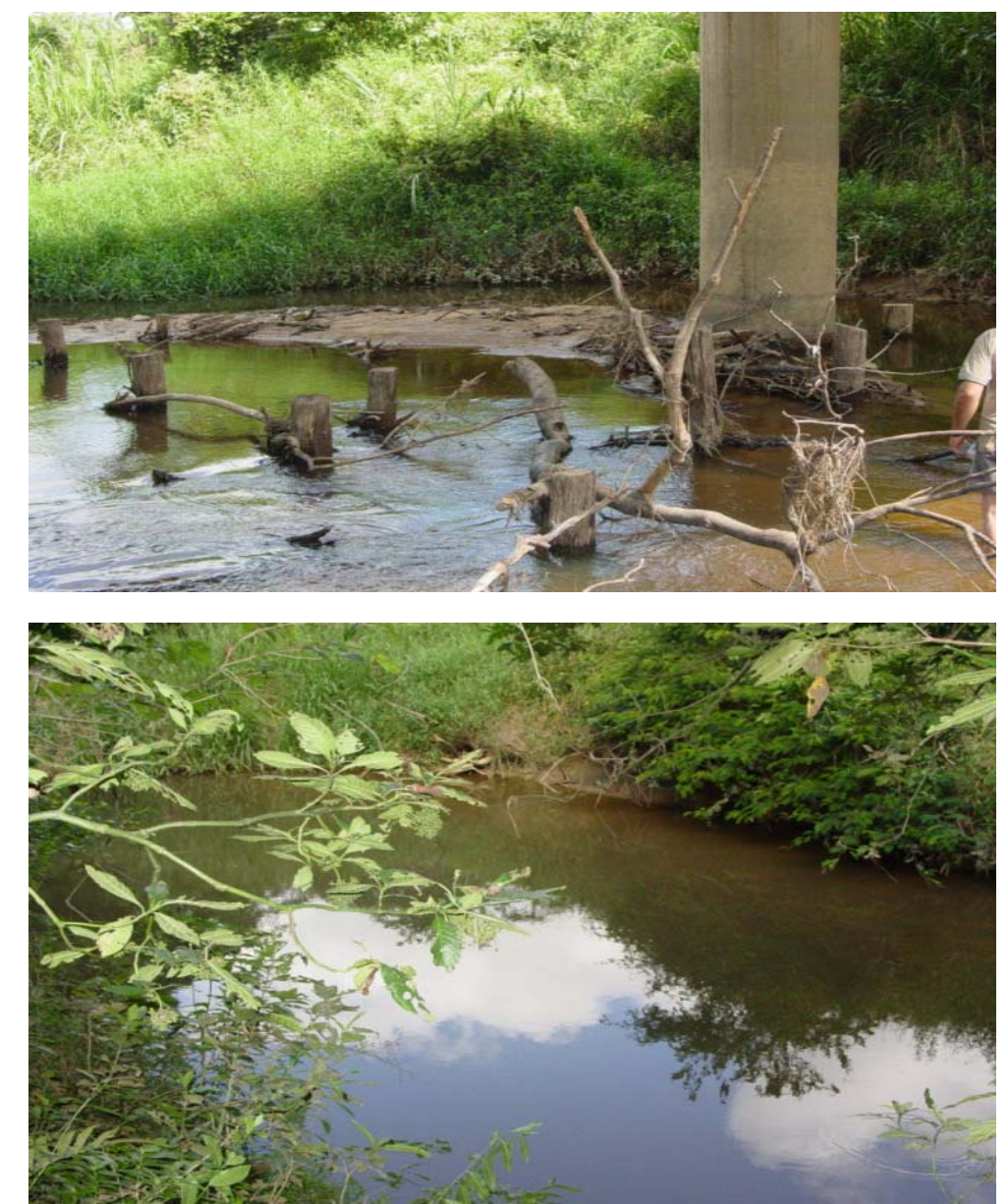

Figura XVII: Rio Canha - Pontos amostrais 7 e 8, respectivamente, indicando a foz.

\subsubsection{Compartimento água}

Na tabela 2 são apresentadas as variáveis físicas e químicas analisadas na água, bem como os métodos utilizados. As variáveis temperatura, $\mathrm{pH}$, condutividade e oxigênio dissolvido foram medidas in situ no momento da coleta, com sonda multiparamétrica (YSI, modelo 556 MPS), previamente calibrada. As análises de condutividade elétrica e turbidez foram feitas com o auxílio de um condutivímetro e turbidímetro de bancada, respectivamente, no laboratório de campo. As medidas de alcalinidade também foram realizadas no laboratório de campo. Ainda em campo, as amostras foram filtradas com filtro Whatman - GFC de $47 \mathrm{~mm}$ de diâmetro e 1,2 $\mu \mathrm{m}$ de poro, e o filtrado armazenado em freezer a temperatura de $18^{\circ} \mathrm{C}$ negativos para análise de nutrientes dissolvidos (nitrito, nitrato e fosfato inorgânico). Para os sólidos em suspensão, as amostras foram filtradas em campo, com filtro Milipore - AP40 de $47 \mathrm{~mm}$ de diâmetro e 0,8 a 8 
$\mu \mathrm{m}$ de poro. Em seguida, foram armazenadas em freezer para posterior transporte até o laboratório Biotace-EESC-USP para análise. Para a determinação da concentração da clorofila $a$, a extração foi feita no laboratório com etanol 80\%. A análise dos extratos em espectrofotometria seguiu a metodologia descrita em APHA (1999) e a leitura foi realizada no comprimento de onda de $665 \mathrm{~nm}$. Para a determinação da clorofila $a(\mu \mathrm{g} / \mathrm{L})$ foi utilizada a metodologia descrita em Nush (1980) e modificada segundo a Norma Holandesa (Nederlandse Norm NEN 6520, 1981). Amostras para nutrientes totais (nitrogênio amoniacal e nitrogênio total) foram separadas em frascos de PVC, sem filtração e congeladas $\left(-18{ }^{\circ} \mathrm{C}\right)$ para posterior análise, segundo APHA, 1999.

Tabela 2. Métodos de determinação das variáveis físicas e químicas analisadas na água.

\begin{tabular}{|c|c|c|c|}
\hline VARIÁVEIS & UNIDADE & Método & Referência Bibliográfica \\
\hline Condutividade Elétrica & $\mu \mathrm{S} . \mathrm{cm}^{-1}$ & Potenciométrico & \\
\hline Oxigênio Dissolvido* & $\operatorname{mg} . L^{-1}$ & Potenciométrico & \\
\hline Temperatura* & ${ }^{\circ} \mathrm{C}$ & Potenciométrico & \\
\hline $\mathrm{pH}^{*}$ & - & Potenciométrico & \\
\hline Alcalinidade* & mg. $L^{-1}$ & 2320B-4d & APHA (1999) \\
\hline Sólidos em suspensão - Totais, & $\operatorname{mg} . \mathrm{L}^{-1}$ & 2540-D e E/Gravimétrico & APHA (1999) \\
\hline \multicolumn{4}{|l|}{ Orgânicos e Inorgânicos* } \\
\hline Nitrogenio Amoniacal* & $\operatorname{mg} \cdot \mathrm{L}^{-1}$ & $4500-\mathrm{C}$ & APHA (1999) \\
\hline Nitrito & $\mu \mathrm{g} . \mathrm{L}^{-1}$ & 4500-B/Espectrofotométrico & APHA (1999) \\
\hline Nitrato* & $\operatorname{mg} . \mathrm{L}^{-1}$ & 4500-B/Espectrofotométrico & APHA (1999) \\
\hline Fosfato Inorgânico & $\mu \mathrm{g} . \mathrm{L}^{-1}$ & 4500-E/Espectrofotométrico & APHA (1999) \\
\hline Nitrogênio Total* & $\operatorname{mg} . \mathrm{L}^{-1}$ & $4500-\mathrm{B}$ & APHA (1999) \\
\hline Demanda Bioquímica de Oxigênio* & $\mathrm{mgO}_{2} \cdot \mathrm{L}^{-1}$ & 4500-C (Modificação pela Azida) & APHA (1999) \\
\hline
\end{tabular}

\subsubsection{Compartimento sedimento}


Os sedimentos foram coletados diretamente do leito do rio e acondicionados em potes plásticos de $1 \mathrm{Kg}$ para análise de granulometria. As análises seguiram a metodologia proposta por Nogueira (2005).

\subsection{Variáveis Hidrológicas}

\subsubsection{Precipitação, Nível d'água, Velocidade de escoamento e Vazão}

No presente trabalho foram utilizados apenas os totais precipitados registrados pelas estações climatológicas instaladas na Bacia do rio Jacupiranga e Pariquera-Açú, além dos dados disponibilizados pelo Centro Integrado de Informações Agrometeorológicas do Instituto Agronômico de Campinas (CIIAGRO-IAC - www.ciiagro.iac.sp.gov.br). Para obtenção da precipitação média foi utilizada a metodologia do polígono de Thiessen

O nível da água foi obtido através da leitura de réguas hidrométricas (duas vezes ao dia manhã e tarde), durante o período de março a outubro de 2007, as quais foram instaladas em três pontos ao longo do rio.

Foram realizadas medições das velocidades de escoamento $(\mathrm{m} / \mathrm{s})$ e vazão segundo metodologia de Righetto (1998) em três pontos de amostragem ao longo do rio: próximo a nascente, em uma região intermediária e próximo ao encontro com o rio Jacupiranga. Foram feitos também o levantamento das seções transversais nos pontos 1, 4 e 8 na campanha 3 e dos pontos $1,2,4,5,7$ na campanha 4 . O resultado de tais levantamentos encontra-se nos Anexos 1 e 2 deste trabalho.

A curva de permanência para as vazões do rio Canha foram obtidas por Mendiondo (Projeto FAPESP 02/3449-1) segundo metodologia do SIGRH (www.sigrh.sp.gov.br)

\subsection{Utilização do Modelo}

O modelo utilizado no presente trabalho foi o QUAL2K regulamentado pela Agência Norte-americana de Proteção Ambiental (U.S. - Environmental Protection Agency - EPA).

A justificativa para utilização deste modelo relaciona-se ao fato da disponibilidade do mesmo, além de ser uma derivação do modelo QUAL2E, bastante difundido em estudos de qualidade da água. 
O modelo QUAL2K possibilita a inserção de concentrações com variações horárias para as condições de contorno, porém esse trabalho não considerou tal variação, mantendo constantes as concentrações das condições de contorno ao longo de 24 horas.

O Rio Canha possui 27,5 km de extensão, no entanto, para o presente trabalho o trecho fluvial considerado foi de $26,8 \mathrm{~km}$, uma vez que esta é a localização do último ponto de coleta. O rio foi dividido em trechos de acordo com o uso e ocupação do solo. A tabela a seguir apresenta tal divisão, bem como as características físicas do local:

Tabela 3: Representação dos trechos simulados

\begin{tabular}{|c|c|c|c|}
\hline Trecho & Final do Trecho & Distância (km) & Características \\
\hline Nascente & Propriedade Rural & 3 & Mata ciliar/Pecuária \\
\hline Propriedade Rural & Fazenda Raposo & 6 & $\begin{array}{c}\text { Pecuária/Plantações } \\
\text { de banana }\end{array}$ \\
\hline Fazenda Raposo & SP 222 & 15,2 & $\begin{array}{c}\text { Plantações de } \\
\text { banana/Área urbana }\end{array}$ \\
\hline
\end{tabular}

A divisão dos elementos foi feita com base na distância entre os pontos de coleta:

Tabela 4: Representação dos elementos simulados

\begin{tabular}{|c|c|}
\hline Elementos & Alcance (km) \\
\hline 1 & 3 \\
\hline 2 & 2 \\
\hline 3 & 6 \\
\hline 4 & 2,9 \\
\hline 5 & 6 \\
\hline 6 & 5,4 \\
\hline 7 & 0,9 \\
\hline
\end{tabular}

A calibração do modelo para as variáveis hidráulicas foi feita da seguinte maneira:

- Vazão: foi utilizada a vazão média, sendo que a diferença entre a vazão do trecho de jusante com o trecho de montante foi considerada como uma fonte difusa;

- Velocidade de escoamento: a velocidade média de cada elemento foi inserida no modelo e sua calibração foi feita com base na declividade da bacia e no $n$ de Manning para canais naturais; 
- Altura da água: foi utilizada a altura média de cada elemento e sua calibração foi obtida com base na rugosidade de canal ( $n$ de Manning).

- Para as variáveis limnológicas utilizou-se os dados obtidos nas diferentes campanhas para as diferentes estações do ano. A subtração dos dados de jusante com montante foi considerada como fonte difusa para calibração do modelo.

- Os parâmetros utilizados para calibração são aqueles sugeridos pelo próprio modelo, os quais julgou-se serem os mais utilizados da literatura. Tais dados são apresentados no Anexo 3 do presente trabalho.

- A análise de sensibilidade foi realizada para os parâmetros hidráulicos do modelo.

O cálculo das cargas específicas apresentadas nos resultados foi feito através da multiplicação da concentração das variáveis limnológicas pela vazão, em seguida, os valores obtidos foram divididos pela área acumulada de cada sub-bacia. Já a variação dessas cargas, apresentadas no anexo 4), foram calculadas da seguinte maneira:

- Variação da Vazão (+)

\section{Equação 4.1}

$$
\left(V_{\text {máx }} * A_{s}\right)-Q
$$

em que:

$V_{\text {máx }}=$ velocidade máxima na seção $(\mathrm{m} / \mathrm{s})$;

$A_{s}=$ Área da seção $\left(\mathrm{m}^{2}\right)$;

$Q=$ Vazão na seção $\left(\mathrm{m}^{3} / \mathrm{s}\right)$

- Variação da Vazão (-)

\section{Equação 4.2}

$$
\left(V_{\text {mim }} * A_{s}\right)-Q
$$


em que:

$V_{\min }=$ velocidade mínima de escoamento na seção $(\mathrm{m} / \mathrm{s})$;

$A_{s}=$ Área da seção $\left(\mathrm{m}^{2}\right)$;

$Q=$ vazão na seção $\left(\mathrm{m}^{3} / \mathrm{s}\right)$

- Variação da Velocidade (+)

\section{Equação 4.3}

$$
V_{\text {máx }}-V
$$

sendo que:

$V_{\text {máx }}=$ Velocidade máxima de escoamento na seção $(\mathrm{m} / \mathrm{s})$;

$V=$ velocidade de escoamento na seção $(\mathrm{m} / \mathrm{s})$

- Variação da Velocidade (-)

\section{Equação 4.4}

$$
V-V_{\text {min }}
$$

sendo que:

$V=$ Velocidade de escoamento na seção $(\mathrm{m} / \mathrm{s})$;

$V_{\min }=$ Velocidade mínima de escoamento na seção $(\mathrm{m} / \mathrm{s})$;

- As variações (+ / -) da altura da água (H) foram obtidas em campo.

- Variação das cargas específicas (+)

\section{Equação 4.5}

$$
\left(\frac{C o n c * V a r_{Q_{+}}}{A}\right)
$$


em que:

Conc $=$ Concentração do composto (Kg/ano);

$\operatorname{Var}_{Q^{+}}=$Variação da vazão $(+)(\mathrm{L} / \mathrm{s})$;

$A=$ Área acumulada de cada sub-bacia (ha)

- Variação das cargas específicas (-)

\section{Equação 4.6}

$$
\left(\frac{\text { Conc } * V a r_{Q-}}{A}\right)
$$

em que:

Conc $=$ Concentração do composto (Kg/ano);

$\operatorname{Var}_{\mathrm{Q}-}=$ Variação (-) da vazão (L/s);

$\mathrm{A}=$ Área acumulada de cada sub-bacia (ha) 


\section{RESULTADOS}

\section{1. $\quad$ Aspectos gerais}

A partir de características como declividade da bacia, bem como formação geológica, morfologia e rugosidade do canal, o rio Canha foi classificado segundo Rosgen (1996) como do tipo G4. Esse tipo de rio é caracterizado por uma declividade variando de $0,02 \mathrm{~m} / \mathrm{m}$ a $0,039 \mathrm{~m} / \mathrm{m}$, com sinuosidade maior que 1,2, relação largura/profundidade menor que 12 e taxa de entrincheiramento menor que 1,4 .

Os rios do tipo G4 apresentam-se entrincheirados na maioria de seu curso com moderada declividade, possuem alta carga de sedimentos provenientes da cabeceira e são suscetíveis à erosão. As características morfológicas dos rios classificados como G4 são apresentadas na figura a seguir e comparadas com as obtidas em campo para o rio Canha (Figura XIX).

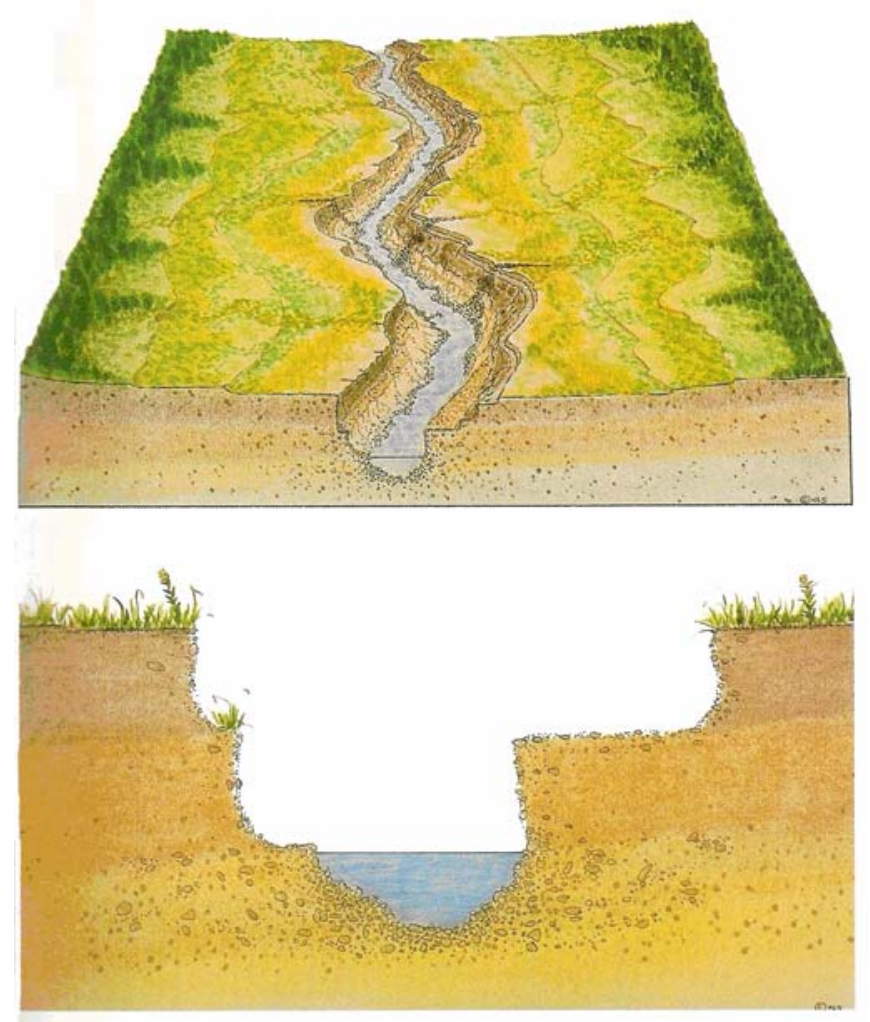

Figura XVIII: Representação da estrutura morfológica e da seção transversal de um canal fluvial do tipo G4. Fonte: Adaptado de Rosgen (1996). 

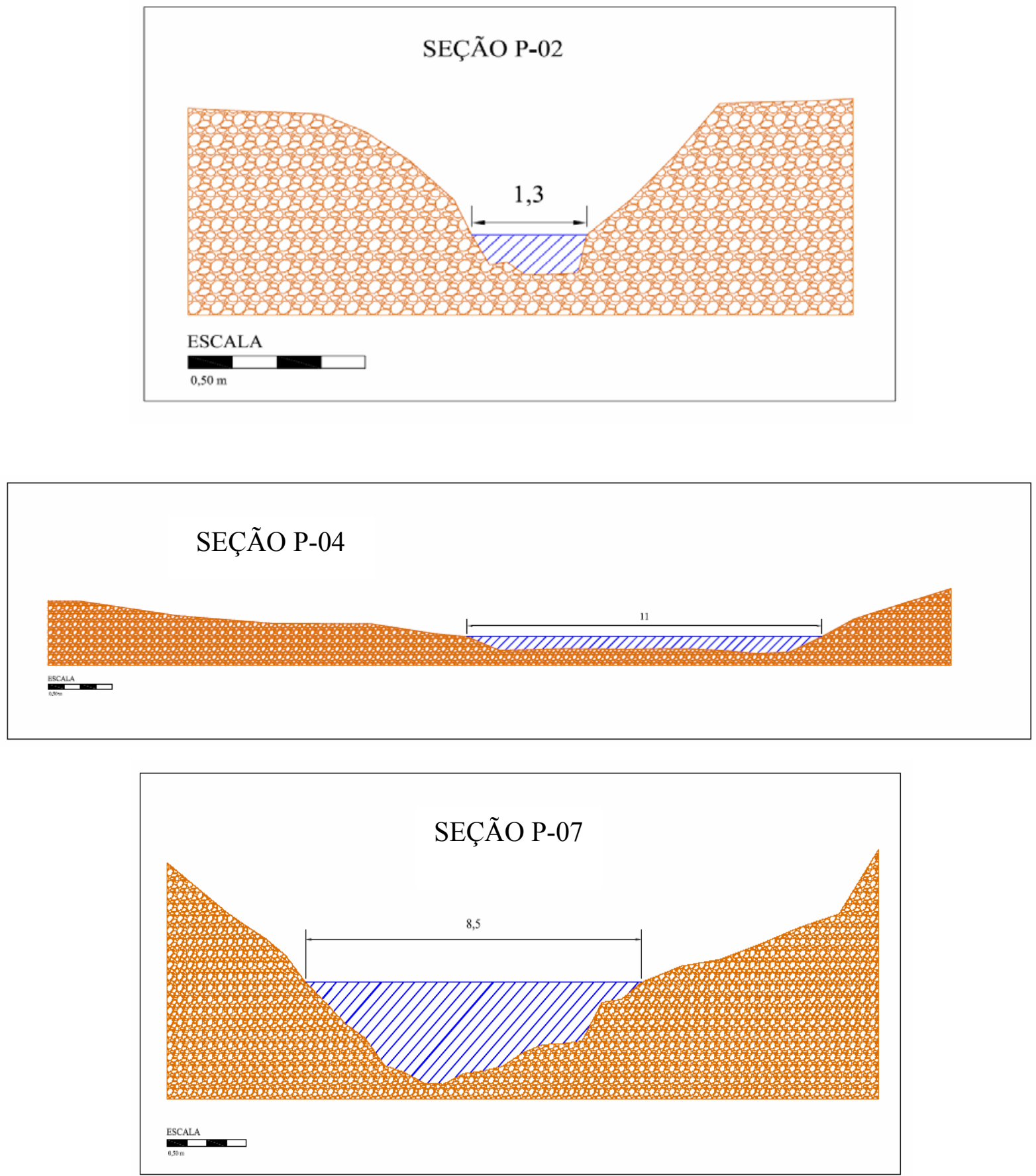

Figura XIX: Representação das seções transversais do rio Canha, da nascente (P02), médio curso (P04) e foz (P07). As demais seções são apresentadas nos Anexos.

A tabela a seguir apresenta a área de drenagem acumulada do rio Canha, bem como o comprimento do canal e de cada ponto de amostragem. Além disso, os tipos de uso e ocupação do solo são apresentados em termos de porcentagem para cada estação amostral ( $U_{1}$ - Formação Florestal; $\mathrm{U}_{2}-$ Agricultura; $\mathrm{U}_{3}-$ Pastagem; $\mathrm{U}_{4}-$ Água; $\mathrm{U}_{5}$ - Área Urbana; $\mathrm{U}_{6}-$ Solo Exposto; $\mathrm{U}_{7}$ 
- Nuvens; $\mathrm{U}_{8}$ - Sombra; $\mathrm{U}_{9}$ - Campos). É importante salientar que apesar da elevada percentagem de formações florestais os outros tipos de usos, como pastagem e agricultura, ocorrem exatamente no entorno do corpo d'água, como pode ser evidenciado na Figura VIII.

Tabela 5: áreas de drenagem acumuladas, comprimento do canal e respectivos tipos de usos e ocupação do solo.

\begin{tabular}{|c|c|c|c|c|c|c|c|c|}
\hline $\begin{array}{c}\text { Estação } \\
\text { Amostral }\end{array}$ & $\begin{array}{c}\text { Área de } \\
\text { Drenagem } \\
\text { acumulada } \\
\left(\mathrm{Km}^{2}\right)\end{array}$ & $\begin{array}{c}\text { Comprimento } \\
\text { do canal } \\
\text { acumulado } \\
\text { (Km) }\end{array}$ & $\mathrm{U}_{1}$ & $\mathbf{U}_{2}$ & $\mathbf{U}_{3}$ & $\mathbf{U}_{4}$ & $\mathbf{U}_{5}$ & $\mathrm{U}_{9}$ \\
\hline 1 & 0,93 & 1 & 99,1 & & & & & 0,086 \\
\hline 2 & 5,7 & 5 & 96,23 & 0,25 & 0,08 & 0,08 & & 1,25 \\
\hline 3 & 8,17 & 8 & 92,53 & 0,81 & & 0,32 & & 0,81 \\
\hline 4 & 65,01 & 11 & 80,54 & 2,81 & 2,11 & 1,33 & & 1,75 \\
\hline 5 & 69,6 & 13 & 69,68 & 21,77 & 3,04 & 1,74 & & 3,48 \\
\hline 6 & 100,36 & 16 & 65,03 & 19,51 & 1,3 & 0,19 & 0,19 & 1,3 \\
\hline 7 & 124,94 & 21 & 46,11 & 11,39 & 1,62 & 0,81 & 4,88 & 1,62 \\
\hline 8 & 125,88 & 25 & 12,76 & 12,76 & 6,38 & 6,38 & 42,55 & 5,10 \\
\hline
\end{tabular}

* Os tipos de usos ausentes na tabela ficaram abaixo do limite de contagem do planímetro.

O diagrama unifilar (Figura XX) complementa a tabela acima e apresenta a distância entre os pontos amostrais e os principais tributários (ordem 3, 4 e 5). 


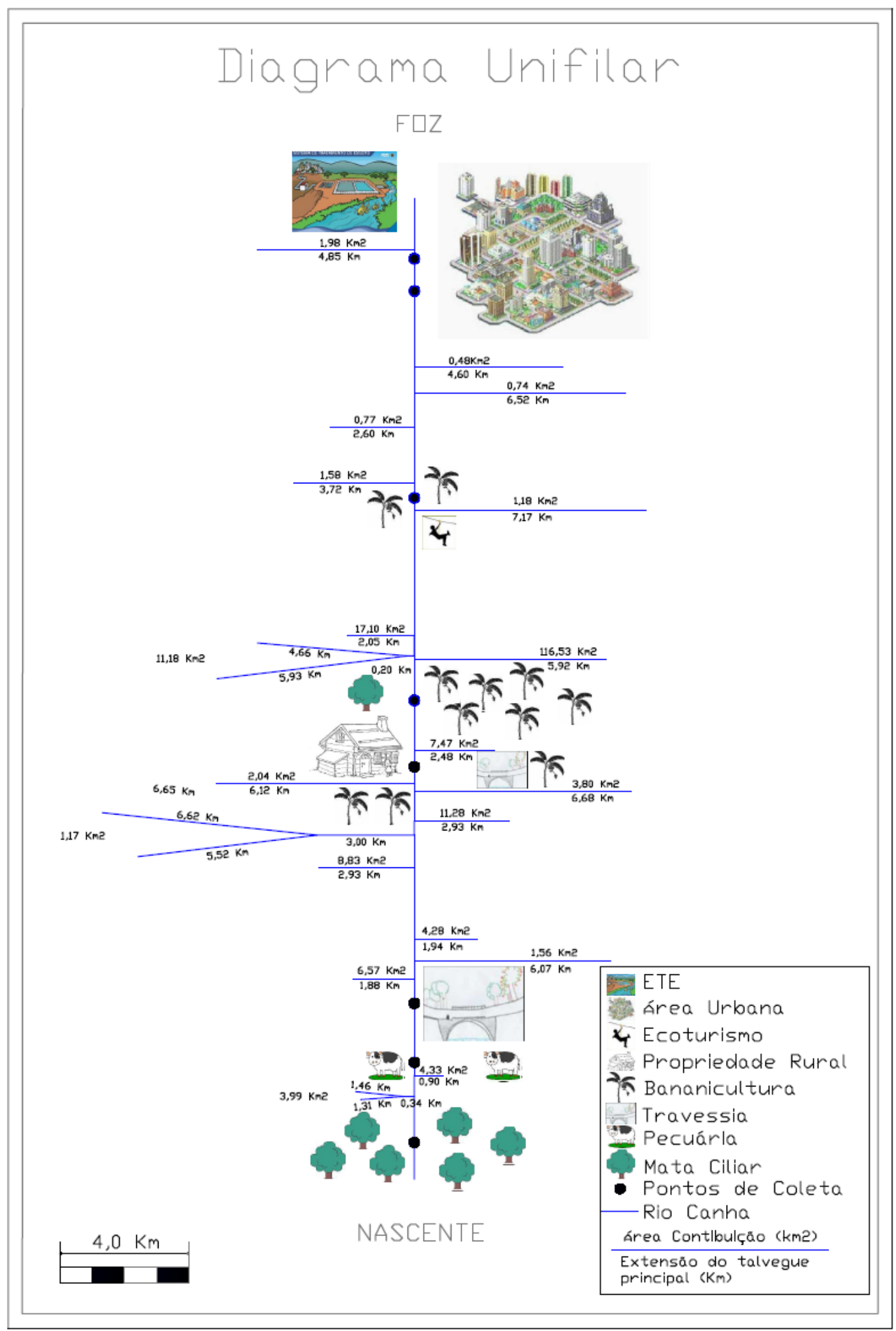

Figura XX:Diagrama unifilar 


\subsection{Parâmetros Hidrológicos e Hidráulicos}

Os totais precipitados na bacia do rio Canha foram obtidos através de um polígono de Thiessen, conforme apresentado abaixo:

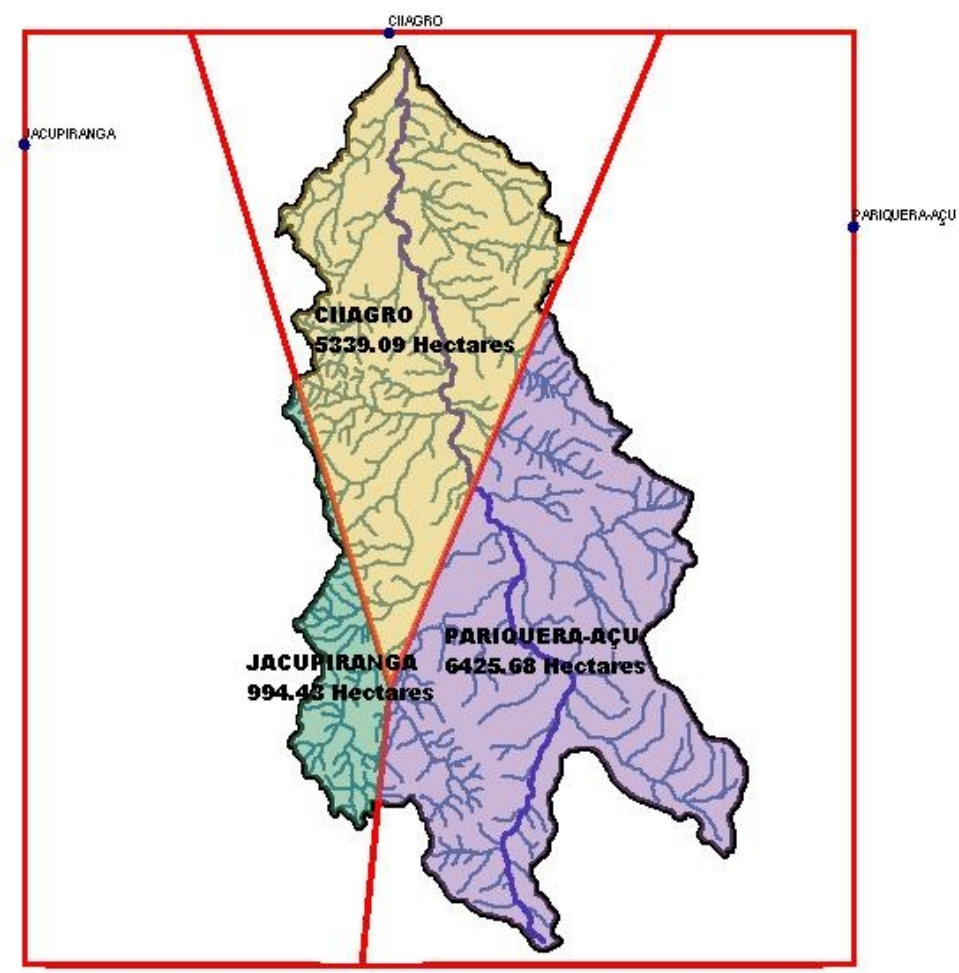

Figura XXI: Polígono de Thiessen para a bacia do rio Canha

Os dados médios de precipitação são apresentados nas figuras a seguir, as quais representam a precipitação média no período de agosto/06 a outubro/07 (Figura XXII) e a precipitação relacionada com a altura da água para o período de março a outubro de 2007 (Figura

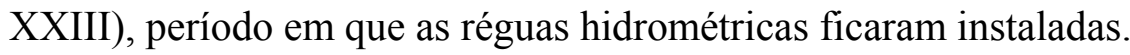




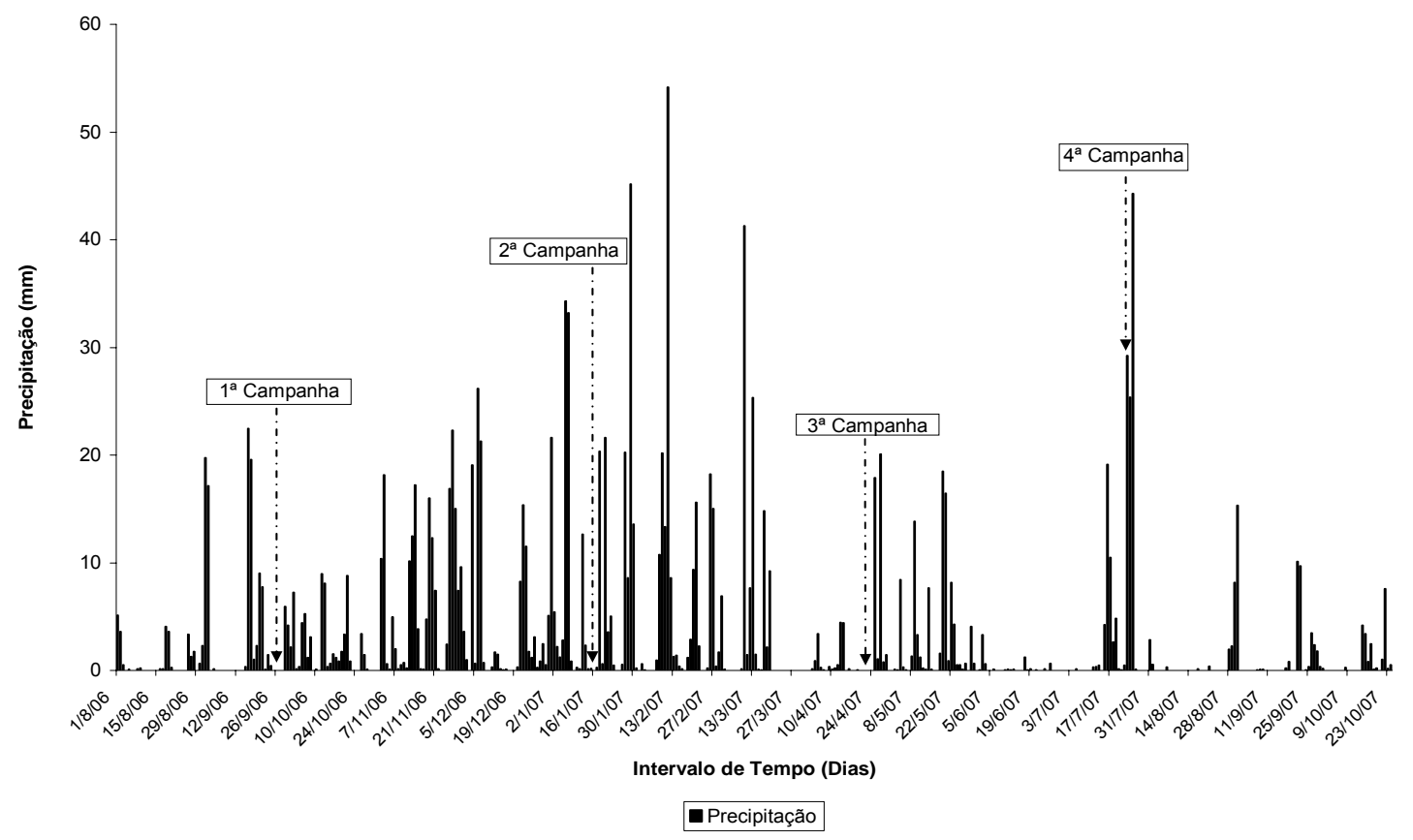

Figura XXII: Precipitação média para o período de agosto/06 a outubro/07

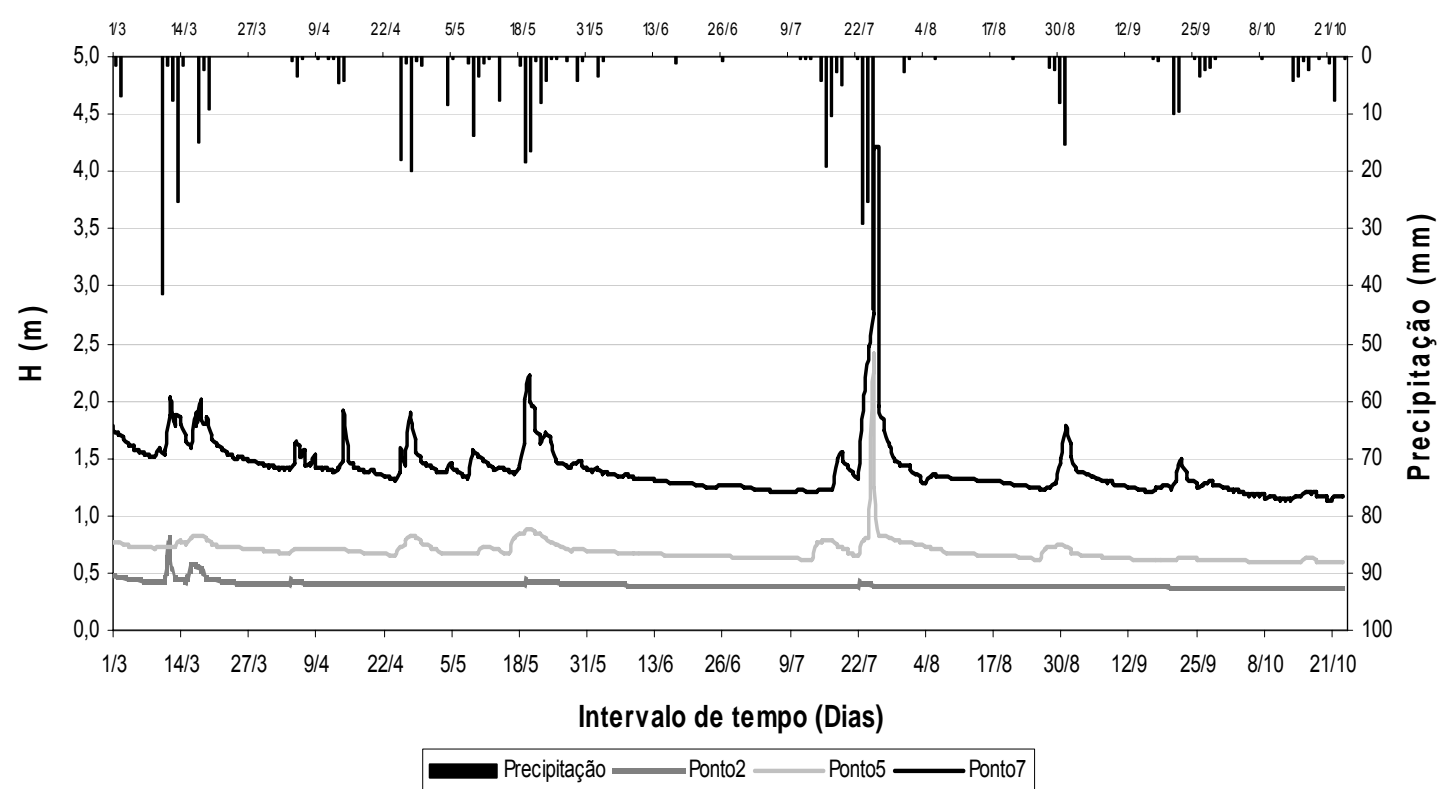

Figura XXIII: Relação precipitação e nível da água para o período de março/07 a outubro/07. 
Tabela 6: Dados referentes às campanhas

\begin{tabular}{|c|c|c|c|c|c|c|c|}
\hline Campanha & Período & Data & $\begin{array}{c}\text { Hora } \\
\text { Início }\end{array}$ & $\begin{array}{c}\text { Hora } \\
\text { Fim }\end{array}$ & $\begin{array}{c}\text { Temp } \\
\text { Ar }\left({ }^{\circ} \mathbf{C}\right)\end{array}$ & $\begin{array}{c}\text { I.P.A.* } \\
(\mathbf{m m})\end{array}$ & $\begin{array}{c}\text { Radiação } \\
\left(\mathbf{W} / \mathbf{m}^{2}\right)\end{array}$ \\
\hline 1 & Primavera & $27 / 09 / 06$ & $7: 00$ & $12: 00$ & 18,6 & 9,6 & 101 \\
\hline 2 & Verão & $15 / 01 / 07$ & $7: 05$ & $12: 00$ & 27,8 & 15,6 & 252 \\
\hline 3 & Outono & $23 / 04 / 07$ & $7: 00$ & $12: 30$ & 25,2 & 0 & 193 \\
\hline 4 & Inverno & $23 / 07 / 07$ & $7: 00$ & $12: 30$ & 16,4 & 62,7 & 25 \\
\hline
\end{tabular}

*I.P.A.: Índice de Precipitação Antecedente (7 dias).

No Brasil, mais precisamente no estado de São Paulo, a estação chuvosa concentra-se nos meses de outubro a março, no entanto no ano de 2007 ocorreu uma peculiaridade em relação aos picos pluviométricos, que se concentraram principalmente no mês de julho, o qual normalmente é caracterizado por intensa estiagem (Figura XXII). Pode ser observado na Figura XXIII que o nível máximo do Rio Canha ocorreu no mês de julho, coincidindo com o alto índice de precipitação. Os meses de março a maio também apresentaram alguns picos, porém a precipitação não foi tão intensa. Os maiores valores de vazão também coincidem com o maior índice de precipitação e com a cota máxima do rio Canha.

A figura XXIV apresenta a variação da vazão longitudinalmente e temporalmente. As maiores vazões foram observadas na campanha 4, com variação de $19 \mathrm{~L} / \mathrm{s}$ a $4619 \mathrm{~L} / \mathrm{s}$ da nascente à foz. As menores vazões foram registradas na campanha 1, apresentando menor valor na nascente $(14 \mathrm{~L} / \mathrm{s})$ e maior na foz $(595 \mathrm{~L} / \mathrm{s})$. Em relação às cargas específicas, estas variaram com maiores valores na nascente e menores na foz em todas as estações do ano.

\section{XXIV}

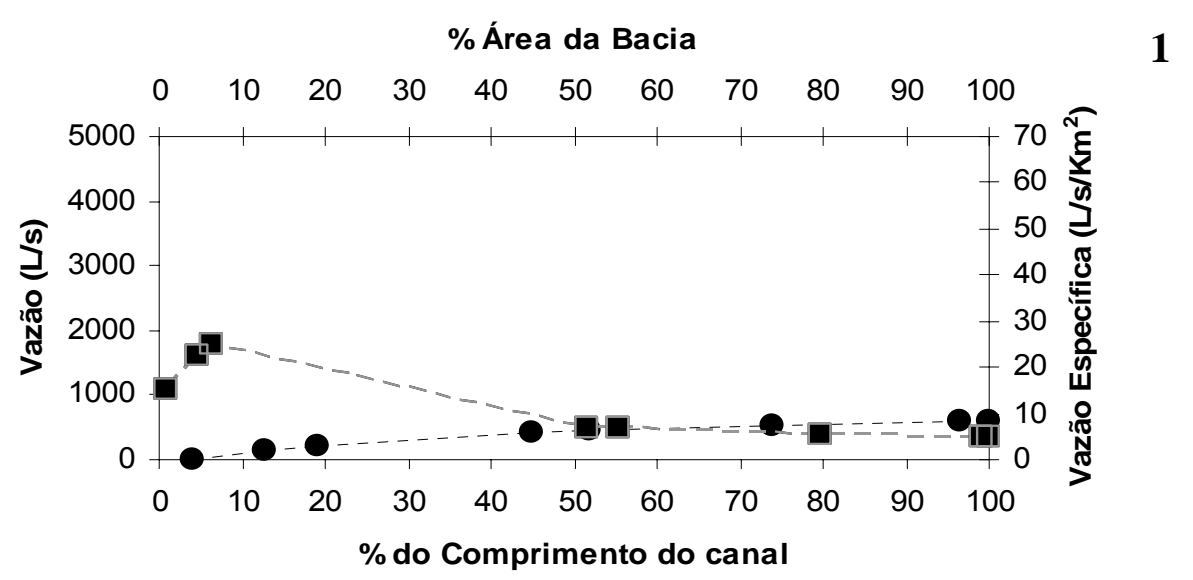



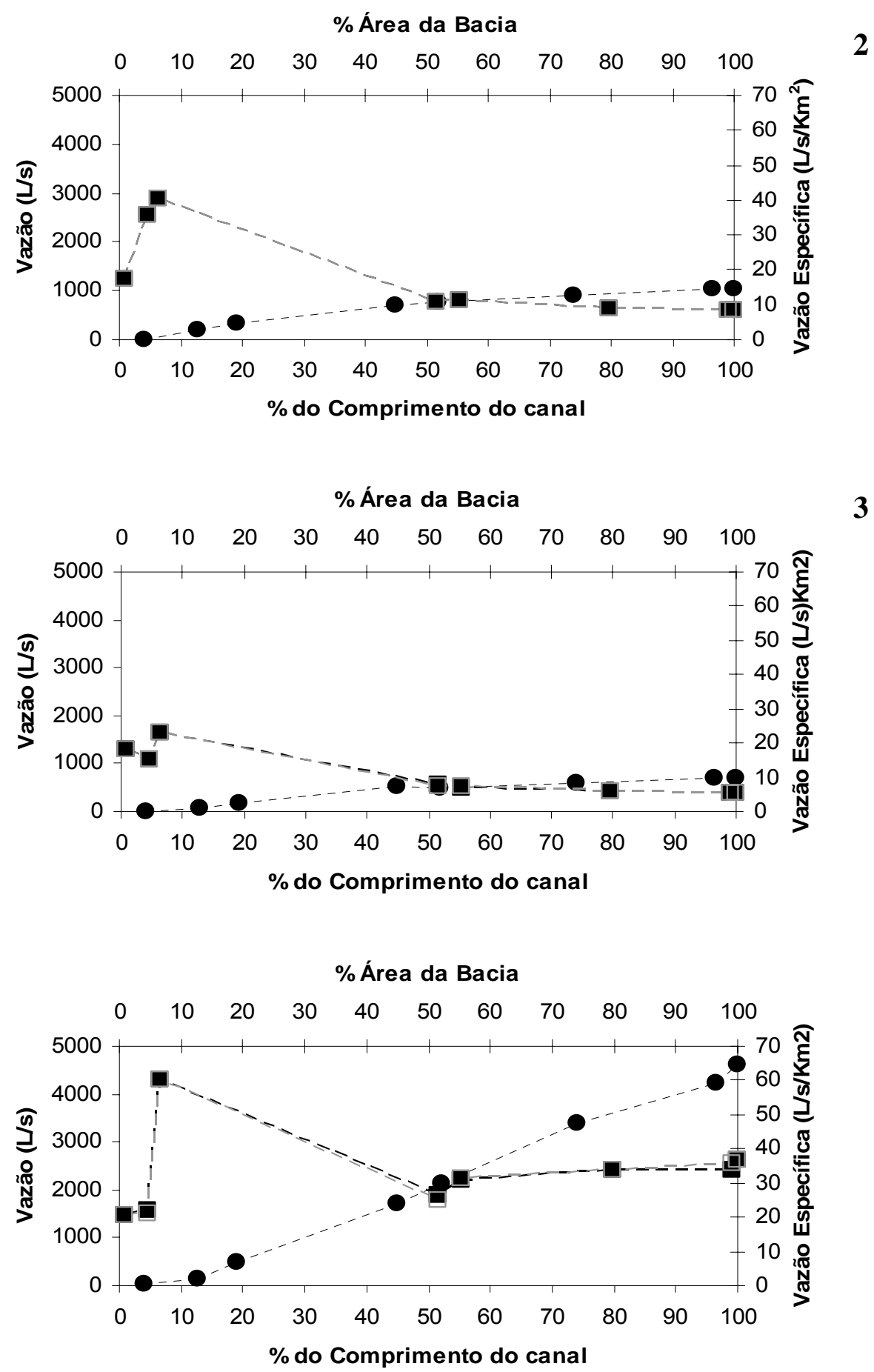

Figura XXIV: Variação da vazão ao longo do eixo longitudinal do Rio Canha nas diferentes estações do ano (1 -

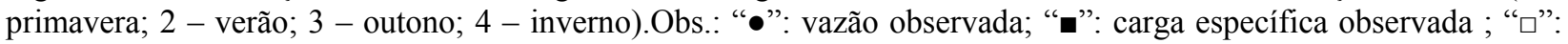
carga específica simulada. 
A figura que segue apresenta a curva de permanência para as vazões observadas a partir da regionalização das vazões do rio Canha.

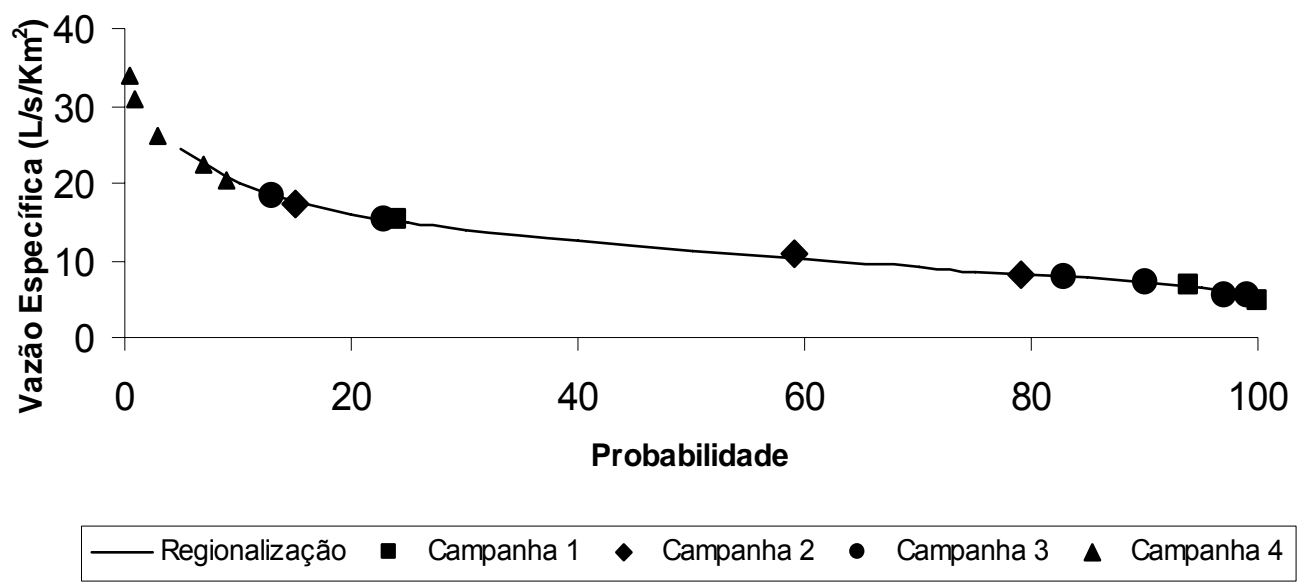

Figura XXV: Curva de permanência para as vazões do rio Canha. Fonte: Projeto FAPESP nº2/3449-1

A vazão observada em qualquer seção transversal do rio e com qualquer área de drenagem a montante tem uma porcentagem, indicada nas abscissas, da amostras de vazões superiores ou iguais a ela. Deste modo, as vazões observadas nas quatro campanhas cobrem todo o intervalo de vazões regionalizadas, desde 0,5\% a $100 \%(0,5 \%<\mathrm{P}<100 \%)$.

Para a campanha las vazões observadas foram para permanências de $23 \%<\mathrm{P}<100 \%$. Já em relação à campanha 2 , este intervalo esteve entre $15 \%$ e $80 \%$, as vazões observadas para a campanha 3 recobrem um intervalo expressivo de $15 \%$ a $100 \%$, enquanto que a campanha 4 , esse intervalo foi menor $0,5 \%<\mathrm{P}<9 \%$. 
Tabela 7: Velocidade de Escoamento $(\mathrm{m} / \mathrm{s})$, área de casa seção $\left(\mathrm{m}^{2}\right)$, vazão $(\mathrm{L} / \mathrm{s})$, número de Froude e número de Reynolds ao longo do eixo longitudinal do rio Canha, nas quatro estações do ano.

\begin{tabular}{|c|c|c|c|c|c|c|c|c|c|c|c|c|c|c|c|}
\hline \multirow{2}{*}{$\begin{array}{c}\text { Pontos } \\
\text { Campanhas }\end{array}$} & \multicolumn{5}{|c|}{1} & \multicolumn{5}{|c|}{2} & \multicolumn{5}{|c|}{4} \\
\hline & V & A & Q & Fr & $\operatorname{Re}$ & V & A & Q & $\mathrm{Fr}$ & $\mathrm{Re}$ & $\mathrm{V}$ & A & Q & $\mathrm{Fr}$ & $\mathrm{Re}$ \\
\hline 1 & 0,11 & 0,09 & 14 & 0,11 & 10986 & & & 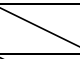 & & & 0,73 & 0,57 & 432 & 0,61 & 103897 \\
\hline 2 & 0,16 & 0,1 & 16 & 0,15 & 17710 & & & 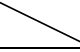 & 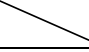 & & 0,39 & 1,81 & 705 & 0,2 & 111625 \\
\hline 3 & 0,15 & 0,11 & 17 & 0,14 & 16451 & 0,32 & 0,27 & 87 & 0,21 & 71787 & 0,61 & 0,83 & 508 & 0,4 & 136433 \\
\hline 4 & 0,16 & 0,12 & 19 & 0,14 & 19180 & 0,5 & 0,25 & 127 & 0,33 & 113522 & 0,61 & 2,57 & 1704 & 0,3 & 244706 \\
\hline
\end{tabular}

\begin{tabular}{|c|c|c|c|c|c|c|c|c|c|c|c|c|c|c|c|}
\hline \multirow{2}{*}{$\begin{array}{c}\text { Pontos } \\
\text { Campanhas }\end{array}$} & \multicolumn{5}{|c|}{5} & \multicolumn{5}{|c|}{7} & \multicolumn{5}{|c|}{8} \\
\hline & V & $\mathrm{A}$ & Q & $\mathrm{Fr}$ & $\mathrm{Re}$ & V & A & Q & $\mathrm{Fr}$ & $\mathrm{Re}$ & V & $\mathrm{A}$ & $\mathrm{Q}$ & $\mathrm{Fr}$ & $\mathrm{Re}$ \\
\hline 1 & & & & & & & & & & & 0,33 & 1,8 & 595 & 0,2 & 82398 \\
\hline 2 & $\gamma$ & $x$ & 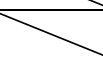 & $\times$ & $\times$ & 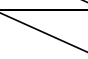 & $\times$ & $\gamma$ & $\gamma$ & & 0,27 & 3,9 & 1038 & 0,14 & 98965 \\
\hline 3 & 0,15 & 3,16 & 494 & 0,088 & 42963 & 0,17 & 4,7 & 690 & 0,05 & 93722 & 0,34 & 2,04 & 700 & 0,22 & 74360 \\
\hline 4 & 0,6 & 3,56 & 2149 & 0,35 & 170708 & 0,27 & 15,85 & 4232 & 0,072 & 375017 & & & & & \\
\hline
\end{tabular}

A tabela 7 apresenta os dados hidráulicos obtidos para o rio Canha, nas diferentes estações do ano. Deve-se ressaltar que as células vazias e as colunas ausentes são dos pontos amostrais onde não houve medição em campo. 


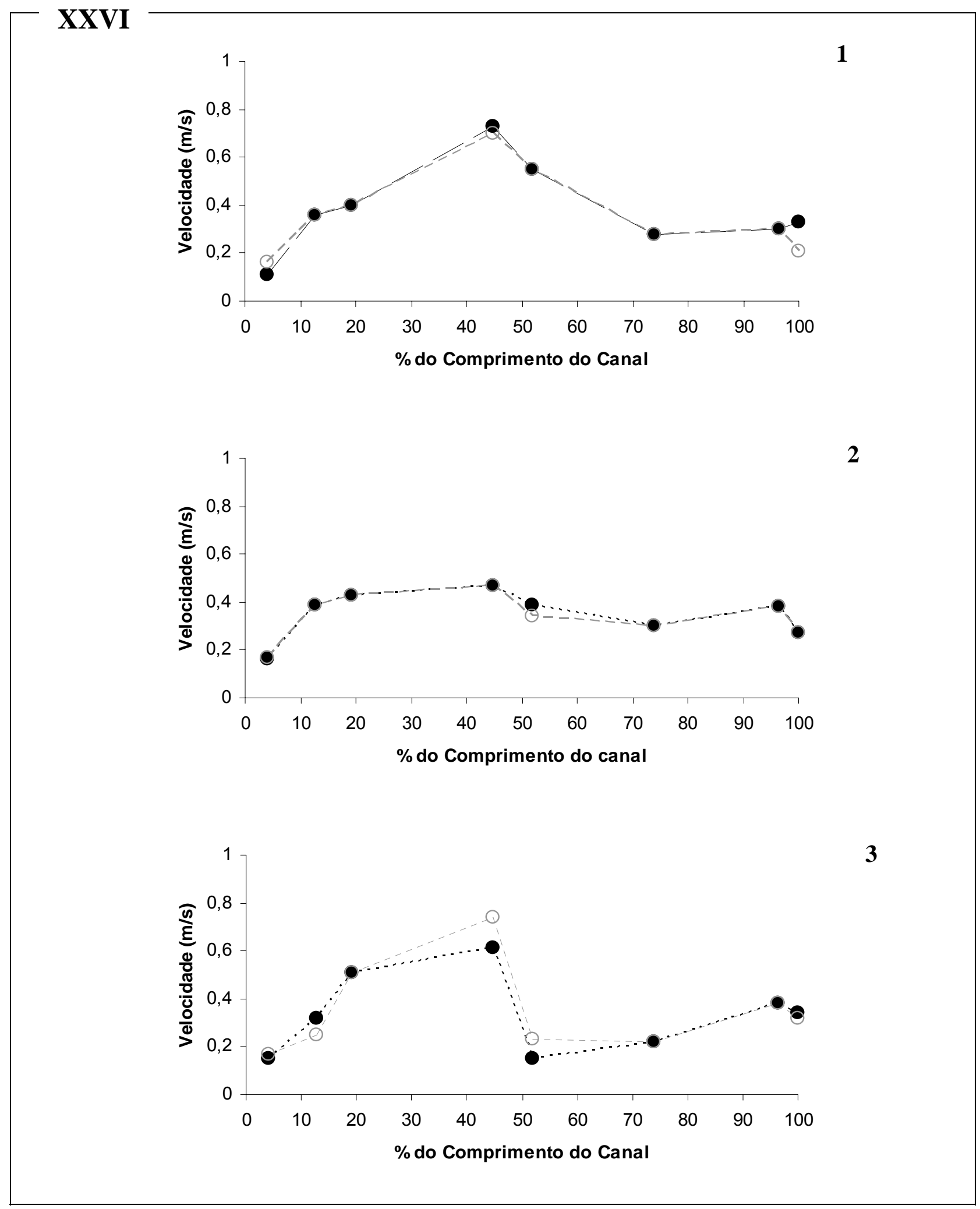




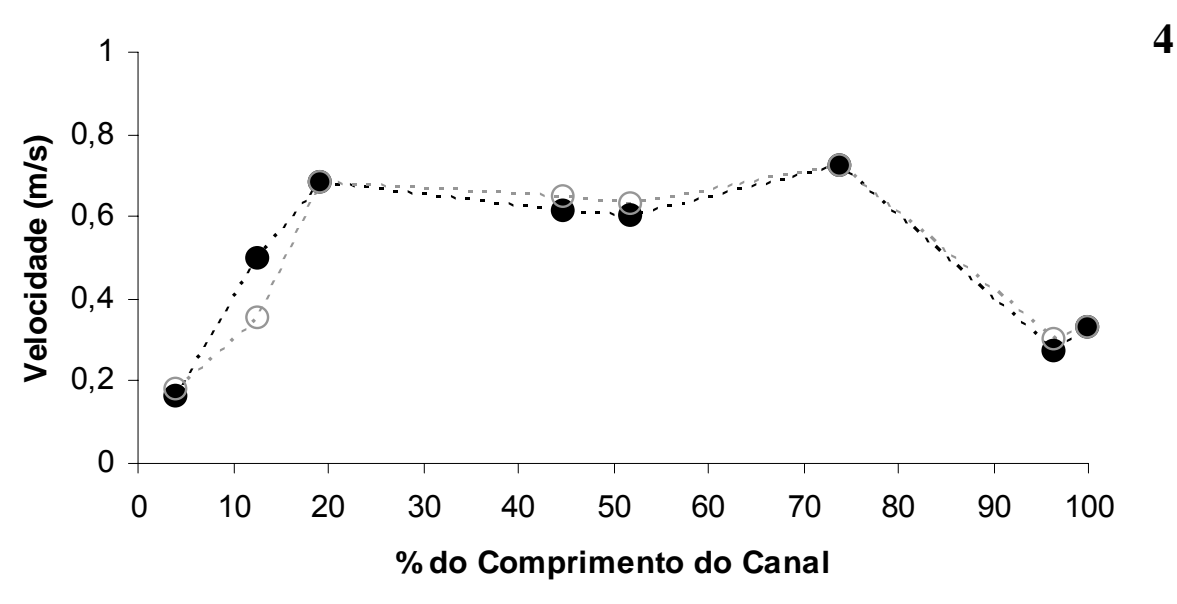

Figura XXVI: Variação da velocidade ao longo do eixo longitudinal do Rio Canha nas diferentes estações do ano (1 - primavera; 2 - verão; 3 - outono; 4 - inverno).Obs.: “•”: velocidade observada; “○”: velocidade simulada.

Em termos longitudinais há uma grande variação da velocidade, principalmente em relação aos pontos do médio curso do rio, os quais se encontram dentro de propriedades rurais, onde foi possível constatar em campo que sofreram grandes interferências antrópicas, como por exemplo, escavação, o que pode favorecer o aumento da velocidade nesses pontos. Tal fato pode ser observado na figura XXVI, que evidencia picos de velocidade entre os pontos amostrais 3 e 4 .

A heterogeneidade espacial foi maior na campanha 1 e a menor na campanha 2, com valores variando de 0,11 a $0,73 \mathrm{~m} / \mathrm{s}$ e 0,16 a $0,39 \mathrm{~m} / \mathrm{s}$, respectivamente. Temporalmente os maiores valores de velocidade da água foram obtidos na campanha 4 e os menores na campanha 3.

Para comprimentos totais até $12 \mathrm{Km}$ da nascente, as velocidades variam entre 0,3 e 0,4 $\mathrm{m} / \mathrm{s}$ no período de IPA baixo (campanhas 1, 2 e 3). Entretanto, para IPA altos (campanha 4) há um crescimento da velocidade até o $\mathrm{Km} 20$.

A figura XXVII demonstra que não houve muita variação da altura da água longitudinalmente, pois a bacia do rio Canha é pequena $\left(127,59 \mathrm{Km}^{2}\right)$ e, portanto escoa a água rapidamente. No entanto, é possível notar, principalmente no que diz respeito à estação caracterizada como chuvosa (campanha 4), que o ponto amostral próximo à foz apresentou-se com grande volume de água, devido à ocorrência de fortes chuvas no dia anterior à campanha.

Em períodos de IPA baixos (campanhas 1, 2 e 3) o comportamento da altura da água é parecido, o qual possui um pequeno aumento a partir do ponto amostral 6 , com queda a partir do 
ponto seguinte. Já em períodos e IPA altos, a altura da água aumenta também a partir do ponto amostral 6, no entanto não há quedas até o ponto 8, que mostra uma tendência de aumento.

A partir das simulações foi possível verificar que a altura da água é fortemente influenciada por parâmetros como declividade, área da seção e $n$ de Mannig.

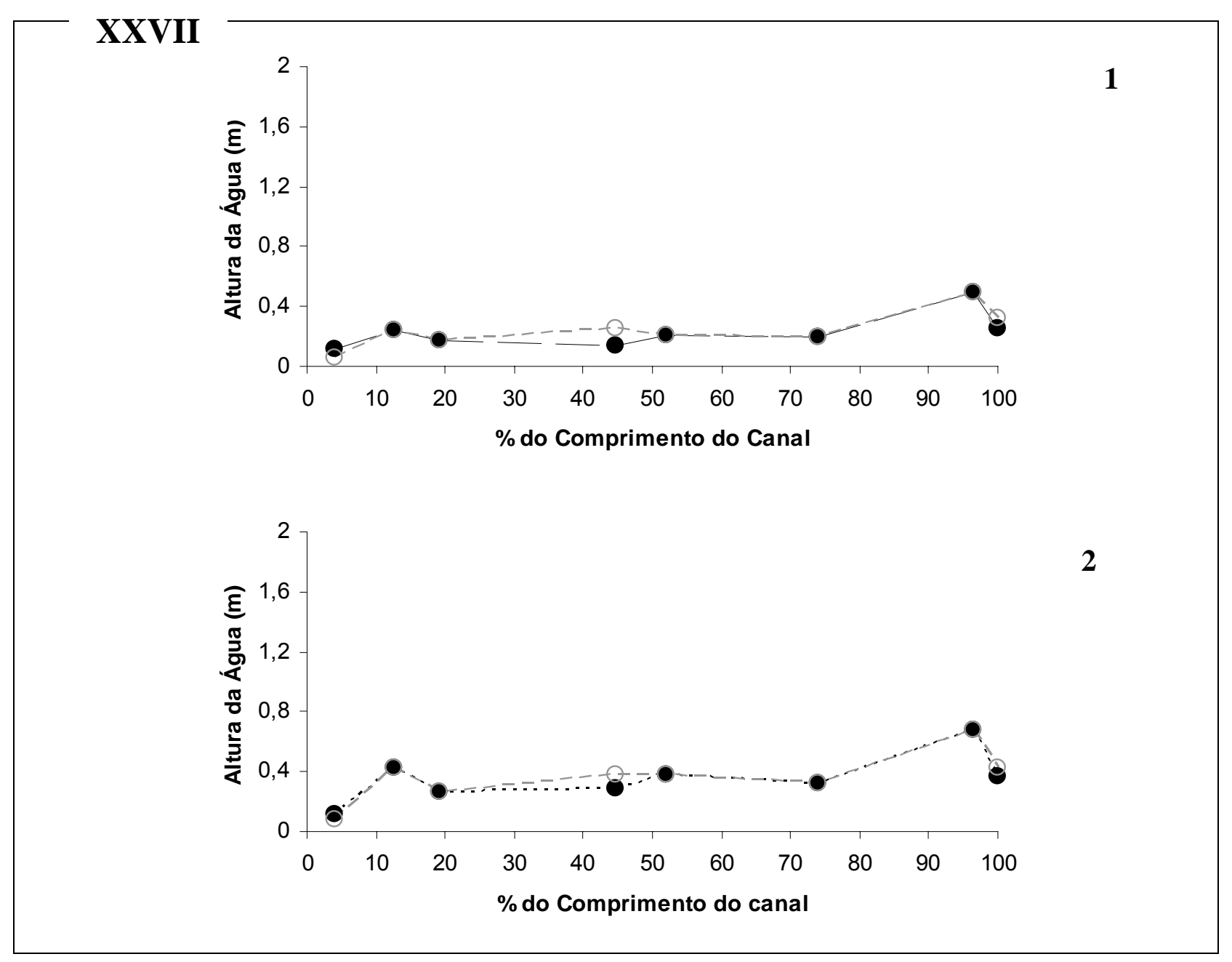



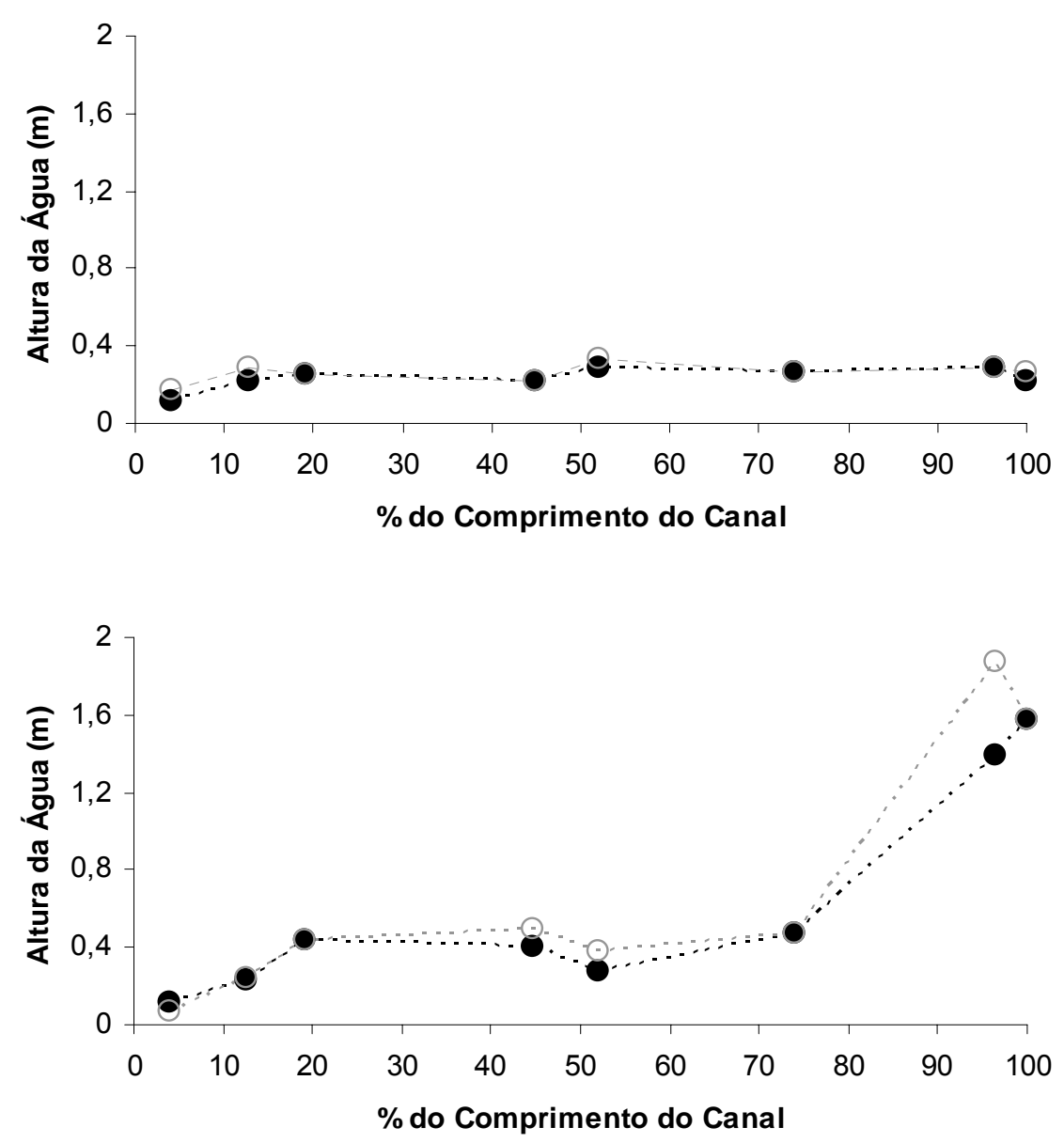

4

Figura XXVII: Variação da altura da água ao longo do eixo longitudinal do Rio Canha nas diferentes estações do ano ( 1 - primavera; 2 - verão; 3 - outono; 4 - inverno).Obs.: "•": cota observada; "○”: cota simulada. 


\subsection{Parâmetros Físicos e Químicos da água}

Os parâmetros físicos e químicos simulados e observados são apresentados abaixo. É importante salientar que o modelo QUAL2K gera, como dados de saída, gráficos de concentração ( $\mathrm{mg} / \mathrm{L})$ versus distância e que para o presente trabalho, tais gráficos foram refeitos. Gráficos de variáveis como temperatura, condutividade elétrica e $\mathrm{pH}$ foram mantidos como os gerados pelo modelo.

No total foram amostrados oito pontos ao longo do Rio Canha, para os parâmetros físicoquímicos, mas para a vazão apenas três, para os meses de setembro e janeiro $(1,4$ e 8$)$ e cinco para os meses de abril $(1,2,4,5$, e 8$)$ e julho (pontos 1, 2, 4, 5 e 7), portanto em termos de carga, para melhor apresentação dos resultados foram utilizados os valores simulados de vazão para obtenção das cargas nos pontos onde a medição desse parâmetro não foi efetuada. A vazão foi um parâmetro muito bem calibrado no modelo, o qual apresentou-se bastante próximo da realidade.

\subsubsection{Temperatura}

Em termos longitudinais a temperatura (Figura XXVIII) possui um gradiente da nascente à foz, apresentando de 1 a $2^{\circ} \mathrm{C}$ de diferença em todo o período amostrado. Um dado importante a ser citado é que devido às distâncias entre as estações amostrais, a temperatura na nascente foi medida no início da manhã enquanto que nas estações mais a jusante a temperatura da água foi obtida já no final da manhã, esse fato pode contribuir para a formação do gradiente longitudinal. A maior heterogeneidade espacial foi observada na campanha 2 e a menor na campanha 4.

Já em relação às diferentes estações do ano, a maior temperatura foi observada em 2 (verão), seguindo por 3 (outono), sendo que em 1 (primavera) as temperaturas estão ligeiramente baixas e em 4 (inverno), elas atingem seu mínimo, apresentando até $8{ }^{\circ} \mathrm{C}$ e diferença entre o verão e o inverno $\left(25,44{ }^{\circ} \mathrm{C}\right.$ no verão e $16,93{ }^{\circ} \mathrm{C}$ no inverno). $\mathrm{O}$ modelo, responde satisfatoriamente à simulação da temperatura, seguindo sempre a mesma tendência (aumentando de montante a jusante), porém devido à divisão da bacia em trechos, pode haver alguns picos ou quedas desse parâmetro nos dados simulados. 


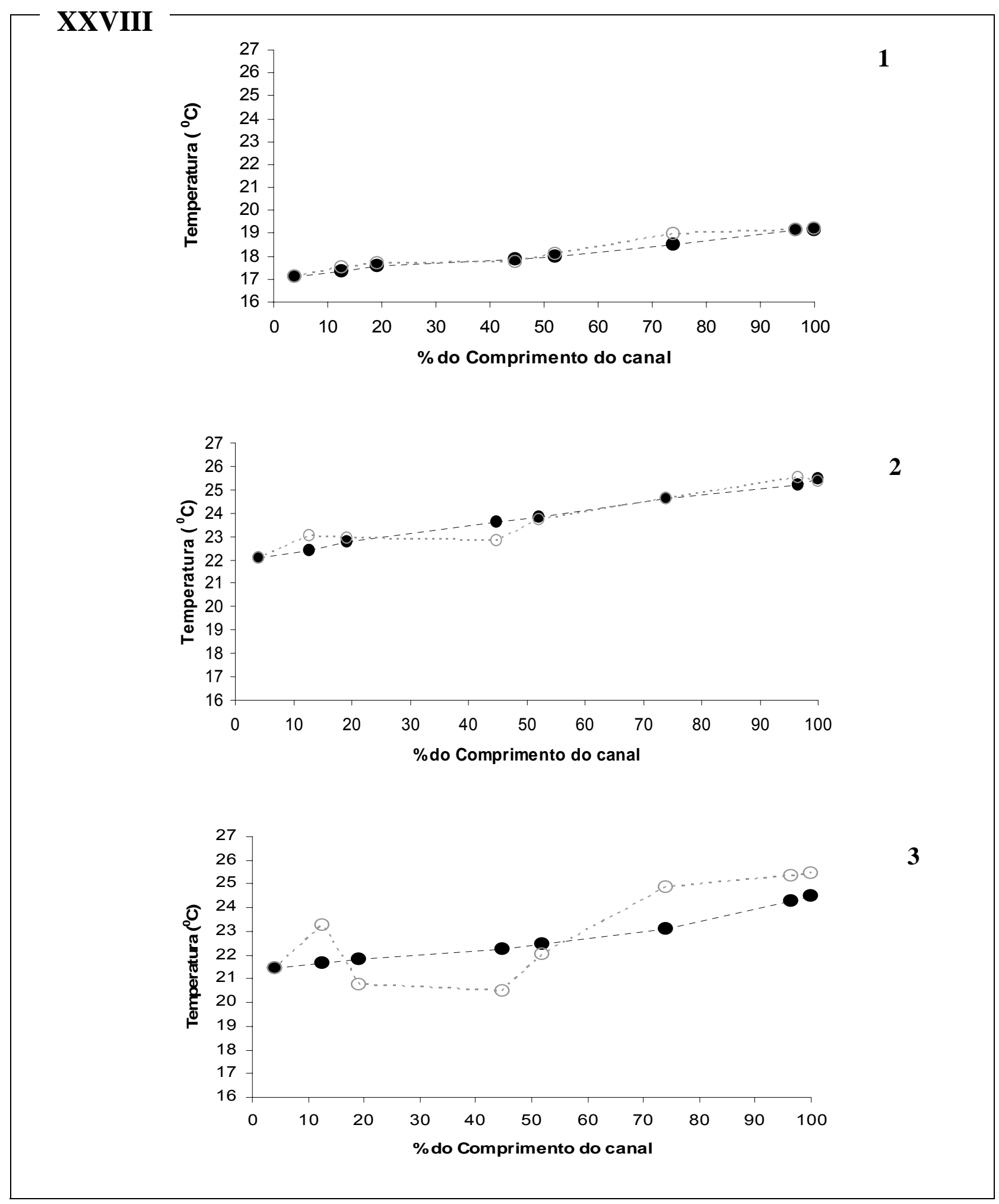




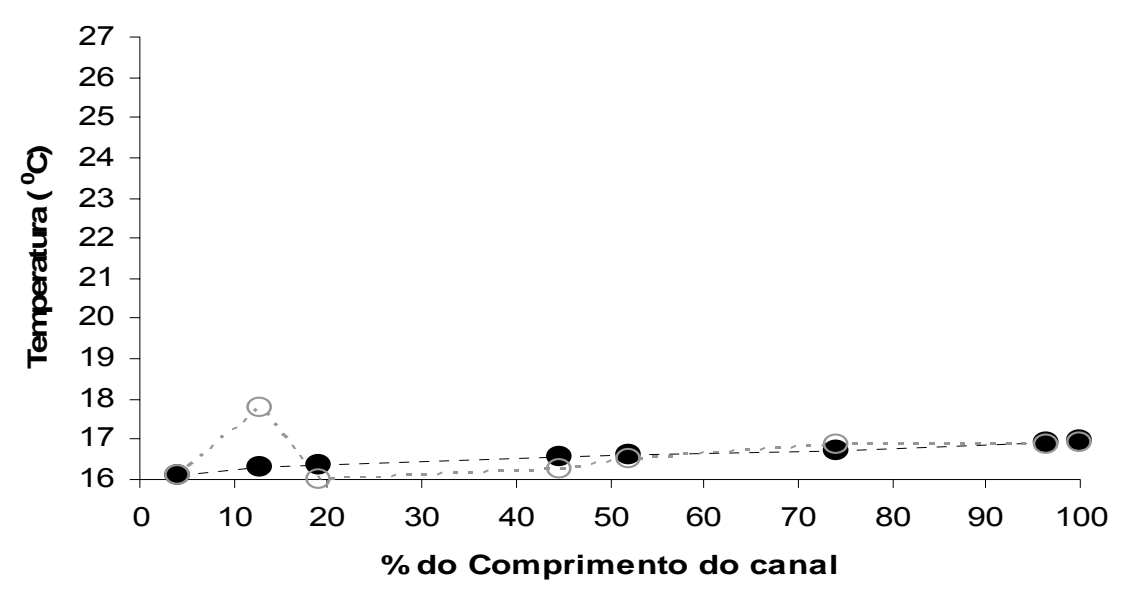

Figura XXVIII: Variação da temperatura ao longo do eixo longitudinal do Rio Canha nas diferentes estações do ano ( 1 - primavera; 2 - verão; 3 - outono; 4 - inverno).Obs.: "•": temperatura observada; “०”: temperatura simulada.

\subsubsection{Oxigênio Dissolvido}

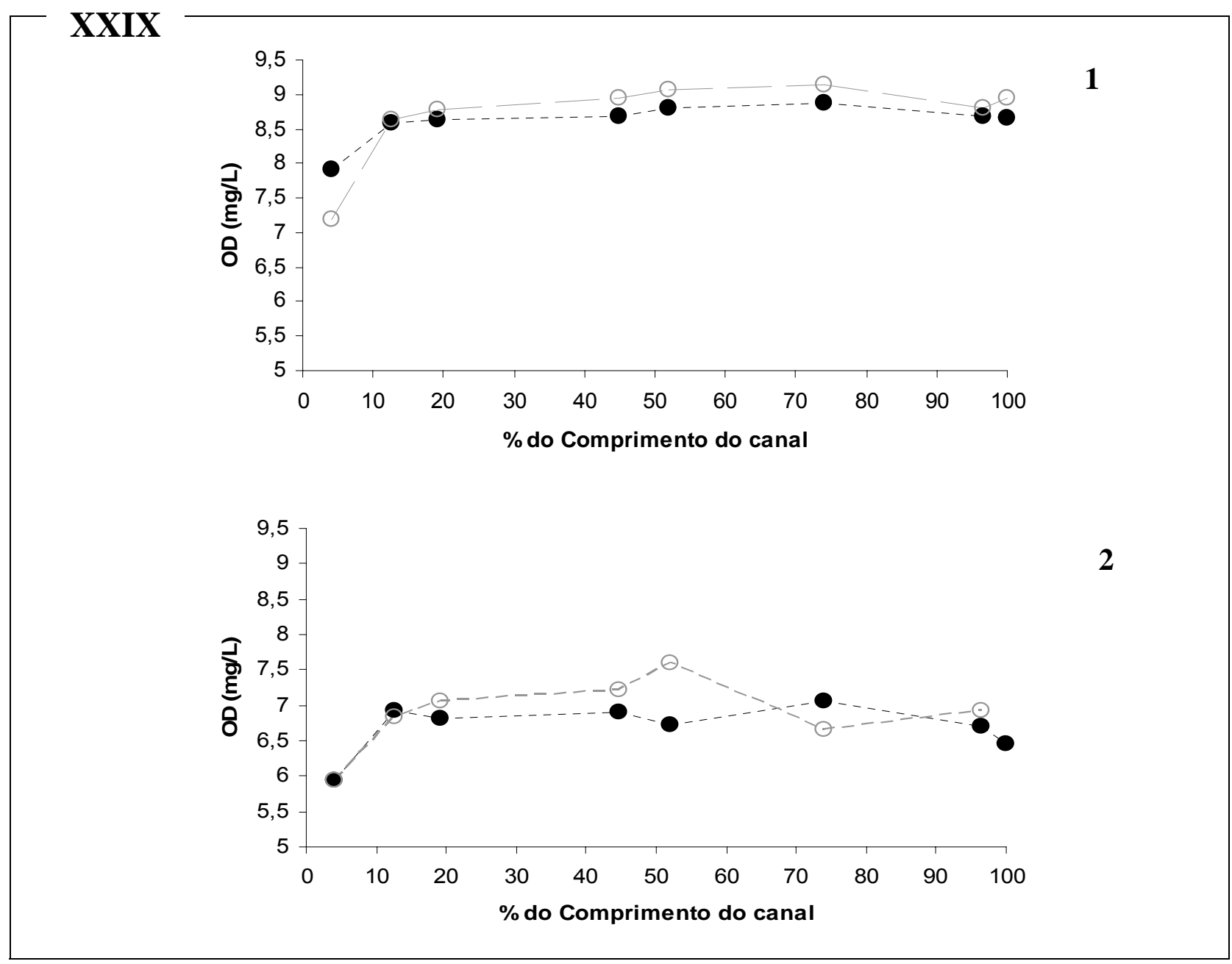



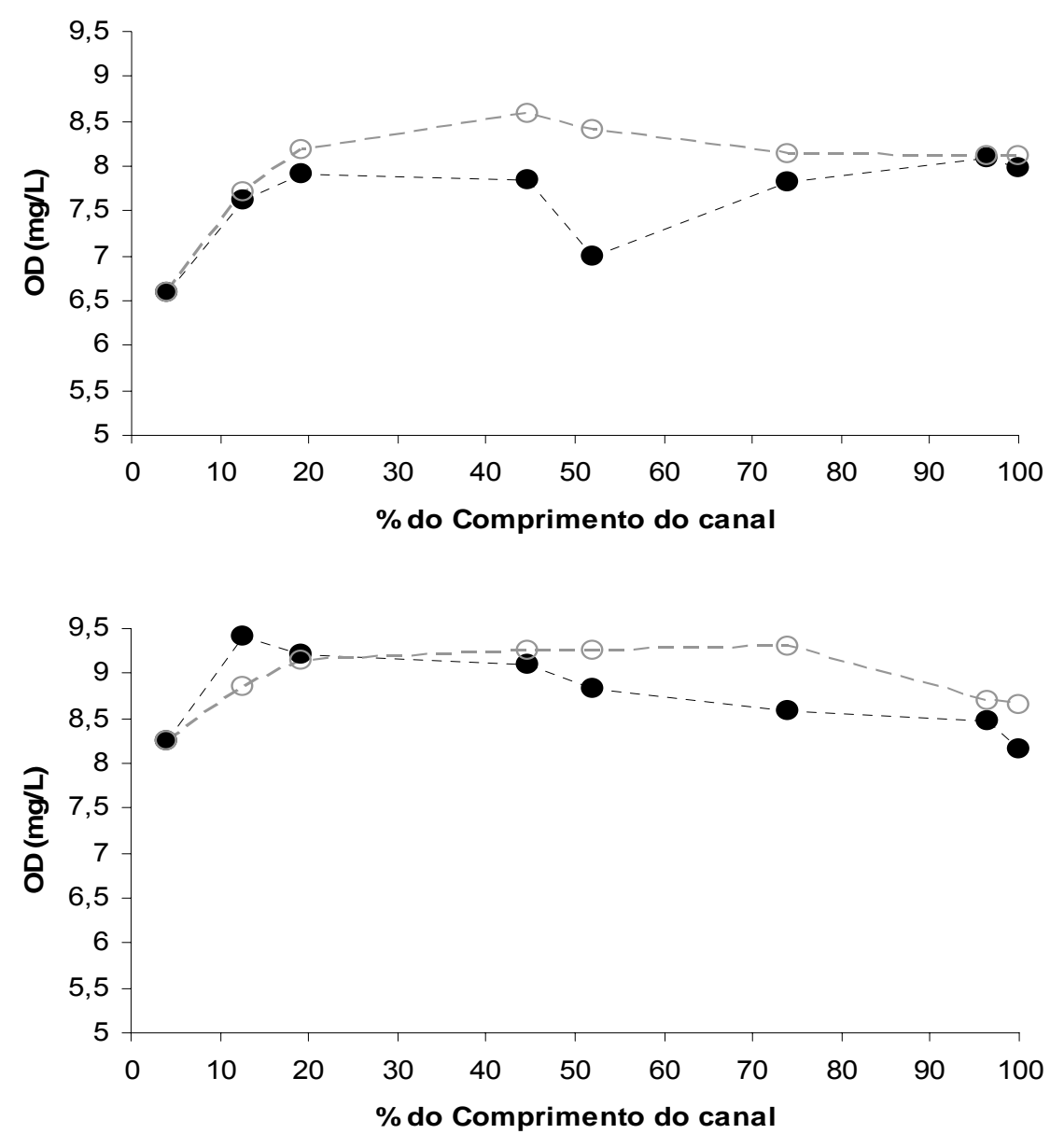

Figura XXIX: Variação de oxigênio dissolvido ao longo do eixo longitudinal do Rio Canha nas diferentes estações do ano (1 - primavera; 2 - verão; 3 - outono; 4 - inverno).Obs.: "•": Concentração observada; "○”: concentração simulada.

Em termos de concentração observou-se que os menores valores de oxigênio dissolvido foram obtidos na nascente do rio, com aumento em médio curso, sendo que para as campanhas 2 , 3 e 4, observou-se ligeira queda no ponto amostral 5, houve também uma queda nos pontos próximos à foz em todas as estações do ano. Os maiores valores de oxigênio dissolvido foram registrados no período chuvoso (campanha 4), sendo que a estação de coleta 4 apresentou a maior concentração obtida em todas as campanhas $(9,1 \mathrm{mg} / \mathrm{L})$. Os menores registros de oxigênio dissolvido ocorreram na campanha 2 , seguidos por 3 e 1 . A menor concentração desse gás ocorreu na campanha 2, no ponto amostral 1 (nascente - 5,93 mg/L). 
A calibração do modelo QUAL2K para parâmetros como, velocidade de escoamento e altura da água, permitiu verificar que os picos de reaeração ocorreram nos mesmos pontos em todas as estações do ano, porém a campanha 3 apresentou maior heterogeneidade espacial.

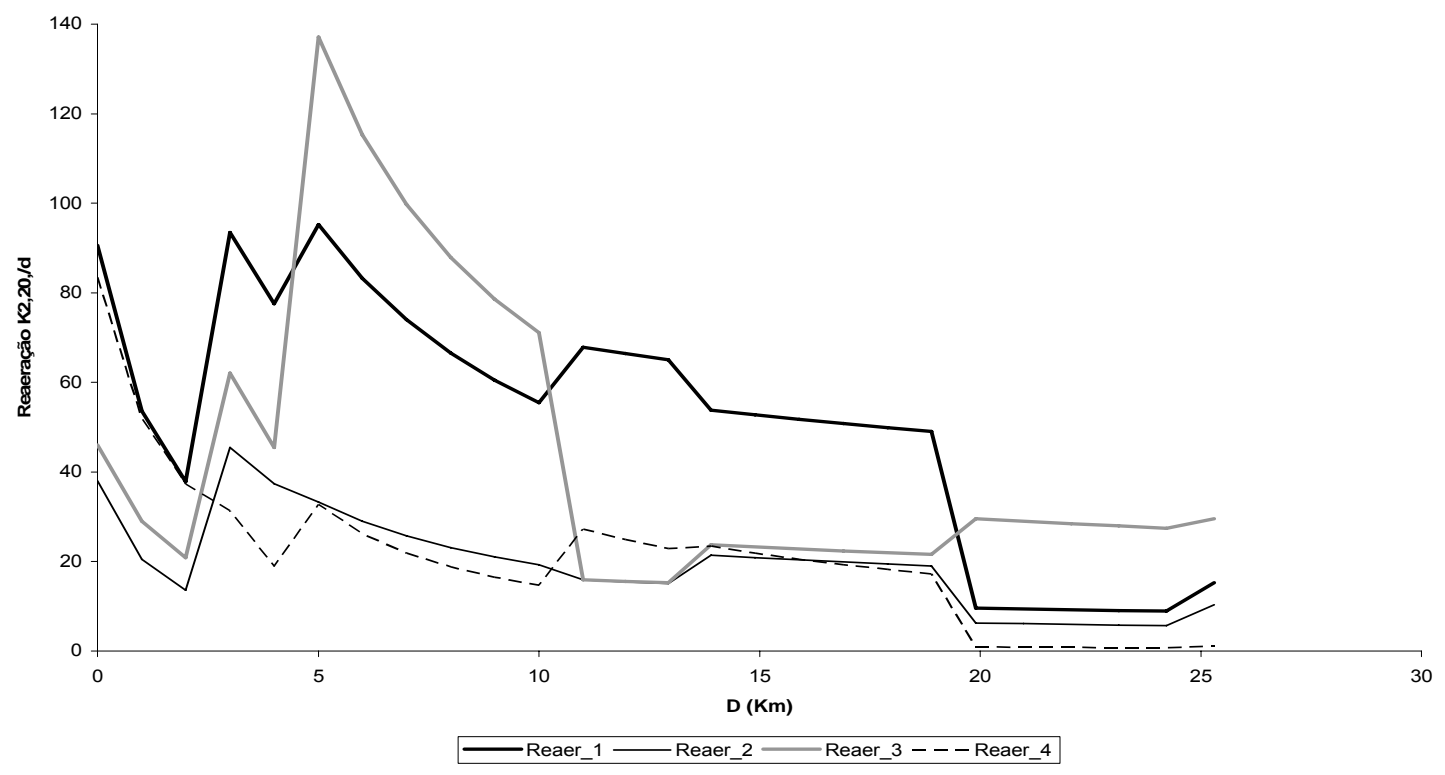

Figura XXX: Dados de reaeração gerados pelo modelo para as diferentes campanhas.

\subsubsection{Demanda Bioquímica de Oxigênio}

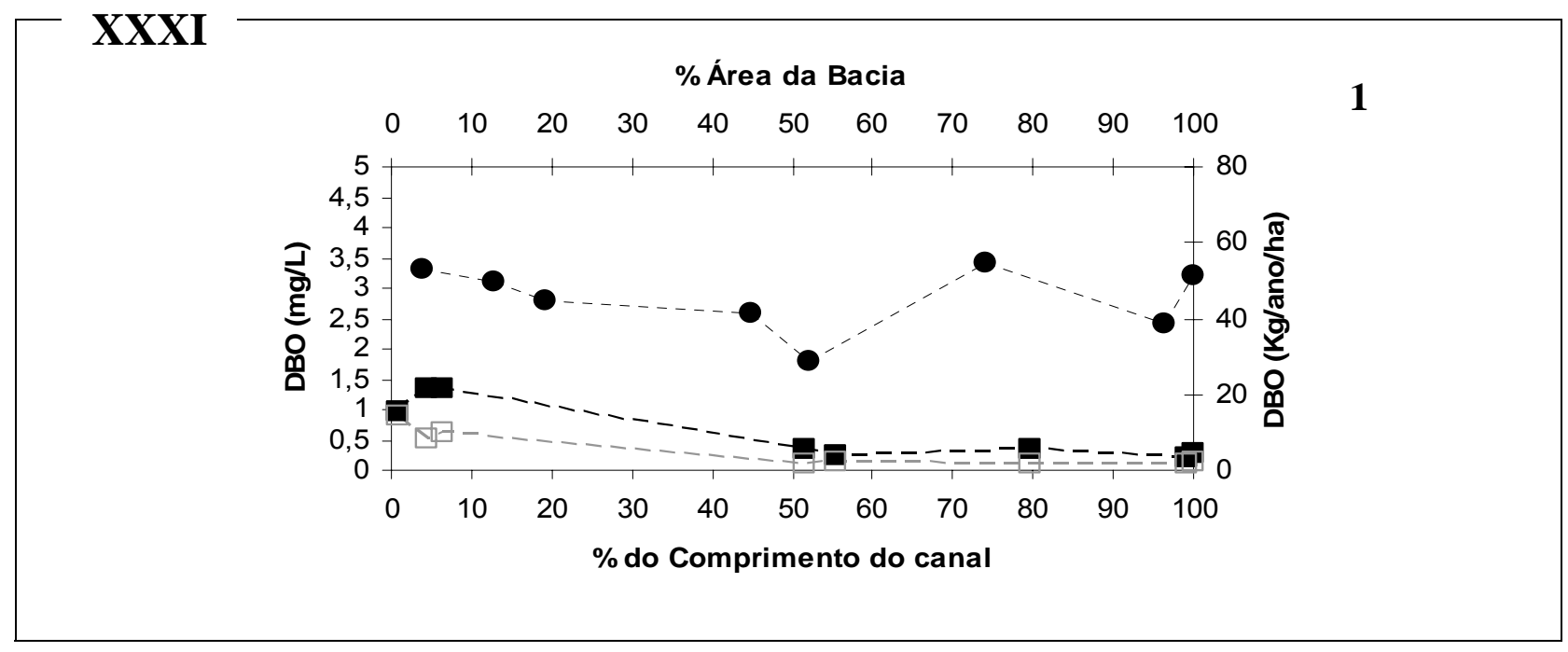



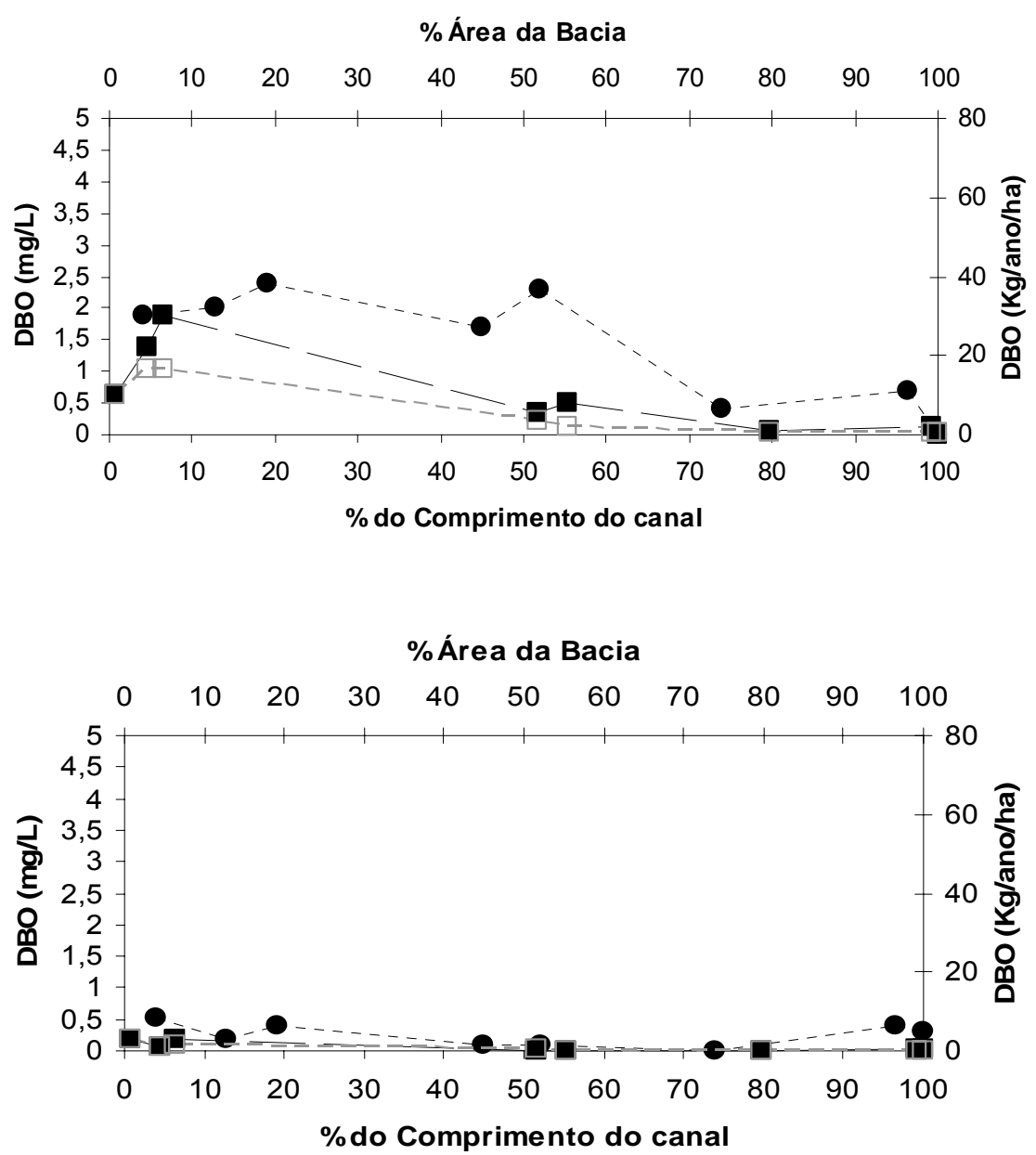

3

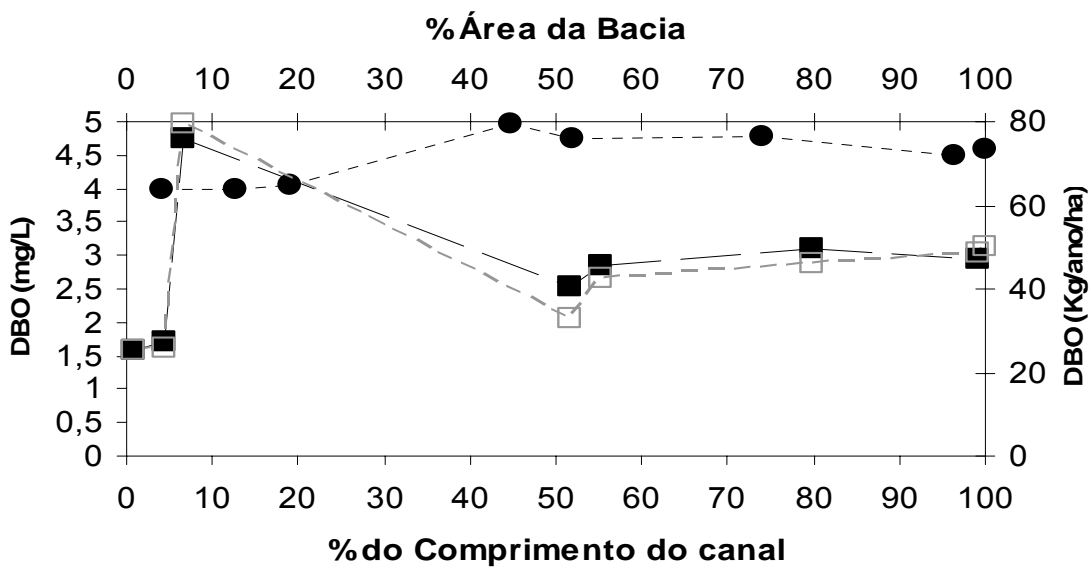

Figura XXXI: Variação da demanda bioquímica de oxigênio ao longo do eixo longitudinal do Rio Canha nas diferentes estações do ano ( 1 - primavera; 2 - verão; 3 - outono; 4 - inverno).Obs.: "•": Concentração observada; “ø”: carga específica observada ; “ロ”: carga específica simulada. 
As maiores concentrações de DBO foram observadas na campanha 4, com valores variando entre $4 \mathrm{mg} / \mathrm{L}$ na nascente e $4.95 \mathrm{mg} / \mathrm{L}$ no ponto amostral 5. Apesar de apresentar as concentrações mais elevadas, observou-se que não houve grande variação entre os valores de concentração ao longo do eixo longitudinal do Rio Canha. A campanha 3 apresentou os menores valores de concentração de $\mathrm{DBO}$, que variaram entre $0 \mathrm{mg} / \mathrm{L}$ no ponto de coleta 6 e $0,6 \mathrm{mg} / \mathrm{L}$ no ponto de coleta 1 .

As cargas específicas seguiram uma tendência de decaimento em direção à foz em todo o período amostrado, sendo que a campanha 4 apresentou os maiores valores de carga.

Os dados simulados seguem os observados, evidenciando o bom desempenho do modelo, uma vez que os dados de oxigênio dissolvido foram bem calibrados principalmente no que diz respeito às condições hidráulicas do rio.

\subsubsection{Sólidos Suspensos Totais}

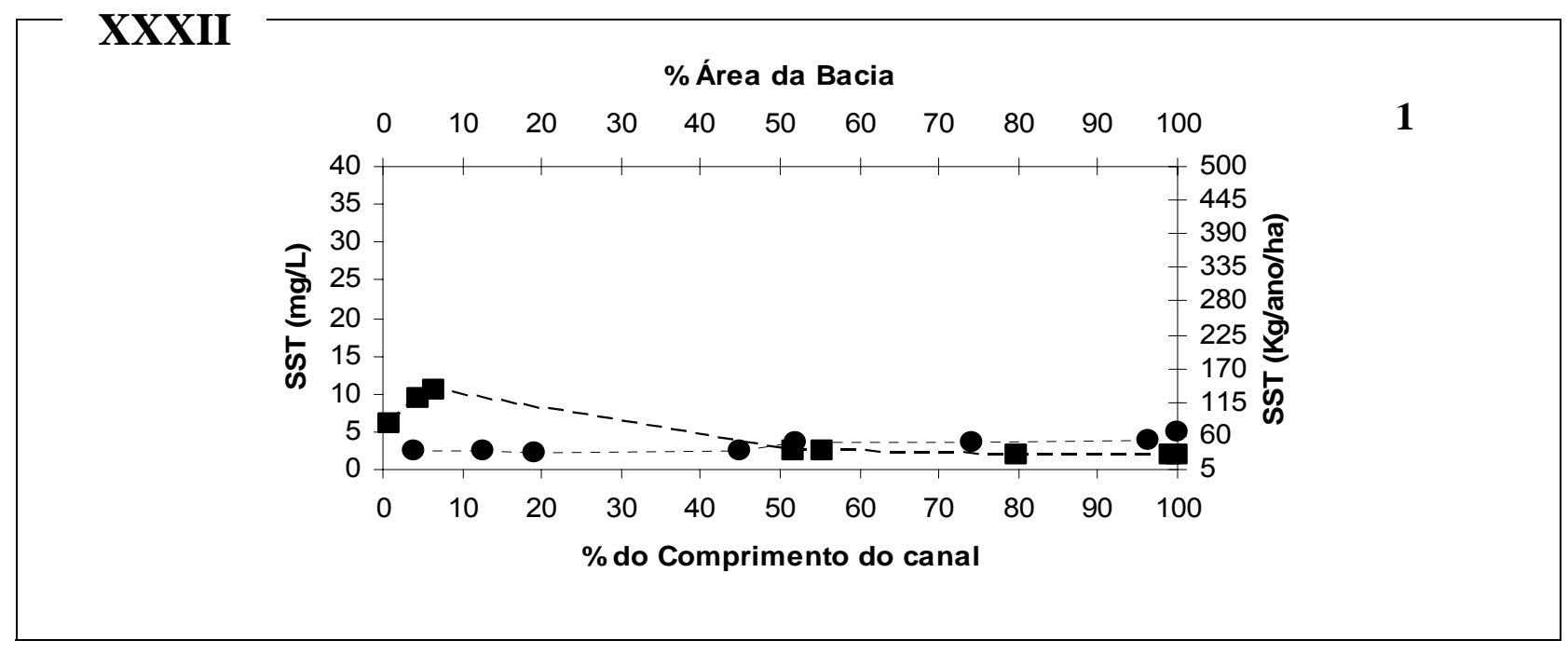




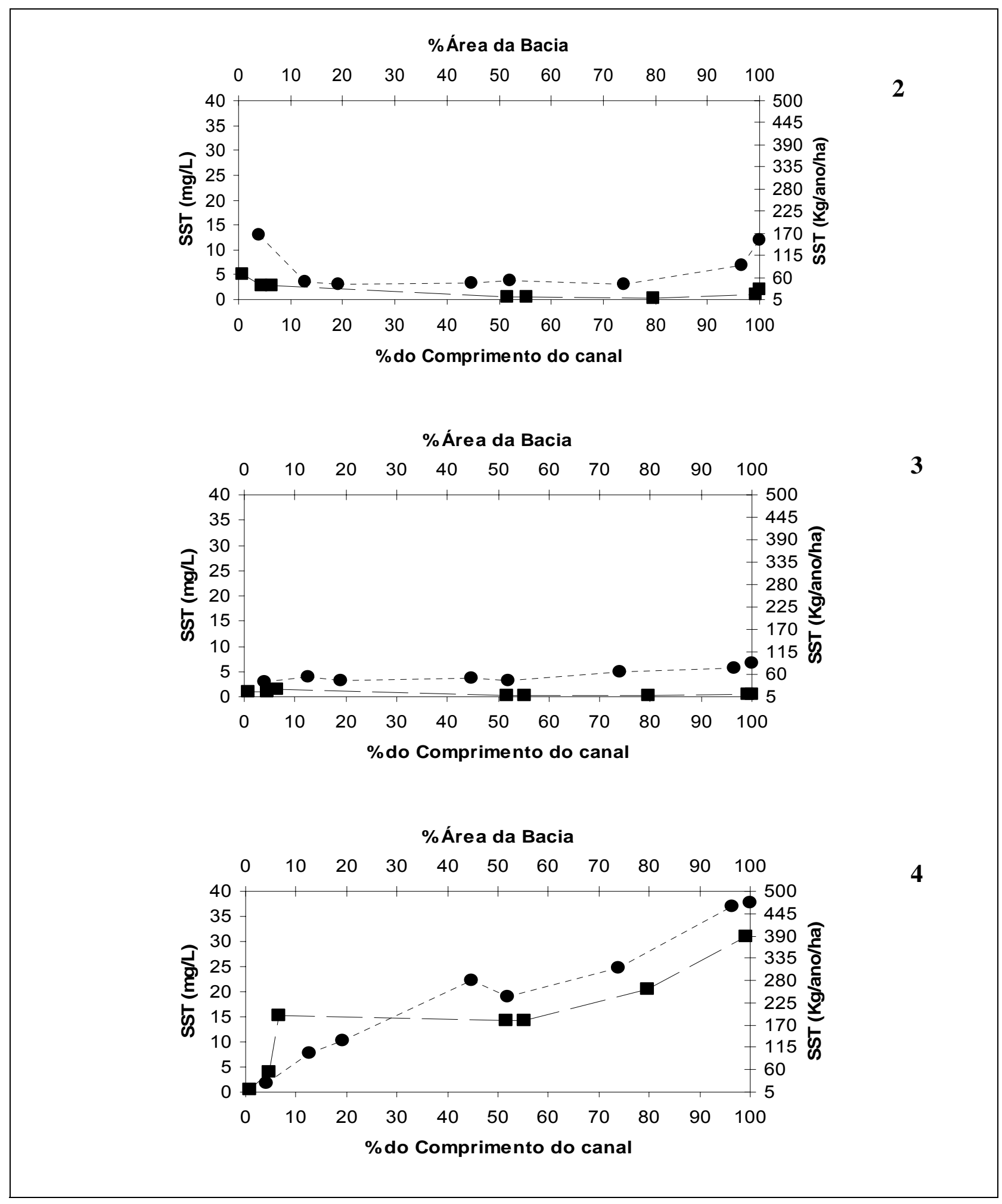

Figura XXXII: Variação de Sólidos Suspensos Totais ao longo do eixo longitudinal do Rio Canha nas diferentes estações do ano (1 - primavera; 2 - verão; 3 - outono; 4 - inverno).Obs.: "•": Concentração observada; "ø": carga

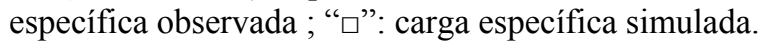


Em todas as campanhas as concentrações de sólidos totais crescem da nascente à foz, sendo que a campanha 4 apresentou os maiores valores dessa variável e os menores valores foram registrados na campanha 3. As cargas específicas dos sólidos totais diminuíram em direção à foz em todas as campanhas exceto na campanha 4, na qual as cargas seguiram a mesma tendência das concentrações.

\subsubsection{Sólidos Suspensos Orgânicos}

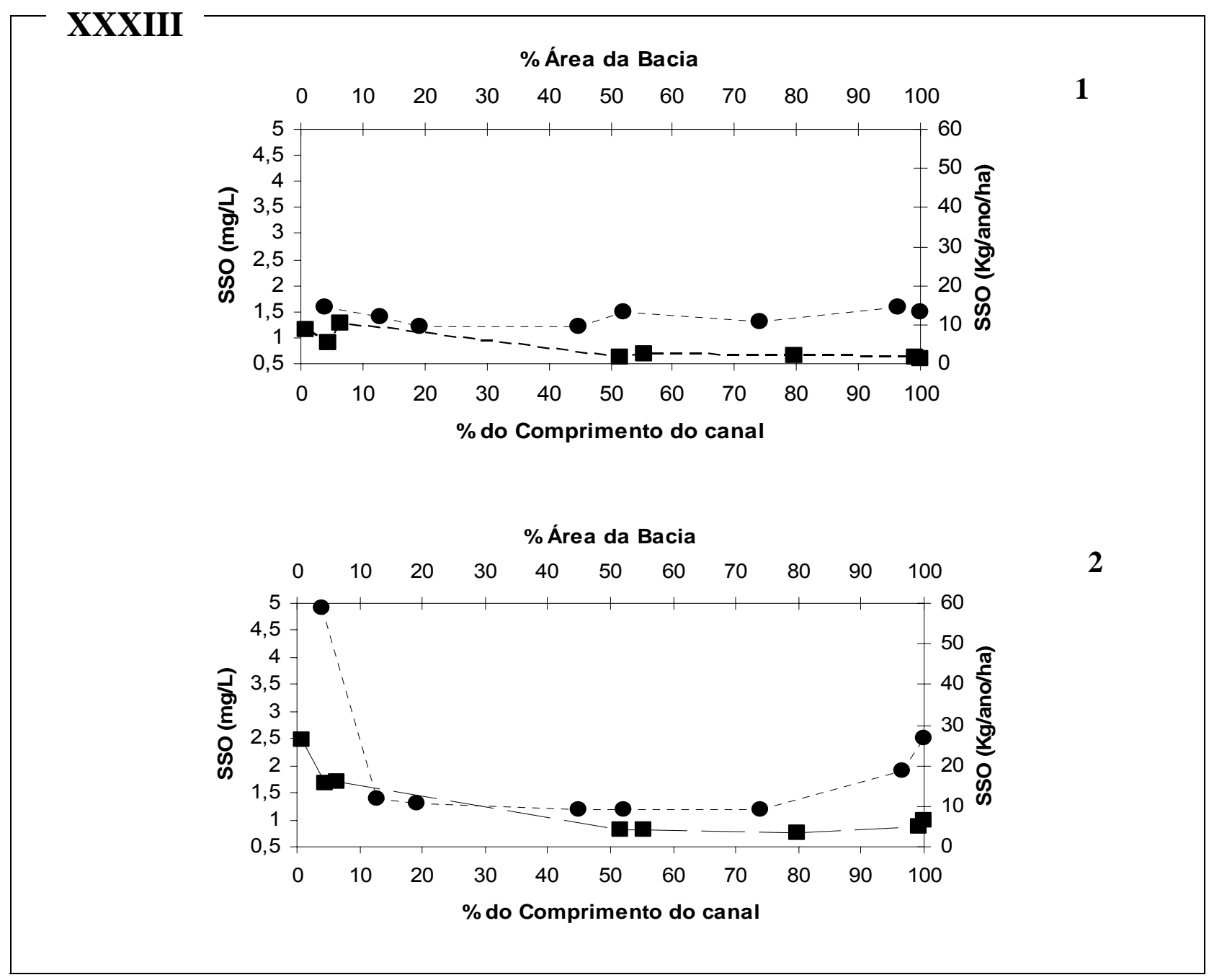




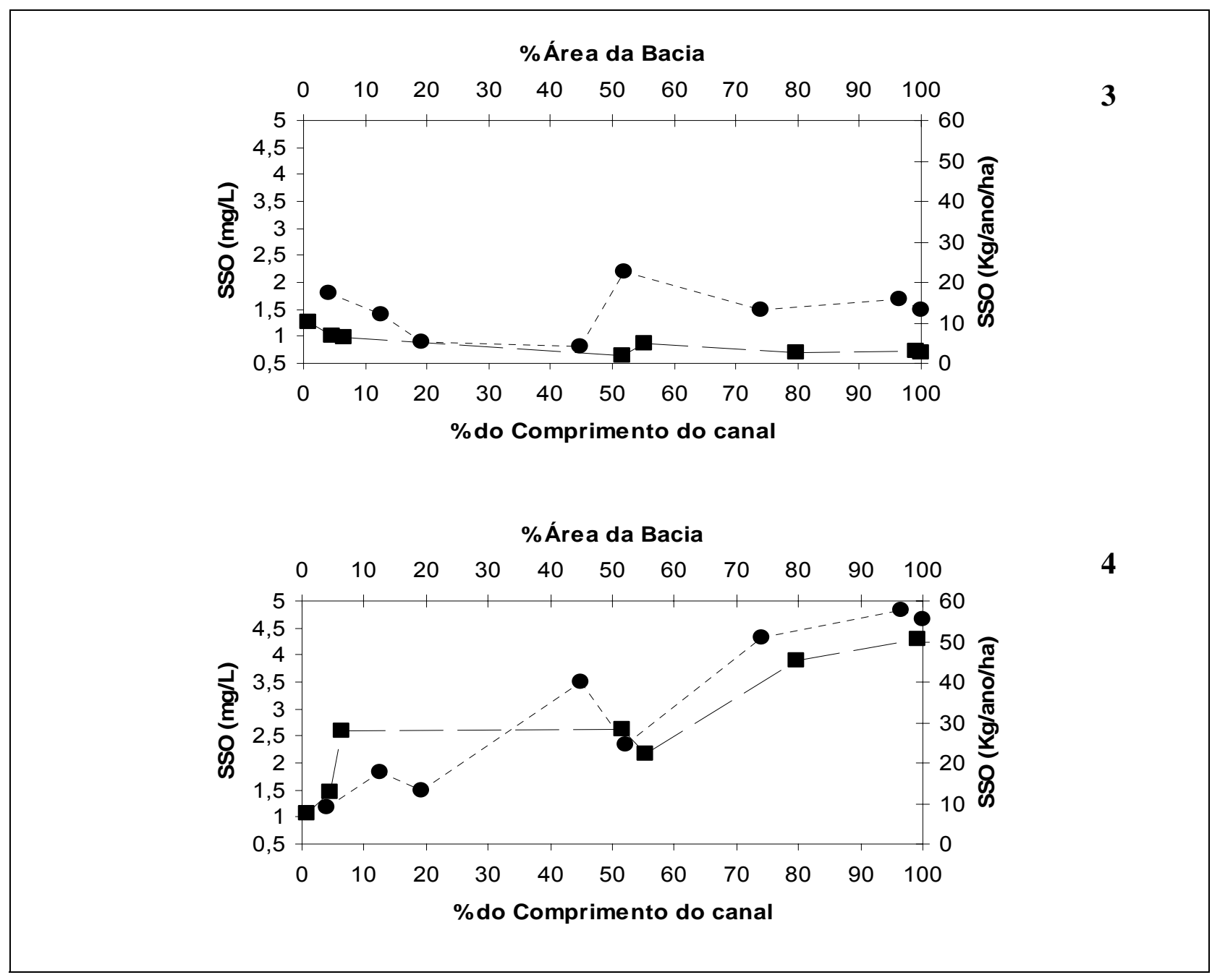

Figura XXXIII: Variação de Sólidos Suspensos Orgânicos ao longo do eixo longitudinal do Rio Canha nas diferentes estações do ano (1 - primavera; 2 - verão; 3 - outono; 4 - inverno).Obs.: "•": Concentração observada; "ø": carga

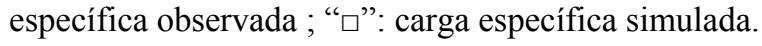

Nas campanhas 1 e 4 verificou-se um aumento na concentração de sólidos suspensos orgânicos (SSO) de montante à jusante, entretanto as campanhas 1 e 3 as maiores concentrações de SSO foram obtidas na nascente com diminuição à jusante, sendo que na campanha 3 observou-se um pico no médio curso do rio. O maiores valores de concentração de SSO foram obtidos na campanha 4 e os menores na campanha 1.

Em relação às cargas específicas, para todas as campanhas houve um decréscimo da nascente à foz, excetuando-se a campanha 4 que seguiu a mesma tendência da concentração. 


\subsubsection{Sólidos Suspensos Inorgânicos}

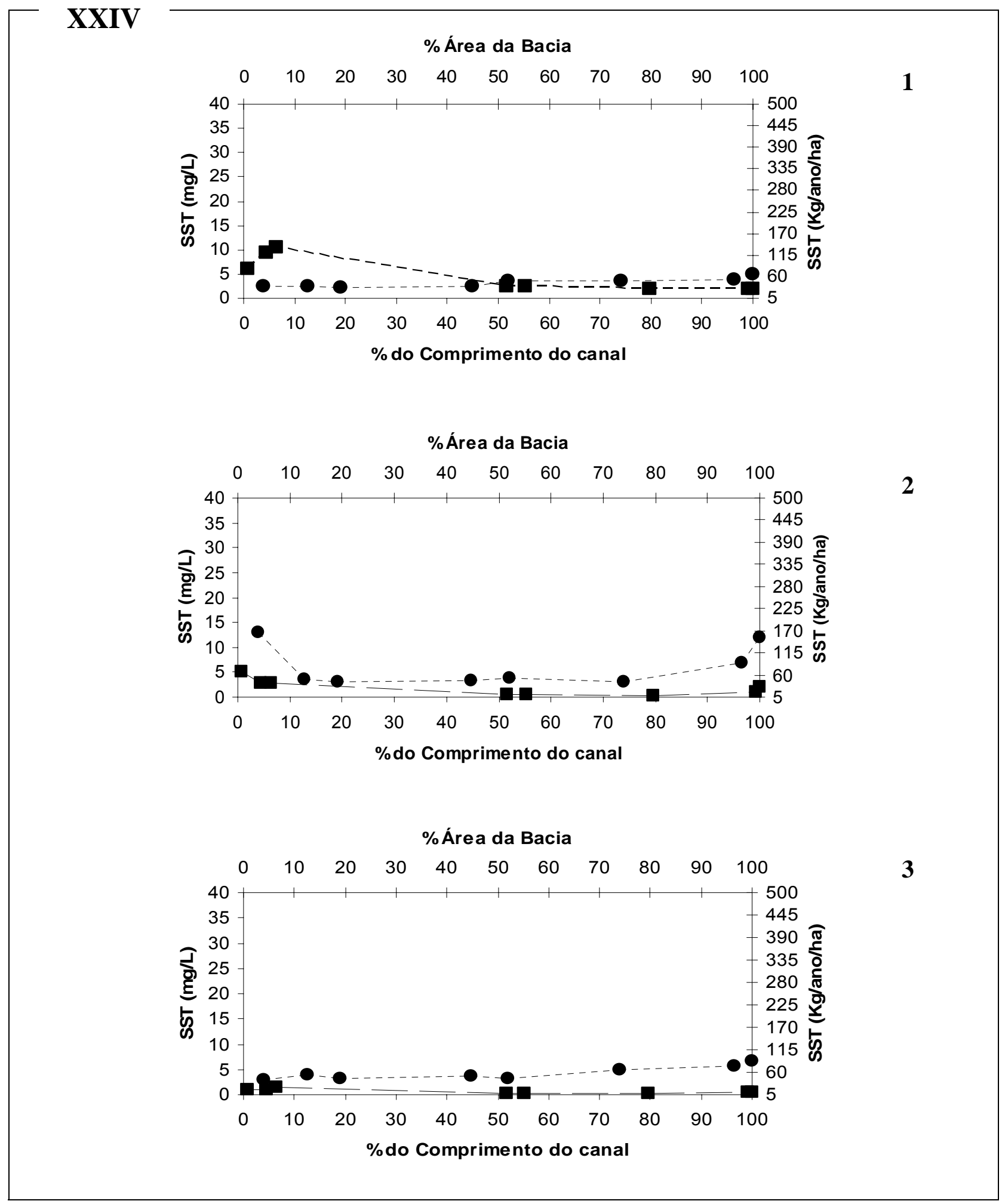




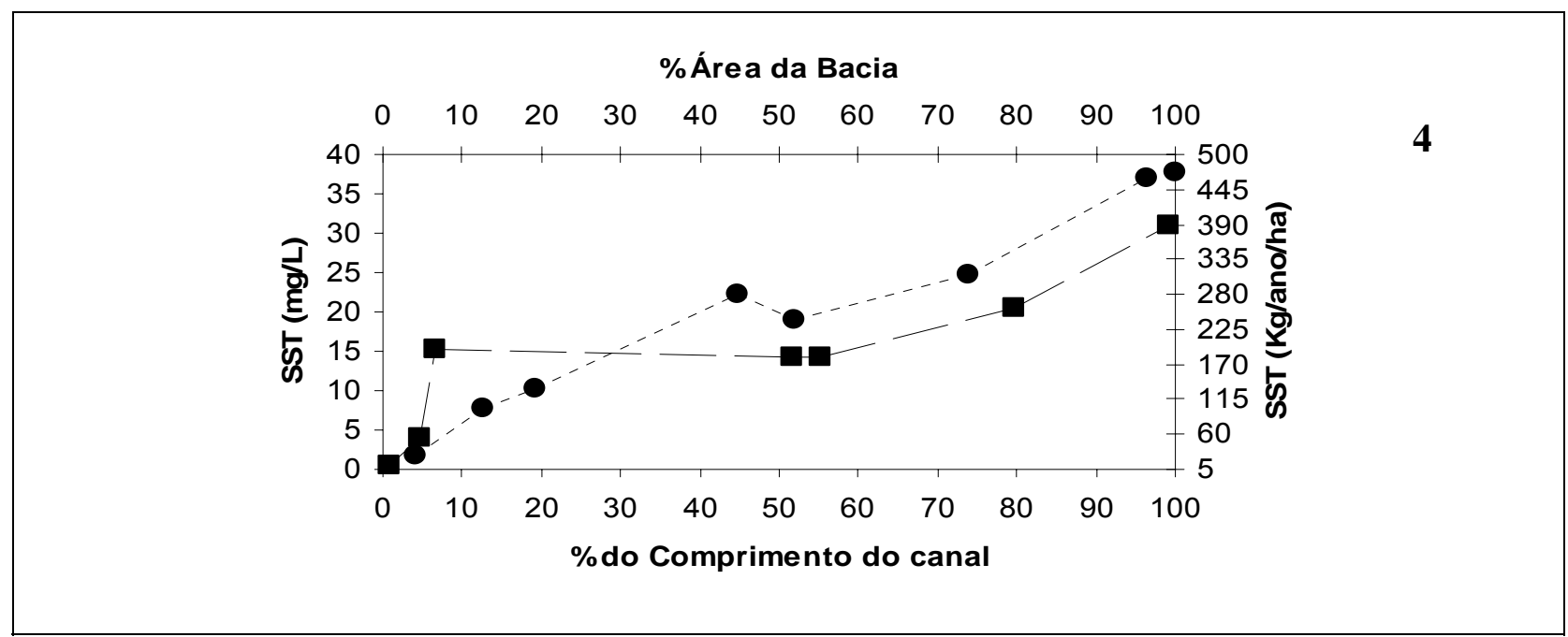

Figura XXXIV: Variação de Sólidos Suspensos Inorgânicos ao longo do eixo longitudinal do Rio Canha nas diferentes estações do ano ( 1 - primavera; 2 - verão; 3 - outono; 4 - inverno).Obs.: “•”: Concentração observada; “ø”: carga específica observada ; “口”: carga específica simulada.

A partir da figura XXXIV é possível observar uma tendência de aumento da concentração dos sólidos suspensos inorgânicos (SSI) que ocorre de montante para jusante. A campanha 4 apresentou maior heterogeneidade espacial, com valores variando de $0,66 \mathrm{mg} / \mathrm{L}$ na nascente a 33 $\mathrm{mg} / \mathrm{L}$ na foz. Em relação à variação sazonal, esta ocorreu da seguinte maneira, maior carga e concentração de sólidos na campanha 4, período chuvoso, principalmente nos trechos não preservados da bacia, que se iniciam a partir do ponto amostral 2. As campanhas 2 e 3 possuem valores intermediários de sólidos, já a campanha 1 apresentou as menores cargas e concentrações para essa variável. 


\subsubsection{Clorofila $\underline{a}$}

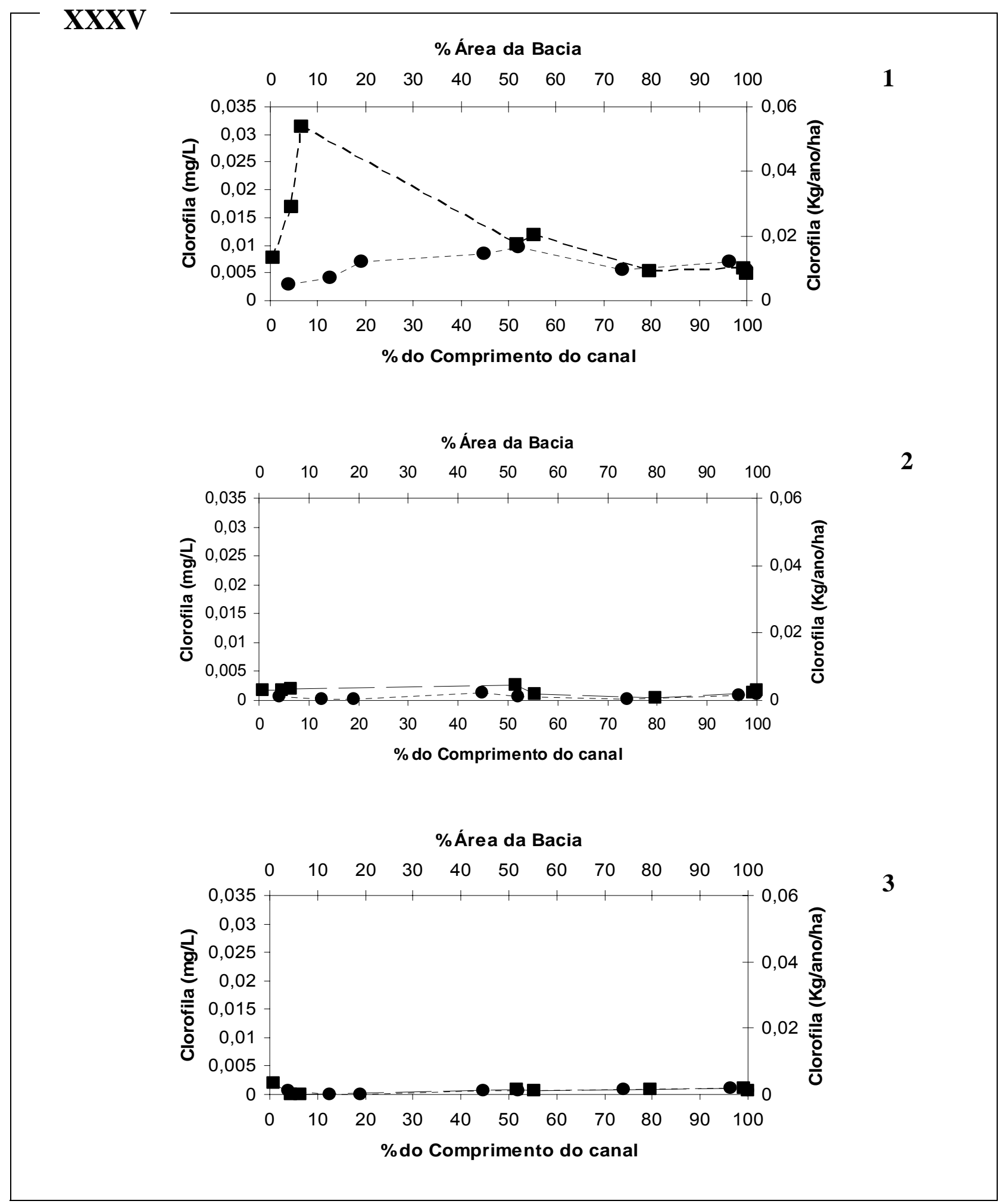




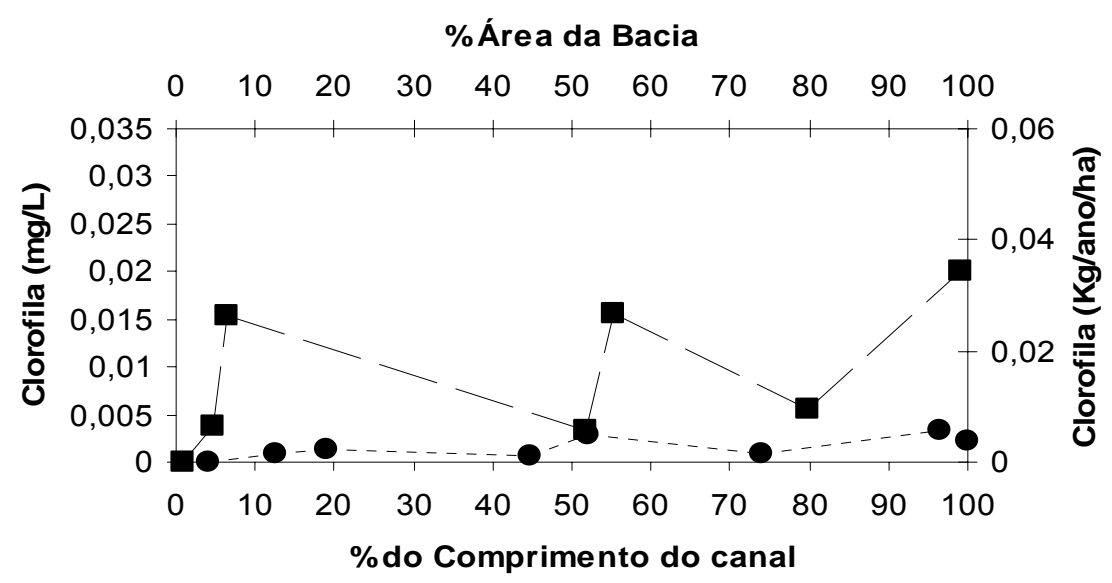

Figura XXXV: Variação de Clorofila ao longo do eixo longitudinal do Rio Canha nas diferentes estações do ano (1 primavera; 2 - verão; 3 - outono; 4 - inverno).Obs.: “•”: Concentração observada; "ø”: carga específica observada.

As concentrações de clorofila aumentaram da nascente ao médio curso do rio Canha e posteriormente tiveram um ligeiro declínio em direção à foz em todas as estações do ano, as cargas específicas seguiram a mesma tendência. As maiores concentrações e cargas foram observadas na campanha 1 e as menores na campanha 3, sendo que nos pontos de coleta 2 e 3 obteve-se como concentração $0 \mathrm{mg} / \mathrm{L}$.

A campanha 4 registrou $0 \mathrm{mg} / \mathrm{L}$ de clorofila apenas na nascente e os maiores valores de carga e concentração foram obtidos nos pontos amostrais 7 e 8 (3,26 e 2,33 mg/L; 0,034 e 0,026 $\mathrm{Kg} / \mathrm{ano} / \mathrm{ha}$, respectivamente).

A figura XXXVI mostra a curva de permanência para vazões regionalizadas para o rio Canha, as respectivas vazões observadas e as cargas de clorofila $\underline{a}$. Essa figura permite inferir hipóteses acerca de vazões ecológicas, uma vez que indica as variações de clorofila sobre uma amplitude de vazões para o rio Canha.

Deste modo, de acordo com as condições empregadas pelo modelo QUAL2K (Figura VI), o possível aumento de clorofila a sugere um aumento da produtividade que é contrabalanceada por eventos de respiração, morte e precipitação do fitoplâncton durante as campanhas 1, 2 e 3 . Isso é esperado para um amplo intervalo de vazões, entre $15 \%$ e 100\%. No entanto, a campanha 4 apresenta cargas específicas de clorofila $a$ aproximadamente seis vezes maior aos anteriores, indicando um aumento da produção. Esses valores contradizem o resultado esperado, já que esta 
campanha caracterizou-se por sua baixa luminosidade e temperatura, porém com alta vazão específica e provavelmente conexão do rio com as margens e/ou várzeas.

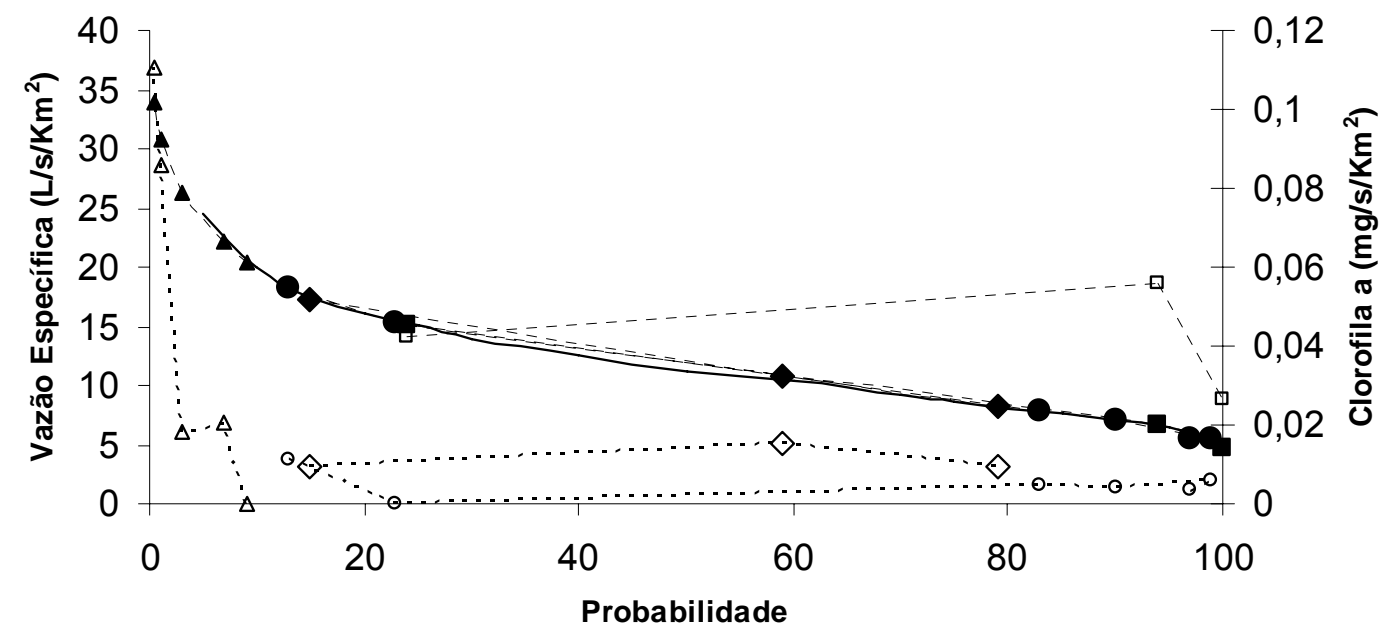

Figura XXXVI: Vazões de permanência, vazões observadas e dados de clorofila $\underline{a}$ para o rio Canha

\subsubsection{Condutividade Elétrica}

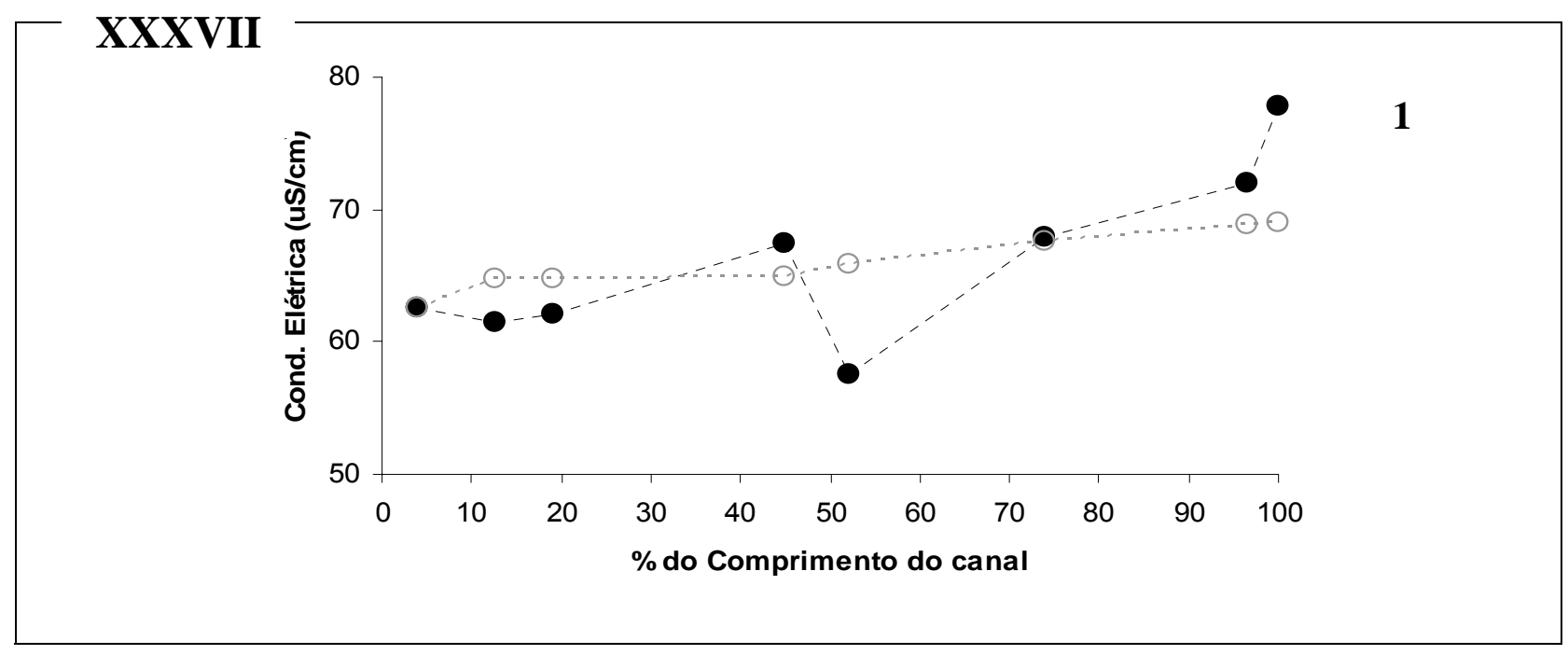



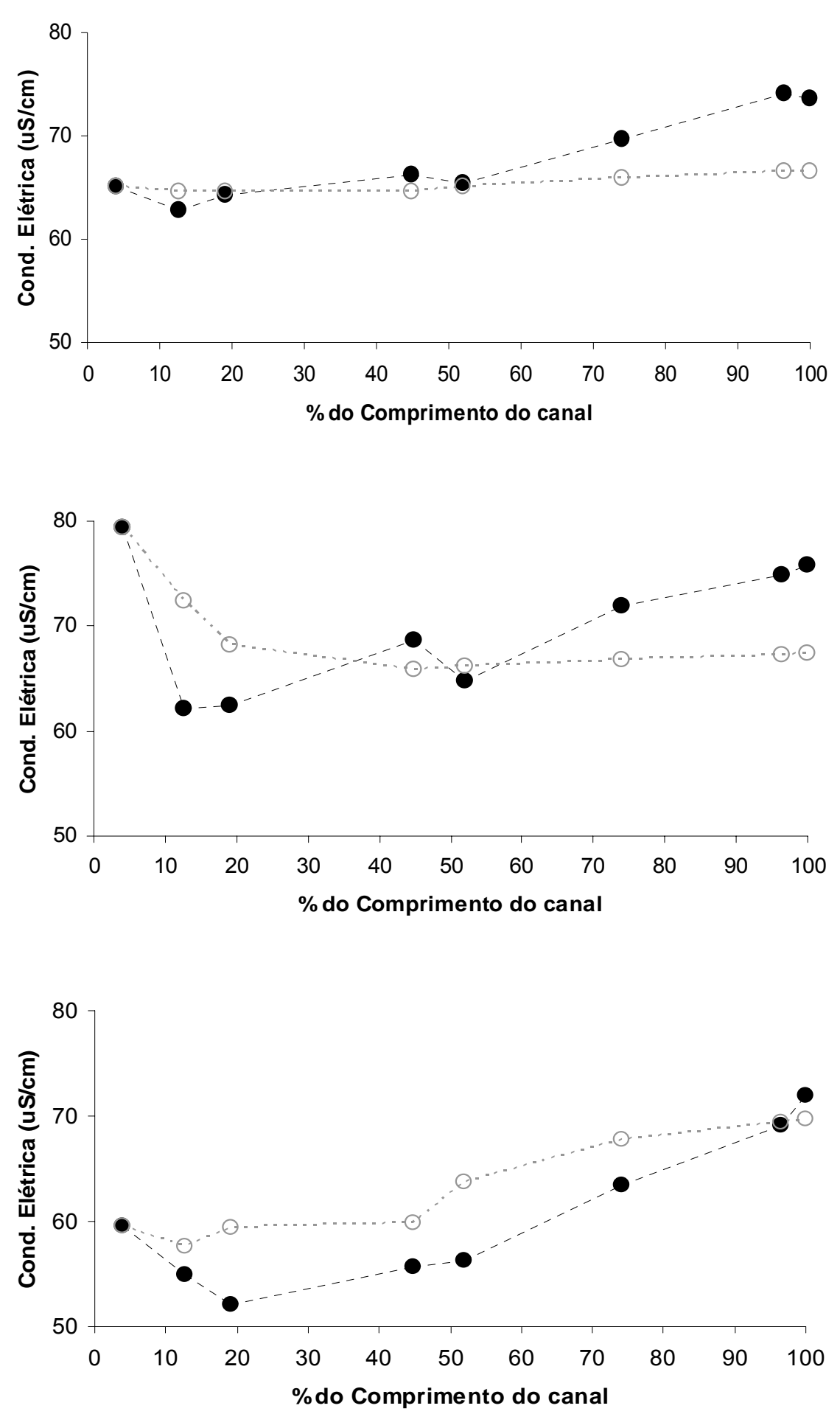

Figura XXXVII: Variação de Condutividade Elétrica ao longo do eixo longitudinal do Rio Canha nas diferentes estações do ano ( 1 - primavera; 2 - verão; 3 - outono; 4 - inverno).Obs.: "•": Concentração observada; "०": Concentração simulada. 
Longitudinalmente, a condutividade elétrica aumentou de montante para jusante em todas as estações do ano. A campanha 3 apresentou maior peculiaridade nos valores de condutividade elétrica, a qual apresentou-se alta na nascente, diminuindo na zona intermediária do rio, com um aumento no final do curso d'água. Já as campanhas 1 e 2 não apresentaram grandes diferenças nos valores de condutividade elétrica. A campanha 4 apresentou maior variação longitudinal e os menores valores de condutividade em relação às outras estações sazonais.

Temporalmente observou-se a mesma tendência na variação da condutividade elétrica e valores bastante próximos nas campanhas 1,2 e 3, apenas na campanha 4 os valores tiveram grande decréscimo.

\subsubsection{Alcalinidade}

\section{XXXVIII}
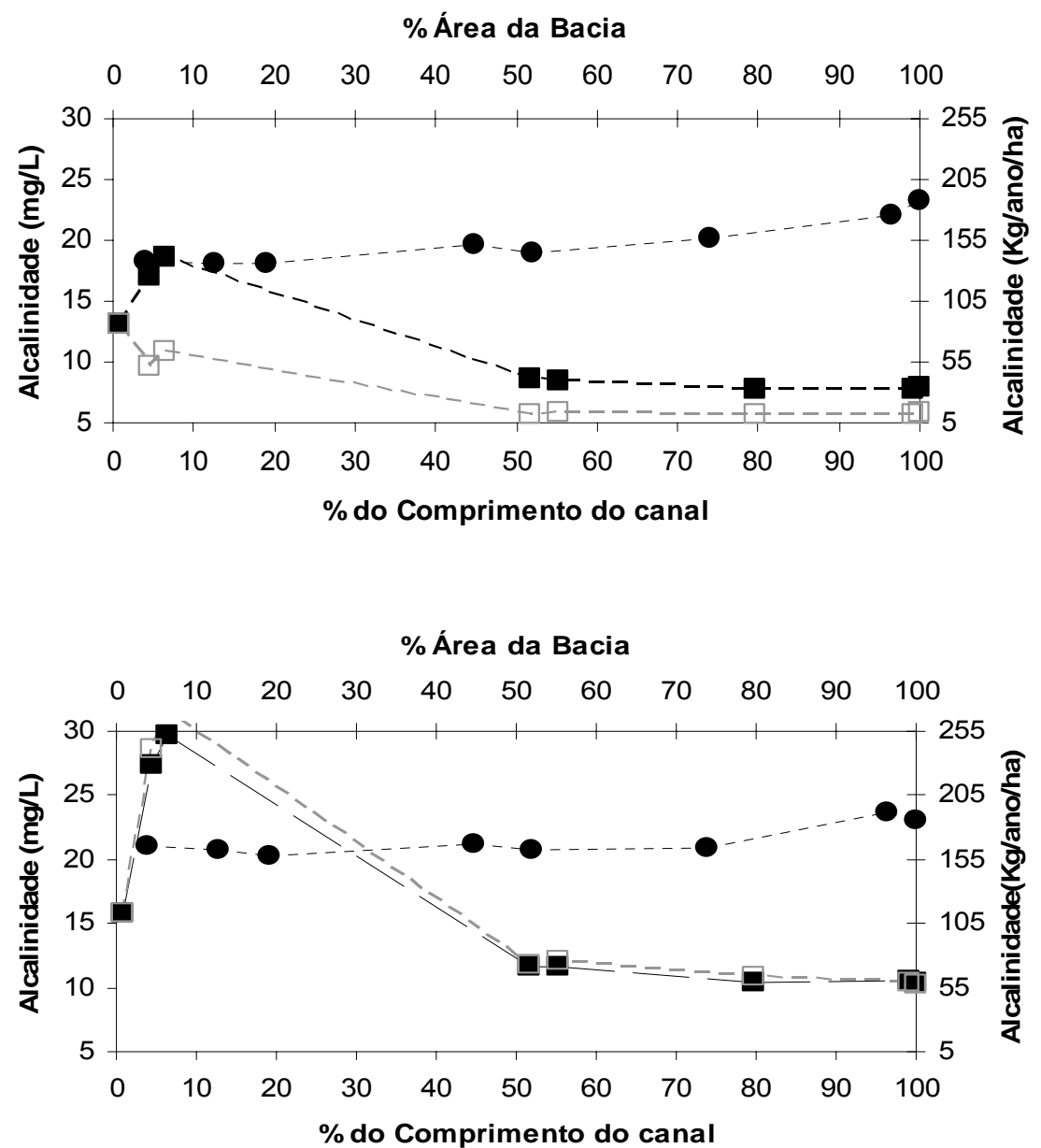

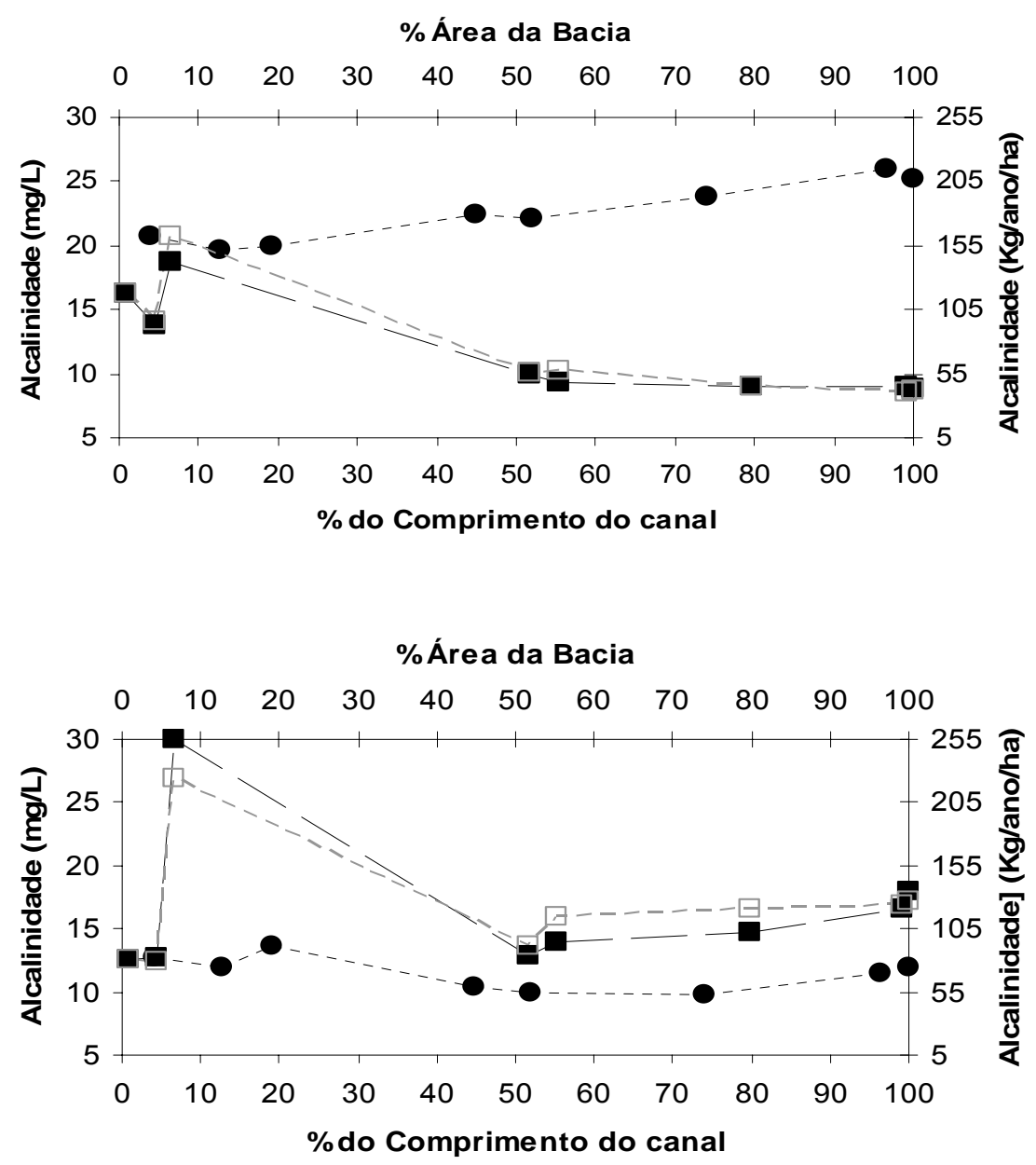

Figura XXXVIII: Variação de Alcalinidade ao longo do eixo longitudinal do Rio Canha nas diferentes estações do ano (1 - primavera; 2 - verão; 3 - outono; 4 - inverno).Obs.: "•”: Concentração observada; "ø”: carga específica observada ; “ $\square ”$ : carga específica simulada.

Através da figura XXXVIII é possível observar a formação de um gradiente longitudinal de montante à jusante no Rio Canha, o qual apresentou menores concentrações nos pontos amostrais próximos à nascente, aumentando gradativamente em direção à foz. A campanha 4 apresentou as menores concentrações de alcalinidade seguidos pelas campanhas 1 e 2. Já em relação à carga específica, esta apresentou-se maior na nascente com diminuição até os pontos próximos à foz, sendo que a campanha 1 apresentou os menores valores de alcalinidade e os maiores foram obtidos na campanha 4 . 
Sazonalmente, os valores de concentração não variaram muito entre as campanhas 1, 2 e 3, em termos de carga específica há uma grande amplitude nos valores de alcalinidade devido às vazões, maiores em 2 e 4 .

5.3.10. $p H$

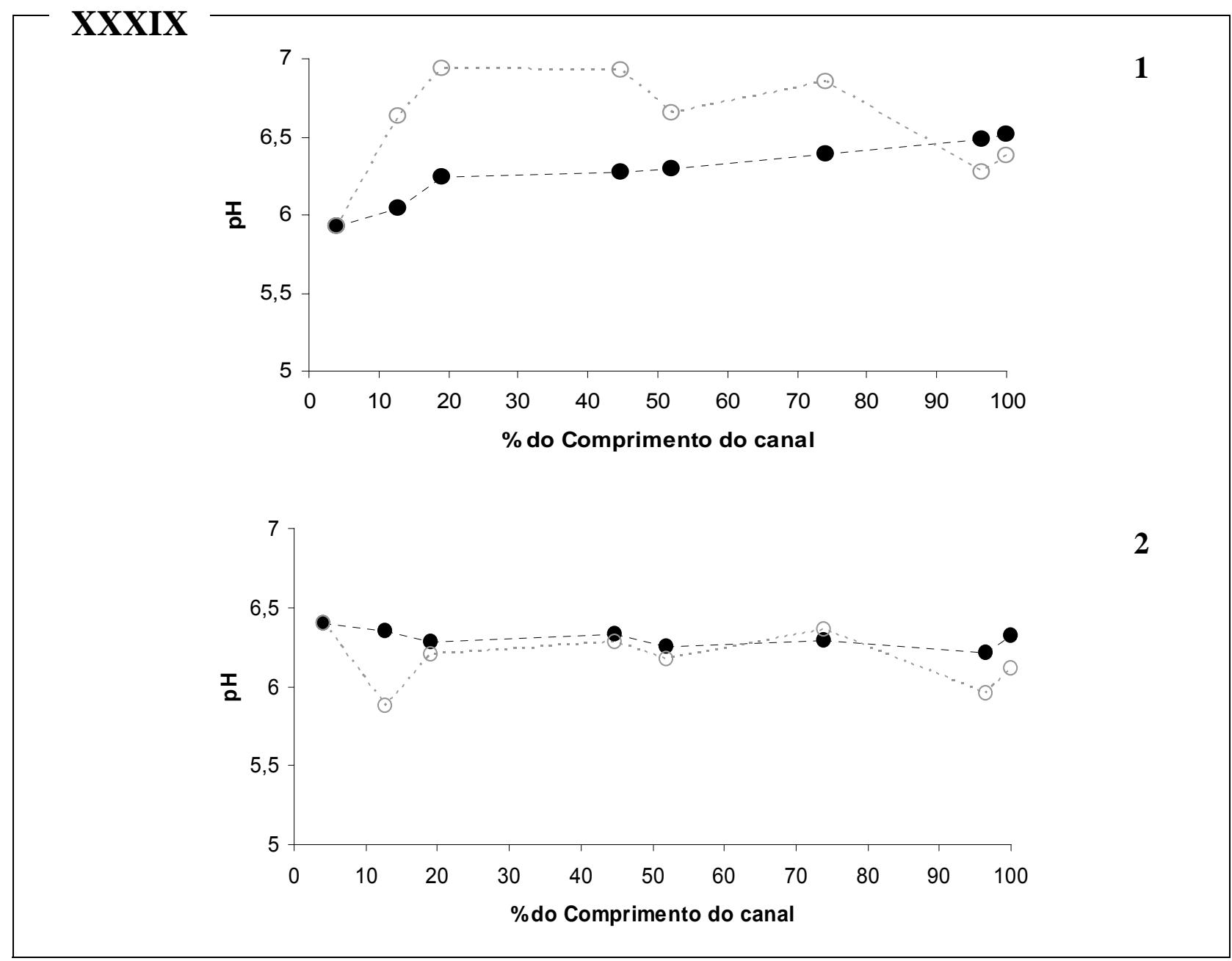



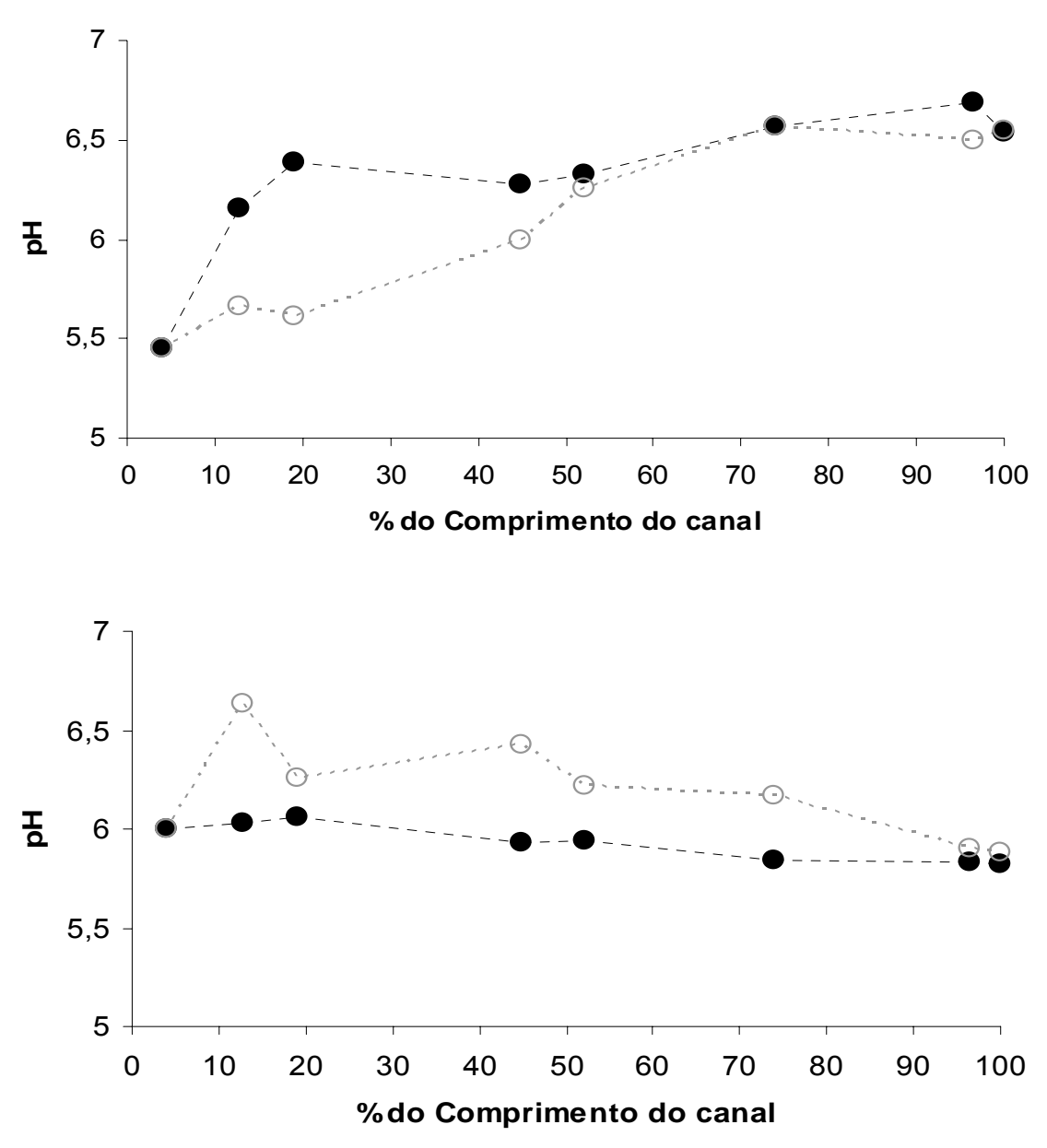

Figura XXXIX: Variação do pH ao longo do eixo longitudinal do Rio Canha nas diferentes estações do ano (1 primavera; 2 - verão; 3 - outono; 4 - inverno).Obs.: “•”: Dado observado; “०”: Dado simulado.

Os valores de $\mathrm{pH}$ não sofreram muita variação longitudinal e mantiveram o mesmo padrão de variação temporal. Apenas na campanha 4, estação chuvosa, observou-se pequena queda desse parâmetro, com valores variando entre 6,06 (maior valor - ponto de coleta 3) e 5,82 (menor valor - foz). Em todas as campanhas os valores de $\mathrm{pH}$ mantiveram uma pequena faixa de variação (de 0,5 a 1$)$. 
5.3.11. Turbidez

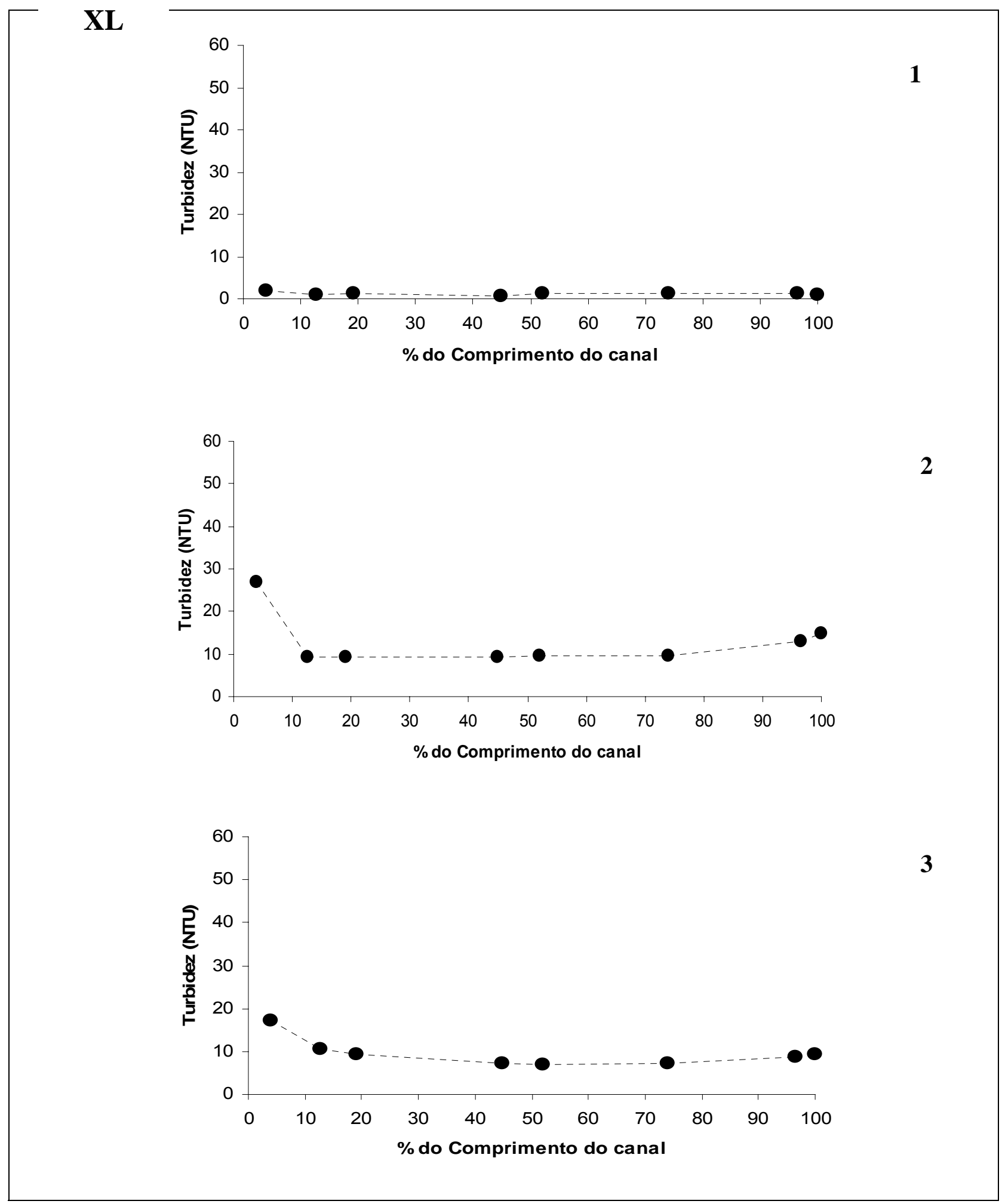




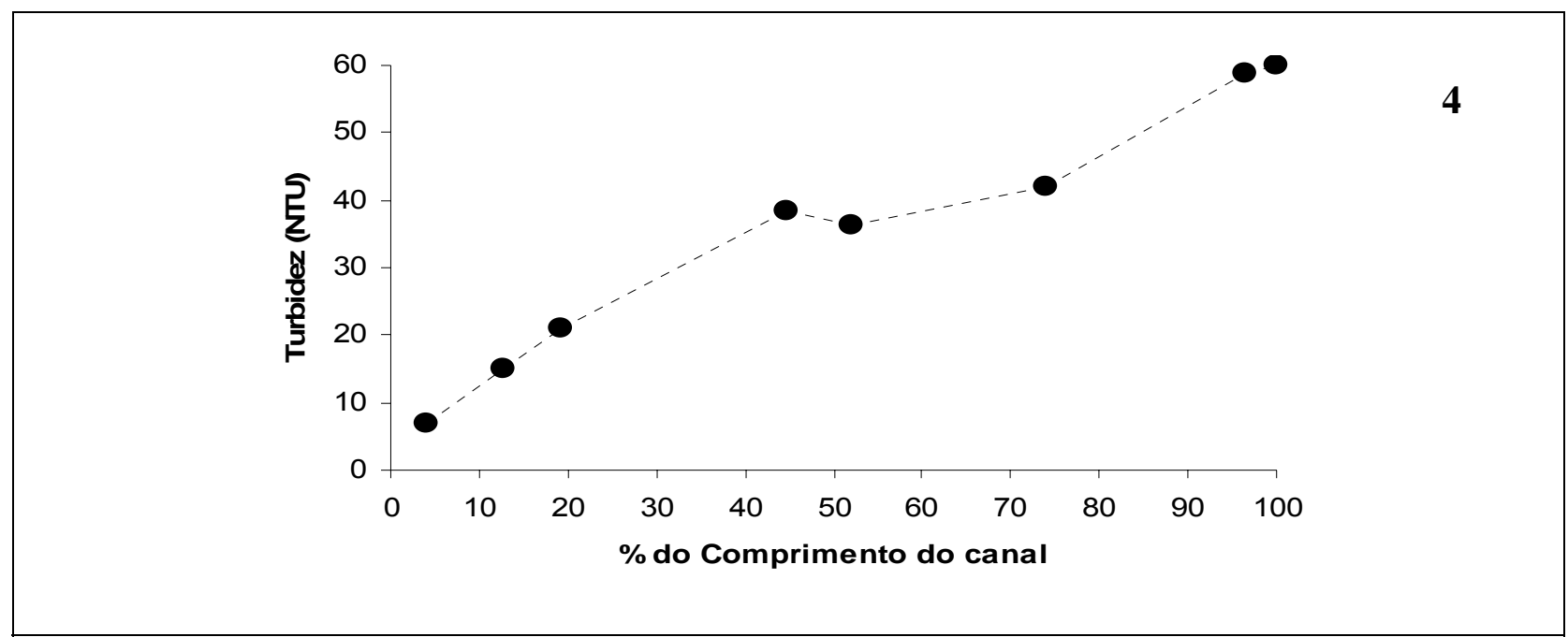

Figura XL: Variação da Turbidez ao longo do eixo longitudinal do Rio Canha nas diferentes estações do ano (1 primavera; 2 - verão; 3 - outono; 4 - inverno).Obs.: "•”: Concentração observada.

Em todas as campanhas, exceto na campanha 4 os valores de turbidez decresceram da nascente à foz. A campanha 1 apresentou os menores valores dessa variável, já a campanha 4 apresentou os maiores valores de turbidez, os quais aumentaram da nascente a foz.

\subsubsection{Nitrogênio Total}

\section{XLI}

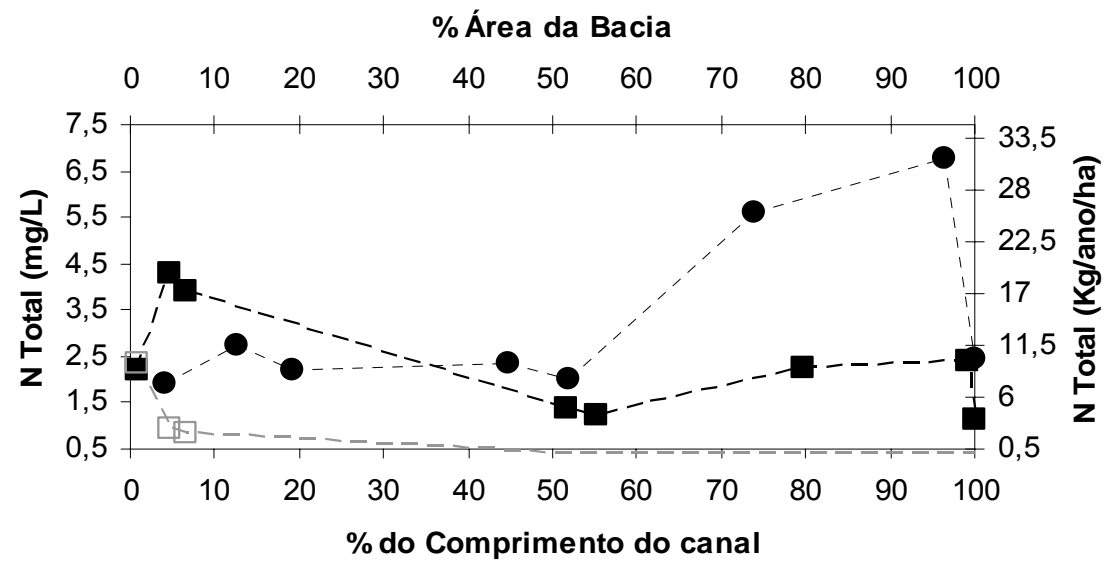



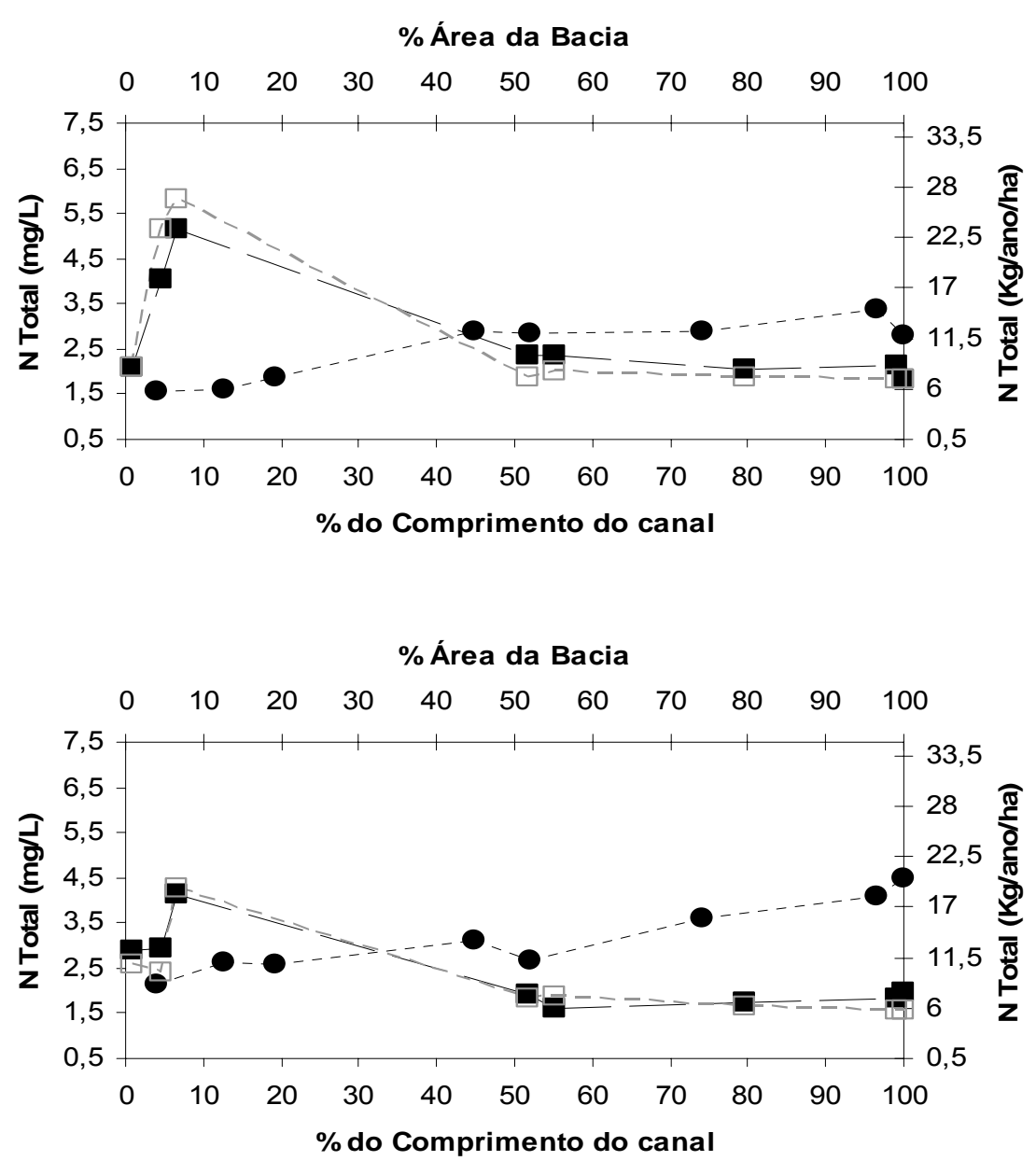
A figura XLI permite verificar que a concentração de nitrogênio total sofre variação, aumentando de montante à jusante ao longo do eixo longitudinal do rio Canha, durante todo o período de amostragem. As menores concentrações de nitrogênio total foram observados na nascente, nas campanhas 1,2, 3 e 4, sendo que a mínina concentração registrada na nascente ocorreu na campanha $4(1,3 \mathrm{mg} / \mathrm{L})$.

As maiores concentrações foram obtidas na campanha 1, sendo que esta apresentou maior heterogeneidade espacial. Ainda em relação a esta campanha, foi possível observar que as concentrações de nitrogênio total tiveram um acréscimo a partir de ponto amostral 6 , decaindo novamente no ponto 8 .

Em relação às cargas específicas, as campanhas 1, 2 e 3, como era de se esperar, apresentaram uma queda dos valores do médio curso em diante do rio, sendo que apenas a campanha 4 seguiu uma tendência diferenciada com picos em diferentes pontos ao longo do eixo longitudinal do Rio Canha, apresentando a maior carga no ponto 8.

As maiores cargas específicas de nitrogênio total foram registradas na campanha 4, porém as maiores concentrações foram observadas na campanha 1 (máximo de 6,79 mg/L - ponto amostral 4), que também apresentou as menores cargas.

A figura seguinte evidencia o balanço de nitrogênio total entre os pontos amostrais analisados. Observa-se que todas as campanhas apresentaram um balanço de massa negativo entre os pontos amostrais 3 e 4. Entretanto, todas as campanhas, exceto a campanha 4 apresentaram balanço de massa positivo entre os pontos de coleta 1 e 2 , porém, em relação os pontos 2 e 3, apenas a campanha 1 registrou balanço de massa negativo. 


\section{XLII}
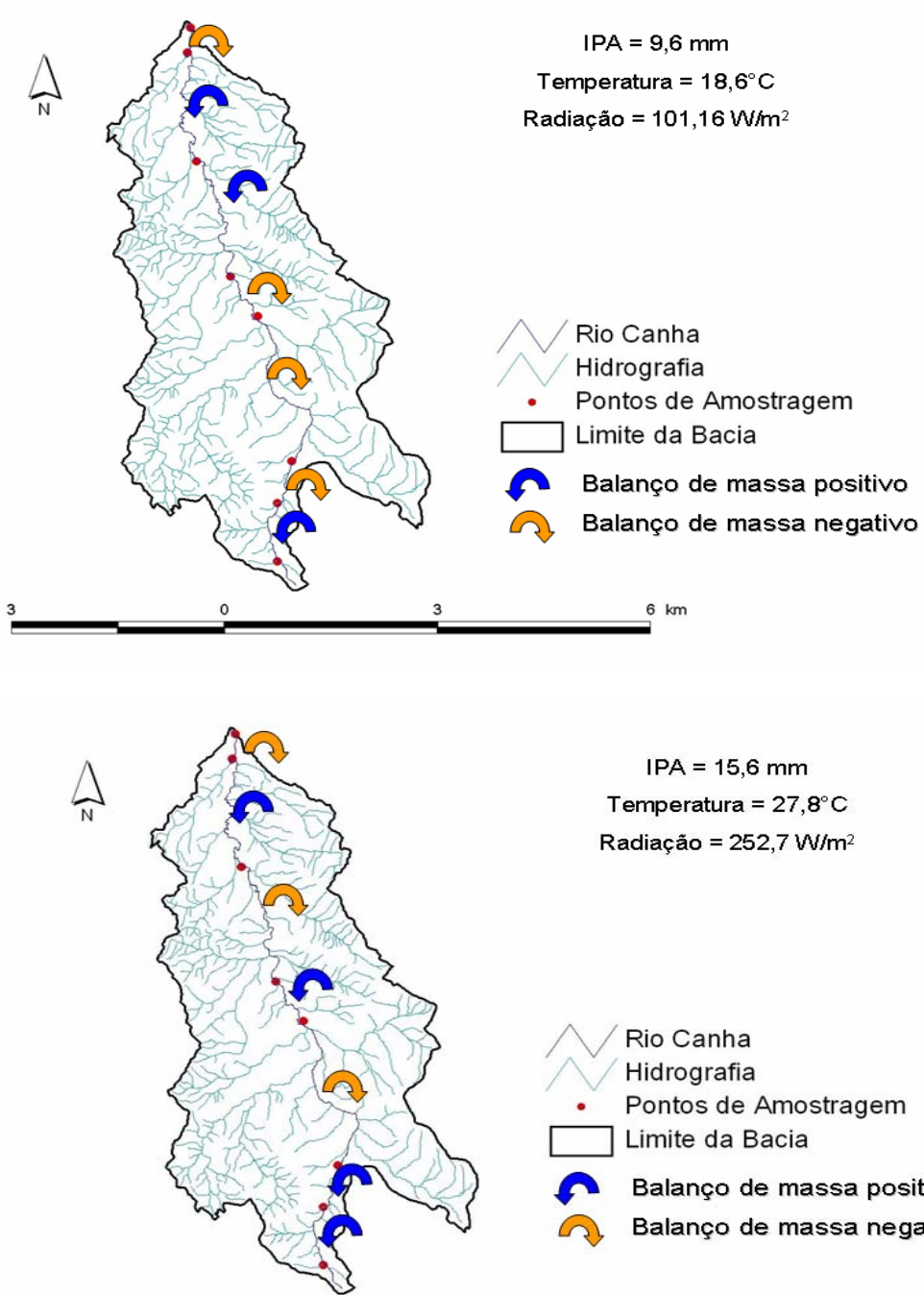

$\mathrm{IPA}=15,6 \mathrm{~mm}$

Temperatura $=27,8^{\circ} \mathrm{C}$

Radiação $=252,7 \mathrm{~W} / \mathrm{m}^{2}$

Rio Canha

Hidrografia

- Pontos de Amostragem

Limite da Bacia

- Balanço de massa positivo

B. Balanço de massa negativo
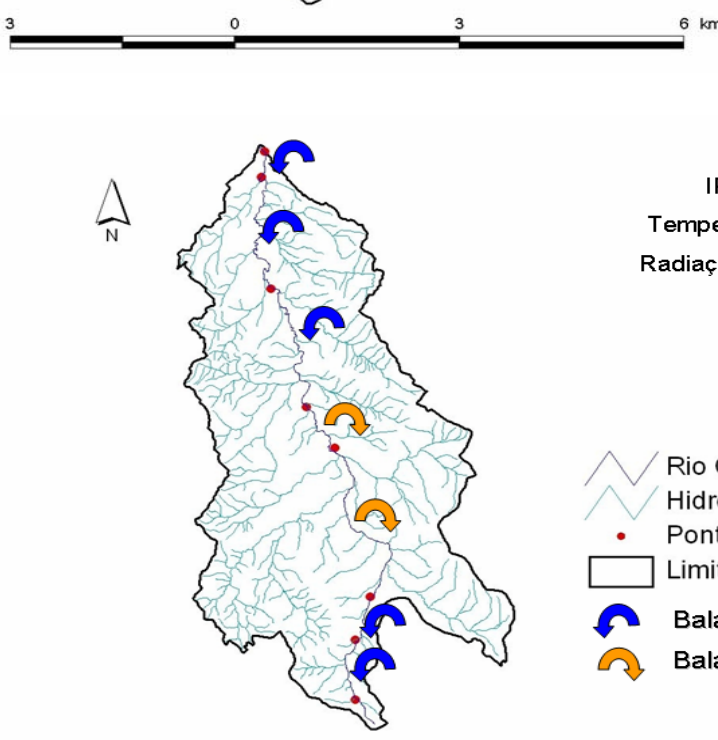

$\mathrm{IPA}=0 \mathrm{~mm}$

Temperatura $=25,2^{\circ} \mathrm{C}$

Radiação $=193,2 \mathrm{~W} / \mathrm{m}^{2}$

Rio Canha

Hidrografia

- Pontos de Amostragem

Limite da Bacia

- Balanço de massa positivo

(.) Balanço de massa negativo

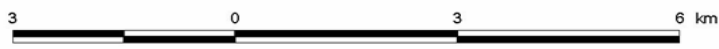




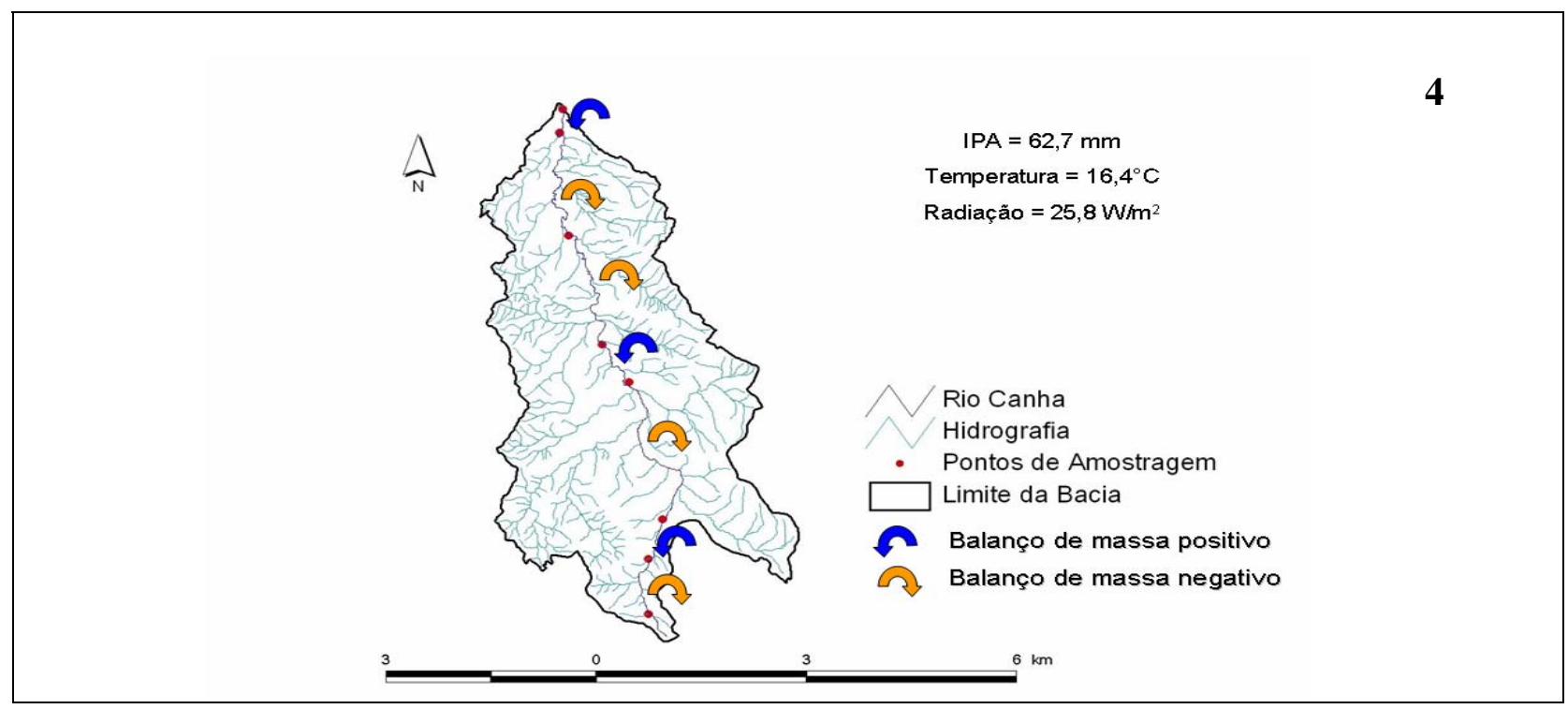

Figura XLII: Balanço de massa para o nitrogênio total ao longo do eixo longitudinal do rio Canha nas quatro estações do ano.

Os dados de granulometria serão apresentados juntamente com os dados de nitrogênio total, a fim de se contrastar hipóteses da alta concentração desse elemento com o tipo de sedimento presente no leito do rio Canha.

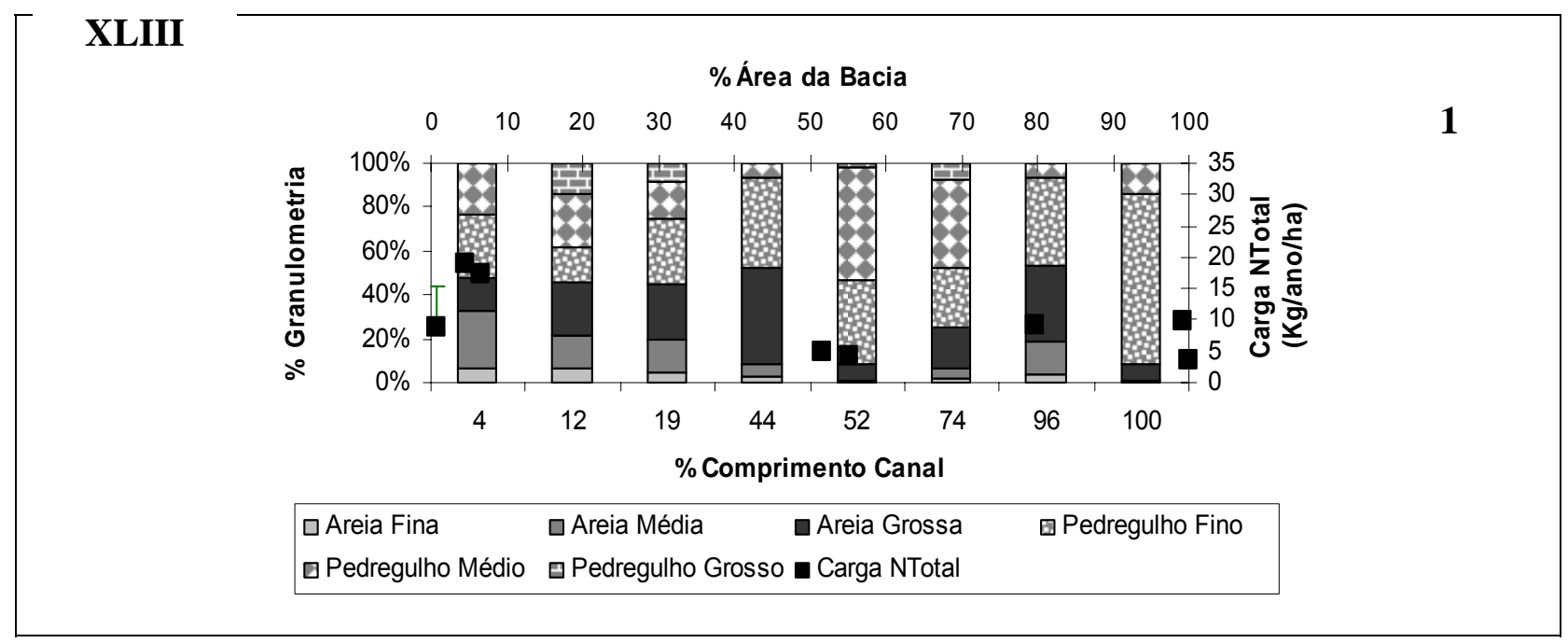



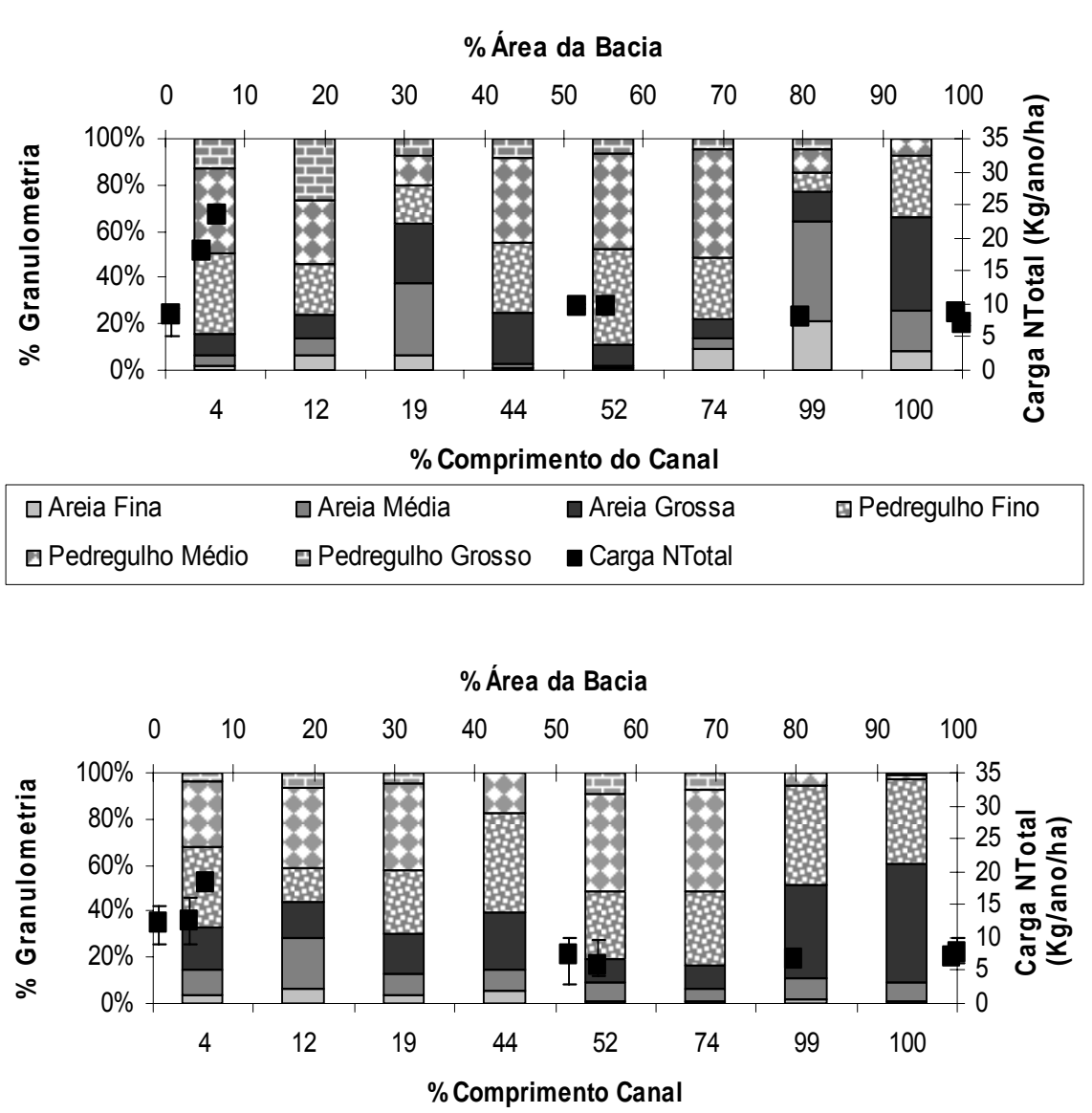

\begin{tabular}{|c|c|c|}
\hline$\square$ Areia Fina & $\square$ Areia Grossa & $\square$ Pedregulho Fino \\
\hline$\square$ Pedregulho Médio & ๑ Pedregulho Grosso $\square$ Cargas NTotal & \\
\hline
\end{tabular}

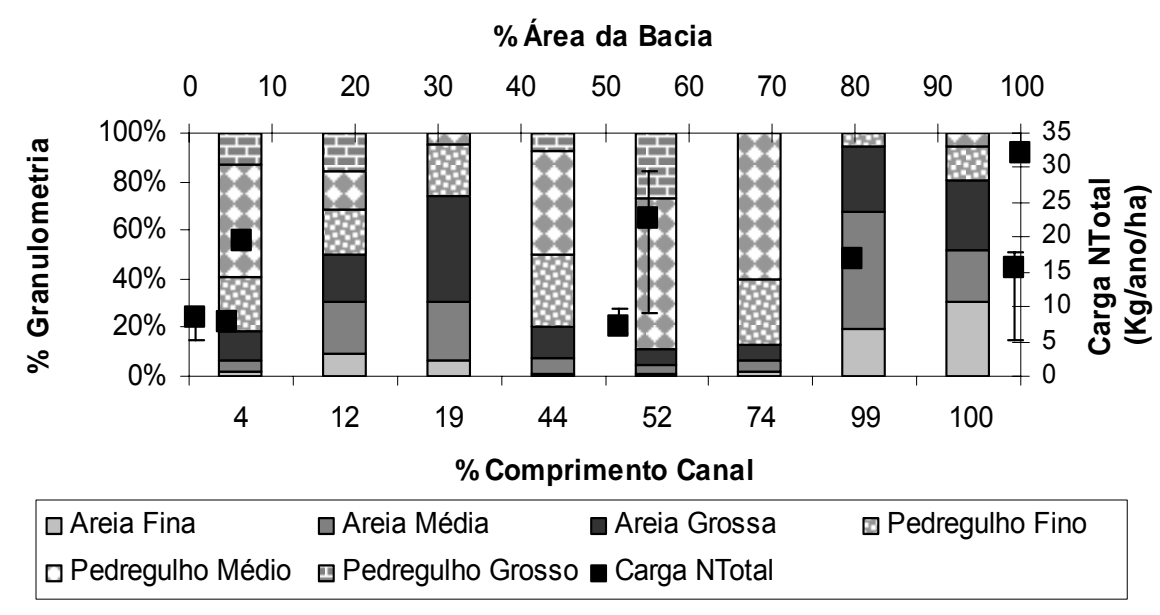

Figura XLIII: Variação da carga específica de Nitrogênio Total e composição do sedimento ao longo do eixo longitudinal do Rio Canha nas diferentes estações do ano ( 1 - primavera; 2 - verão; 3 - outono; 4 - inverno) 
É possível observar através da figura XLIII que há uma diminuição da fração de areia total entre os pontos amostrais 4 e 5 , durante todas as campanhas. Ainda em relação à fração de areia total, foi possível notar um aumento desta fração a partir do ponto amostral 7, em todas as campanhas, exceto na campanha 1, a qual apresentou baixa fração de areia na estação de coleta 8 .

As cargas de nitrogênio total apresentam uma diminuição de montante para jusante que se inicia no ponto de coleta 4 , sendo que apenas a campanha 4 apresenta diferença no padrão desse comportamento, com ligeiro aumento de cargas a partir do ponto amostral 5.

\subsubsection{Nitrogênio Orgânico}

\section{XLIV}
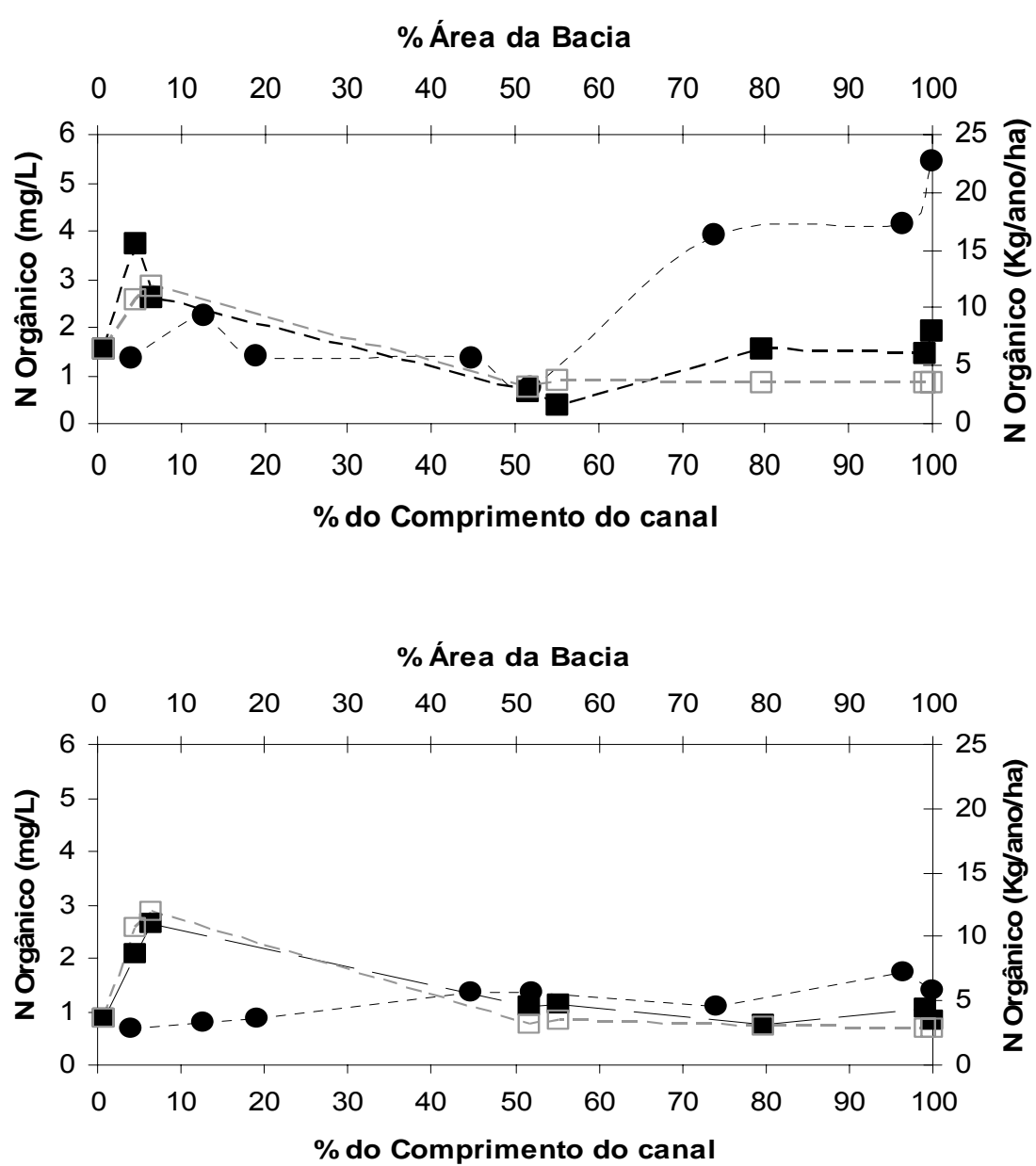

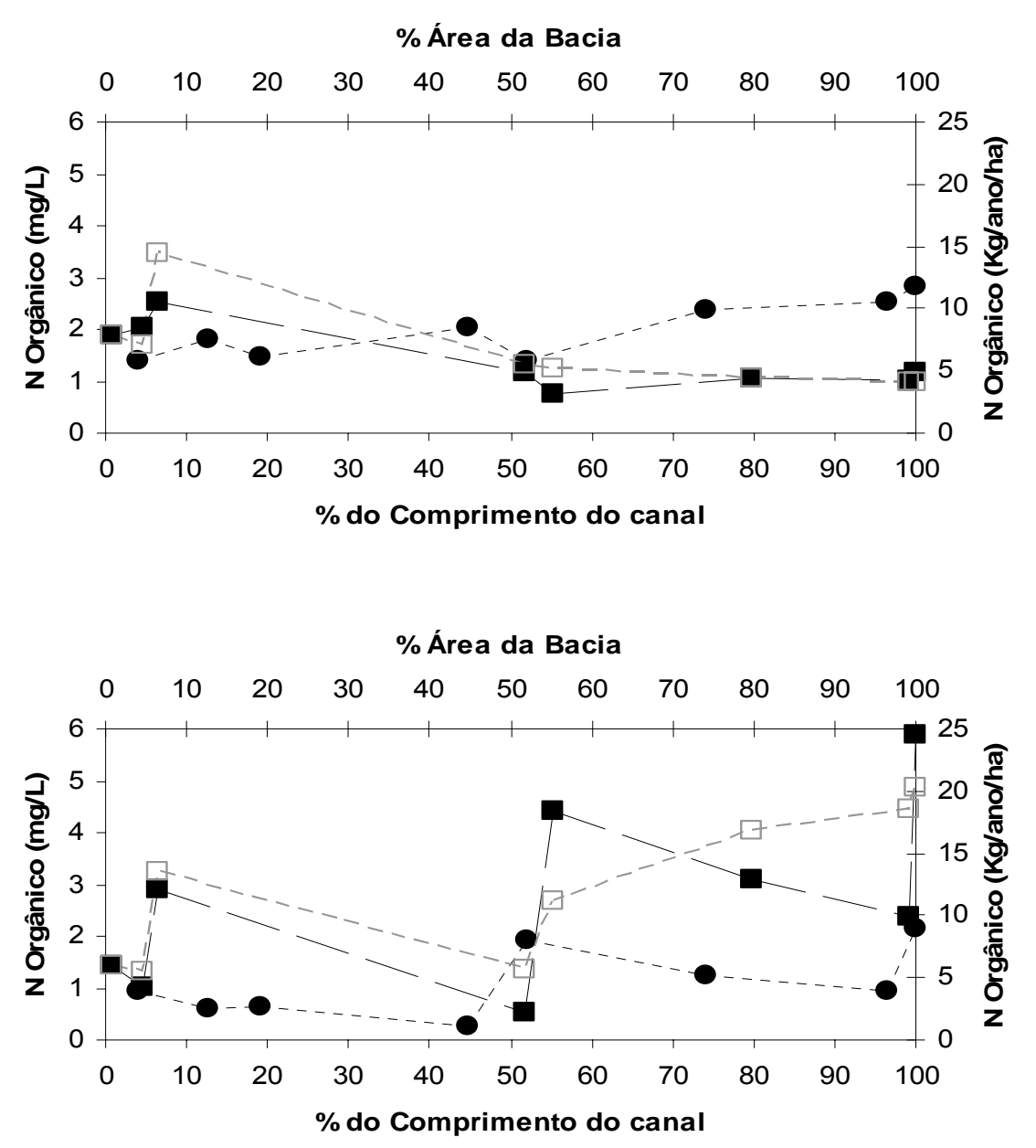

Figura XLIV: Variação de Nitrogênio Orgânico ao longo do eixo longitudinal do Rio Canha nas diferentes estações do ano (1 - primavera; 2 - verão; 3 - outono; 4 - inverno).Obs.: "•”: Concentração observada; “๓”: carga específica observada ; “ $\square$ ": carga específica simulada.

As maiores concentrações de nitrogênio orgânico foram registradas na campanha 1, com valores variando de $1,36 \mathrm{mg} / \mathrm{L}$ na nascente a $5,44 \mathrm{mg} / \mathrm{L}$ na foz. Em médio curso, mais precisamente no ponto amostral 5 a concentração desse composto teve uma queda, reduzindo-se para $0,75 \mathrm{mg} / \mathrm{L}$. A campanha referente ao período chuvoso (campanha 4) apresentou as menores concentrações de nitrogênio orgânico com variação de $0,94 \mathrm{mg} / \mathrm{L}$ na nascente e $2,15 \mathrm{mg} / \mathrm{L}$ na foz, esses valores apenas cresceram em direção à foz, assim como nas campanhas 2 e 3. Foi também na campanha 4 que observou-se a maior heterogeneidade espacial.

Em relação às cargas específicas de nitrogênio orgânico, em todas as campanhas, como era de se esperar, estas decaíram em direção à foz. As campanhas 2 e 3, de maneira geral, 
apresentaram cargas similares em valores, e registraram os menores valores. As maiores cargas foram obtidas na campanha 4, sendo que seu declínio em direção à foz foi menos acentuado em relação às demais campanhas. A maior carga foi registrada no ponto amostral 8 (24,45 $\mathrm{Kg} / \mathrm{ano} / \mathrm{ha})$ e a menor no ponto de coleta 4 (2,2 Kg/ano/ha).

\subsubsection{Nitrogênio Amoniacal}

XLV
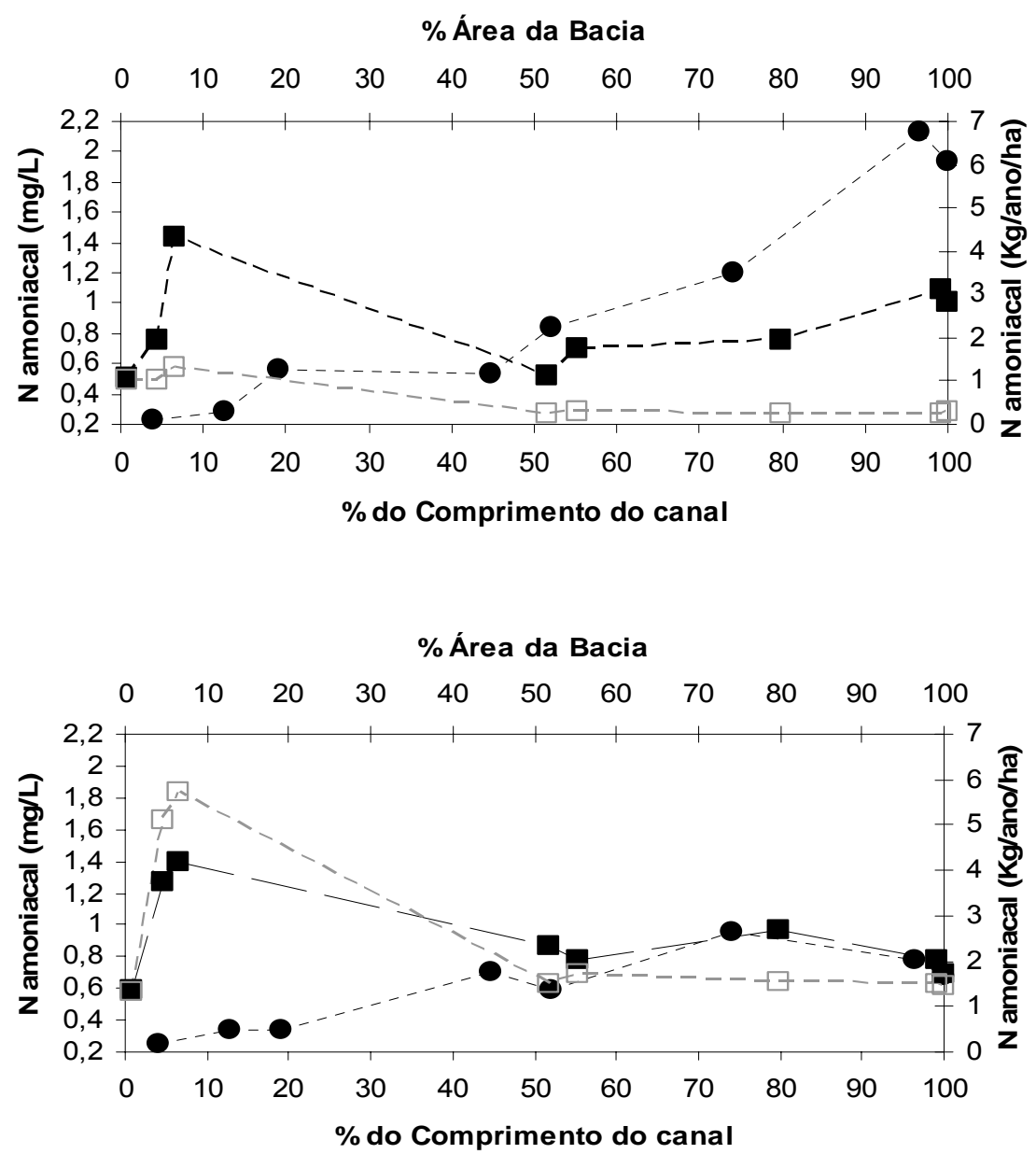

2 

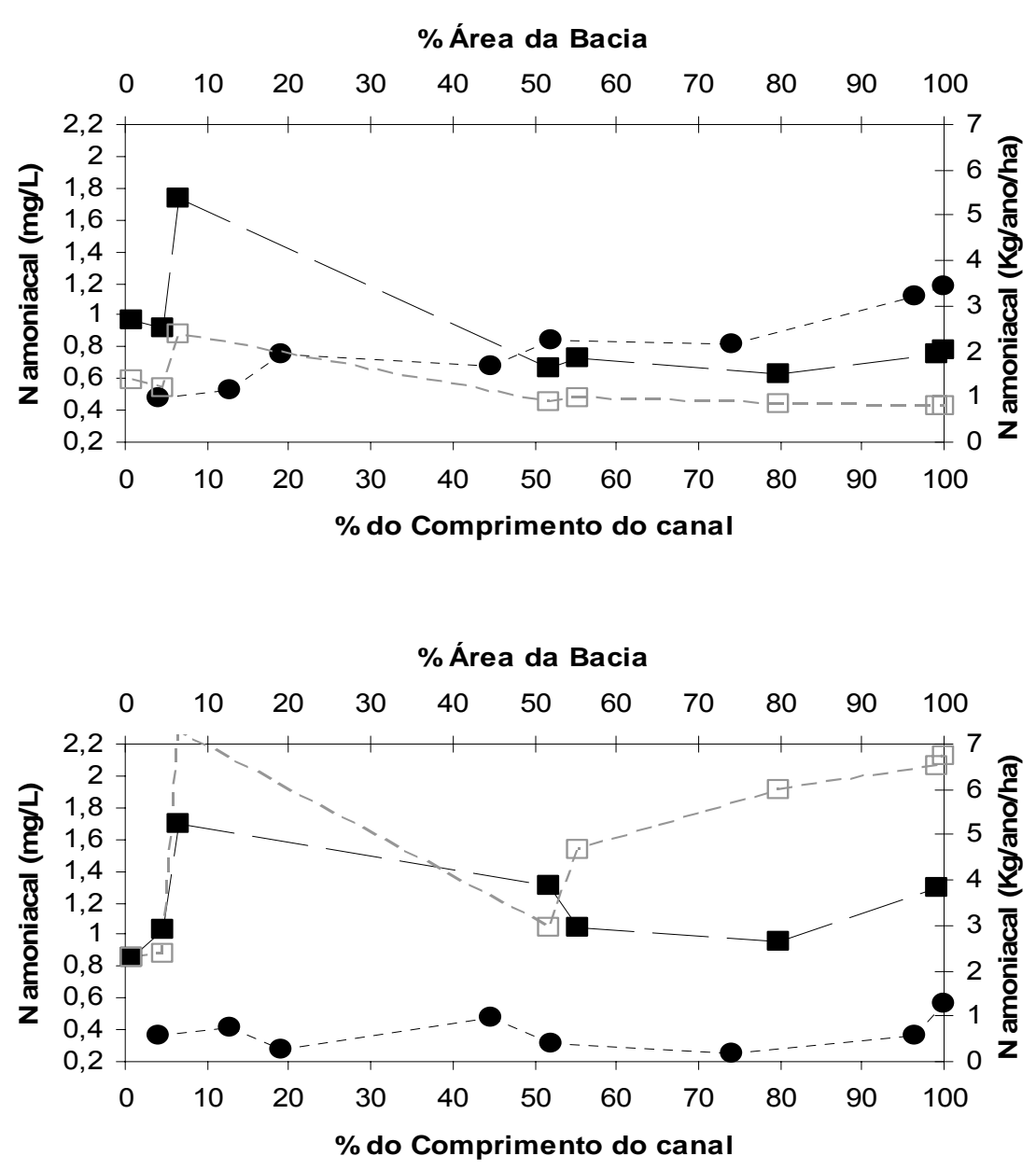

Figura XLV: Variação de Nitrogênio Amoniacal ao longo do eixo longitudinal do Rio Canha nas diferentes estações do ano (1 - primavera; 2 - verão; 3 - outono; 4 - inverno).Obs.: “•”: Concentração observada; "ø”: carga específica observada; “ " ": carga específica simulada.

Em todas as campanhas a concentração de nitrogênio amoniacal aumentou da nascente à foz, com maiores valores na campanha 1 e menores na campanha 4. A campanha 1 também apresentou maior heterogeneidade espacial em relação à concentração desse composto. Em relação às cargas específicas, em todas as campanhas houve uma diminuição nos valores de nitrogênio amoniacal da nascente à foz e as maiores cargas específicas de nitrogênio amoniacal foram obtidas na campanha 4.

Temporalmente os valores de nitrogênio amoniacal decaíram gradativamente da campanha 1 à 4,em termos de concentração e as cargas tiveram um aumento na campanha 4 . 


\subsubsection{Nitrito}

\section{XLVI}
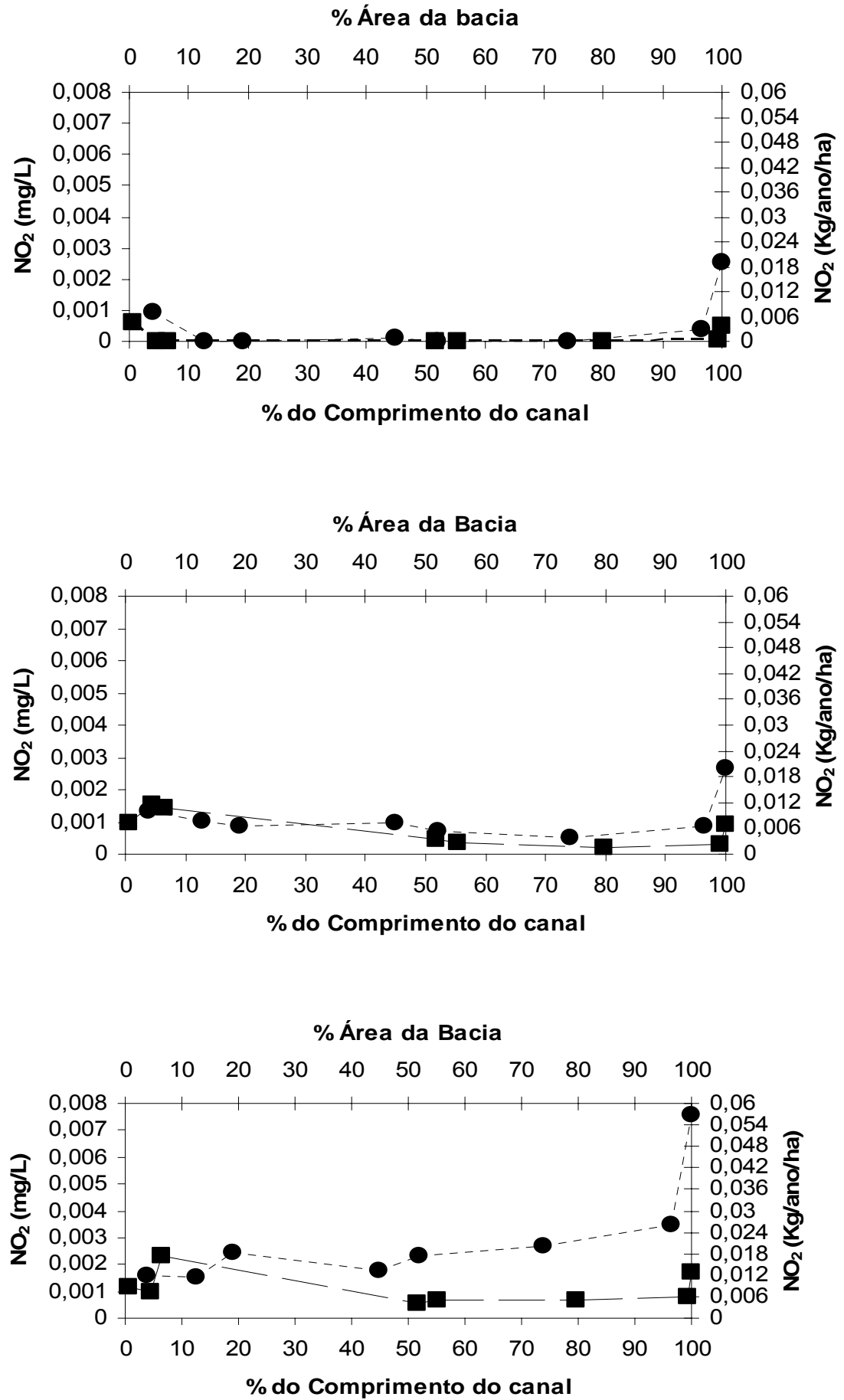


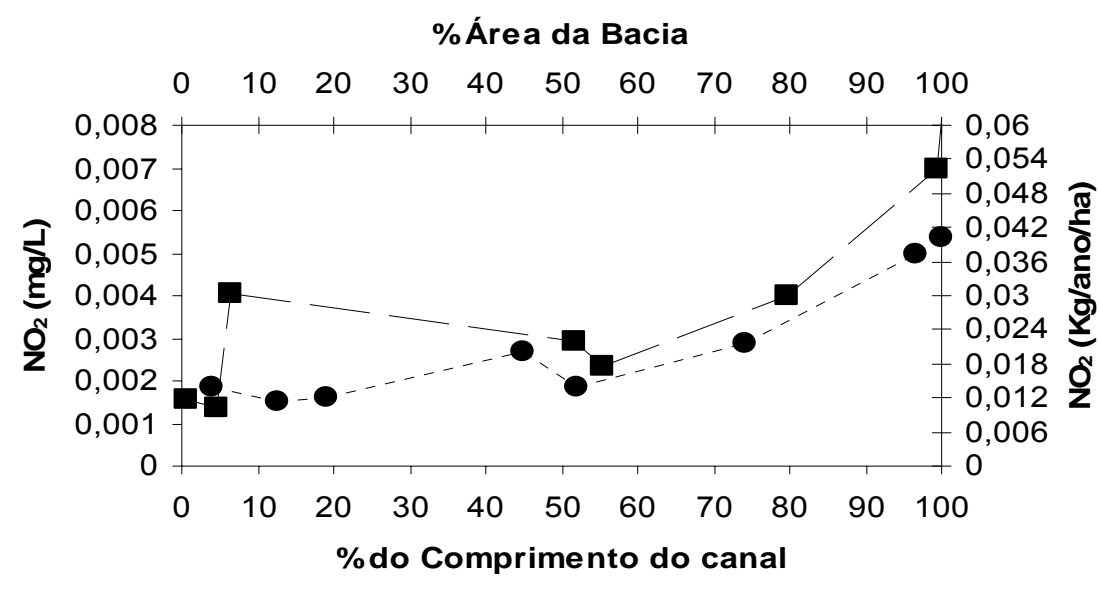

Figura XLVI: Variação de Nitrito ao longo do eixo longitudinal do Rio Canha nas diferentes estações do ano (1 primavera; 2 - verão; 3 - outono; 4 - inverno).Obs.: “•”: Concentração observada; "ø”: carga específica observada.

As concentrações de nitrito, nas quatro estações do ano, aumentaram da nascente à foz. A campanha 3 apresentou os maiores valores de concentração desse composto, variando de 0,0015 $\mathrm{mg} / \mathrm{L}$ na nascente a $0,0075 \mathrm{mg} / \mathrm{L}$ na foz. As menores concentrações foram registradas na campanha 1, na qual os pontos amostrais 3, 5 e 6 apresentaram $0 \mathrm{mg} / \mathrm{L}$. É possível notar através da figura XLVI um decaimento das concentrações de nitrito que ocorreram no médio curso do rio, durante todo o período de amostragem.

Em relação às cargas específicas, estas decaíram da nascente à foz em todas as campanhas, exceto na campanha 4, na qual as cargas aumentaram em direção à foz. Na campanha 4 também foram registradas as maiores cargas. 


\subsubsection{Nitrato}

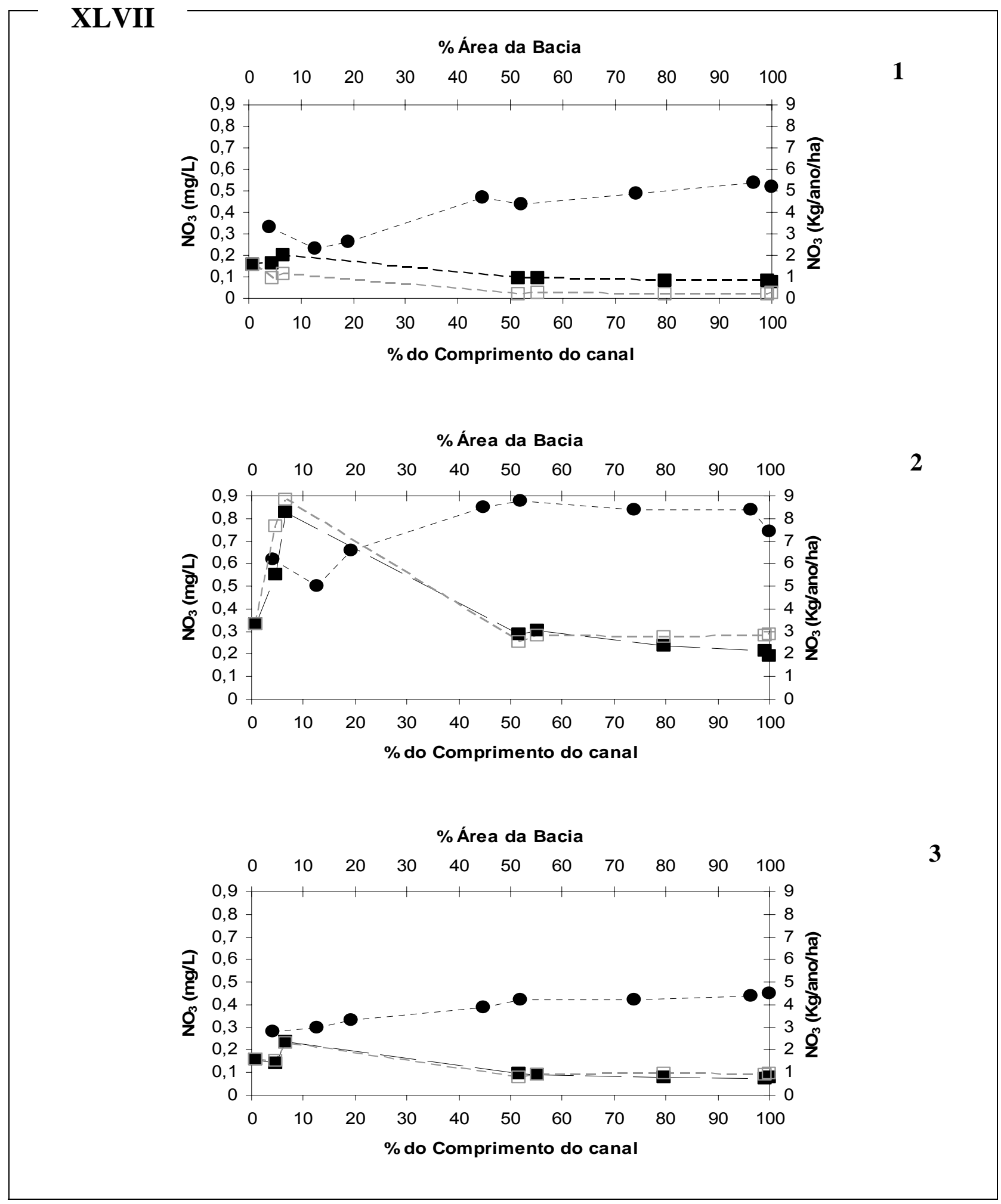




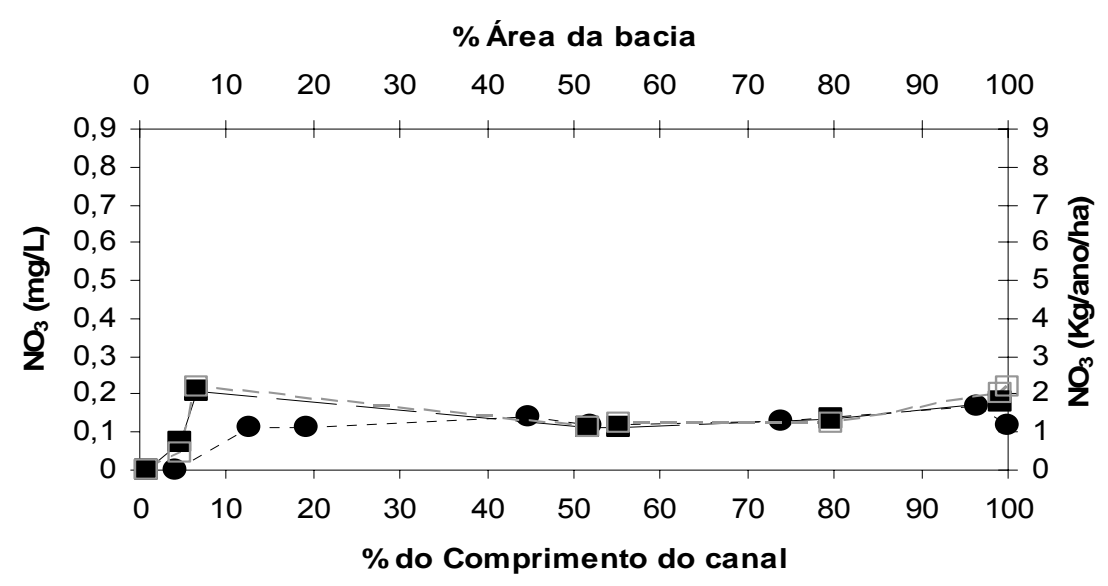

Figura XLVII: Variação de Nitrato ao longo do eixo longitudinal do Rio Canha nas diferentes estações do ano (1 primavera; 2 - verão; 3 - outono; 4 - inverno).Obs.: “•”: Concentração observada; “ø”: carga específica observada ; “口": carga específica simulada.

É possível verificar através da figura XLVII que a variação espacial do nitrato ocorreu de forma gradativa da nascente, onde registrou-se os menores valores de concentração, à foz. As menores concentrações de nitrato foram obtidas na nascente para todo o período de coleta, e na campanha 4 registrou-se valor $0 \mathrm{mg} / \mathrm{L}$ para nitrato nesse mesmo ponto de coleta. As seções amostrais próximas à foz apresentaram concentrações mais elevadas de nitrato, sendo que o valor máximo registrado em todo o período observado para esse ponto amostral foi de $0,74 \mathrm{mg} / \mathrm{L}$, na campanha 2. Ainda em relação à campanha 2, esta apresentou maior variabilidade espacial, com a maior concentração de nitrato no ponto de coleta $4(0,85 \mathrm{mg} / \mathrm{L})$. As maiores concentrações foram obtidas na campanha 2 (verão) e na campanha 1 (primavera).

Em termos de cargas específicas todas as campanhas apresentaram maiores valores na nascente, os quais decaíram em direção à foz, porém a campanha 4 apresentou cargas menores na nascente aumentando à jusante. As menores cargas foram registradas na campanha 1 seguida da campanha 3, já a campanha 2 apresentou as maiores cargas. 


\subsubsection{Fosfato Inorgânico}

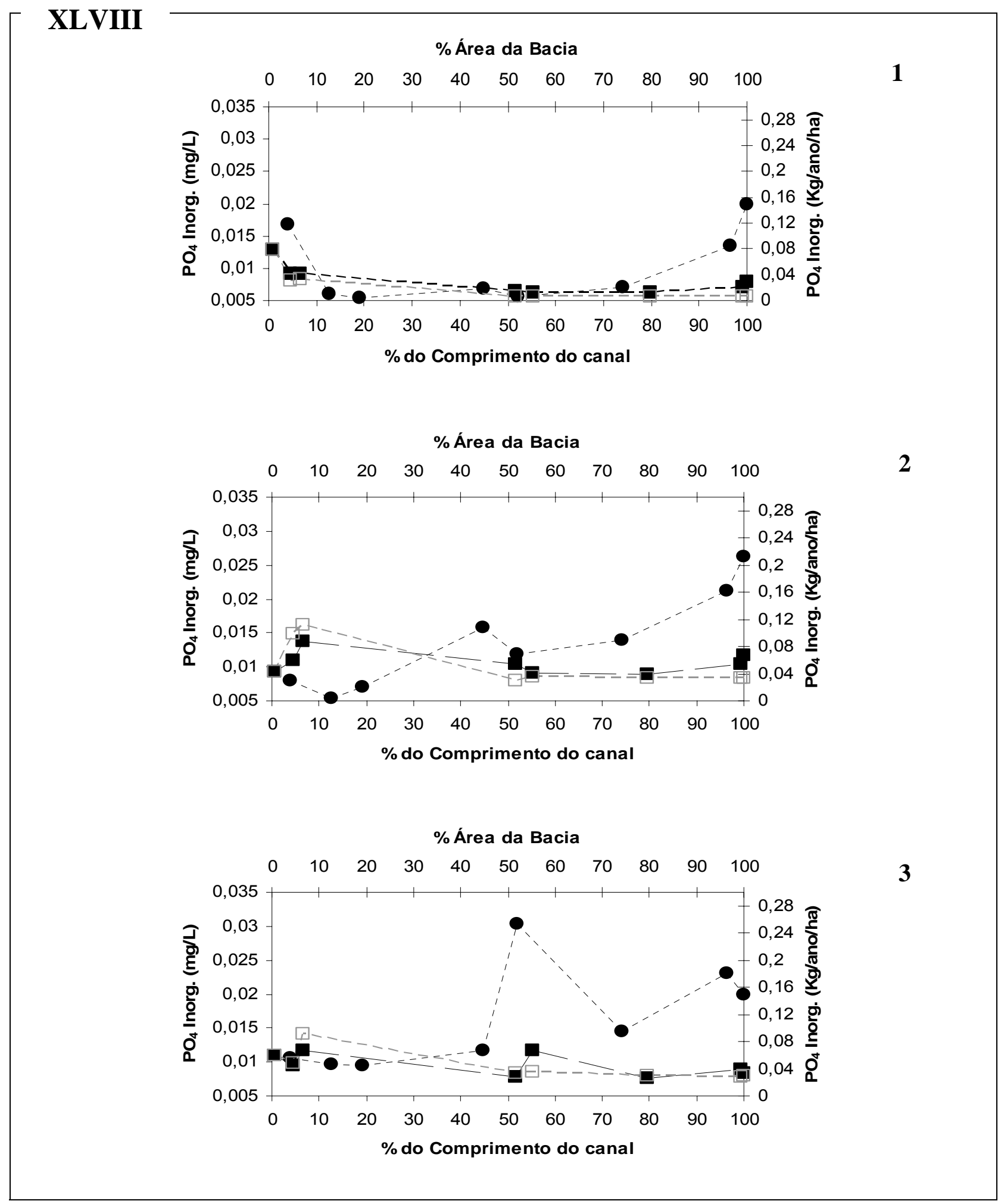




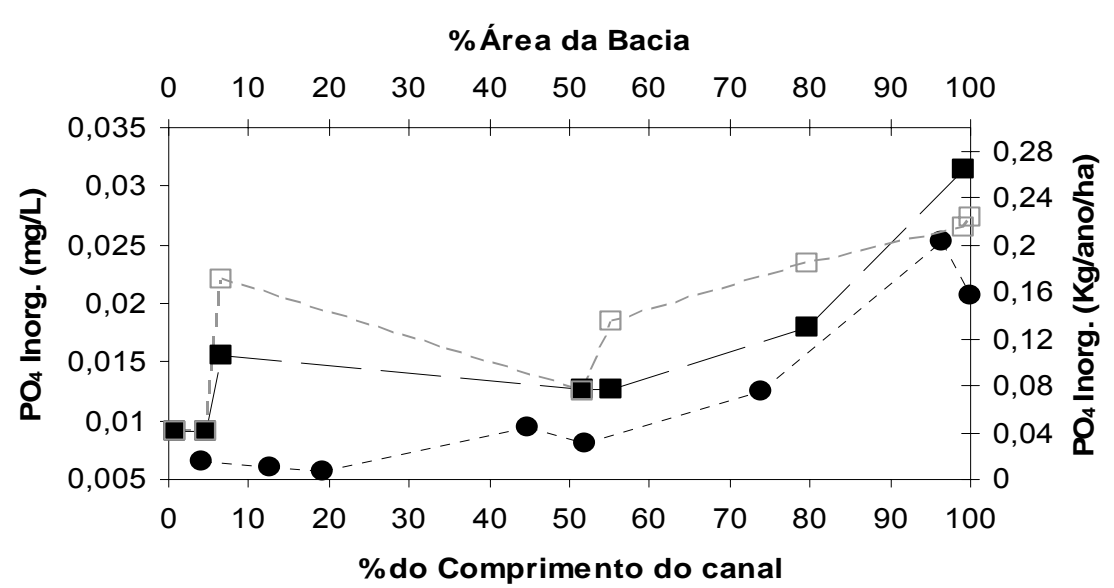

Figura XLVIII: Variação de Fosfato Inorgânico ao longo do eixo longitudinal do Rio Canha nas diferentes estações do ano (1 - primavera; 2 - verão; 3 - outono; 4 - inverno).Obs.: “•”: Concentração observada; "ø”: carga específica observada ; “ 口”: carga específica simulada.

Longitudinalmente as concentrações de fosfato seguiram a tendência de aumentar de montante para jusante. A campanha 1 apresentou uma queda nas concentrações desse composto na parte de médio curso do rio, já a campanha 3 apresentou um pico na mesma região. A campanha 3 registrou os maiores valores de concentração e os menores valores foram obtidos na campanha 1.

As cargas específicas de fosfato inorgânico tiveram um decréscimo da nascente à foz, exceto para a campanha 4, onde os maiores valores de carga foram registrados na foz (ponto 7 $0,26 \mathrm{Kg} / \mathrm{ano} / \mathrm{ha}$ ). As menores cargas desse composto foram observadas nas campanhas 1 seguida da 2 . 


\section{DISCUSSÃO}

Os processos que ocorrem numa bacia hidrográfica estão intimamente relacionados à sua geomorfologia, a velocidade de escoamento, por exemplo, possui relação direta com o tipo de formação da bacia, determinando o tipo de escoamento e o tempo de residência das partículas e, portanto as reações que ali ocorrem. Para rios sem interferência antrópica espera-se que a velocidade diminua gradativamente em direção à foz, enquanto que a vazão aumente proporcionalmente (VANNOTE, 1980).

A velocidade de escoamento e a vazão no rio Canha comportaram-se, longitudinalmente, obedecendo à teoria do Continuum Fluvial proposta pelo autor supracitado. Temporalmente essas variáveis seguiram os padrões de precipitação, apresentando um rápido escoamento da água, devido principalmente à alta declividade dos pontos próximos à nascente. Além disso, a ausência de fontes pontuais de poluição ao longo do Rio Canha sugere uma continuidade das variáveis altura da água, velocidade de escoamento e vazão.

Bunn et al. (2002) ressaltam que a alteração do regime de chuvas e conseqüente diminuição da vazão são tidos como contínua ameaça para a sustentabilidade dos recursos hídricos, influenciando a ecologia dos rios de acordo com a formação física de habitats, perda de espécies, manutenção da conectividade lateral do rio com sua respectiva área de várzea e finalmente alterações dos processos biológicos que ocorrem em um corpo d'água. O rio Canha, particularmente no período de coleta, apresentou uma alteração no regime de chuvas, que deveria ter tido seu pico na campanha 2, entretanto, a tabela 6 deixa evidente que o maior índice de precipitação, com antecedência de 7 dias das campanhas, foi registrado na campanha 4.

Richter et al. (1997) enfatizam que as componentes hidrológicas, tais como duração, tempo e freqüência são essenciais para conservação dos rios e manutenção da biota aquática nativa, bem como funções dos ecossistemas aquáticos. Deste modo, os autores propõem a utilização de modelos que têm como ponto de partida o registro de vazões durante um período em que as ações antrópicas foram negligenciáveis assim, as variações dos parâmetros podem ser justificadas pela interferência humana, propondo guias de gerenciamento e estratégias adaptativas. Nos trabalhos de Petts (et al.1995) e Brookes (1995) ficaram evidentes as alterações causadas nos ecossistemas aquáticos com a alteração do regime de chuvas, seja esta para mais ou para menos. 
O modelo QUAL2K não utiliza a precipitação como um dado de entrada, porém as variáveis hidráulico-hidrológicas possuem forte correlação, sendo possível obter variações da vazão e altura da água para cada período do ano através da calibração.

De acordo com Poff et al. (1997) a integridade ecológica de um rio depende de sua dinâmica natural e o regime natural de chuvas influencia fortemente a qualidade das águas, fontes de energia, habitat físico e interações do ecossistema aquático. A tabela a seguir apresenta as conseqüências das alterações nos sistemas hídricos e as conseqüentes respostas dos mesmos (Poff et al. 1997): 
Tabela 8: Alterações antrópicas dos sistemas fluviais, conseqüente mudança no regime hidrológico e a respectiva resposta do sistema.

\begin{tabular}{|c|c|c|}
\hline Alterações & Mudança Hidrológica & Resposta \\
\hline Represamento & $\begin{array}{l}\text { Movimento de sedimentos a } \\
\text { jusante; redução da magnitude } \\
\text { e freqüência das chuvas. }\end{array}$ & $\begin{array}{c}\text { Erosão do } \\
\text { canal/assoreamento; formação } \\
\text { de ilhas e canais secundários. }\end{array}$ \\
\hline $\begin{array}{l}\text { Urbanização, drenagem e } \\
\text { retificação }\end{array}$ & $\begin{array}{l}\text { Aumento da magnitude e } \\
\text { freqüência de chuvas; redução } \\
\text { da infiltração no solo. }\end{array}$ & $\begin{array}{l}\text { Alargamento do canal; erosão; } \\
\text { desconexão rio/planície }\end{array}$ \\
\hline $\begin{array}{l}\text { Canalização, bombeamento de } \\
\text { água subterrânea. }\end{array}$ & $\begin{array}{c}\text { Redução das chuvas e da } \\
\text { infiltração; redução do nível } \\
\text { superficial da água }\end{array}$ & $\begin{array}{l}\text { Erosão do rio e da planície de } \\
\text { inundação; desconexão do } \\
\text { rio/planície; redução da } \\
\text { migração do canal e formação } \\
\text { de canais secundários. }\end{array}$ \\
\hline $\begin{array}{l}\text { Alteração dos componentes } \\
\text { magnitude e freqüência. }\end{array}$ & $\begin{array}{l}\text { Aumento da variação das } \\
\text { chuvas e variação da vazão. }\end{array}$ & $\begin{array}{l}\text { Alteração do nível da água, } \\
\text { aumento de algas e matéria } \\
\text { orgânica, alteração do ciclo de } \\
\text { vida e perda de espécies, } \\
\text { alteração no fluxo de energia, } \\
\text { estabelecimento de espécies } \\
\text { exóticas, empobrecimento da } \\
\text { planície de inundação. }\end{array}$ \\
\hline Alteração temporal & Perda de picos sazonais & $\begin{array}{l}\text { Alteração do ciclo de } \\
\text { reprodução das espécies, } \\
\text { alteração da estrutura da } \\
\text { cadeia alimentar, morte da } \\
\text { flora e fauna, migração. }\end{array}$ \\
\hline $\begin{array}{c}\text { Alteração da duração das } \\
\text { chuvas }\end{array}$ & $\begin{array}{c}\text { Estiagem prolongada/ cheia } \\
\text { prolongada e alteração da } \\
\text { duração das cheias }\end{array}$ & $\begin{array}{l}\text { Redução/eliminação da } \\
\text { cobertura vegetal, redução da } \\
\text { diversidade de espécies, } \\
\text { aumento da concentração de } \\
\text { compostos tóxicos; perda de } \\
\text { habitat. }\end{array}$ \\
\hline Taxa de mudança & $\begin{array}{c}\text { Mudanças rápidas no estágio } \\
\text { do rio/ recessão de cheia } \\
\text { acelerada }\end{array}$ & Perda de espécies \\
\hline
\end{tabular}

Fonte: Adaptado de Poff et al. (1997).

No decorrer das campanhas foi possível notar que o rio Canha apesar de possuir nascente preservada com mata ciliar, em alguns pontos de coleta, como o ponto 4 por exemplo, sofreram algumas modificações devido à interferência humana, dentre as quais constatou-se escavação do leito do rio, que acarretou na formação de um banco de areia próximo à margem, além da evidente falta da cobertura vegetal original que persiste até a foz do rio. Tais alterações podem 
aumentar a velocidade de escoamento em determinados pontos, ou como constatou-se no ponto amostral 5, um aumento da profundidade do rio, devido à formação de remansos, os quais associou-se à atividades de lazer, uma vez que foi observada a utilização da ponte, localizada sobre o rio, por moradores da região para prática de natação.

A figura XXVI nos revela a formação de uma região com velocidade praticamente constante nas três primeiras campanhas, este fato pode estar relacionado com a formação dos remansos citados anteriormente, e inclusive devido à pequena represa presente no rio, utilizada para captação de água. É indispensável citar que nenhuma medição, tanto das variáveis hidráulico-hidrológicas, como das limnológicas foram realizadas na represa devido à impossibilidade de adentrar o local, já que este permanecia fechado com cadeados.

O número de Froude ( $\mathrm{Fr}$ ) permite classificar os escoamentos em lêntico ou lótico, assim para Froudes maiores do que 1, diz-se que o escoamento é supercrítico ou turbulento, já para Fr menores que 1 , o escoamento é subcrítico ou lento.

A partir do número de Froude, os engenheiros e mais atualmente os biólogos, passaram a analisar os habitats aquáticos segundo características hidráulicas do canal em estudo. Deste modo, Danehy e Hasset (1996) sugerem que a distribuição e tamanho de algumas espécies estão diretamente relacionadas com o número de Froude e consequentemente com o tipo de escoamento que pode variar em cada seção transversal ao longo do leito do rio (número de Reynolds).

O rio Canha, de uma maneira geral, pode ser classificado como um rio de escoamento turbulento, apresentando corredeiras na maioria dos pontos amostrais, sendo possível, através do número de Froude, considerá-lo com um escoamento supercrítico. O número de Reynolds, apresentado na tabela 7, também indica essa classificação. Tal fato pode ser justificado pela pelo fato do rio Canha ser um rio de cabeceira, com alta declividade em seus pontos próximos à nascente, que se localizam na serra de Pariquera-Açú. Apesar disso, alguns pontos amostrais, localizados em médio curso, apresentam remansos e pequenas áreas alagadiças, sugerindo segundo Buffagni (et al. 2000) a presença de habitas funcionais e pontos de ciclagem de matéria.

$\mathrm{O}$ conceito de habitats funcionais é descrito pelo autor (op cit.) como unidades distintas, reconhecíveis e classificáveis com base nos atributos físicos e químicos de um rio. Este conceito é mais aplicável à comunidades e em rios onde há ocorrência de mudanças abruptas, causando modificação nas condições hidráulicas e composição do substrato. 
O número de trabalhos que reconhece a importância da integração ecologia - hidráulica fluvial - geomorfologia é pequeno e a efetividade com que tem se abordado temas relacionados à habitat é pequena, já que esta depende fortemente de uma abordagem que leve em consideração a formação de hábitats sobrepostos em curso hídrico com diferentes comunidades desempenhando diferentes papéis (BUFFAGNI et al. 2000). A associação de dados qualitativos com dados quantitativos, mais especificamente com dados hidráulicos, nesse caso o número de Froude, sugere mesmo que indiretamente a formação de hábitats funcionais (HARPER et al. 2000).

O número de Froude surge como uma alternativa para classificação de hábitats, já que ele pode ser obtido para as distintas seções transversais de um curso d'água, uma vez que leva em consideração a relação velocidade/profundidade. Embora sua utilidade ecológica tenha sido justificada por sua relação com a densidade de espécies de alguns macroinvertebrados bentônicos, Buffagni (et al. 2000) cita que permanece incerto se o Fr poderia ser utilizado para caracterizar, em termos de hábitat, um ambiente extenso. Com base nessas afirmações, o rio Canha, que comparado os demais rios da região, apresenta-se relativamente bem preservado e com poucas interferências antrópicas, poderia ser objeto de estudo mais detalhado em relação à sua macrofauna e características hidráulicas. Ferraz (2008), em estudo realizado com a comunidade bentônica do rio Canha, comenta que a variação espacial da mesma se deve principalmente à interferências antrópicas, tipo de substrato e características geomorfológicas do sistema, denotando assim, a importância e estudos que integrem ecologia - hidrologia hidráulica.

O monitoramento das variáveis limnológicas constitui-se numa ferramenta muito importante para o manejo da qualidade dos recursos hídricos, uma vez que a variação das mesmas pode ser analisada espacial e temporalmente, permitindo uma avaliação das condições de determinado corpo d'água (CALIJURI e BUBEL, 2006).

Galbraith e Burns (2007) relatam que o tamanho da bacia, sua declividade, bem como a hidrologia e o tipo de uso e ocupação do solo desempenham um papel fundamental na qualidade da água. Assim o presente trabalho, objetiva integrar a limnologia, a hidrologia e a hidráulica para caracterização dos processos que ocorrem no rio Canha.

Segundo Zalewski \& Robarts (2003) á água doce está se tornando um recurso escasso em escala global, portanto é necessário que haja uma visão mais abrangente no que diz respeito aos 
problemas ambientais, a qual deve envolver programas interdisciplinares que integrem a limnologia e a hidrologia.

A discussão da presente pesquisa pautou-se numa nova abordagem que vem surgindo por meio da integração de pesquisadores que procuravam soluções de problemas ambientais, mais especificamente relacionados à disponibilidade e qualidade das águas - a ecohidrologia. Como resultado dessa integração três princípios foram formulados visando fornecer um escopo de trabalho, um objetivo e uma metodologia para a ecohidrologia (ZALEWSKI \& ROBARTS, 2003):

- Princípio hidrológico: Integração da paisagem, hidrologia e biota como entidade única;

- Princípio ecológico: Comportamento evolutivo da estabilidade do ecossistema submetido a stress, utilizando o entendimento entre hidrologia e biota;

- Princípio ecotecnológico: Uso das propriedades do ecossistema como uma ferramenta de gerenciamento dos processos que controlam a dinâmica do sistema e a hidrologia.

Assim, o presente trabalho utilizou tais princípios incorporando-os às teorias ecológicas dos sistemas fluviais para explicar os processos que ocorreram tanto espacialmente como temporalmente no rio Canha.

Por influenciar as reações que ocorrem no corpo d'água, bem como a disponibilidade de oxigênio na água, a temperatura torna-se um parâmetro muito importante a ser estudado. De acordo com a teoria do Continuum Fluvial proposta por Vannote et al. (1980), a temperatura da água é menor nas cabeceiras, as quais são alimentadas por águas subterrâneas e na maioria das vezes coberta por vegetação. Porém, em córregos menores, a heterogeneidade espacial desta variável é maior, pois o pequeno volume de água responde mais rapidamente às mudanças de temperatura do meio circundante. O rio Canha, quando comparado com os demais rios presentes na região, assume pequeno porte, ficando mais suscetível à variações longitudinais de temperatura, além disso, como sua nascente é bem preservada, a temperatura nesse ponto é sempre menor, em todas as estações do ano. O gradiente longitudinal da temperatura no rio Canha possivelmente está correlacionado à presença de mata ciliar na nascente, a qual vai desaparecendo gradativamente desde o ponto de coleta 2 até o ponto de coleta 8 , próximo à foz do rio, já a heterogeneidade temporal, justifica-se pela própria sazonalidade.

A solubilidade do oxigênio aumenta com o declínio da temperatura, assim a concentração desse gás está intimamente relacionada com a variação da temperatura e da pressão atmosférica 
(MARGALEF, 1983). A maior concentração de oxigênio dissolvido foi obtida no mês relativo ao inverno (campanha 4), no qual a temperatura apresentou-se mais baixa. Assim, o mês que apresentou menores valores de temperatura, apresentou consequentemente maiores valores de oxigênio dissolvido, e os menores valores de OD foram registrados no mês de maior temperatura (campanha 2 - janeiro).

Os valores de OD do rio Surma, Bangladesh, foram menores no período seco, devido à alta concentração de matéria orgânica nesse período e à baixa vazão associada (ALAM et al. 2007). O rio Canha apresentou precipitação relativamente baixa para o que é realmente esperado para o período relativo à campanha 2, deste modo o mesmo pode ser considerado como seco, corroborando com os dado obtidos para o rio Surma.

Em todas as campanhas, as menores concentrações de oxigênio dissolvido foram obtidas na nascente, fato que pode estar correlacionado com a presença da mata ciliar, a qual favorece reações oxidativas, diminuindo a concentração desse gás. Em médio curso, as concentrações tiveram um aumento, provavelmente devido à declividade, turbulência e pouca profundidade do rio Canha. Já os pontos próximos à foz apresentaram um declínio nos valores de oxigênio, devido possivelmente à maior profundidade do local, menor declividade e influência do processo de urbanização. Campolo et al. (2002) citam que no rio Arno, Itália, as concentrações de oxigênio são maiores nas partes altas e que com o aumento da profundidade a concentração desse gás tende a diminuir.

Já no Rio Bangpakong, Tailândia, foi observada uma heterogeneidade temporal em relação à concentração de oxigênio dissolvido, sendo que os maiores valores foram obtidos na estação chuvosa, (Bordalo et al. 2001), assim como no rio Canha.

Todas as estações amostrais, em todas as campanhas, mantiveram os limites estabelecidos de acordo com o enquadramento dos corpos d'água pelos usos preponderantes (CONAMA 357/05 - BRASIL, 2005), que é de 5mg/L.

Em relação à simulação, o modelo QUAL2K respondeu bem às variações de oxigênio ao longo do eixo longitudinal do Rio Canha, uma vez que os dados hidráulicos foram bem calibrados e estes influenciam fortemente as concentrações simuladas de OD. Através das observações das equações apresentadas no manual do modelo QUAL2K foi possível perceber que há um consumo de oxigênio pela DBO considerada lenta, entretanto no balanço de oxigênio dissolvido tal consumo não é indicado. Contudo não é possível saber se este é apenas um erro no 
manual ou se realmente o balanço de oxigênio dissolvido do QUAL2K tem uma falha, já que este modelo é do tipo caixa preta. Outra importante notação a ser feita é que as equações utilizadas para a reaeração foram obtidas a partir de estudos feitos em rios temperados, assim o $\mathrm{K}_{2}$ empregado no modelo é para ambientes totalmente diferentes dos situados em clima tropical.

A estação chuvosa (campanha 4) caracterizou-se por apresentar as maiores concentrações de DBO, já a campanha 3 registrou os menores valores. Tal fato pode estar relacionado ao escoamento superficial que propicia a entrada de diversas substâncias para o leito do rio, e como o Rio Canha possui seu entorno bastante modificado por atividades de agropecuária e agricultura, o aumento da precipitação pode ter lixiviado maior quantidade de matéria orgânica para dentro do corpo d'água.

Jonnalagadda \& Mhere (2001) encontraram no rio Odzi, Zimbabwe, menores concentrações de DBO na estação seca e maiores na chuvosa. Enquanto Benassi (2002) encontrou maiores valores de DBO na no período de seca apenas nas estações localizadas após a entrada de efluentes, associando tal fato à baixa capacidade de depuração de compostos no período seco.

Alam et al. (2007) também encontraram os maiores valores de DBO no período seco, justificando esse resultado pela baixa vazão do rio Suma, Bangladesh, além da entrada pontual de poluição e modificação da paisagem da bacia por interferência humana.

Kotti et al. (2005) estudando três rios no noroeste da Grécia tentaram estabelecer uma relação entre a qualidade das águas dos mesmos. Os autores concluíram, em relação à DBO, que a concentração da mesma é baixa, ficando abaixo dos padrões permitidos na Grécia. Além disso, relataram que tal resultado pode ser atribuído à presença de matéria orgânica complexa, difícil de ser degradada em cinco dias.

Dunette \& O'Brien $^{2}$ (1992) apud Kotti (et al. 2005) e Petts \& Eduljie ${ }^{3}$ (1994) apud Kotti (et al. 2005) classificam os rios, de acordo com a concentração de DBO, da seguinte maneira: classe 1, considera-se a água de boa qualidade, com valores de DBO abaixo de $3 \mathrm{mg} / \mathrm{L}$; classe 2 , água considerada com qualidade satisfatória; classe 3 , água de qualidade pobre; classe 4 , água de má qualidade, com valores de DBO acima de $12 \mathrm{mg} / \mathrm{L}$.

\footnotetext{
${ }^{2}$ Duntte, D.A.; O’Brien, R.J. (1992). The science of global change: The impacto f human activies on the environment, ACS.

${ }^{3}$ Petts, G.; Eduljie, G. (1994). Environmental impacto f assessment for waste treatment and disposal facilities. Wiley Interscience, New York.
} 
A água do Rio Canha, segundo a classificação acima, pode ser considerada entre boa e satisfatória. De acordo com a resolução CONAMA 357/05, os corpos d'água classe 2, como no caso do Rio Canha, devem apresentar DBO até $5 \mathrm{mg} / \mathrm{L}$, padrão que foi atendido em todas as campanhas.

Como era de se esperar as cargas específicas de DBO diminuíram em direção à foz do Rio Canha, devido ao aumento da área de contribuição acumulada. A maior carga específica foi observada na campanha 4 , de acordo com as altas vazões do período.

O modelo QUAL2K separa a DBO em dois tipos: rápida e lenta. A DBO rápida é aquela frequentemente utilizada e comumente conhecida como $\mathrm{DBO}_{5}$, já a $\mathrm{DBO}$ lenta não foi muito bem caracterizada no manual do modelo, sendo possível entender apenas que esta está relacionada à compostos de carbono difíceis de serem degradados, e tal degradação seria feita por microorganismos que liberam exoenzimas no meio. Assim esse processo não deveria ser chamado de DBO e sim de hidrólise, uma vez que esses microorganismos não consomem oxigênio para liberação das exoenzimas.

No rio Canha, a variação espacial dos sólidos suspensos totais deu-se de montante à jusante em todas as estações do ano, fato que pode estar correlacionado com a degradação da mata ciliar, aumento da agricultura e urbanização. Prado (1999) relata que o aumento das atividades antrópicas no entorno de um curso d'água refletem a variação de sólidos presentes na água.

As maiores concentrações de SST foram obtidas na campanha 4, período chuvoso. Moccellin encontrou, para o rio Jacupiranguinha - Baixo Ribeira de Iguape,SP, maior concentração de SST também no período chuvoso, atribuindo tal ocorrência à lixiviação do solo. O trabalho realizado por Bordalo (et al. 2001) no rio Bangpakong, Tailândia, também registrou as maiores concentrações dessa variável no período de precipitações mais intensas.

Já Alam (et al. 2007) citam que a maior concentração de SST no rio Surma, Bangladesh, foi obtida na época de seca, atribuindo isso à maior capacidade de assimilação dos corpos d'água no período chuvoso.

As cargas específicas de todo o período estudado diminuíram em direção à foz, exceto na campanha 4, na qual esse valor manteve-se elevado nos pontos amostrais próximo à foz. Esse resultado pode ser atribuído às altas concentrações de SST associadas às altas vazões, que mesmo uma área de contribuição grande manteve esse valor elevado. 
Os sólidos suspensos orgânicos não apresentaram um padrão definido, sendo que as menores concentrações das campanhas 1 e 4 foram registradas na nascente, aumentando em direção à foz, já nas campanhas 2 e 3 observou-se uma diminuição de SSO em direção à foz. As cargas em todos os períodos estudados decresceram de montante à jusante, exceto na campanha 4.

Durante todas as campanhas houve um predomínio dos sólidos inorgânicos sobre os orgânicos, denotando a contribuição de fatores naturais, como intemperismo das rochas e fatores relacionados às atividades humanas, como erosão e lixiviação do solo.

A maior variação longitudinal, tanto da carga como da concentração de sólidos inorgânicos suspensos foi observada na campanha 4, caracterizada como chuvosa. Esse fato pode estar correlacionado com o uso e ocupação do solo, pois a nascente, bem preservada, apresenta os menores valores dessa variável, ou seja, a mata ciliar pode atuar como um filtro impedindo tais partículas de adentrarem o corpo d'água. Nos trechos de jusante caracterizados por agricultura intensa e urbanização, o carreamento de partículas para dentro da água é favorecido devido à erosão das margens.

A variação temporal da carga de sólidos suspensos inorgânicos pode estar relacionada com fatores naturais, como intemperismo das rochas no período chuvoso, como também à erosão do solo e precipitação de partículas devido às baixas vazões. Souza e Tundisi (2003) relatam que quanto maior a riqueza do solo; menor quantidade de mata ciliar e maior influência antrópica, a quantidade de sólidos inorgânicos tende a aumentar.

A simulação de sólidos suspensos inorgânicos teve pequena variação quando comparado com os dados observados dessa variável. A divisão da bacia em trechos e o alargamento do canal a partir de médio curso podem favorecer tais diferenças, no entanto todas elas se mantiveram dentro das variações esperadas.

As concentrações de clorofila aumentaram da nascente até médio curso do rio Canha, declinando posteriormente até a foz. As cargas específicas seguiram esse mesmo padrão.

As maiores cargas específicas e concentrações foram registradas na campanha 1 , já as menores na campanha 3.

De um modo geral, as concentrações de clorofila $\underline{a}$ foram baixas, sendo que nas campanhas 3 (pontos amostrais 2 e 3) e campanha 4 (ponto amostral 1) as concentrações estiveram abaixo do limite de detecção. 
Benassi (2002) menciona que as concentrações de clorofila foram maiores em pontos onde há ausência de mata ciliar e pequenas profundidades no ribeirão Bonito, principalmente no período chuvoso. O mesmo padrão não foi registrado para o rio Canha, uma vez que as campanhas 1 e 3 são consideradas secas e até médio curso do rio pode-se observar sombreamento, seja pela mata ciliar remanescente ou pelas plantações de banana. Sendo assim, pode-se dizer que as concentrações e cargas de clorofila $\underline{a}$ não seguiram um padrão definido.

Outro aspecto que pode ser ressaltado em relação aos valores de clorofila $\underline{a}$ é que estes são inversamente proporcionais aos valores de fosfato inorgânico, fração mais assimilável pelos vegetais.

$\mathrm{O}$ comportamento apresentado pela clorofila $\underline{a}$ em relação às vazões observadas e às vazões de permanência indica que o fitoplâncton é a fração que mais contribui para as cargas desse composto, nas campanhas 1, 2 e 3. Já na campanha 4 pode-se dizer que as algas de fundo ou fitobentos são os maiores contribuintes de clorofila $\underline{a}$ para o sistema, uma vez que grande parte do sedimento foi removida e revolvida pela passagem da onda de cheia no período dessa campanha. Assim, as altas vazões, que favoreceram o aumento da turbulência, foi o fator primordial para o aumento da carga de clorofila $\underline{a}$ na calha do rio, denotando mais uma vez a importância de se aliar estudos que integrem ecologia, hidráulica fluvial e hidrologia.

Portanto, as campanhas que apresentaram número de Reynolds e Froude menores também apresentaram as menores cargas de clorofila $\underline{a}$, enquanto que a campanha que registrou elevados valores dessas variáveis teve valores de clorofila mais pronunciados. Esse resultado permite supor que a produtividade do rio Canha é maior em períodos de altas vazões, entretanto os valores de clorofila obtidos nas campanhas com vazões menores estão dentro da faixa de variação obtidas para rios do tipo oligotrófico. Desta maneira, para vazões com probabilidade de ocorrência entre $15 \%$ e $100 \%$, a clorofila $\underline{a}$ diminui gradativamente com o aumento da probabilidade, sugerindo que mesmo com vazões bastante baixas (campanha 1, por exemplo) a clorofila mantém-se como esperado para o sistema em estudo. Todas as campanhas as concentrações de clorofila $\underline{a}$ estiveram bastante abaixo do permitido pela Resolução CONAMA $357 / 05(30 \mu \mathrm{g} / \mathrm{L})$.

Em estudo realizado numa pequena área alagável preservada em Sacramento, Califórnia (EUA), Ahearn (et al. 2006) concluíam que o pulso de inundação, ou seja, os processos de conexão e desconexão do rio com sua respectiva planície, são fundamentais para manutenção da 
biomassa algal na planície de inundação. A concentração de clorofila nesse local apresentou-se como função do tempo de residência da água e condições físicas da mesma, além disso, os autores supracitados afirmaram que os picos de clorofila $\underline{a}$ ocorreram no período de desconexão da planície alagável com o rio, além de indicarem o papel da hidráulica fluvial nos processos ecológicos.

A condutividade elétrica fornece informações sobre o metabolismo do ecossistema aquático, denotando a forte relação existente entre as águas de uma bacia de drenagem com sua formação geológica e ainda entrada de material alóctone, podendo indicar a presença de poluentes.

Esta variável reflete a condição de poluição inorgânica, relacionando-a com elementos ionizados presentes na água (JONNALAGADDA e MHERE, 2001). Assim, os padrões de variação da condutividade elétrica seguem os mesmos padrões de variação da carga de sólidos suspensos inorgânicos, ou seja, com aumento de montante a jusante. A campanha 3 é a única que apresenta alto valor dessa variável na nascente, provavelmente devido ao revolvimento do sedimento no momento da coleta.

A variação longitudinal da condutividade elétrica ocorreu de montante para jusante no rio Canha, padrões semelhantes aos encontrados por Jonnalagadda e Mhere (2001) no Rio Odzi, Zimbabwe, os quais foram atribuídos à entrada de efluentes no corpo d'água. O Rio Canha não apresenta fontes pontuais de poluição, no entanto, as áreas de pastagens e agricultura podem contribuir sobremaneira para a carga difusa que adentra o corpo d'água. Além disso, muitos casebres presentes no entorno do rio utilizam ligações clandestinas de esgoto, contribuindo para o aumento da condutividade elétrica.

Alam (et al. 2007) também encontraram variação longitudinal da condutividade elétrica de montante para jusante no rio Surma, Bangladesh, com maiores valores no período seco. Os autores relacionaram essa variação com a entrada de efluentes industriais e à baixa vazão, respectivamente.

A campanha 3 (outono) apresentou baixas vazões, esse fato pode contribuir para o aumento da condutividade nesse período. Benassi (2002) relacionou a alta condutividade elétrica no período de menores vazões com a capacidade do Ribeirão Bonito em assimilar certas substâncias. 
A variação longitudinal da condutividade elétrica no Rio Congost, Espanha, foi atribuída por Prat \& Munné (2000) à forte urbanização e industrialização nos pontos próximos à foz, além disso, em períodos chuvosos, os valores dessa variável tiveram um acréscimo denotando que a lixiviação do solo foi um fator importante para a qualidade das águas. Já no Rio Canha foi possível observar que as chuvas influenciaram diretamente a condutividade elétrica, fazendo com que esta diminuísse com o aumento da vazão, provavelmente devido à maior contribuição dos pequenos tributários nesse período, os quais são provenientes de regiões de drenagem com influência predominantemente florestal, além da maior assimilação dos corpos d'água nesse mesmo período.

Em relação ao modelo QUAL2K, este não faz menção ao cálculo da condutividade elétrica, entretanto é de se esperar que este tenha relação direta com os sólidos suspensos inorgânicos.

A alcalinidade é um indicador da capacidade tampão do sistema, ou seja, ela está diretamente relacionada com os valores de $\mathrm{pH}$ e também de condutividade elétrica. O Rio Canha apresenta $\mathrm{pH}$ ligeiramente ácido e alta carga de sólidos suspensos inorgânicos na água, fato que pode estar relacionado às variações longitudinais da alcalinidade. As maiores cargas de alcalinidade foram observadas na campanha 4, devido às altas vazões, já em termos de concentração, a campanha 3 apresentou os maiores valores, suscitando a hipótese de que após fortes chuvas, como ocorreu na campanha 4, a capacidade tampão do meio é baixa. A amplitude sazonal pode ser atribuída aos eventos de chuva e entrada de material alóctone.

É importante ressaltar que as variáveis alcalinidade e $\mathrm{pH}$ foram simuladas no presente trabalho, porém a alcalinidade é fortemente influenciada pela disponibilidade de carbono orgânico total, que por sua vez é dependente da respiração do fitoplâncton e das algas de fundo. Já o pH tem relação direta com a alcalinidade. Nenhuma das variáveis relacionadas ao fitoplâncton foi simulada no presente trabalho, podendo acarretar assim em erros na simulação.

$\mathrm{O}$ pH é uma importante variável física por influenciar a absorção de nutrientes pelo sistema aquático (BILLY, et al. 2000). A nascente do Rio Canha por ser circundada por mata ciliar pode contribuir para a diminuição dos valores desse parâmetro, devido a processos de decomposição.

Muitos autores citam que as entradas de efluentes industriais, bem como, o manejo inadequado do solo podem contribuir para o aumento do $\mathrm{pH}$ (SILVA \& SACOMANI, 2000), a 
ausência de fontes pontuais de poluição no Rio Canha é compensada pela modificação da paisagem a partir do médio curso do rio, o que pode contribuir para o aumento do $\mathrm{pH}$ nesses pontos.

Os meses de maiores vazões (campanhas 2 e 4) apresentaram uma queda do $\mathrm{pH}$ da nascente à foz, já as campanhas 1 e 3 , com menores vazões, registraram aumento desse valor de montante à jusante. Assim como para a condutividade elétrica, os meses mais secos têm menor capacidade de assimilação de alguns compostos, o que acarreta num aumento de $\mathrm{pH}$, enquanto que nos meses mais chuvosos, a alta vazão tende a diluir tais substâncias e consequentemente diminuir o $\mathrm{pH}$.

Alam (et al. 2007) também encontraram valores de $\mathrm{pH}$ ligeiramente mais baixos no período de baixas vazões para o rio Surma, Bangladesh. Maier (1983) ${ }^{4}$ apud Bubel (1998) cita que o $\mathrm{pH}$ dos rios brasileiros varia de neutros a ácidos. Os valores de $\mathrm{pH}$ do rio Canha encontram-se dentro dessa variação.

A turbidez no rio Canha, em todas as campanhas mantiveram o padrão de decrescimento da nascente em direção à foz, exceto na campanha 4, na qual essa variável aumentou de montante para jusante. Tal ocorrência pode ser justificada pelas altas precipitações na campanha 4, que carreiam partículas para dentro do leito do rio, além do revolvimento do sedimento. Como a turbidez está relacionada com os mais diversos tipos de materiais em suspensão, os resultados dessa variável podem ser contrastados com os de sólidos suspensos totais e inorgânicos, que também aumentaram de montante a jusante com altos valores no período chuvoso.

A variação longitudinal da turbidez nos períodos mais secos pode ser explicada pelo aumento da profundidade de montante a jusante e diminuição da declividade, que propicia o processo de sedimentação das partículas.

$\mathrm{O}$ nitrogênio, juntamente com o fósforo são os macronutrientes mais importantes para o metabolismo de um ecossistema aquático. As concentrações de nitrogênio aumentaram da nascente à foz em todas as estações do ano, sendo que as menores concentrações desse composto foram registradas na nascente em todo o período de coleta. Essa heterogeneidade espacial pode estar relacionada com o tipo de uso e ocupação do solo, que varia muito ao longo da bacia em estudo, além disso, o predomínio da cultura de banana, que utiliza elevados teores de nitrogênio

\footnotetext{
${ }^{4}$ Maier, M.H. (1983). Geoecologia, hidrografia, hidroquímica, clima e processos antrópicos da bacia do rio Jacaré Pepira (SP). Tese Doutorado, 305p. Universidade Federal de São Carlos.
} 
na fertilização das plantações, pode influenciar a carga desse elemento na água. Assim, os altos valores de nitrogênio em pontos mais a jusante do corpo hídrico, podem representar o impacto causado tanto pela agricultura como pela urbanização.

As maiores concentrações de nitrogênio total foram obtidas na campanha 1 (primavera), fato que pode estar relacionado à entrada clandestina de esgotos e à baixa vazão que impossibilita o corpo hídrico de depurar compostos. Benassi (2002) também encontrou, para o ribeirão Bonito, maiores concentrações de nitrogênio total no período seco, relacionando este fato à diferenças no processo de autodepuração entre os períodos seco e chuvoso. Entretanto, Brigante et el. (2003) citou que as concentrações de nitrogênio total foram reduzidas no período seco no rio MogiGuaçú, atribuindo esse fato à maior lixiviação do solo nos períodos chuvosos.

Temporalmente a maior variação do nitrogênio total dá-se nos períodos com mais intensidade chuvosa, corroborando com os dados obtidos por Caruso (2000) em Otago, Nova Zelândia. $\mathrm{O}$ autor (op cit.) comenta ainda que encontrou altas concentrações desse composto na parte mais baixa da bacia, principalmente no período chuvoso, o que difere do Rio Canha.

Em relação às cargas específicas, como era de se esperar, estas diminuem da nascente em direção à foz, devido ao alto valor da área acumulada nos pontos mais à jusante. A campanha 4 apresentou os maiores valores de carga específica, entretanto nos pontos próximos à foz, devido às altas vazões registradas nesse período, os teores de nitrogênio se mantiveram relativamente altos, apenas no ponto 4 houve uma grande diminuição dessa carga, que pode ser justificada pelo aumento da largura do rio nesse ponto.

Prado (1999), em trabalho realizado no médio rio Pardo comenta que as cargas de nitrogênio total não diminuíram no período chuvoso, atribuindo este fato ao despejo de esgotos, pois apenas fontes difusas não seriam capazes de manter elevadas cargas de nitrogênio em períodos de altas vazões.

Assim como no rio Canha, Reginato e Piechota (2004) encontraram maiores cargas de nitrogênio total nos períodos chuvosos, atribuindo esse resultados à fontes difusas de poluição, apesar de terem concluído que as fontes pontuais são as maiores causas de poluição das águas dos rios em Las Vegas.

Alexander (et al. 2007) ressaltam que o fluxo de nitrogênio nos cursos d'água tem efeito cumulativo, devido aos processos que controlam o transporte desse composto do ecossistema 
terrestre para o aquático. Deste modo, segundo os mesmos autores a hidrologia tem papel fundamental no transporte de nitrogênio, seja pela drenagem da bacia ou via precipitação.

Os autores (op cit.) comentam ainda que rios de baixa ordem têm seu curso bastante dendrítico e são drenados por pequenos córregos, deste modo, qualquer alteração, seja no regime hidrológico ou condições físico-químicas do meio podem aumentar as concentrações de diferentes substâncias, comprometendo a qualidade das águas. O rio Canha se enquadra nessas características, assim possíveis modificações tanto na nos pequenos córregos de montante, como nos rios de maior ordem que drenam a bacia do rio Canha podem ter causado aumento dos teores de nitrogênio nesse curso d'água.

O nitrogênio pode ser um nutriente limitante em muitos ambientes aquáticos, mas atualmente são raros os sistemas hídricos que têm sua produtividade diminuída devido à falta desse elemento. Essa situação ocorre devido ao crescente impacto humano sobre os ecossistemas que carreiam as mais diversas formas de nitrogênio para dentro das águas (FISHER et al. 2007).

Com base nessa afirmação, os autores (op cit.) comentam a necessidade da adoção do conceito de cargas críticas para gerenciamento e manutenção da qualidade das águas poluídas, principalmente por nitrogênio. O conceito de cargas críticas foi concebido na Europa e é amplamente utilizado pelos países da União Européia por tomadores de decisão. Cargas críticas podem ser definidas como a quantidade de uma substância, nesse caso o nitrogênio, que pode adentrar um corpo d'água sem causar danos aos indicadores biológicos e químicos (FISHER op. cit.).

Essa abordagem pode servir como ferramenta para medidas de proteção de ecossistemas aquáticos, uma vez que Fisher (et al. 2007) constataram um aumento da quantidade das formas de nitrogênio advindos de atividades como agricultura, criação de gado, atividades industriais, urbanização, entre outros, em algumas partes dos Estados Unidos.

Ainda em relação aos Estados Unidos, Tufford (et al. 2003) comentam que as bacias da costa sudeste desse país estão sofrendo grandes mudanças devido ao rápido crescimento urbano e industrial. Nesse contexto, os autores analisaram 10 pequenas bacias quanto à concentração de nutrientes, sendo que as mesmas drenam desde áreas altamente impactados à outras mais preservados. Os resultados obtidos a partir de tal análise demonstram que as áreas mais preservadas apresentaram maiores concentrações de nitrogênio dissolvido e nitrogênio amoniacal, enquanto que as áreas urbanas tiveram maiores concentrações de nitrato e fósforo 
total. Esses dados podem estar relacionados com o tipo de uso e ocupação do solo, além de refletirem a origem e o tempo de poluição.

O nitrogênio total, no modelo QUAL2K, é gerado como um dado de saída a partir do balanço de nitrogênio orgânico, nitrogênio amoniacal e nitrato.

Em relação à associação do tipo de substrato e as altas cargas de nitrogênio total, pode-se inferir que, de um modo geral, há uma relação entre a carga desse composto e o aumento da fração média e grossa de pedregulho, principalmente entre os pontos amostrais 2 e 5 . Porém observa-se desconexão dessa hipótese quando se observa a campanha 4 nos pontos próximos à foz, que apresentam altas cargas de nitrogênio total e baixos valores da fração de pedregulho.

Nas campanhas com IPA altos, observou-se uma queda mais pronunciada da fração de areia, evidenciando que com a maior turbulência e vazão dos períodos chuvosos, o transporte de material mais fino é mais eficiente. Nesse período, há aumento da fração de pedregulho com o aumento da carga de nitrogênio total, suscitando a hipótese de menor deposição e troca desse composto com o sedimento, uma vez que a superfície de contato do pedregulho é menor que da areia.

As principais fontes do nitrogênio orgânico em um corpo d'água são decomposição de folhas e microorganimos, assim pode-se dizer para o Rio Canha que tais fontes têm efeito significativo sobre a concentração desse composto, uma vez que, para a maioria das sub-baacias de drenagem observou-se contribuição de mais de $80 \%$ de área florestada.

A campanha 1 apresentou as maiores concentrações de nitrogênio orgânico, fato que pode estar correlacionado com o processo de decomposição citado anteriormente, se tal premissa estiver correta, pode-se dizer que as altas vazões diluem esse composto, uma vez que as menores concentrações do mesmo foram obtidas no período chuvoso (campanha 4). As altas concentrações encontradas a partir de médio curso podem ter sido influenciadas pelo tipo de uso e ocupação do solo, que encontra-se tomado por agricultura e área urbana.

Em relação ao modelo QUAL2K, a simulação dos dados de nitrogênio orgânico são realizadas de modo que este aumenta devido à morte das plantas e perde-se via hidrólise e precipitação. Como nenhuma variável referente à plantas foi simulada no presente trabalho, as diferenças entre os dados observados e simulados podem estar relacionadas com isso.

Para o nitrogênio amoniacal, pode-se afirmar no presente estudo, que o processo de nitrificação é mais intenso, uma vez que os teores de oxigênio dissolvido na água são 
relativamente altos. A variação espacial da concentração de nitrogênio amoniacal remete supor que as maiores contribuições de nitrogênio amoniacal sejam provenientes do escoamento superficial das plantações de banana, atividades como pecuária e também devido ao processo de urbanização. Dados semelhantes foram obtidos por Bordalo et al. (2001) no Rio Bangpakong, na Tailândia.

A campanha 1 apresentou maiores concentrações de nitrogênio amoniacal, enquanto que a campanha 4 registrou as menores concentrações desse composto, assim pode-se dizer que as altas vazões tiveram um efeito diluente. Benassi (2002) também apresentou para o ribeirão Bonito as maiores concentrações de nitrogênio amoniacal no período seco e as menores no período chuvoso, fato que a autora relacionou à baixa precipitação e conseqüentemente baixa vazão, o que diminuiu a capacidade de diluição do rio.

Alam (et al 2007) também relacionaram a menor concentração de nitrogênio amoniacal à alta capacidade de assimilação do rio Surma, Bangladesh, no período chuvoso.

As maiores cargas de nitrogênio amoniacal foram obtidas na campanha 4, sugerindo que o processo de nitrificação é mais intenso, uma vez que os teores de nitrogênio total obtidos na campanha 4 não são os mais altos. A Resolução CONAMA 357/05 pressupõe para corpos d'água utilizados para o abastecimento público e, portanto considerados como classe 2, como no caso do Rio Canha, o valor máximo estabelecido para a concentração de nitrogênio amoniacal a um $\mathrm{pH} \leq$ 7,5 é de $13,3 \mathrm{mg} / \mathrm{L}$, ou seja, em todas as estações amostrais de todas as campanhas apresentaram valores abaixo do limite estabelecido.

A concentração de amônia aumenta devido à hidrólise do nitrogênio orgânico e respiração do fitoplâncton, nesse caso, essa componente foi desconsiderada. A perda desse composto se dá via nitrificação e fotossíntese, a qual também foi desconsiderada no presente trabalho. Como a concentração de nitrogênio amoniacal é relativamente alta no rio Canha, talvez o processo de nitrificação seja recente.

Geralmente as concentrações de nitrito são baixas em corpos d'água, no entanto a presença desses nutrientes em alta concentração são indicadores de águas poluídas.

Espacialmente as concentrações de nitrito aumentaram da nascente à foz em todas as campanhas, fato que pode estar atrelado ao uso do solo na bacia, ma vez que último trecho do curso d'água teve suas características bastante modificadas. 
Um padrão similar foi registrado por Oliveira (2003 a), a autora verificou que o córrego Cancã apresentou baixas concentrações de nitrito, observando um aumento desse nutriente na última estação de coleta.

As maiores concentrações de nitrito foram obtidas na campanha 3, período de menos intensidade chuvosa, assim como para o rio Betari (DOMINGOS, 2002). É importante salientar que as concentrações de nitrito ficaram bastante abaixo daquelas estabelecidas pela Resolução CONAMA 357/05 para rios de classe 2, que é de 1,0 mg/L.

Em relação às cargas específicas de nitrito, estas decaíram de montante à jusante, exceto na campanha 4. As estações de coleta localizadas mais a jusante possuem maior área de contribuição, já que este é um valor acumulado, deste modo todas as campanhas apresentaram declínio nos valores de nitrito nesses locais, exceto a campanha 4. Esse resultado pode ser justificado pelas altas vazões do período e, também, pela grande contribuição da bacia para a entrada desse composto.

De acordo com WETZEL (1983), o nitrato é a forma salina e completamente oxidada mais abundante nos sistemas aquáticos e também a mais utilizada pelos vegetais. Além disso, um corpo d'água que apresenta altas concentrações de nitrato pode refletir um estado de poluição mais antiga, uma vez que esse composto está relacionado com as reações oxidativas que ocorrem num corpo hídrico, ou seja, é o estágio final do processo de nitrificação (VON SPERLING, 1995).

As concentrações de nitrato aumentaram em direção à foz em todas as campanhas, sendo que a nascente apresentou as menores concentrações em todo período amostrado. As maiores concentrações foram registradas na campanha 2 e as menores na campanha 4, assim pode-se dizer que devido aos altos índices de precipitação que antecederam a campanha 4, esse composto foi diluído e que apesar das chuvas menos intensas na campanha 2 , as concentrações de nitrato foram elevadas provavelmente devido às altas temperaturas que favorecem as reações de oxidação biológica.

Os altos valores de concentração nos trechos finais do rio podem estar relacionados com o uso e ocupação do solo da bacia. Oliveira (2003) e Santos (2000) encontraram altos valores de nitrato nos trechos onde a influência antrópica era maior, assim como ocorre no rio Canha.

A resolução CONAMA 357/05 pressupõe que os corpos d'água utilizados para abastecimento público e portanto considerados como classe 2 possuem uma concentração de 
nitrato de até $10 \mathrm{mg} / \mathrm{L}$, valor bastante acima daqueles observados no Rio Canha, cuja concentração máxima desse composto ocorreu na campanha 2 nos pontos próximos à foz (entre $0,84$ e $0,88 \mathrm{mg} / \mathrm{L})$.

A campanha 2 apresentou, no ponto amostral 4, a maior carga e concentração de nitrato, provavelmente devido à grande interferência antrópica nesse ponto, que localiza-se dentro de uma propriedade rural, com cultivo de banana. Além disso, foi possível observar que essa seção apresenta indícios de assoreamento diminuindo a profundidade do leito do rio e a velocidade da água.

Todas as estações do ano apresentaram maiores cargas específicas nos pontos próximos à nascente (pontos 2, 3 e 4) apesar da baixa vazão e da área de contribuição ser menor em relação aos pontos mais a jusante, evidenciando que a pecuária e até mesmo a presença de resquícios de mata ciliar contribuem para a oxidação do nitrogênio mais fortemente.

O rio Jadro, na Croácia, apresenta altas cargas de nitrogênio, principalmente no que diz respeito ao nitrato e em período chuvoso Giljanovic (2006) vincula esse resultado com o crescente processo de ocupação das cidades no entorno do rio, já que a poluição por nitrato caracteriza uma poluição mais antiga.

No modelo QUAL2K a concentração de nitrato aumenta devido à nitrificação da amônia e perde-se via desnitrificação e fotossíntese. Lembrando que a fotossíntese não foi considerada nas simulações do presente trabalho.

Souza \& Tundisi (2003) relatam que o uso e ocupação do solo e o estado da cobertura vegetal influenciam a qualidade das águas, sobretudo nos teores de nitrogênio e fósforo, principalmente naquelas ocupadas por agricultura.

Silva \& Sacomani (2001) encontraram para o Rio Pardo, Botucatu, maiores concentrações de fosfatos após a passagem do corpo d'água por áreas de agricultura. As concentrações de fosfato inorgânico no Rio Canha aumentaram da nascente à foz, ou seja, aumentaram após a passagem de áreas com menor influência antrópica para as áreas de maior interferência.

As maiores concentrações desse composto foram registradas na campanha 3 e as menores na campanha 1. Em estudo realizado por Moccellin (2005) no rio Jacupiranguinha, localizado também na região do baixo Ribeira de Iguape, a autora relata que nos meses de inverno (período seco) foram registradas as menores concentrações de fosfatos, como no presente trabalho o 
inverno caracterizou-se como a estação chuvosa, pode-se dizer que esses resultados corroboram com os obtidos para o Rio Canha.

Benassi (2002) observou que o Ribeirão Bonito apresentou maiores concentrações das formas fosfatadas no período de menor ocorrência de chuvas, atribuindo tal fato à menor capacidade de diluição do corpo d'água. Já Bordalo et al. (2001) atribuíram as altas concentrações de fosfatos, ao longo do Rio Bangpakong (Tailândia), aos altos índices pluviométricos que contribuíram para o aumento do escoamento superficial.

Pode-se dizer que o rio Canha apresenta-se bastante vulnerável ao baixo índice pluviométrico, já que foi possível perceber um aumento das concentrações da maioria das variáveis analisadas. Porém, após eventos de precipitação essa situação mudou, com a diminuição dessas concentrações e aumento dos níveis de oxigênio, fator indispensável para manutenção da qualidade da água. Já as cargas sofreram grande influência das altas vazões.

Propostas de manejo de bacia para manutenção da biota e para diminuição das concentrações de nutrientes são a conservação da mata ciliar, além de manutenção e/ou criação de ecótonos que retêm água através do processo de evapotranspiração e assim mantêm uma quantidade de água adequada para manutenção do ciclo hidrológico na bacia (ZALEWSKI, 2000).

Galbraith e Burns (2007) afirmam a necessidade de trabalhos que contemplem as características geomorfológicas da bacia para o entendimento dos processos que ocorrem em um curso d'água, principalmente no que diz respeito à ciclagem de nutrientes, podendo-se estabelecer correlações positivas e negativas através da análise estatísticas de dados limnológicos, de geomorfologia e uso e ocupação do solo.

Janauer (2000) completa que para o entendimento dos processos que ocorrem numa bacia, é necessária a associação de dados que integrem os conceitos ecológicos dos sistemas fluviais e as escalas. Mendiondo (2001) propõe a integração rio - bacia - várzea para manejo sustentável dos sistemas lóticos, visando conceito de diversidade e dinâmica, resiliência e vulnerabilidade, além da continuidade.

Almeida-Neto (2007), em trabalho realizado também no Baixo Ribeira de Iguape, subbacia do rio Jacupiranguinha, constatou a importância da conectividade lateral do rio com sua respectiva planície de inundação como um sistema redutor de carga. $\mathrm{O}$ autor encontrou relação direta entre as variáveis hidrológicas e limnológicas, como por exemplo, biomassa, condutividade 
elétrica, demanda química de oxigênio, nitrogênio e fósforo. Demonstrando ser evidente a importância de estudos que integrem o sistema como um todo.

Para o rio Canha, em termos de declividade, formação do solo e seu tipo de uso e ocupação, além da hidrologia podem ser associados com os dados obtidos de qualidade da água. A declividade favorece a oxigenação da água, principalmente até médio curso do rio, fato que mantém estável a qualidade da água e do sistema como um todo. Em relação à pedologia, o entorno do rio Canha é formado quase que totalmente por glissolos, que se caracteriza por um tipo de solo pobre em drenagem, constituído por material mineral, já a grande maioria da bacia é dominada por cambissolos, ricos em matéria orgânica e ideais para plantações, pois sua fertilidade varia de baixa a alta.

Assim, é possível associar a formação do solo com seu tipo de uso e ocupação, que para o rio Canha, vem sendo bastante modificado pela agricultura e mais à jusante pelo processo de urbanização. A bananicultura, atividade mais desenvolvida na região de estudo, ocupa um lugar de destaque no Brasil por fazer parte dos hábitos alimentares dos brasileiros, entretanto é comum encontrar, em regiões onde essa atividade é bastante desenvolvida, o baixo manejo do solo na pós-colheita (EMBRAPA 2008).

Segundo Yuan e Myamoto (2005) muitas substâncias aplicadas em bacias dominadas pela agricultura ou até mesmo utilizadas para pastagem ou em processo de urbanização são lixiviadas para o curso d'água em períodos chuvosos, entretanto muitos desses compostos são diluídos pelas altas vazões. Em períodos de seca, com o aumento da evaporação, a concentração de diversas substâncias tende a aumentar, entretanto esses fatores são altamente dependentes do tipo de uso e ocupação do solo, bem como formação litológica da bacia e distribuição das chuvas.

Reginato e Piechota (2004) ressaltam a importância do monitoramento de fontes não pontuais de poluição para monitoramento de qualidade da água, principalmente naqueles cursos d'água que recebem fontes pontuais de poluição. Esse monitoramento funcionaria como estratégia para manutenção de qualidade das águas, uma vez que seria possível determinar em que período do ano as cargas difusas são maiores, sendo possível desta maneira, melhorar a eficiência de tratamento dos efluentes que adentram o rio via fontes pontuais. Desse modo, o comprometimento das águas seria menor.

De acordo com a análise dos resultados, pode-se afirmar que estes estão de acordo com as afirmações feitas por Yuan e Myamoto (2005). As cargas específicas para a maioria das 
substâncias analisadas aumentaram no período chuvoso, enquanto que a concentração apresentou-se alta também em períodos de seca, indicando que tantos os processos de lixiviação com os de diluição e evaporação são importantes para manutenção da qualidade da água do rio Canha.

Os mesmos autores (op cit.) citam que os principais processos que controlam a composição química da água do rio Pecos, Novo México, são evaporação e diluição, apesar de ocorrerem em menor proporção, processos de ganho ou perda de sais via interação com água subterrânea e armazenamento dos mesmos nos diferentes compartimentos do curso d'água, principalmente sedimento. Um estudo mais detalhado sobre os tipos de solo a sua influência na concentrações e substâncias seria de grande relevência para manejo desse corpo d'agua, já que ficou evidente a presença de gleissolos.

Em relação à hidrologia, Shrivastava (2006) comenta que a retirada de água de determinados cursos de água afetam sobremaneira o regime de chuvas de uma região, influenciando consequentemente na preservação de espécies da flora e na fauna. Esse fato pode ser comprovado no trabalho piloto realizado na ilha de Trinidad, ao sul do Caribe, o qual teve sua diversidade ecológica diminuída com o aumento de retirada de água para irrigação, além do comprometimento da qualidade da água (SHRIVASTAVA op cit.).

Foi possível observar em campo que os pontos amostrais com paisagem mais modificada, por exemplo, ponto de coleta 4, apresentam indícios de assoreamento e escavação, o que diminuiu o nível da água nesse local. O regime de chuva durante o período de coleta mostrou-se modificado, com grandes picos numa época que deveria ser seca. A qualidade da água sofreu influência tanto do período seco como do período chuvoso, sugerindo que as vazões devem ser mantidas em níveis aceitáveis (vazão ecológica) para manutenção do ambiente, bem como manejo do solo para evitar que o processo de lixiviação comprometa a qualidade das águas.

O baixo número de Froude e Reynolds e as baixas vazões permitiram evidenciar um aumento da deterioração da qualidade da água, ainda que o rio Canha seja um dos rios mais preservados da região e sua qualidade esteja dentro dos padrões estabelecidos para classe 2. A associação da clorofila a, variável que pode tanto ser considerada química como biológica, pode sugerir níveis mínimos aceitáveis para o rio Canha.

Wang (et. al. 2007) analisaram as mudanças que ocorreram no tipo de uso e ocupação do solo no período de 1956 a 2000, no médio curso da bacia do rio Heihe, China, e sua relação com 
alteração dos processos hidrológicos para esta região. Os autores concluíram que para o período estudado, as modificações do uso do solo foram rápidas e marcantes, com substituição da vegetação nativa por, principalmente, áreas de agricultura e em menor escala urbanização e industrialização. Tais modificações acarretaram num aumento do escoamento na parte alta da bacia e grande diminuição na foz do rio, associando este fato à grande modificação da paisagem e uso do solo em médio curso do rio, local designado pelos autores como área de dissipação de cheias.

Os autores (op cit.) relacionaram ainda o aumento do escoamento na parte alta da bacia e sua respectiva diminuição da parte baixa da mesma, com as modificações da vazão de base e picos de cheia, os quais estão atrelados à precipitação, mais intensas na parte de montante da bacia estudada.

Em relação aos modelos matemáticos que simulam a qualidade da água em rios, estes são ferramentas para planejamento, gestão e monitoramento ecohidrológico dos cursos de água (TUCCI, 1998; SHANAHAN et al., 2001; WANGA et al., 2005; CHAPRA et al. 2006, entre outros). Além disso, esses modelos integram a ecohidráulica fluvial e demonstram-se adequados para diretrizes de conservação e recuperação dos sistemas fluviais (MENDIONDO, 2000).

O QUAL2K apesar de algumas limitações é um modelo bastante adequado para simulação da qualidade em rios, podendo ser utilizado como ferramenta para tomadas de decisão. Esse modelo integra componentes de hidráulica fluvial, de hidrologia e de qualidade da água. Os resultados observados e simulados remeteram à possibilidade de uma visão integrada da ecohidrologia fluvial, sendo necessária reflexão sobre conceitos como resistência, vulnerabilidade e resiliência, apontando os trabalhos de Janauer (2000), Zalewski (2000) e Zalewski e Wagner (2004). O presente trabalho pretendeu integrar ecologia com alguns conceitos de hidráulica fluvial, pois segundo tal associação as pesquisas passariam a ter um foco mais holístico, contribuindo para execução de trabalhos futuros, funcionando como pesquisa de base para discussões mais detalhadas e que empreguem novas tecnologias. 


\section{CONCLUSÃO}

A conclusão da presente pesquisa está embasada nos objetivos específicos desta dissertação:

1 - Coletar experimentalmente indicadores fisicos e químicos da água, temporalmente (sazonais) e espacialmente (longitudinais) no rio.

- Os dados de qualidade da água coletados no rio Canha apresentaram variação longitudinal e temporal, para todas as campanhas e variáveis. As variações longitudinais refletiram-se na qualidade da água de montante para jusante, demonstrando a interferência das modificações presentes na bacia. Já as variações temporais evidenciaram que períodos distintos, caracterizados por Índice de Precipitação Antecedente, Radiação Solar Incidente e Temperatura da água com suas características particulares influenciaram a concentração e a carga específica dos indicadores físicos e químicos de qualidade da água;

- Os altos teores de oxigênio observados no rio Canha, o caracterizam como um ambiente mais redutor, favorecendo processos como a nitrificação;

- A predominância de sólidos suspensos inorgânicos denota a contribuição do intemperismo físico e químico das rochas, além da lixiviação do solo causada por interferências antropogênicas, nos resultados dessa variável;

- A variação temporal apresentada pela condutividade elétrica, com menores valores no período chuvoso, demonstra o efeito de diluição das águas, contribuindo para os resultados de qualidade da água em termos de concentração das substâncias;

- As formas de nitrogênio, principalmente o nitrogênio total, apresentaram altas concentrações e cargas em relação aos demais indicadores de qualidade da água e ao que era esperado para o rio Canha, evidenciando que a nitrificação é o processo dominante nesse sistema;

- Todas as variáveis de qualidade da água do rio Canha apresentaram-se dentro dos limites estabelecidos pela Resolução CONAMA 357/05 para rios de classe 2.

2 - Estudar os controles morfo-hidráulicos do curso d'água e suas variáveis hidrológicas em dependência sazonal do ciclo de transformação chuva-vazão. 
- A declividade possui relação direta com a velocidade de escoamento da água, ambas apresentaram interferência nos processos limnológicos que ocorreram no curso d'água, como por exemplo, a quantidade de oxigênio dissolvido, o qual é responsável por reações de oxidação que influenciam a qualidade da água;

- O escoamento em todo o leito do rio caracterizou-se como turbulento, com altos números de Froude e Reynolds, os quais variaram em cada seção do rio nos diferentes períodos de amostragem. Tais resultados refletiram nos processos que ocorrem no rio Canha, pois foi possível notar que após eventos críticos a fração de cascalho no leito no rio foi maior em pontos mais a jusante do mesmo, fato que compromete as reações de troca com sedimento e consequentemente o processo de precipitação de compostos;

- Os pontos de coleta 4 e 5 , que se localizam respectivamente a $51 \%$ e $55 \%$ da área de drenagem da bacia, tiveram suas características de profundidade e velocidade de escoamento alteradas devido a interferências antrópicas, principalmente agricultura;

- No que diz respeito aos períodos de baixas vazões evidenciou-se altas concentrações e baixas cargas da maioria das variáveis analisadas, comprometendo a qualidade da água do rio Canha. Já em relação ao período chuvoso, tais concentrações diminuíram, porém as cargas foram altas devido às altas vazões. Esses resultados indicam que, para o período seco, a qualidade da água reflete os processos autóctones, enquanto que para o período chuvoso, a carga das variáveis está relacionada com os processos alóctones.

- O comportamento das variáveis hidráulico-hidrológicas como vazão, velocidade de escoamento e altura da água seguiram os preceitos da teoria do Continuum Fluvial.

\section{3 - Estimar a influência do uso e ocupação do solo na bacia hidrográfica sobre os indicadores experimentais e conforme os controles ecohidrológicos.}

- Apesar de a maior parte da bacia ser ocupada por áreas de floresta, principalmente na nascente (99\%), o entorno do rio apresenta-se bastante modificado por atividades como pecuária, em menor quantidade (máximo de 6,4 na foz) e agricultura, mais especificamente bananicultura, em grande quantidade (máximo de $23 \%$ no ponto amostral 5 - 55\% do alcance da bacia). Resquícios de mata ciliar são apenas encontrados na nascente e em pequena quantidade no ponto amostral 2 (4,5\% do alcance da bacia). Os usos preponderantes da microbacia são: formação 
florestal e área urbana, que aumentou consideravelmente nos pontos próximos à foz - alcançando 42,6\%. Esses dados foram diretamente associados com a degradação da qualidade da água de montante a jusante;

- O cultivo de banana, principal atividade da região, exige quantidades significativas de nitrogênio no solo, fato que justifica a grande quantidade desse composto encontrado no curso d'água;

- A área referente ao perímetro urbano apresenta-se bastante modificada, com relação direta com a baixa qualidade da água. Nos pontos amostrais 7 e 8 (99\% e 100\% de alcance da bacia, respectivamente), dentro do perímetro urbano, a qualidade da água tornou-se bastante comprometida no período amostrado. Além disso, próximo ao ponto amostral 8, encontra-se a estação de tratamento de esgoto do município, que pode interferir de alguma maneira na qualidade da água desse local;

4 - Calibrar e simular um modelo matemático unidimensional de qualidade da água no curso d'água da bacia experimental contrastando hipóteses de processos ecohidrologicos do sistema fluvial com os dados experimentais coletados longitudinal e sazonalmente

- As simulações de qualidade da água mostraram-se fortemente dependentes da calibração dos dados hidráulicos, os quais sofreram influência direta da rugosidade ( $n$ de Manning) dos trechos amostrados e da divisão da bacia em trechos;

- O rio Canha, por ser de pequeno porte e estar inserido numa área de serra, não admitiu que seu eixo longitudinal fosse dividido em pequenos trechos de tamanho semelhante. Dessa maneira a divisão, para as simulações, foi feita de acordo com os pontos amostrais, assim as diferenças entre os valores simulados e observados relacionaram-se a esse tipo de divisão da bacia, pois o modelo não interpreta quedas abruptas e/ou aumentos rápidos das variáveis. Assim, de modo geral, as simulaçõse do modelo QUAL2K acompanharam razoavelmente bem as variáveis empregadas;

- A partir dos resultados obtidos notou-se a influência do escoamento superficial na qualidade da água, o qual funciona como uma fonte difusa de poluição. Deste modo, evidenciou-se que os dados empregados como fontes difusas de poluição são extremamente importantes para obtenção de dados de qualidade da água mais condizentes com a realidade; 
- As concentrações das variáveis de qualidade da água interpretadas em função do comprimento do rio e as cargas específicas relacionadas com unidade de área incremental da bacia evidenciam uma abordagem holística. Além disso, o enfoque ecohidrológico permitiu a integração da ecologia, com a hidrologia e tipos de uso e ocupação do solo;

- É possível afirmar que o próprio modelo oferece abordagens holística e ecohidrológica a partir dos dados de entrada exigidos para calibração do mesmo. O QUAL2K, de acordo com o presente trabalho, pode ser utilizado como ferramenta para gerenciamento de qualidade da água e para tomadas de decisão. 


\section{RECOMENDAÇÕES}

Segundo o que foi apresentado nesta pesquisa, são feitas algumas recomendações:

- Para avaliar os processos qualitativos que ocorrem em um rio, aliando-os a dados quantitativos afim de uma abordagem ecohidrológica eficiente, é necessária a implantação de uma rede de monitoramento de qualidade da água, de fontes pontuais e difusas de poluição e de dados hidráulicos-hidrológicos, para que se tenha uma série histórica e uma avaliação efetiva de longo prazo;

- Para trabalhos com modelo de qualidade da água sugere-se que se tenha, a priori, conhecimento profundo dos processos e dos dados de entrada no modelo antes das coletas de campo, pois muitas vezes a forma de obtenção dos dados de campo não permite seu emprego no modelo;

- Se possível calibrar e simular todas as variáveis propostas pelo modelo ou pelo menos escolher com atenção àquelas a serem empregadas, uma vez que alguns dados influenciam em outros no processo de calibração e simulação;

- Como no Brasil muitos rios apresentam planícies alagáveis recomenda-se, para trabalhos de simulação de qualidade, que os modelos empregados permitam a inserção desse tipo de dados, para que se tenha uma abordagem holística, ecohidrológica e principalmente da influência dessas áreas na qualidade das águas. Além da integração dos conceitos diversidade, resiliência, vulnerabilidade e continuidade;

- Sugere-se, para trabalhos futuros, a estimativa da vazão ecológica e indica-se o cálculo da mesma com base na relação produção/respiração fitoplanctônica como metodologia a ser testada em pesquisas posteriores. 


\section{REFERÊNCIAS BIBLIOGRÁFICAS}

ALAM, J.B.; HOUSSAIN, A., KHAN, S.K.; BANIK, B.K. ISLAM, M.R.; MUYEN, Z.; RAHMAN, M.H. (2007). Deterioration of water quality of Surma river. Env. Monit. Assess. V.134, p. 233-242.

ALEXANDER, R.B.; BOYER, E.W.; SMITH, R.A.; SCHWARZ, G.E.; MOORE, R.B. (2007). The role of headwater streams in downstream water quality. Journal of American Water Resources Association, v.43, n¹, p.41-59.

ALMEIDA-NETO, P. (2007). Análise experimental de hidrogramas visando a ecologia fluvial de áreas alagadas em bacias afluentes do Baixo Ribeira de Iguape, SP. Primeira qualificação (Mestrado). Escola de Engenharia de São Carlos-USP, 36p.

ALMEIDA-NETO, P; MENDIONDO, E.M. (2008).Ecohidrologia de pulsos sobre várzeas: conceitos, exemplos e cenários (em fase de preparação).

AHEARN, D.A.; VIERS, J.H.; MOUNT, J.F.; DALHGREN, R.A.(2006). Priming the productivity pump: flood pulse driven trends in a suspended algal biomass distribution across a restored floodplain. Freshwater Biology, 51, 1417-1433.

APHA-AMERICAN PUBLIC HEATH ASSOCIATION. (1999). Standard methods of the examination of water and wastewater. 20ed. Washington, D.C.

BATTALHA, B.L. (1986). Autodepuração nos cursos da água. Revista DAE, v.46, n.144, p. 2732. 
BENASSI, S. F.(2002). Estudo das variáveis limnológicas e do processo de autodepuração na "Descontinuidade Serial” do Riberão Bonito (SP). Dissertação (Mestrado). Escola de Engenharia de São Carlos, Universidade de São Paulo. 120p.

BILLY,V.C.; MARCHANT, P. R.; LAIR, N.; VALADAS, B. (2000). Impact of agricultural practices on a small headwater stream: terrestrial and aquatic characteristics and self-purifying processes. Hydrobiologia n ${ }^{\circ} 421$ p 119-139.

BONELL, M.(2002) Ecohydrology - a completely new idea? Hydrological Sciences Journal 47:809-810.

BORDALO, A.A.; NILSUMRANCHIT, W. CHARLERMVAT, K. (2001). Water quality and uses of Bangpakong River (Eastern Thailand) Water Research v.35, n15, p. 3635-42.

BORGES, A.C.; RIBAS, M.M.F.; CALIJURI, M.C.; MENDIONDO, E.M. (2005). Aspetos quali-quantitativos dos recursos hídricos na bacia do Rio Jacupiranga como instrumento de avaliação de qualidade ambiental. In: XVI Simpósio Brasileiro de Recursos Hídricos, João Pessoa. Anais: ABRH.

BRASIL 2005. Resolução CONAMA 357/2005. Dispõe sobre a classificação dos corpos de água e diretrizes para seu enquadramento, bem como estabelece as condições de lançamento de efluentes e dá outras providências. Diário Oficial da República Federativa do Brasil. Brasília.

BRIGANTE, J.; ESPINDOLA, E.L.G.; POVINELLI, J.; NOGUEIRA, A.M. (2003). Caracterização física, química e biológica da água do rio Mogi-Guaçu. In: BRIGANTE, J.; ESPINDOLA, E.L.G (eds). Limnologia Fluvial: um estudo no rio Mogi-Guaçu. Ed. Rima, São Carlos, SP.

BROOKES, A.(1995). The importance of high flows for riverine environment. In: The ecological basis for river management. Harper, D. M. \& Fergurson, A. J. D. John Wiley \& Sons Ltd, New York 
BUBEL, A.P.M. (1998). Caracterização limnológica do rio do Peixe (Microrregião geográfica de Botucatu - SP), em duas épocas do ano (períodos de seca e chuva). Dissertação (Mestrado) apresenatada à Escola de Engenharia de São Carlos, Universidade de São Paulo, 217p.

BUNN, S.E.; ARTHINGTON, A.H. (2002) Basic principles and ecological consequences of the altered flow regimes for aquatic diversity. Environmental Management, v.30, $\mathrm{n}^{\circ} 4, \mathrm{p} .492-507$.

BUFFAGNI, A.; CROSA, G.A.; HARPER, D.M.; KEMP, J.L. (2000).Using a macroinvertebrate species assemblages to identify river channel habitat units: an application of the functional habitats concept to a large, unpolluted Italian river ( River Ticino, northern Italy). Hydrobiologia, 435: 213-225.

CALIJURI, M.C.; OLIVEIRA, H.T. (2000). Manejo da Qualidade de Água: Uma Abordagem Metodológica. In: CASTELLANO, E.G.; CHAUDHRY, F.H. (Org.). Desenvolvimento sustentado: problemas e estratégias. Projeto Reenge. EESC-USP p. 39-58.

CALIJURI, M.C.; BUBEL, A.P.M. (2006). Conceituação de microbacias. In: LIMA, W.P.; ZAIKA, M.J.B. (Org). As Florestas Plantadas e a Água. Rima, p. 45-60.

CAMPOLO, M.; ANDREUSSI, P.; SOLDATO, A. (2002). Water quality control in the River Arno. Water Research v.36, p.2673-80.

CÂMARA, C. D.(2004). Critérios e indicadores para o monitoramento hidrológico de florestas plantadas. Tese (Doutorado). Escola de Engenharia de São Carlos-USP. 170p.

CARUSO, B.S. (2002) Temporal and spatial patterns of extreme low flows and effects on the stream ecosystems in Otago, New Zealand. Journal of Hydrology, v.257, p. 115-133.

C.A.T.I. Coordenadoria de Assistência Técnica Integral. Projeto LUPA - Levantamento das Unidades de Produção Agropecuária. Disponível em: www.cati.sp.gov.br Acesso em 27/11/06. 
CHAPRA, S.C. (1999).Surface Water Quality Modeling. Mc Graw Hill. Massachusets, 844p.

CHAPRA, S. C. \& PELLETIER, G. J. (2006). QUAL2K: a Modeling Framework forsimulating river and stream water quality: documentation and user manual. Civil and Environmental Engineering Dept., Tufts University, Medford, MA

CETESB- Companhia de Tecnologia de Saneamento Ambiental. (2005). Relatório de água interiores no estado de São Paulo. Disponível em www.cetesb.sp.gov.br. Acesso em 19/04/06.

COX, B.A.(2003). A review of currently available in-stream water-quality models and their applicability for simulating dissolved oxygen in lowland rivers. The Science of the Total Environmental, v.314-316, p. 335-377.

CUNGE, J.A.; HOLLY Jr, F.M.; VERWEY, A. (1980). Practical aspects of computational river hydraulics. Pitman Advanced Publishing Program. London.

DNER-ME- Departamento Nacional de Estrada de Rodagem. (1994). Norma 041/94. Capitulo 4

DOMINGOS, M.D. (2002). Limnologia do rio Betari (Iporanga,SP) e a relação com o estado de conservação de sua bacia hidrográfica - subsídios para o desenvolvimento sustentável. Tese (Doutorado) apresentada à Escola de Engenharia de São Carlos, Universidade de São Paulo, 272 p.

DROLC, A.; KONCAN, J.Z. (1996). Water quality modeling of river Sava, Slovenia. Water Research, v.30, n.11, p.2587-2592.

DANEHY, R.J.; HASSET, J.M. (1996). Stream habitat quantification by use of the Froude number. Stream notes. Stream Systems Technology Center.

EIGER, S. (2002 a). In: MANCUSO, P.C.S.; SANTOS, H.F. (org). Reuso da Água. 1 ed, v.1, Editora Manole, p. 233-259.

EIGER, S. (2002 b). Modelagem matemática da qualidade da água. In: MANCUSO, P.C.S.; SANTOS, H.F. (org). Reuso da Água. 1 ed, v.1, Editora Manole. 
ELWOOD, J. W.; NEWBOLD, J. D.; O’ NEIL, R. V. \& VAN WINKLE, W. (1983). Resource spiraling: an operation paradigm for analyzing lotic ecosystems. In: The dynamics of lotic ecosystems. Ann. Arbor Publishers, Ann, Arbor, MI, 3

EMBRAPA - Empresa Brasileira de Pesquisa Agropecuária (www.embrapa.br - acesso em 12/01/08).

FERRAZ, I.C.(2008). Estudo das variáveis limnológicas do rio Canha (baixo Ribeira de Iguape -SP) com enfoque para a comunidade bentônica como bioindicadora. Dissertação de Mestrado (em fase de preparação). Escola de Engenharia de São Carlos, Universidade de São Paulo.

FISHER, L.S.; MAYS, P.A.; WYLIE, C.L. (2007). An overview of nitrogen critical loads for policy makers, stakeholders, and industries in the United Sates. Water Air soil Pollut. 179:3-18.

GALBRAITH, L.M.; BURNS, C. W. (2007). Linking land-use, water body type and water quality in Southern New Zealand. Landscape Ecology n² 22, p. 23-241.

GASTALDINI, M.C.C. (1982) Análise do mecanismo de autodepuração do rio Jacaré-Guaçu através de Modelo de Qualidade da Água. Dissertação (Mestrado). Escola de Engenharia de São CarlosUniversidade de São Paulo, 160p.

GILJANOVIC, N.S. (2006). The pollution load by nitrogen and phosphorus in the Jadro River. Environmental Monitoring Assessment, 123:13-30.

HANNAH, D.M.; WOOD, P. J.; SADLER, J.P. (2004). Ecohydrology and hydroecology: a "new paradigm?” Hydrological Processes n¹8, p.3439-3445.

HARPER, D.M.; KEMP, J.L.; VOGEL, B.; MALCOLM, D.N. (2000). Towards the assessment of "ecological integrity" in running waters of United Kingdon. Hydrobiologia, 422/423: 133142. 
HORMANN, G.; HORN, A.; FOHRER, H. (2005). The evaluation of land-use options in mesoscale catchments. Prospects and limitations of eco-hydrological models. Ecological Modelling, v.187, p.3-14.

IBGE - INSTITUTO BRASILEIRO DE GEOGRAFIA E ESTATÍSTICA, (2005). Tabela das estimativas das populações residentes. Disponível em www.ibge.gov.br. Acesso em 11/04/2006.

JONNALAGADDA, SB.; MHERE, G. (2000). Water quality of the Odzi River in the eastern highlands of Zimbabwe. Water Research. v.35, n.10, p.2371-76.

JANAUER, G.A. (2000) Ecohydrology: fusing concepts and scales. Ecological Engineering, 16 p. 9-16.

JUNK, W. J.; BAYLEY, P. B.; SPARKS, R. E. (1989). The flood pulse concept in riverfloodplain systems. Can. Spec. Publ. Fish. Aquat. Sci. v.106: p. 110-227.

KNAPIK, H.; FRANÇA, M.; FERNANDES, C.; MASINI, L.; MARIN, M.C.; PORTO, M.F.A. (2006). Análise crítica da calibração de modelos de qualidade de água em rios - estudo de caso da bacia do alto Iguaçu. In: Workshop sobre Gestão Estratégica de Recursos Hídricos, Brasília.

KOTTI, M.E. VLESSIDIS, A.G.; THANASOULIAS, N.C.; EVMIRIDIS, N.P. (2005). Assessment of river water quality in Northwestern Greece. Water Resources Management, v.19, p. $77-94$

LIMA, W. P. e ZÁKIA, M. J. B.(2000). Saúde Ambiental da microbacia. In: LIMA, W. P. e ZÁKIA, M. J. B.(Org) As florestas plantadas e a água. Rima, p. 1-8.

MARGALEF, R. (1983). Limnología. Barcelona: Omega, 1100p. 
MARGALEF, R. (1994) The place of epicontinental waters in global ecology. In: MARGALEF, R. (org). A paradigm of planetary problems. Elservier Science B.V., p.195-218.

MARTINS, E. S. P. R; PAIVA J. B. D.(2000). Monitoramento de Recursos Hídricos: Quantidade. In PAIVA \& PAIVA (org). Hidrologia Aplicada a Gestão de Pequenas Bacias Hidrográficas Editora ABRH cap. 20.

MENDIONDO, E. M. (2001) Contribuições da análise de incertezas para a recuperação ambiental de bacias pela abordagem interdisciplinar de Geobiohidrologia. Tese de Doutorado, Universidade Federal do Rio Grande do Sul, Porto Alegre, RS.

MENDIONDO, E. M. ; TUCCI, C. E. M. ; CLARKE, R. T. ; GOLDENFUM, J. A. ; CASTRO, N. M. R. ; CHEVALLIER, P (2002). Space-time observations in nested catchment experiments of representative basins. In: D. Schertzer et al (Org.). Predictions in Ungauged Basins: Oxford: Wallingford Press, v. 309, p. 164-172.

MINSHAlL, G.W., CUMMINS, K.W., PETERSEN, R.C., CUSHING, C.E., BRUNS, D.A., SEDELL, J.R. \& VANNOTE, R.L. (1985). Developments in stream ecosystem theory. Canadian Journal of Fisheries and Aquatic Sciences, 42: 1045-1055.

MOCCELLIN, J. (2005). A microbacia do rio Jacupiranguinha como unidade de estudo para sustentabilidade dos recursos hídricos no Baixo Ribeira de Iguape-SP. Dissertação (Mestrado). Escola de Engenharia de São Carlos, Universidade de São Paulo. 151p.

MONTGOMERY, D.R. (1999). Process Domains and the River Continuum. Journal of the American Water Resources Asociation, v.35, n.2, p.397-410. 
NOGUEIRA, J.B. (2005). Análise Granulométrica. In: NOGUEIRA, J.B. Mecânica dos solos Ensaios de laboratório. EESC/USP/Departamento de Geotecnia. p.93-107.

ODUM, E. P. (1988) Ecologia. Rio de Janeiro, Guanabara

OLIVEIRA, S. R. (2003 a). Avaliação da qualidade de água e da carga de nutrientes do córrego Cancã, município de São Carlos-SP. Dissertação (Mestrado). Escola de Engenharia de São Carlos, Universidade de São Paulo. 141p.

OLIVEIRA, A.P.F.M. (2003 b) Qualidade da água de abastecimento - desde o uso e ocupação do solo da bacia do Ribeirão das Pitangueiras às torneiras dos usuários: Estudo de caso do município de Barretos, SP. Dissertação (Mestrado). Escola de Engenharia de São Carlos, Universidade de São Paulo. 137p

PARK, S.S.; LEE, Y.S. (2002). A water quality modeling study of the Nakdong River, Korea. Ecological Modelling, v.152, p 65-75.

PETTS, G.; MADDOCK, I.; BICKERTON, M.; FERGUSON, A.J.D.(1995). Linking hydrology and ecology: the scientific basis for river management. In: The ecological basis for river management. Harper, D. M. \& Fergurson, A. J. D. John Wiley \& Sons Ltd, New York

PRADO, R.B. (1999). Influência do uso e ocupação do solo na qualidade da água: Estudo no médio rio Pardo-SP (período de 1985 - 1997). Dissertação (Mestrado). Escola de Engenharia de São Carlos, Universidade de São Paulo, 209p.

PRAT, N.; MUNNÉ, A. (2000). Water use and quality and stream flow in Mediterraneam stream. Water Research v.34, n15, p3876-81. 
POFF, N.L.; ALLAN, J.D.; BAIN, M.B. KARR, J.R.; PRESTEGAARD, K.L.; RICHTER, B.D.; SPARKS, R.E.; STROMBERG, J.C. (1997). A paradigm for river conservation and restoration. Bioscience, v. 47, n.11, p. 769-784.

RAUCH, W.; HENZE, M.; KONCSOS, L.; REICHERT, P.; SHANAHAN, P.; SOMLYÓDY, L.; VANROLLENGHEM, P. River Water Quality Modelling: I. State of the Art. Wat. Sci. Tech, v.38, n.11, p.237-244.

REGINATO, M.; PIECHOTA, T.C. (2004). Nutrient contribuition of nonpoint source runoff in the Las Vegas Valley. Journal of the American Water Association 40(6):1537-1551.

RICE, S.P.; GREENWOOD, M.T.; JOYCE, C.B. (2001). Tributaries, sediment sources, and the longitudinal organization of macroinvertebrate fauna along the river systems. Canadian Journal Fisheries and Aquatic Science, v.58, p.824-840.

RICHTER, B.D.; BAUMGARTNER, J.V.; WEGIGTON, R.; BRAUN, D.P. (1997). How much water does a river need? Freshwater biology, v.37, p. 231-249.

RIGHETTO, A.M. (1998). Hidrologia e Recursos Hídricos, EDUSP, São Carlos

ROSGEN, D.; SILVEY, H.L. (1996) Applied river morphology, 2 ed. Colorado.

SABATER, F.; ARMENGOL, J.; SABATER, S. (1989). Measuring Discontinuities in the Ter River. Regulated Rivers: Research \& Management; v. 3, p. 133-142.

SANTOS, E.T. (2000). Caracterização ambiental da alta bacia do Rio Aquidauana/MS e indentificação dos impactos do uso e ocupação do solo na qualidade dos recursos hídricos. Dissertação (Mestrado). Escolae Engenharia de São Carlos, Universidade de São Paulo. 132p.

SHANAHAN, P., BORCHARDT, D., HENZE, M., RAUCH, W., REICHERT, P., SOMLYÓDY, L. VANROLLEGHEM, P. (2001). River Water Quality Model no. 1 (RWQM1): I. Modelling approach. Water Science and Technology. v 43 (5): 1-9. 
SHRIVASTAVA, G. (2006). Ecohydrology and water resouces management: a pilot study in Trinidad. Hydrological Sciences, n51, v.6, pp. 1163-1176.

SILVA, A.M.M.; SACOMANI, L.B. (2000). Using chemical and physical parameters to define the quality of Pardo River water (Botucatu - SP - Brazil). Water Research v.35, n.6; p.1609-16.

SOUZA, A.D.G.; TUNDISI, J.G. (2003). Water quality in watershed of the Jaboatão River (Pernambuco - Brasil): A case study. Brazilian Archieves of Biolgy and Tecnology v.46, n.4, p.711-221.

STATZNER, B. \& HIGLER, B. (1985). Questions and coments on the River Continuum Concept._Canadian .Journal of Fisheries and Aquatic Science. v.42, p-1038-1044.

TUCCI, C.E.M. (1998). Modelos Hidrológicos. Editora da Universidade, 669p.

TUFFORD, D.L.; SAMARGHITAN, C.L.; McKELLAR, H.N.; PORTER, D.E.; HUSSEY, J.R. (2003). Impacts of urbanization on nutrient concentrations in small southeastern coastal stream. Journal of the American Water resources Association, p.301-312.

TUNDISI, J.G. (1999). Limnologia no Século XXI: Perspectivas e Desafios. In: VII Congresso Brasileiro de Limnologia. Florianópolis, Anais.

USEPA (2007). Agência de Proteção dos Estados Unidos da América (wwww.epa.gov - acesso em 14/03/2006).

VANNOTE, R. L.; MINSHALL, G. W.; CUMMINS, K. W.; SEDELL, J. R, \& CUSHING, C. E. (1980). The River Continuum Concept. Canadian Journal of Fisheries and aquatic Science, v. $37, \mathrm{n} 1, \mathrm{p}-130-137$

VON SPERLING, M. (1995). Introdução à qualidade das águas e ao tratamento de esgotos. Belo Horizonte. DESA/UFMG. 
WANGA, X., HOMER, M., DYER, S., WHITE-HULL, C., DU, C. (2005). A river water quality model integrated with a web-based geographic information system. Journal of Environmental Management 75 (3): 219-228

WANG, G.; LIU. J.; KUBOTA, J.; CHEN, L. (2007). Effects of land-use changes on hydrological processes in the middle basin of the Heihe River, northwest China. Hydrological Processes, 21, 1370-1382.

WARD, J. V. e STANFORD, J. A. (1983) The Serial Discontinuity Concept in Lotic Ecosystems. In: FONTAINE, T. D. \& BARTHELL, S. M., EDS. Dynamics of lotic ecosystems. Ann Arbor Scien. Publ., Ann Arbor. Michigan, p.347 - 356.

YUAN, F.; MIYAMOTO, S. (2005) Dominant processes controlling water chemistry of the Pecos River in American Southwest. Geophysical Research Letters, v.32, p.1-4.

ZALEWSKI, M (2000). Ecohydrology - the scientific background to use ecosystem properties as management tools toward sustainability of water resources. Ecological Engineering, v.16, p.1-8.

ZALEWSKI, M.; ROBARTS, R. (2003). Ecohydrology - a new paradigm for integrated water resources management. Sil News v.40, p.1-5. 


\section{ANEXOS}

Anexo 1: Dados obtidos em campo e utilizados na calibração do modelo

\begin{tabular}{|c|c|c|c|c|c|c|c|c|c|}
\hline & Ponto & 1 & 2 & 3 & 4 & 5 & 6 & 7 & 8 \\
\hline \multirow[b]{2}{*}{ 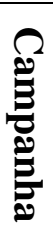 } & Dist. (Km) & 1,14 & 3,61 & 5,44 & 12,75 & 14,8 & 21,06 & 27,45 & 28,45 \\
\hline & Área de Drenagem $\left(\mathrm{Km}^{2}\right)(\mathrm{A})$ & 0,92 & 4,78 & 2,46 & 56,84 & 4,59 & 30,75 & 24,58 & 0,94 \\
\hline \multirow{4}{*}{1} & $\mathrm{~V}(\mathrm{~m} / \mathrm{s})$ & 0,11 & & & 0,73 & & & & 0,33 \\
\hline & $\begin{array}{c}\text { Área Seção Transversal }\left(\mathrm{A}_{\mathrm{T}}\right) \\
\left(\mathrm{m}^{2}\right)\end{array}$ & 0,12 & & & 0,57 & & & & 1,8 \\
\hline & $\mathrm{Q}\left(\mathrm{m}^{3} / \mathrm{s}\right)$ & 0,014 & & & 0,43 & & & & 0,595 \\
\hline & $n$ Manning & 0,08 & & & 0,09 & & & & 0,15 \\
\hline \multirow{4}{*}{2} & $\mathrm{~V}(\mathrm{~m} / \mathrm{s})$ & 0,16 & & & 0,34 & & & & 0,27 \\
\hline & $\begin{array}{c}\text { Área Seção Transversal }\left(\mathrm{A}_{\mathrm{T}}\right) \\
\left(\mathrm{m}^{2}\right)\end{array}$ & 0,1 & & & 1,81 & & & & 3,9 \\
\hline & $\mathrm{Q}$ & 0,016 & & & 0,705 & & & & 1,038 \\
\hline & $n$ Manning & 0,09 & & & 0,22 & & & & 0,13 \\
\hline \multirow{4}{*}{3} & $\mathrm{~V}(\mathrm{~m} / \mathrm{s})$ & 0,15 & 0,32 & & 0,61 & 0,15 & & 0,14 & 0,34 \\
\hline & $\begin{array}{c}\text { Área Seção Transversal }\left(\mathrm{A}_{\mathrm{T}}\right) \\
\left(\mathrm{m}^{2}\right)\end{array}$ & 0,11 & 0,27 & & 0,83 & 3,16 & & 4,7 & 2,04 \\
\hline & $\mathrm{Q}$ & 0,017 & 0,087 & & 0,508 & 0,494 & & 0,69 & 0,7 \\
\hline & $n$ Manning & 0,12 & 0,09 & & 0,3 & 0,3 & & 0,09 & 0,09 \\
\hline \multirow{4}{*}{4} & $\mathrm{~V}(\mathrm{~m} / \mathrm{s})$ & 0,16 & 0,5 & & 0,61 & 0,6 & & 0,27 & \\
\hline & $\begin{array}{c}\text { Área Seção Transversal }\left(\mathrm{A}_{\mathrm{T}}\right) \\
\left(\mathrm{m}^{2}\right)\end{array}$ & 0,12 & 0,25 & & 2,57 & 3,56 & & 15,85 & \\
\hline & $\mathrm{Q}$ & 0,019 & 0,127 & & 1,704 & 2,149 & & 4,232 & \\
\hline & $n$ Manning & 0,08 & 0,09 & & 0,13 & & & 0,25 & \\
\hline
\end{tabular}


Anexo 2: Seções transversais dos pontos amostrais 3, 5, 6 e 8.
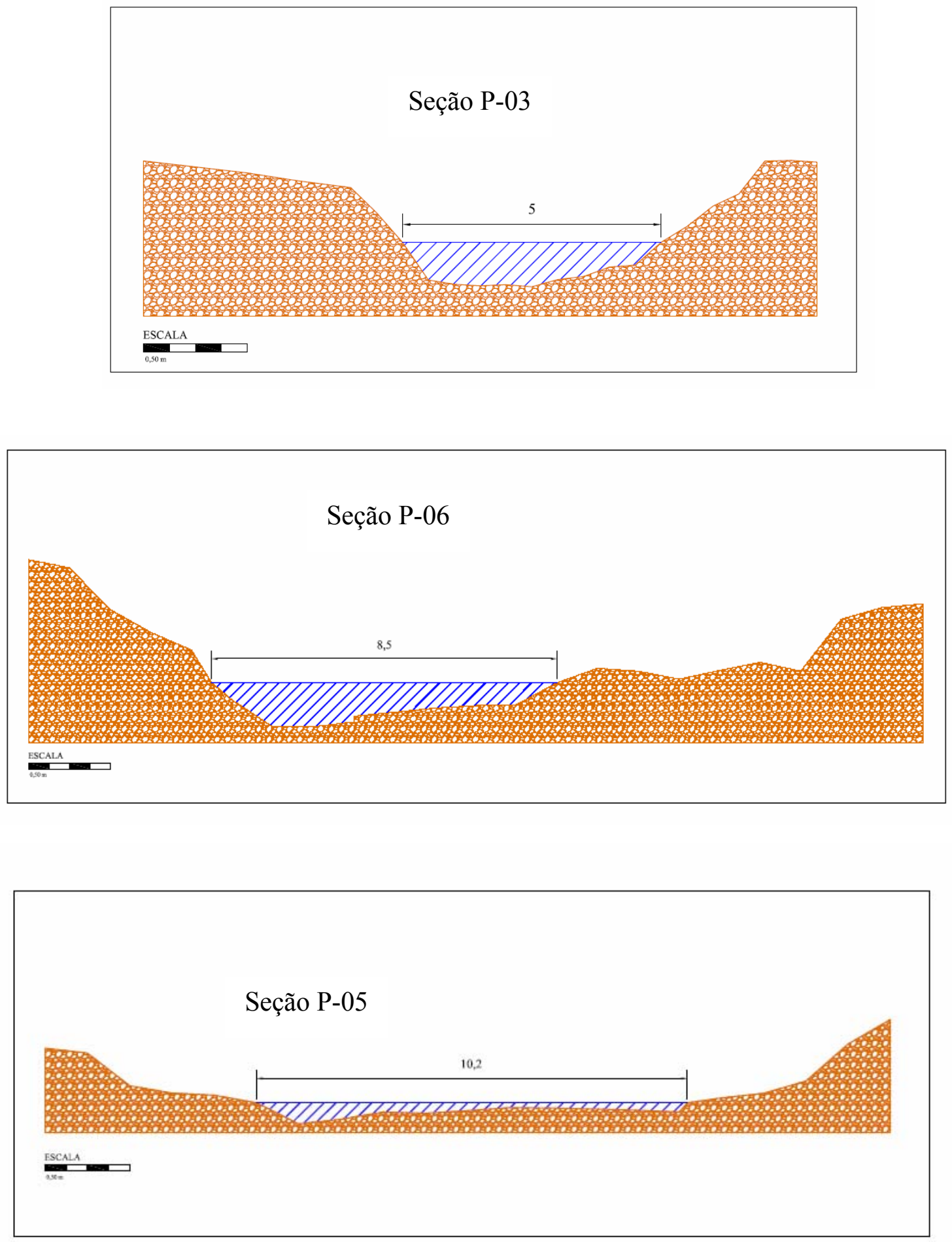


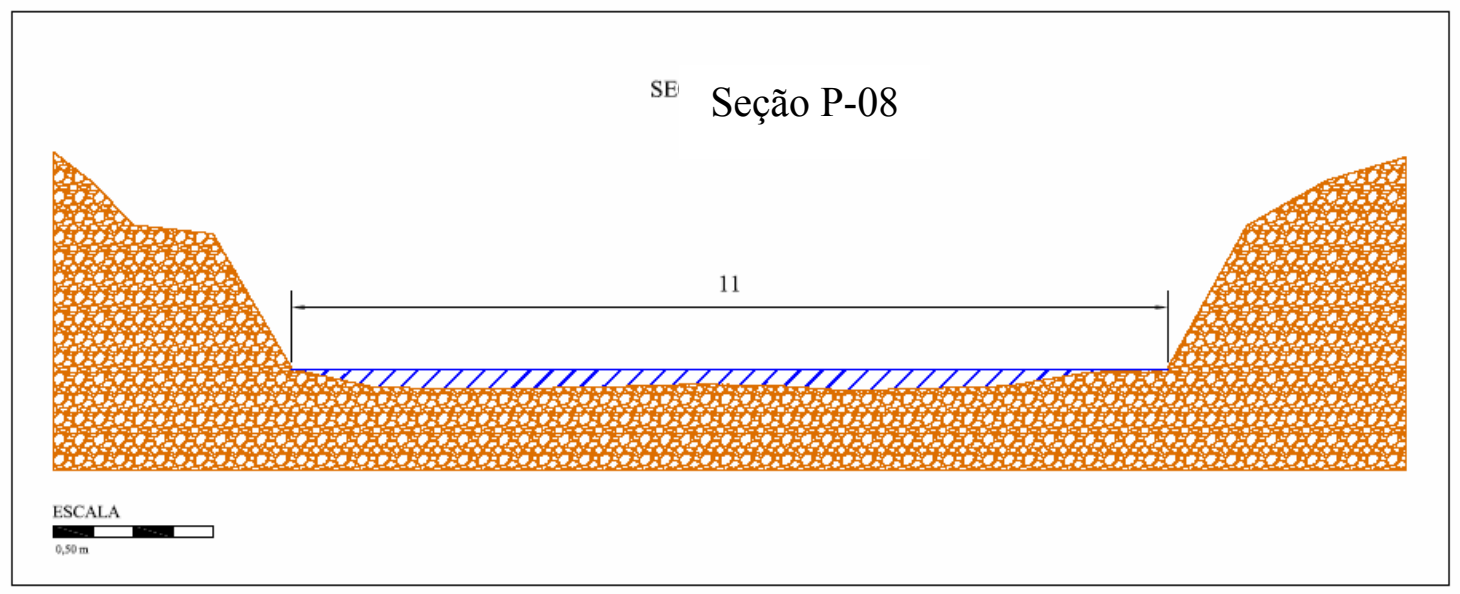


Anexo 3: Parâmetros utilizados nas simulações

\begin{tabular}{|c|c|c|c|}
\hline Parâmetro & Valor & Unidades & Símbolo \\
\hline \multicolumn{4}{|l|}{ Estequiometria } \\
\hline Carbono & 40 & $\mathrm{gC}$ & $\mathrm{gC}$ \\
\hline Nitrogênio & 7,2 & $\mathrm{gN}$ & $\mathrm{gN}$ \\
\hline Fósforo & 1 & $\mathrm{gP}$ & $\mathrm{gP}$ \\
\hline Peso Seco & 100 & $\mathrm{gD}$ & $\mathrm{gD}$ \\
\hline Clorofila & 1 & $\mathrm{gA}$ & gA \\
\hline \multicolumn{4}{|l|}{ Sólidos Inorgânicos Suspensos } \\
\hline Ajuste de Velocidade & 0,3 & $\mathrm{~m} / \mathrm{d}$ & $\mathrm{v}_{\mathrm{i}}$ \\
\hline \multicolumn{4}{|l|}{ Oxigênio } \\
\hline Modelo de Reaeração & O'Connor-Dobbins & & \\
\hline Tempo de Correção & 1,024 & & $\mathrm{q}_{\mathrm{a}}$ \\
\hline Efeito de Reaeração pelo Vento & None & & \\
\hline O2 para Oxidação de Carbono & 2,69 & $\mathrm{gO}_{2} / \mathrm{gC}$ & $\mathrm{r}_{\mathrm{oc}}$ \\
\hline O2 para NH4 nitrificação & 4,57 & $\mathrm{gO}_{2} / \mathrm{gN}$ & $\mathrm{r}_{\mathrm{on}}$ \\
\hline Modelo de Inibição de Oxigênio para Oxidação da CBOD & Exponential & & \\
\hline Parametro de inibção do Oxigênio para oxidação da CBOD & 0,60 & $\mathrm{~L} / \mathrm{mgO} 2$ & $\mathrm{~K}_{\text {socf }}$ \\
\hline Modelo de Inibição do Oxigênio para Nitrificação & Exponential & & \\
\hline Parâmetro de Inibição do Oxigênio para Nitrificação & 0,60 & $\mathrm{~L} / \mathrm{mgO} 2$ & $\mathrm{~K}_{\text {sona }}$ \\
\hline Modelo de Aumento de Oxigênio para desnitrificação & Exponential & & \\
\hline Parâmetro de Aumento de Oxigênio para desnitrificação & 0,60 & $\mathrm{~L} / \mathrm{mgO} 2$ & $\mathrm{~K}_{\text {sodn }}$ \\
\hline Modelo de Inibição de Oxigênio para resp fito & Exponential & & \\
\hline Parâmetro de Inibição de Oxigênio para resp fito & 0,60 & $\mathrm{~L} / \mathrm{mgO} 2$ & $\mathrm{~K}_{\text {sop }}$ \\
\hline Modelo de Aumento de Oxigênio para resp alg & Exponential & & \\
\hline Parametro de Aumento de Oxigênio para resp alg & 0,60 & $\mathrm{~L} / \mathrm{mgO} 2$ & $\mathrm{~K}_{\mathrm{sob}}$ \\
\hline \multicolumn{4}{|l|}{ Lenta CBOD: } \\
\hline Taxa de Hidrólise & 0,1 & $/ \mathrm{d}$ & $\mathrm{k}_{\mathrm{hc}}$ \\
\hline Tempo de Correção & 1,07 & & $\mathrm{q}_{\mathrm{hc}}$ \\
\hline Taxa de Oxidação & 0 & $/ \mathrm{d}$ & $\mathrm{k}_{\mathrm{dcs}}$ \\
\hline Tempo de Correção & 1,047 & & $\mathrm{q}_{\mathrm{dcs}}$ \\
\hline \multicolumn{4}{|l|}{ Rápida CBOD: } \\
\hline Taxa de Oxidação & 0,23 & $/ \mathrm{d}$ & $\mathrm{k}_{\mathrm{dc}}$ \\
\hline Tempo de Correção & 1,047 & & $\mathrm{q}_{\mathrm{dc}}$ \\
\hline \multicolumn{4}{|l|}{ Nitrogênio Orgânico } \\
\hline Hidrólise & 0,2 & $/ \mathrm{d}$ & $\mathrm{k}_{\mathrm{hn}}$ \\
\hline Tempo de Correção & 1,07 & & $\mathrm{q}_{\mathrm{hn}}$ \\
\hline Ajuste de Velocidade & 0,1 & $\mathrm{~m} / \mathrm{d}$ & $\mathrm{v}_{\text {on }}$ \\
\hline \multicolumn{4}{|l|}{ Amônio: } \\
\hline Nitrificação & 1 & $/ \mathrm{d}$ & $\mathrm{k}_{\mathrm{na}}$ \\
\hline Tempo de Correção & 1,07 & & $\mathrm{q}_{\mathrm{na}}$ \\
\hline \multicolumn{4}{|l|}{ Nitrato } \\
\hline Desnitrificação & 0 & $/ \mathrm{d}$ & $\mathrm{k}_{\mathrm{dn}}$ \\
\hline Tempo de Correção & 1,07 & & $\mathrm{q}_{\mathrm{dn}}$ \\
\hline Coeficiente de Transferência do Sedimento para Desnitrificação & 0 & $\mathrm{~m} / \mathrm{d}$ & $\mathrm{v}_{\mathrm{di}}$ \\
\hline Tempo de Correção & 1,07 & & $\mathrm{q}_{\mathrm{di}}$ \\
\hline
\end{tabular}




\begin{tabular}{|c|c|c|c|}
\hline \multicolumn{3}{|l|}{ P Orgânico: } & \multirow[b]{2}{*}{$\mathrm{k}_{\mathrm{hp}}$} \\
\hline Hidrólise & 0,2 & $/ \mathrm{d}$ & \\
\hline Tempo de Correção & 1,07 & & $\mathrm{q}_{\mathrm{hp}}$ \\
\hline Ajuste de Velocidade & 0,1 & $\mathrm{~m} / \mathrm{d}$ & $\mathrm{v}_{\mathrm{op}}$ \\
\hline \multicolumn{4}{|l|}{ P Inorgânico } \\
\hline Ajuste de Velocidade & 2 & $\mathrm{~m} / \mathrm{d}$ & $\mathrm{V}_{\text {ip }}$ \\
\hline Coeficiente de Absorção de P inorgânico & 0 & $\mathrm{~L} / \mathrm{mgD}$ & $\mathrm{K}_{\mathrm{dpi}}$ \\
\hline Constante de Atenuação Média do Sedimento P e oxigênio & 0,05 & $\mathrm{mgO}_{2} / \mathrm{L}$ & $\mathrm{k}_{\mathrm{spi}}$ \\
\hline \multicolumn{4}{|l|}{ Fitoplancton: } \\
\hline Taxa de Crescimento Máxima & 2,5 & $/ \mathrm{d}$ & $\mathrm{k}_{\mathrm{gp}}$ \\
\hline Tempo de Correção & 1,07 & & $\mathrm{q}_{\mathrm{gp}}$ \\
\hline Taxa de Respiração & 0,2 & $/ \mathrm{d}$ & $\mathrm{k}_{\mathrm{rp}}$ \\
\hline Tempo de Correção & 1,07 & & $\mathrm{q}_{\mathrm{rp}}$ \\
\hline Taxa de Mortalidade & 0,2 & $/ \mathrm{d}$ & $\mathrm{k}_{\mathrm{dp}}$ \\
\hline Tempo de Correção & 1,07 & & $\mathrm{q}_{\mathrm{dp}}$ \\
\hline Cosntante de Saturação Média de Nitrogênio & 25 & $\mathrm{ugN} / \mathrm{L}$ & $\mathrm{k}_{\mathrm{sPp}}$ \\
\hline Constante de Saturação Média de Fósforo & 5 & $\mathrm{ugP} / \mathrm{L}$ & $\mathrm{k}_{\mathrm{sNp}}$ \\
\hline Constante de Saturação Média de Carbono Inorgânico & $1,30 \mathrm{E}-05$ & moles/L & $\mathrm{k}_{\mathrm{sCp}}$ \\
\hline Modelo de Luz & Half saturation & & \\
\hline Luz Constante & 100 & langleys/d & $\mathrm{K}_{\mathrm{Lp}}$ \\
\hline Preferência por Amônia & 25 & $\mathrm{ugN} / \mathrm{L}$ & $\mathrm{k}_{\mathrm{hnxp}}$ \\
\hline Ajuste de Velocidade & 0,5 & $\mathrm{~m} / \mathrm{d}$ & $\mathrm{v}_{\mathrm{a}}$ \\
\hline \multicolumn{4}{|l|}{ Algas de Profundidade } \\
\hline Modelo de Crescimento & Zero-order & & \\
\hline Taxa de Crescimento Máxima & 50 & $\operatorname{ngA} / \mathrm{m}^{2} / \mathrm{d}$ or $/$ & $\mathrm{C}_{\mathrm{gb}}$ \\
\hline Tempo de Correção & 1,07 & & $\mathrm{q}_{\mathrm{gb}}$ \\
\hline Modelo de Capacidade de Transporte de primeira ordem & 1000 & $\mathrm{mgA} / \mathrm{m}^{2}$ & $\mathrm{a}_{\mathrm{b}, \text { max }}$ \\
\hline Taxa de Respiração & 0,1 & $/ \mathrm{d}$ & $\mathrm{k}_{\mathrm{rb}}$ \\
\hline Tempo de Correção & 1,07 & & $\mathrm{q}_{\mathrm{rb}}$ \\
\hline Taxa de Escremento & 0,05 & $/ \mathrm{d}$ & $\mathrm{k}_{\mathrm{eb}}$ \\
\hline Tempo de Correção & 1,07 & & $\mathrm{q}_{\mathrm{db}}$ \\
\hline Taxa de Mortalidade & 0,1 & $/ \mathrm{d}$ & $\mathrm{k}_{\mathrm{db}}$ \\
\hline Tempo de Correção & 1,07 & & $\mathrm{q}_{\mathrm{db}}$ \\
\hline Constante Média de Saturação do Nitrogênio Externo & 300 & $\mathrm{ugN} / \mathrm{L}$ & $\mathrm{k}_{\mathrm{SPb}}$ \\
\hline Constante Média de Saturação do Fósforo Externo & 100 & $\mathrm{ugP} / \mathrm{L}$ & $\mathrm{k}_{\mathrm{SNb}}$ \\
\hline Constante Média de Saturação do Carbono Inorgânico & $1,30 \mathrm{E}-05$ & moles/L & $\mathrm{k}_{\mathrm{sCb}}$ \\
\hline Modelo de Luz & Half saturation & & \\
\hline Luz Constante & 100 & langleys/d & $\mathrm{K}_{\mathrm{Lb}}$ \\
\hline Preferência por Amônia & 25 & $\mathrm{ugN} / \mathrm{L}$ & $\mathrm{k}_{\mathrm{hnxb}}$ \\
\hline Quota de Nitrogênio Subexistente & 0,72 & $\mathrm{mgN} / \mathrm{mgA}$ & $\mathrm{q}_{\mathrm{ON}}$ \\
\hline Quota de Fósforo Subexistente & 0,1 & $\mathrm{mgP} / \mathrm{mgA}$ & $\mathrm{q}_{\mathrm{OP}}$ \\
\hline Taxa de Captação de Nitrogênio Máxima & 72 & $\mathrm{mgN} / \mathrm{mgA} / \mathrm{d}$ & $\mathrm{r}_{\mathrm{mN}}$ \\
\hline Taxa de Captação de Fósforo Máxima & 5 & $\mathrm{mgP} / \mathrm{mgA} / \mathrm{d}$ & $\mathrm{r}_{\mathrm{mP}}$ \\
\hline Constante Média de Saturação do Nitrogênio Interno & 0,9 & $\mathrm{mgN} / \mathrm{mgA}$ & $\mathrm{K}_{\mathrm{qN}}$ \\
\hline Constante Média de Saturação do Fósforo Interno & 0,13 & $\mathrm{mgP} / \mathrm{mgA}$ & $\mathrm{K}_{\mathrm{qP}}$ \\
\hline
\end{tabular}




\begin{tabular}{|c|c|c|c|}
\hline \multicolumn{3}{|l|}{ Detritos (POM): } & \multirow[b]{2}{*}{$\mathrm{k}_{\mathrm{dt}}$} \\
\hline Taxa de Dissolução & 0,5 & $/ \mathrm{d}$ & \\
\hline Tempo de Correção & 1,07 & & $\mathrm{q}_{\mathrm{dt}}$ \\
\hline Fração de Dissolução para Rápido CBOD & 1,00 & & $F_{f}$ \\
\hline Ajuste de Velocidade & 0,1 & $\mathrm{~m} / \mathrm{d}$ & $\mathrm{v}_{\mathrm{dt}}$ \\
\hline \multicolumn{4}{|l|}{ Patógenos } \\
\hline Taxa de Decadência & 0,8 & $/ \mathrm{d}$ & $\mathrm{k}_{\mathrm{dx}}$ \\
\hline Tempo de Correção & 1,07 & & $\mathrm{q}_{\mathrm{dx}}$ \\
\hline Ajuste de Velocidade & 1 & $\mathrm{~m} / \mathrm{d}$ & $\mathrm{v}_{\mathrm{x}}$ \\
\hline Fator de Eficiência de Luz & 1,00 & & $\mathrm{a}_{\text {path }}$ \\
\hline \multicolumn{4}{|l|}{$\mathrm{PH}$} \\
\hline Pressão Parcial de Dióxido de Carbono & 347 & ppm & $\mathrm{p}_{\mathrm{CO} 2}$ \\
\hline
\end{tabular}


Anexo 4: Gráficos com variação entre os dados simulados e observados
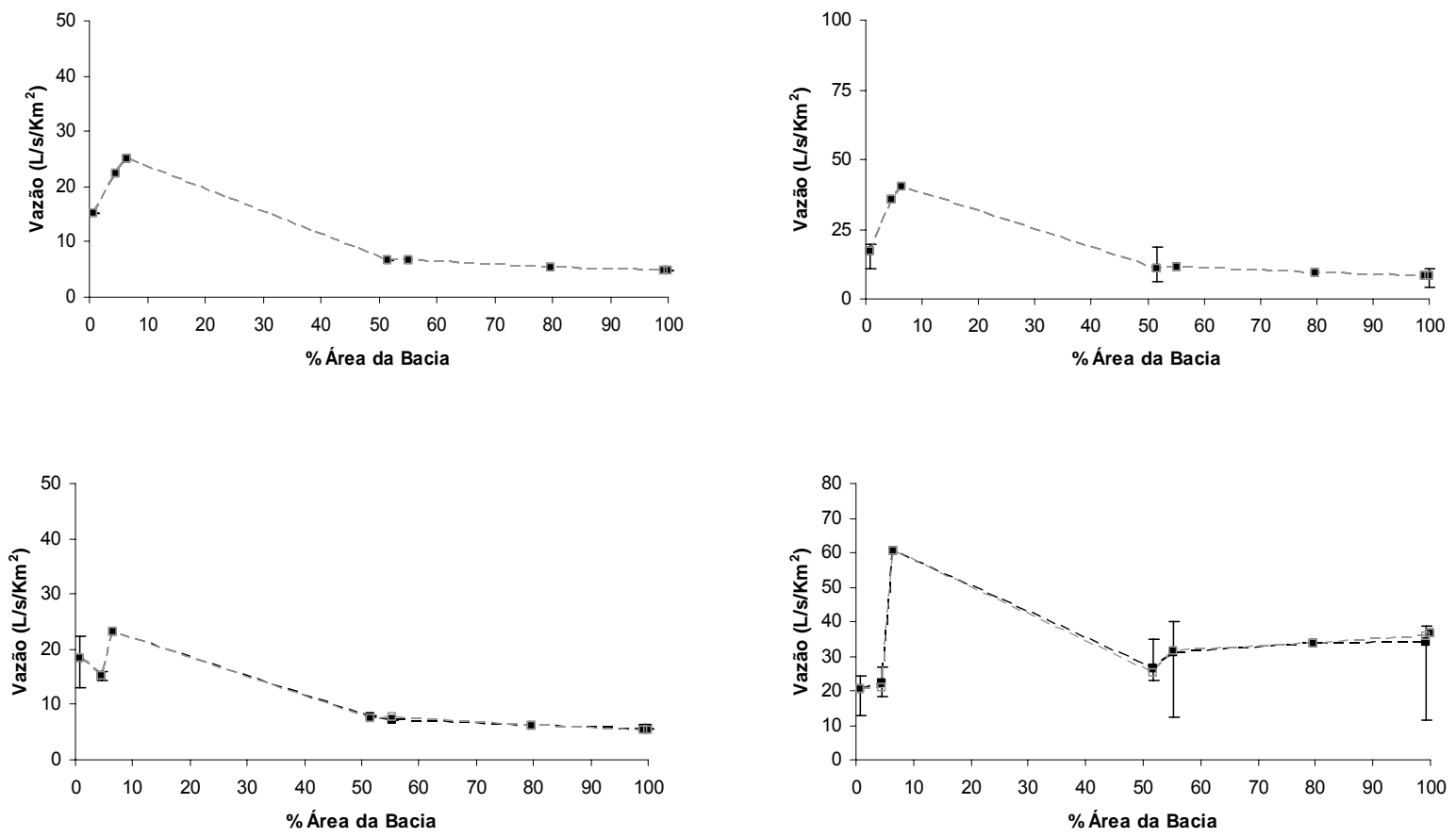

Figura 4.1Variação entre as vazões observadas e simuladas, nas campanhas 1, 2, 3 e 4, respectivamente
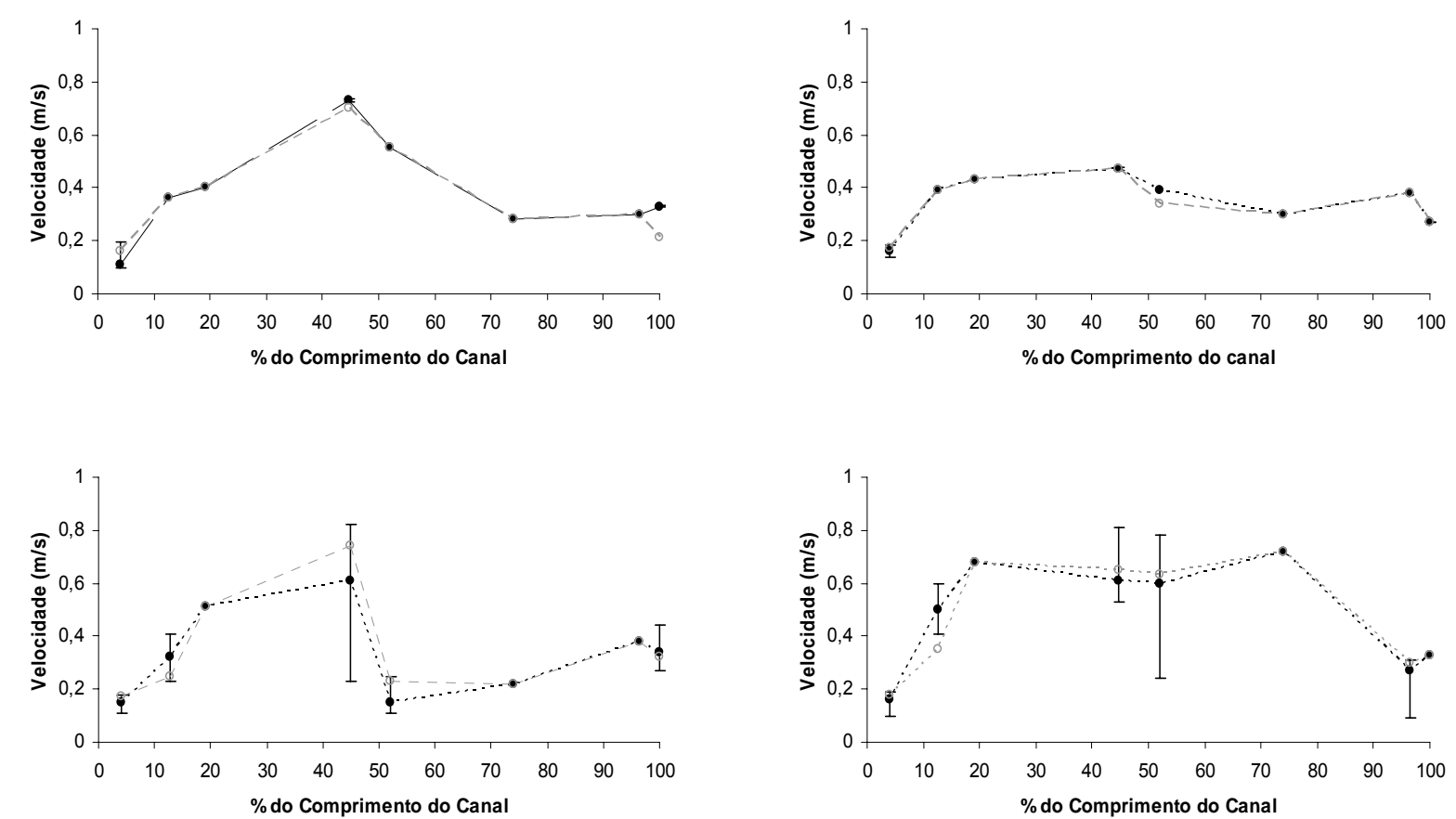

Figura 4.2 Variação entre as velocidades de escoamento observadas e simuladas, nas campanhas 1, 2, 3 e 4, respectivamente. 

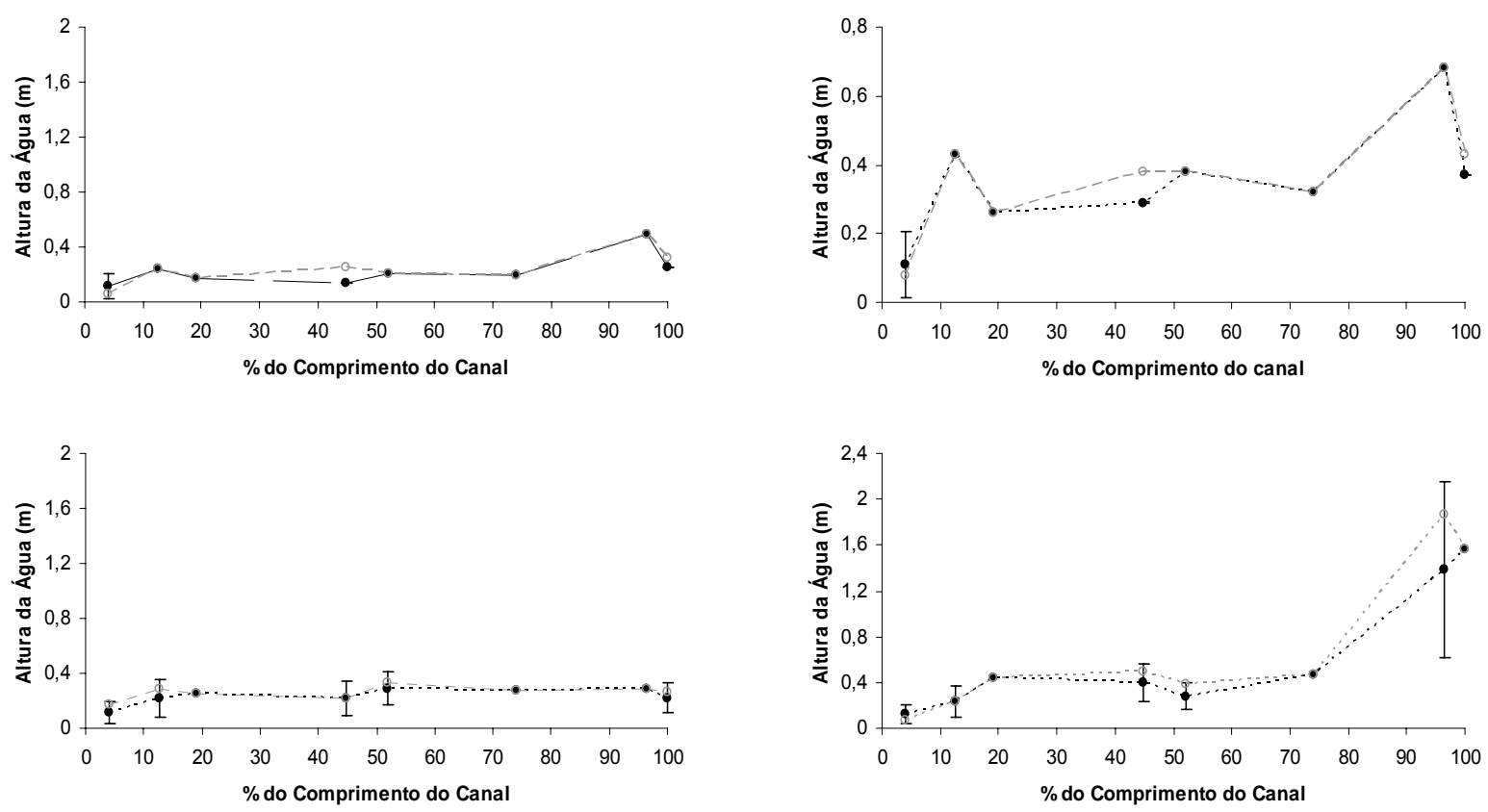

Figura 4.3 Variação entre as alturas da água observadas e simuladas, nas campanhas 1, 2, 3 e 4, respectivamente.
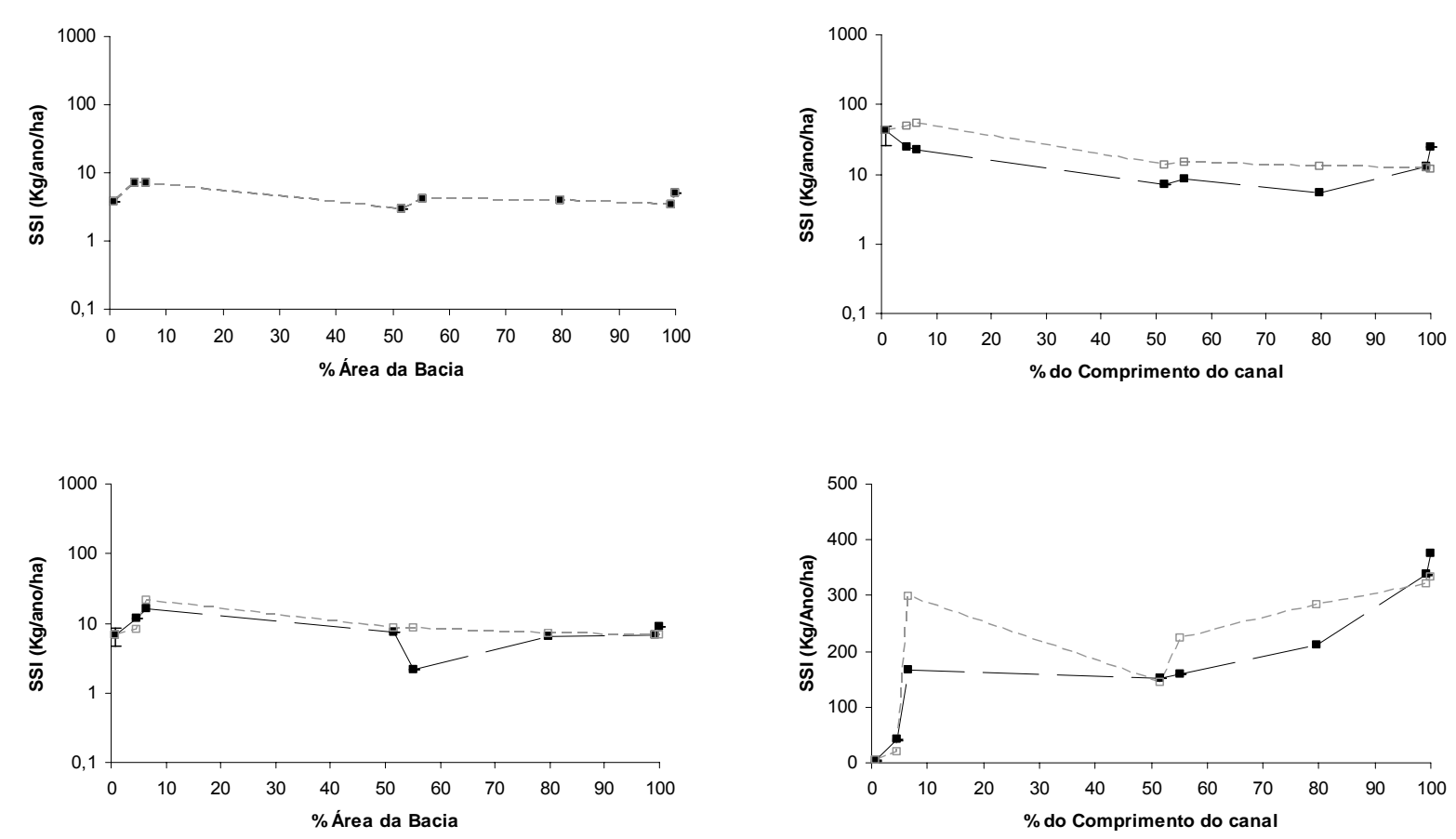

Figura 4.4: Variação das cargas específicas de sólidos suspensos inorgânicos simulados e observados nas campanhas $1,2,3$ e 4 , respectivamente. 

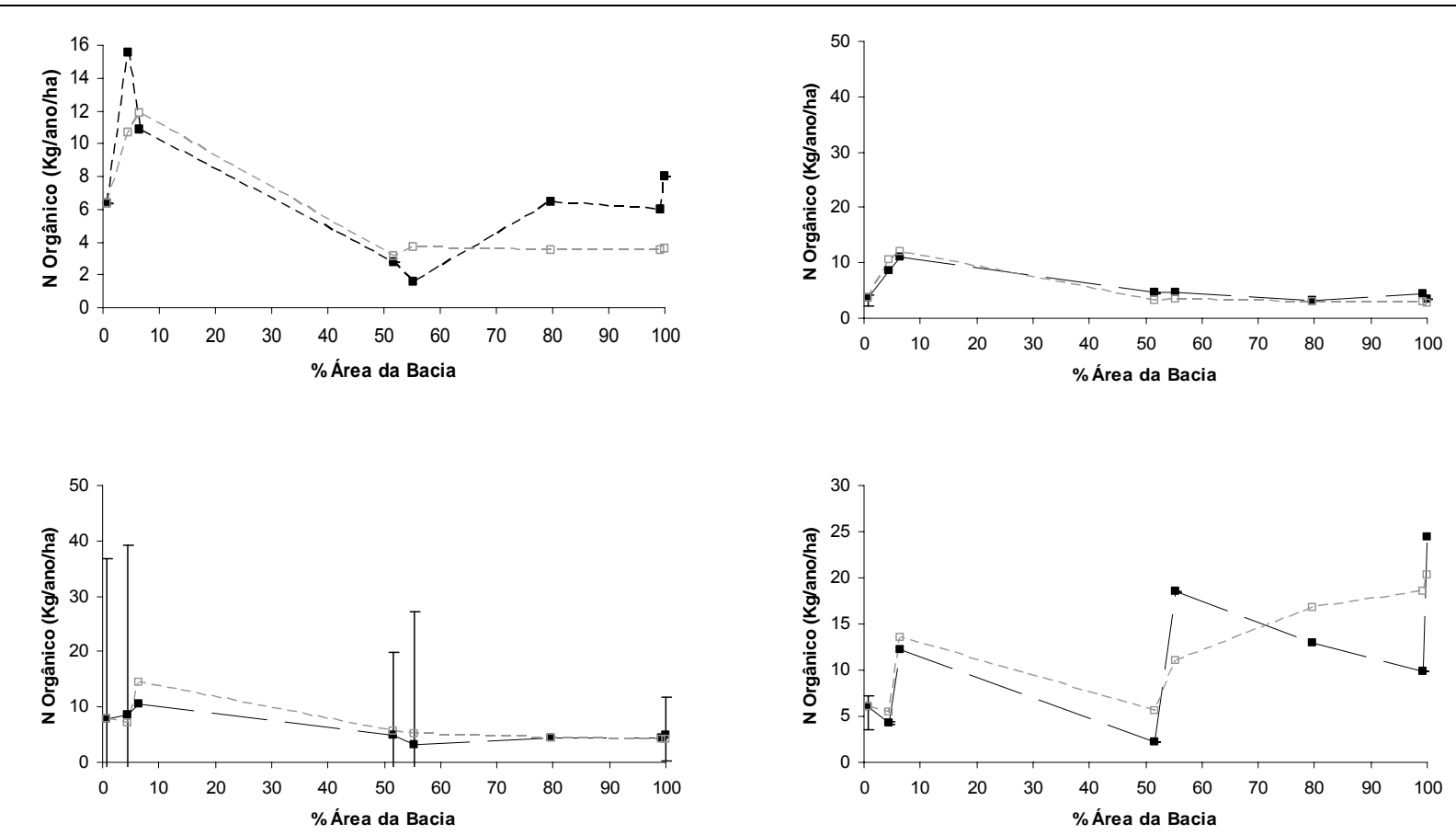

Figura 4.5: Variação das cargas específicas de nitrogênio orgânico simulado e observado, nas campanhas 1, 2, 3 e 4, respectivamente.
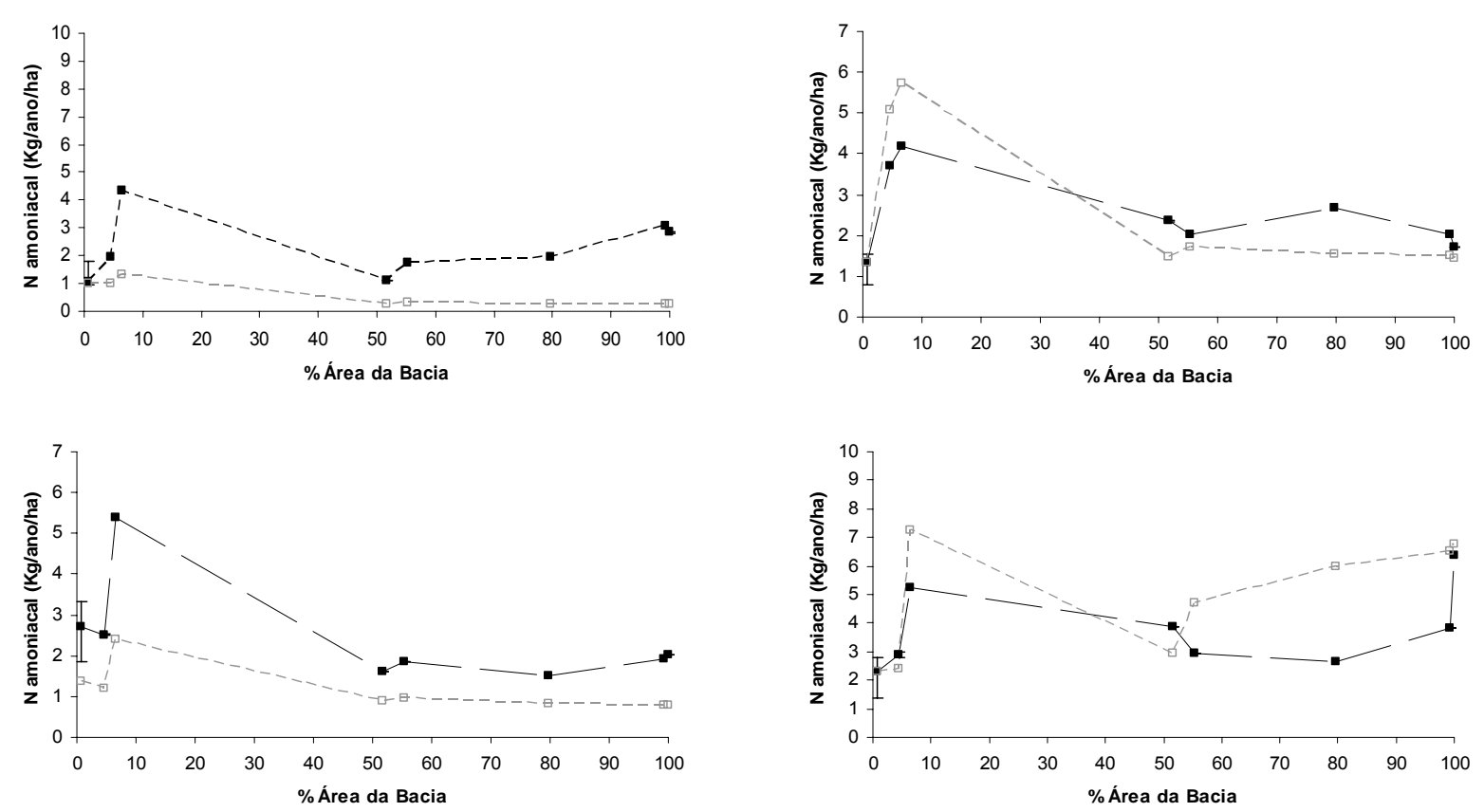

Figura 4.6: Variação das cargas específicas de nitrogênio amoniacal simulado e observado, nas campanhas 1, 2, 3 e 4 , respectivamente. 

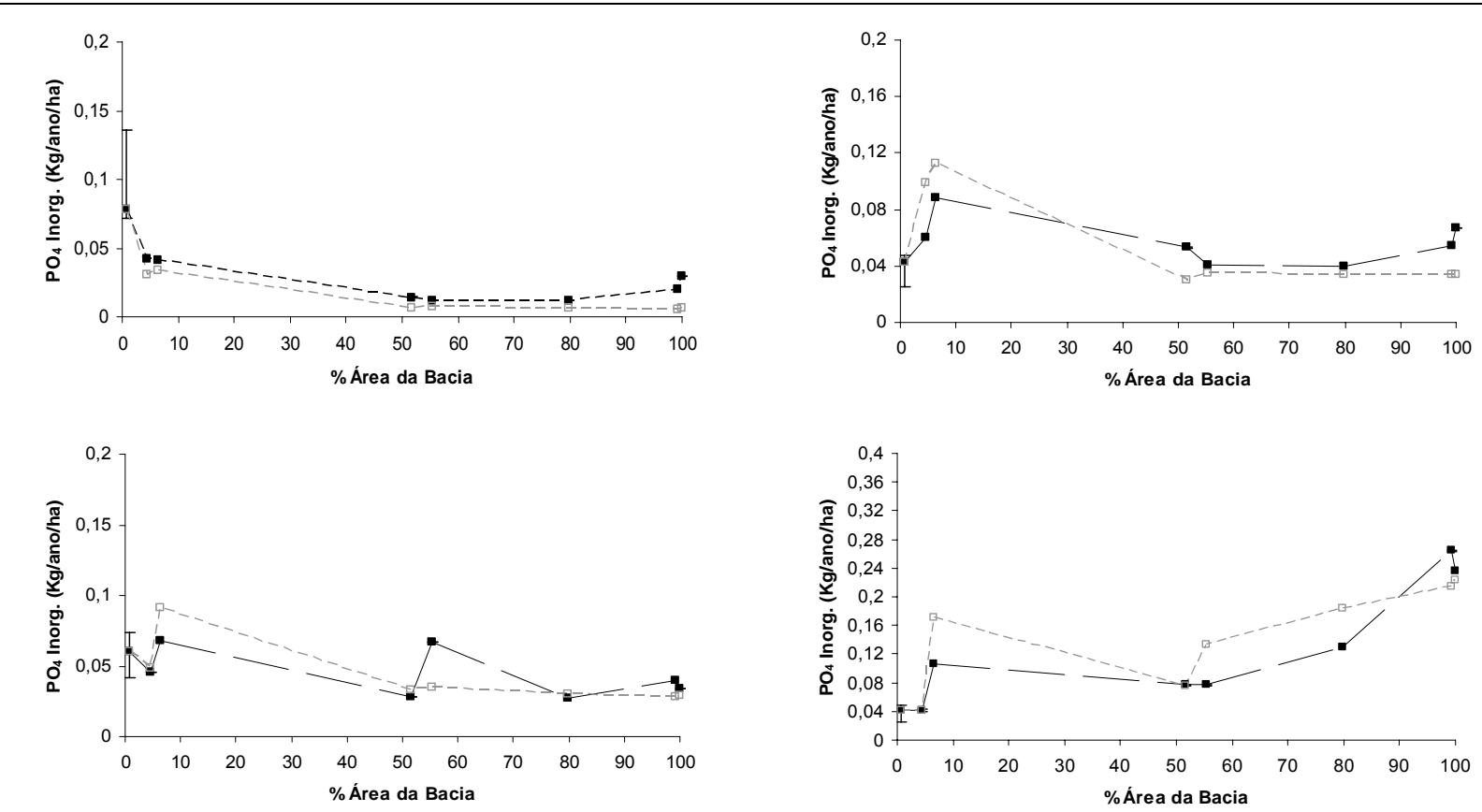

Figura 4.7: Variação das cargas específicas de fosfato inorgânico simulado e observado, nas campanhas 1, 2, 3 e 4, respectivamente.
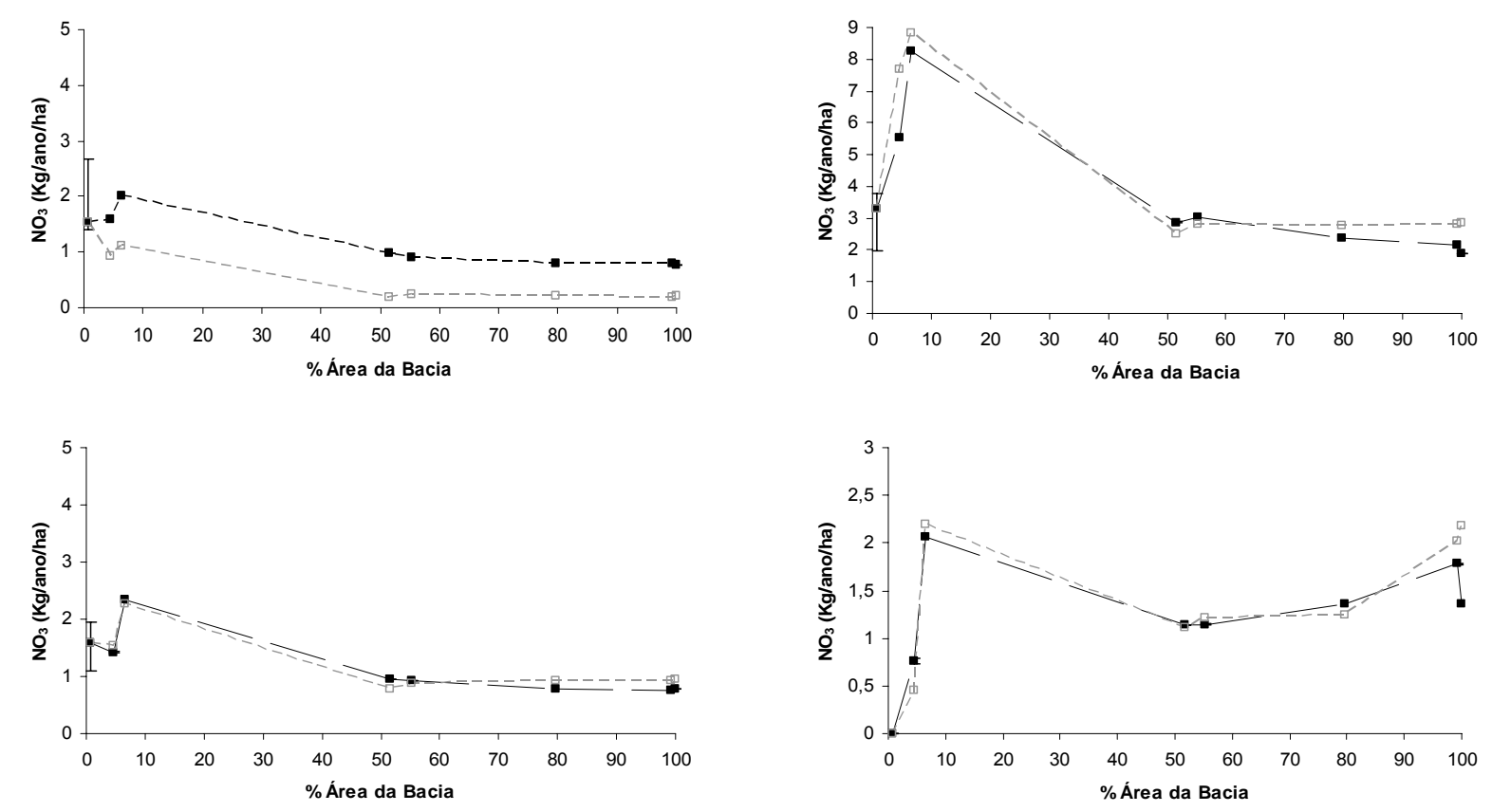

Figura 4.8: Variação das cargas específicas de nitrato simulado e observado, nas campanhas 1, 2, 3 e 4, respectivamente. 

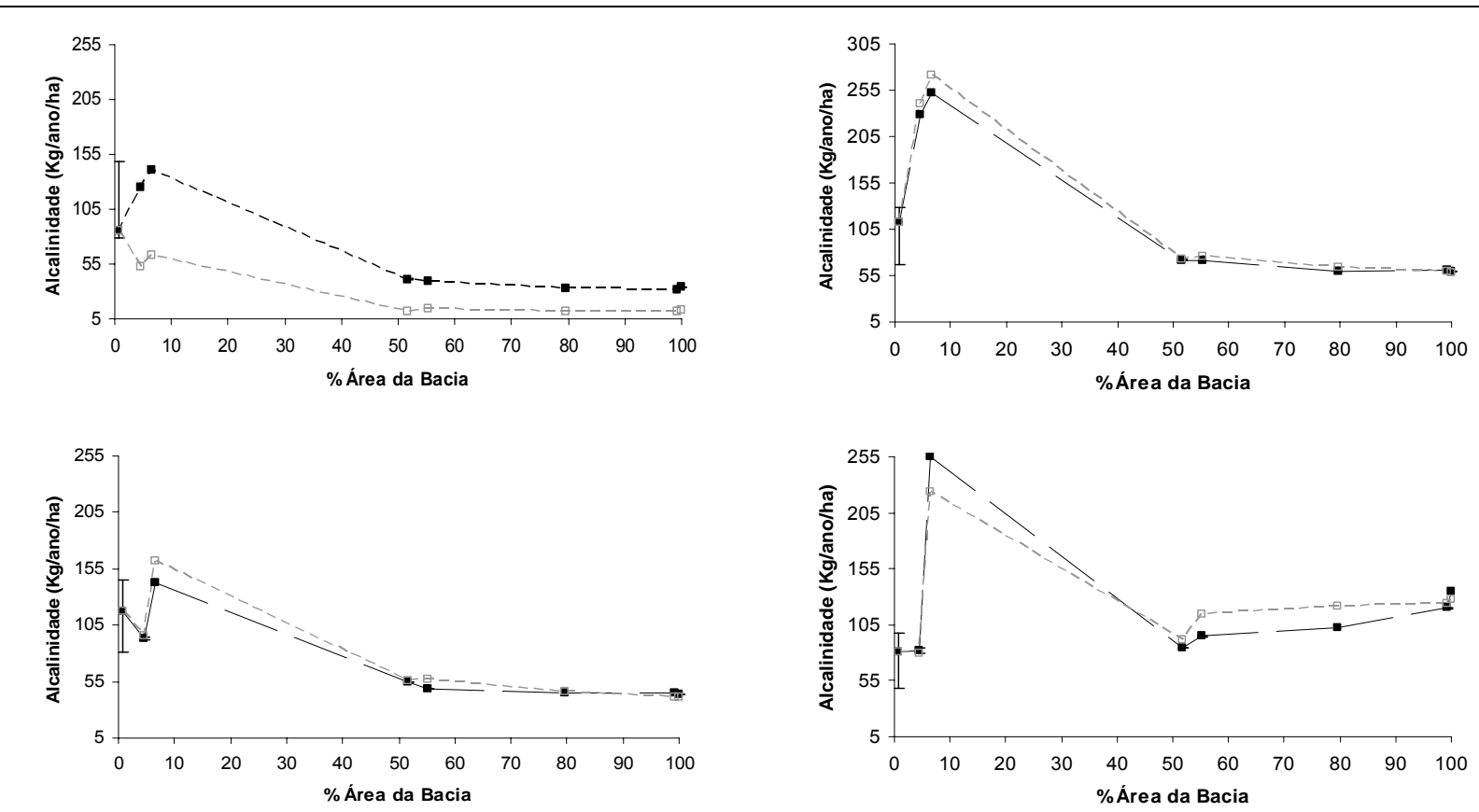

Figura 4.9: Variação das cargas específicas de alcalinidade simulado e observado, nas campanhas 1,2, 3 e 4, respectivamente.
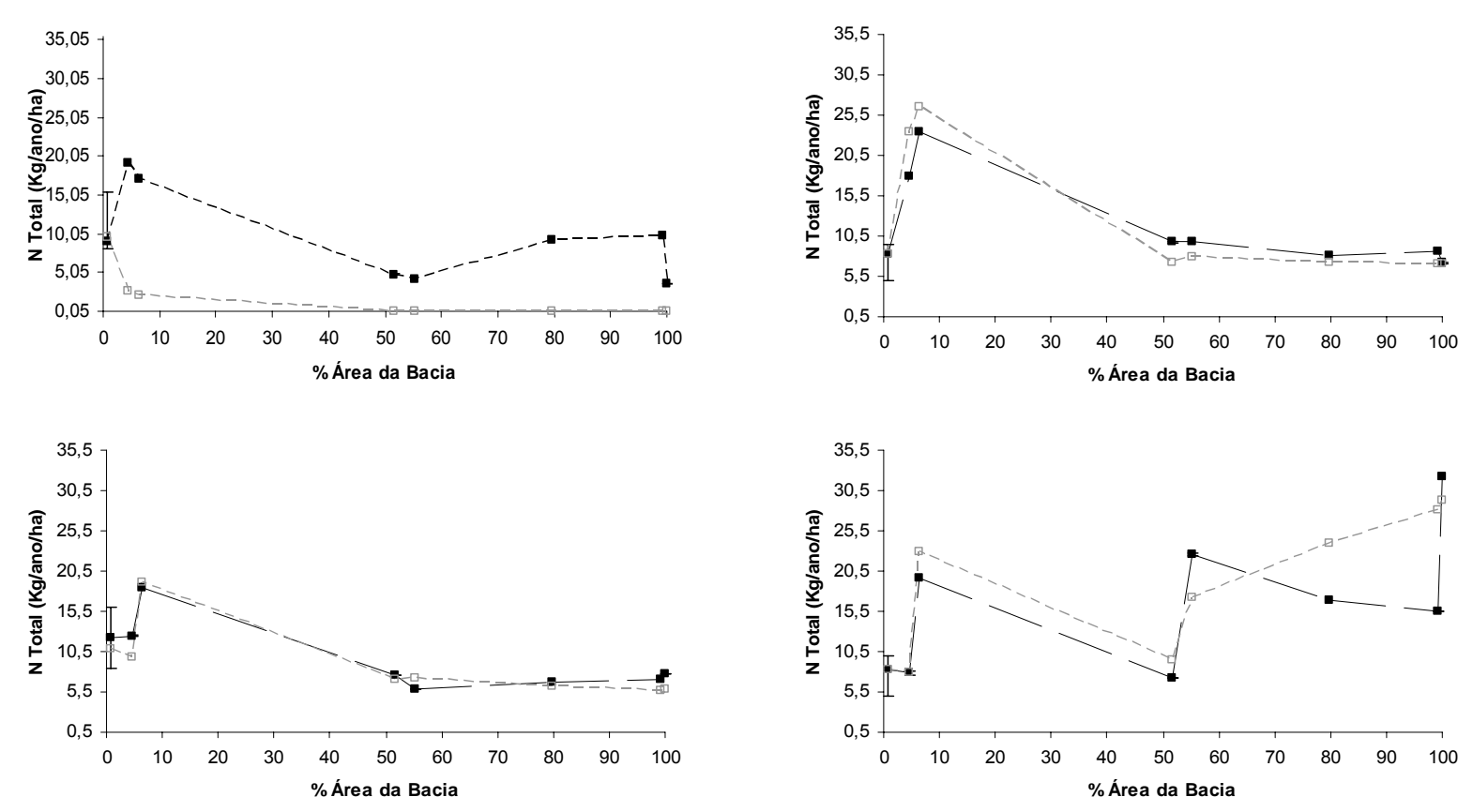

Figura 5: Variação das cargas específicas de nitrogênio total simulado e observado, nas campanhas 1, 2, 3 e 4, respectivamente. 


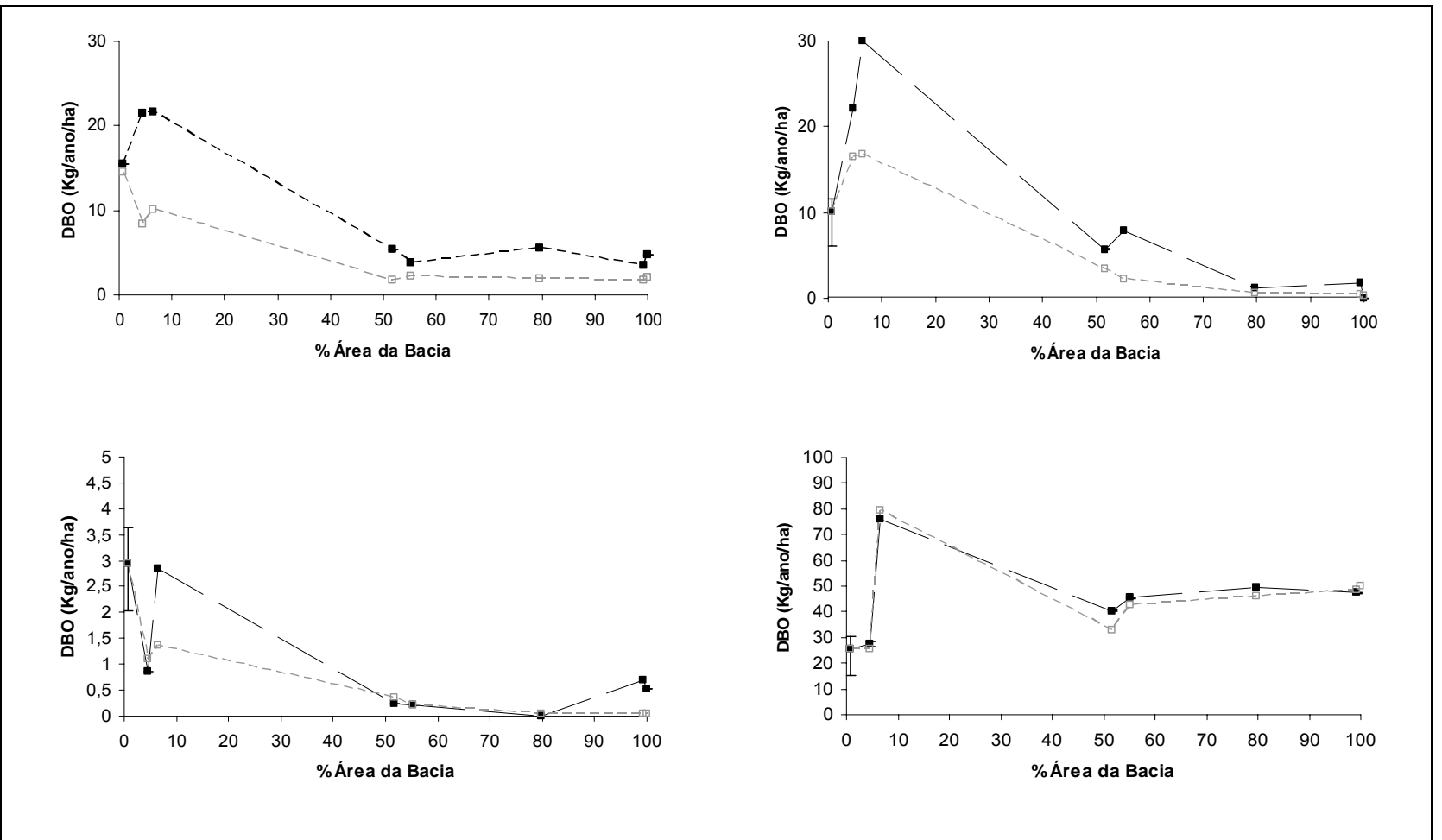

Figura 5.1: Variação das cargas específicas de DBO simuladas e observadas, nas campanhas 1, 2, 3 e 4, respectivamente. 